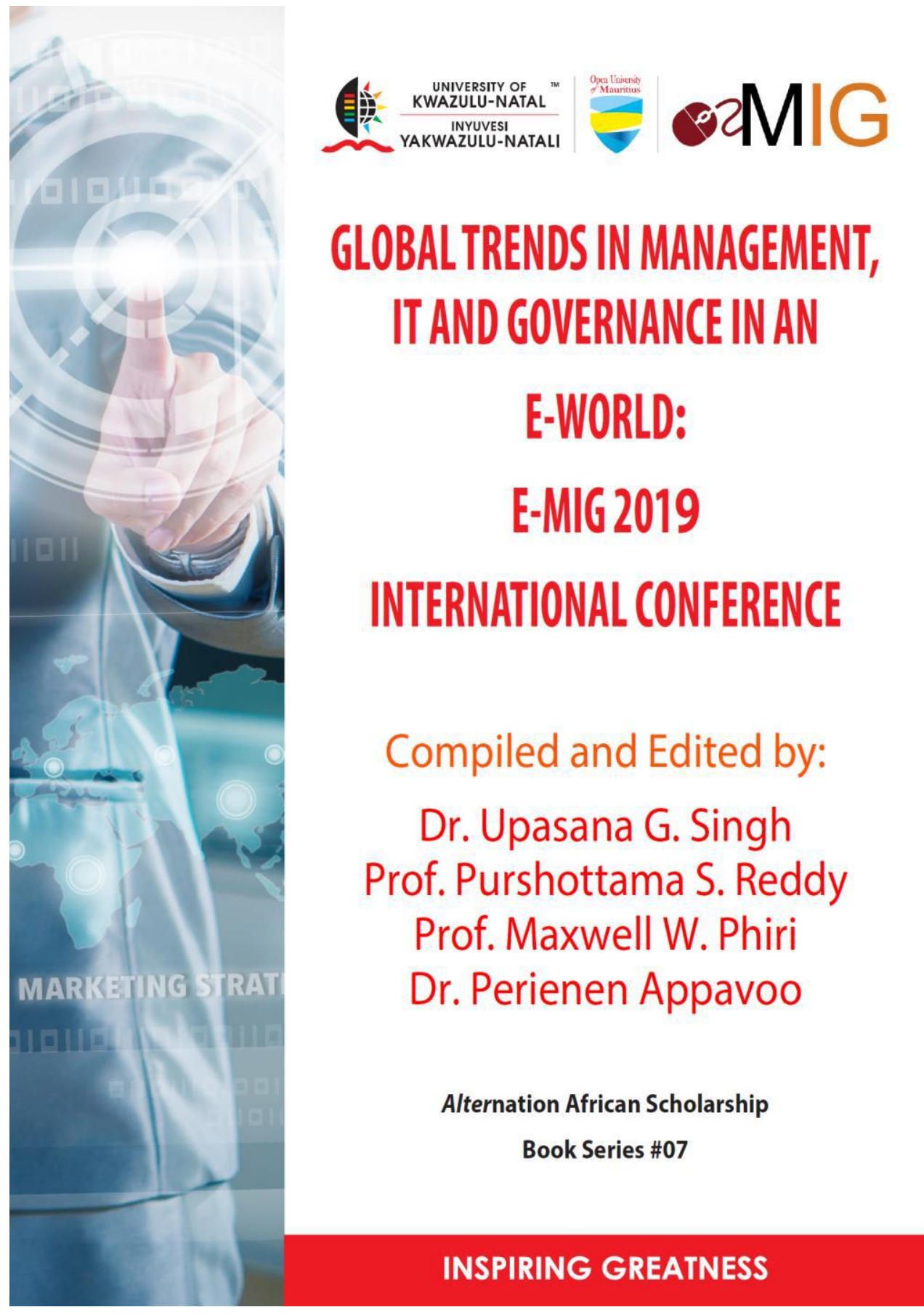





\section{Alternation African Scholarship Book Series (AASBS)}

General Editors

Nhlanhla Mkhize; Relebohile Moletsane; Nobuhle Ndimande-Hlongwa;
Sarah Mosoetsa; Labby Ramrathan; Johannes A. Smit

\section{Lead-Editors}

Nyna Amin University of KwaZulu-Natal; Vivienne Bozalek Cape Peninsula University of Technology; Denzil Chetty University of South Africa; Rubby Dhunpath University of KwaZulu-

Natal; Bekithemba Dube University of the Free State; Mari Haugaa Engh, Norwegian University of Science and Technology; Maserole Kgari-Masondo University of KwaZulu-Natal; Rembrandt Klopper University of Zululand; Simangaliso Kumalo University of KwaZulu-Natal;

Sam Lubbe Mangosuthu University of Technology; Sadhana Manik University of KwaZuluNatal; Cheryl Mohamed Sayeed University of KwaZulu-Natal; Herbert Moyo University of KwaZulu-Natal; Priya Narismulu University of KwaZulu-Natal; Thengani Ngwenya Durban University of Technology; Maheshvari Naidu University of KwaZulu-Natal; Beatrice OkyereManu University of KwaZulu-Natal; Kunle Oparinde Durban University of Technology; Michael

Samuel University of KwaZulu-Natal; Federico Settler, University of KwaZulu-Natal;

Upasana Gitanjali Singh University of KwaZulu-Natal; Lilian Siwila University of KwaZulu-Natal.

Alternation research groups have made decisive and far-sighted knowledge production contributions in the interdisciplinary Arts and Humanities arena for more than twenty-five years. From 2020, it adds the Alternation African Scholarship Book Series (AASBS) to its research outputs system. Via its incisive thematically-focused inter-, multi-, and transdisciplinary, as well as digitally-informed, research approaches, the AASBS not only advances the frontiers of knowledge in Africa's institutions of Higher Learning in designated focus areas, but also critically generates scholarship of, by and with the people(s) of our continent. Historically the research draws on the rich traditions of interactive African intellectualisations, from its earliest civilisations, through struggles for liberation and freedom, to independence and growth. It opens up future epistemic opportunities through intellectual initiative and resourcefulness, while critically contributing to the international advancement of knowledge on all relevant levels. Contributing to research-led constructive, transformative and substantial discourse development in our programmes and disciplines, it also aims at impacting the wellbeing of our people foundationally and all-inclusively in the present. All forms of scientific and social challenge which Africa's societies and communities face, need to be problematised and researched in the Arts and Humanities, in the interest of cooperative and conscientious responsible knowledge generation and foundational conceptual and methodological research impacts. We serve the hopes and aspirations of the people of Africa.

AASBS is committed to the highest levels of inclusive, factually correct and critical, sociallyresponsive and socially-accountable evidence-based research analyses and outputs. Each chapter is reviewed by at least two independent peer reviewers. Through its editing and peerreview system, each volume also builds research leadership, research expertise, and interactive research acumen, capacity and capabilities. 


\section{Alternation African Scholarship Book Series \\ (AASBS)}

Ramrathan, L., N. Ndimande-Hlongwa, N. Mkhize \& J.A. Smit (eds.). Rethinking the Humanities Curriculum in the Time of COVID-19. Volume \#01.

Ndimande-Hlongwa, N., L. Ramrathan, N. Mkhize \& J.A. Smit (eds.). Technology-based Teaching and Learning in Higher Education during the Time of COVID-19. Volume \#02.

Mkhize, N., N. Ndimande-Hlongwa, L. Ramrathan \& J.A. Smit (eds.). Teaching and Learning in Higher Education in the Time of COVID-19. Volume \#03.

Smit, J.A., N. Mkhize, N. Ndimande-Hlongwa \& L. Ramrathan (eds.). Learner and Subject at the Dawn of Digital Humanities Online ResearchLed Teaching and Learning. Volume \#04.

Manik, S. (ed.). From High-risk Sports to Sports as High Risk: Crisis, Capitulation and Creativity during COVID-19. Volume \#05.

Kumalo, S. (ed.). Critical Investigation on Humanitarian Aid in Africa. Volume \# 06.

Singh, U.G., M.W. Phiri, P.S. Reddy \& P. Appavoo (eds.). Global Trends in Management, IT and Governance in an E-World (E-MIG 2019 International). Volume \# 07.

Amin, N. \& R. Dhunpath (eds.). (Re)Learning to Teach in the Context of Crises. Volume \#08.

Bob, U. (ed.). The COVID-19 Pandemic: Impacts of the Corona Virus on Sport and Society. Volume \#09. 
Global Trends in Management, IT and Governance in an

$$
\text { E-World }
$$

(E-MIG 2019 International)

Editors

Upasana G. Singh, Purshottama S. Reddy

Maxwell W. Phiri

Perienen Appavoo

2021 
Published in 2021 in South Africa

CSSALL Publishers (Pty) Ltd

c/o POSTNET SUITE 158

Private Bag X9118

Pietermaritzburg

KwaZulu-Natal

3200

cssall123@gmail.com

Editor-in-Chief: Prof J.A. Smit

University of KwaZulu-Natal

smitj@ukzn.ac.za

Alternation African Scholarship Book Series Volume \#07

(c) CSSALL Publishers (Pty) Ltd

Title: Global Trends in Management, IT and Governance in an E-World (EMIG 2019 International)

Editors: Upasana G. Singh, Purshottama S. Reddy, Maxwell W. Phiri, Perienen Appavoo

ISBN: 978-0-9869936-9-5

DOI number: https://doi.org/10.29086/978-0-9869936-9-5/2021/AASBS07

Cover design by Upasana G. Singh

University of Kwazulu-Natal

Singhup@ukzn.ac.za

All rights reserved. No part of this publication may be reproduced, stored in a retrieval system, or transmitted in any form or by any means electronic, mechanical, photocopying, recording or otherwise, without the prior permission of the copyright holder and publisher.

CSSALL has no responsibility for the persistence or accuracy of URLs for external or third-party internet websites referred to in this volume, and does not guarantee that any content on such websites is, or will remain, accurate or appropriate.

Printed and bound by Print Connection, Tel (031) 202-7766; 202-7766 


\section{Preface}

For some years, the power of mobile technology has been accessible to everyone. Yet not many were making optimum use of it. COVID-19 has changed all that. With the implementation of lockdown and restriction of movement, globally, the importance of digital media has dawned on all. COVID-19 made us realise the importance of the E-World. Even those who had been either averse to e-learning or fearing to step into the e-universe had to embrace the technology to continue with their work, whether in business and retail, or education and research. COVID-19 has accelerated the transitioning of working and learning life into the digital era.

Many professionals, who were initially reluctant to use digital technology, had to adopted it because it helped them to continue with their work, business and education. Whether the CEO who used to spend most of the time at the office, or the educator who has been using the whiteboard to teach learners in class, both have been forced to work remotely and from home, during several months of confinement due to COVID. Of course, the success achieved depended on the extent of preparedness and the tools used.

So, since early 2020, the enforced if not involuntary necessity of using digital technology has been unavoidable. And, even though it has met with some reservations from advocates of face-to-face interaction and communication, before, the value of IT was also soon appreciated. Not only did e-work, e-education and e-research open new possibilities for enhancing and advancing IT capacity and software. It also soon proved vital, if not always popular in all sectors of society globally.

It is then extremely satisfying to see senior business leaders and economists, professors, educators and teachers and learners, as well as seasoned politicians and governance managers and administrators, who had never wanted to use technology in business, to teach their students, or for service delivery, were now doing business online, delivering their lectures using a variety of online software and platforms, and strived to reach their constituencies in the most remote areas. It is also noted that many have come to advocate IT as necessary and indispensable for optimum performance, with great zeal. Even the educator, who thought her subject and technology were miles apart, was amazed to see the great learning value of integrating video, audio, images, statistical tables and diagrams, into lectures and lessons. Textbooks and learning materials were made more appealing and lively by supporting them with the digital and in many cases, social 
media. Similarly, business leaders, economists, politicians, governance officials, and institutional leaders soon learnt the value of being and remaining connected and carrying out work, without necessarily being in the same room or building simultaneously. Even more, many of come to realise the levels of both efficiency and effectiveness that digital media offer to them in their endeavorus.

Therefore, this book, Global Trends in Management, IT and Governance in an E-World, comes at the right time. The research findings will help both the novice and the expert make the right choices for being successful in the e-world. The models, applications, analyses of tools and processes, and the experience of the users presented in the chapters of this book, will undoubtedly play a pivotal role in developing new ways of working and networking, including new. Pedagogies. The availability of the vast array of mobile apps has been shown to constitute a robust set of tools for learning and working. The profound knowledge and long experience of the authors are reflected in their work. The authors, comprising seasoned researchers, academics and practitioners, have left no stone unturned to share their knowledge and experiences. This will appeal to all those eager to harness the technology to improve the way they do things. Students too, will find a treasure of information in the pages of this book.

It is precisely 225 days after the Conference at which the chapters in this book were delivered as papers, that the novel coronavirus was identified in Wuhan, China. At the time, the papers were being presented, the authors hardly knew that their contribution to building the e-World would be highly sought after. The organisers were unaware that the findings of the Conference would prove helpful to everyone desiring to adopt technological advancement to carry out their tasks. That is why the organising teams of the College of Law and Management Studies at the University of KwaZuluNatal, South Africa (UKZN) and that of Open University of Mauritius (OU) deserve our sincere appreciation. Dr P. Appavoo from OU has led the Mauritian team successfully. Dr Upasana G. Singh from UKZN must be congratulated for her dedication and perseverance. She has worked hard to ensure that the Conference is a success and that this book is published. I sincerely wish the best to all the members of the team behind the organisation of the Conference and the publication of this book

\section{Dr. Kaviraj Sharma Sukon, PFHEA}

Director-General, Open University of Mauritius

Chairman, Mauritius Research and Innovation Council 


\section{Contents}

Kaviraj Sharma Sukon

Preface $\mathrm{V}$

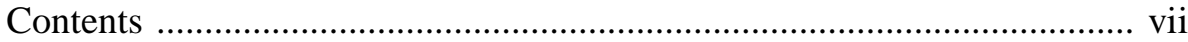

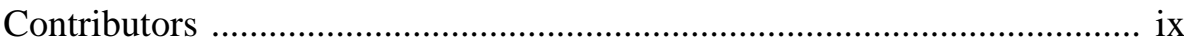

Upasana G. Singh, Purshottama S. Reddy, Maxwell W. Phiri and Perienen Appavoo

Editorial: Global Trends in Management, IT and Governance in an e-World (E-MIG 2019 International)

Dusty-Lee Donnelly

Data Privacy in the Cloud: The Position of Small, Medium and Micro Enterprises Engaged in Mobile Application Development

Mpho Mzingelwa

The Adoption of Information and Communication Technologies (ICTs)

by the Managers of Spaza Shops in Rural South Africa

Paul Kauriki and Lizzy Ofusori

E-Citizenship and its Role in Promoting Participatory Governance in South Africa: A Durban Metropolitan Municipality Case Study 84

Mylet Ursula Dlamini, Jan Meyer and Sam Lubbe

The Evaluation of Municipal Electronic Government Capacity and Service Delivery at Ngaka Modiri Molema District Municipality 106

Lindiwe, N. Kunene, Thokozani P. Mbhele and P.S. Mthembu

Dimensional Objectives for E-Commerce in Africa: The Case of

Company $\mathrm{Z}$

\section{Anisha Ramsaroop}

The Relationship between Career Plateaus and the Career Stages of the University of KwaZulu-Natal Academics

Devika Pillay

Socially Responsive Curriculum: Powerful Knowledge in Marketing Curriculum in South Africa 
Upasana G. Singh and Vandanah Gooria

The COVID-19 Effect on Mauritian Higher Education

Rob Elkington

Emerging Issues in Higher Education Leadership: Results from

Round 1 of a Global Delphi Survey

Judith Terblanche and Yusef Waghid

Cultivating Socially Responsible Chartered Accountant Business

Leaders through Education

Acknowledgment of Reviewers

297

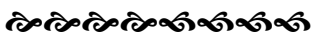




\section{Contributors}

Dr. Perienen Appavoo, holds the post of Senior Academic at the Open University of Mauritius, and is presently heading the Research Office. He holds a PhD in Educational Technology, a Master's Degree in Training and Development and an MSc in Mathematics and Physics. He is the Chair of the Research Committee and the Vice Chair of the Research Ethics Committee. He is a member of the Academic Council and the Research Degree Committee. He chairs the Doctoral Working Committee. He is presently supervising five doctoral students. He has published numerous articles in SCOPUS-indexed journals. He works with a number of foreign universities to foster research collaboration. p.appavoo@open.ac.mu; https://orcid.org/0000000240760739

Mylet Ursula Dlamini, the founding member of NCD is a registered SDF, assessor, moderator and Verifier. She holds a $\mathrm{BSocSc}$ and a Postgraduate diploma in Business Management from the University of Natal, a BCom Honours in Industrial Psychology from UNISA, and also obtained a Masters in Business Administration (HRD). She served as a Learnership/ Client Relations Manager at the Service SETA Career Centre and has worked for various corporates at management level.

Dusty-Lee Donnelly is an admitted Advocate of the High Court of South Africa, and previously practiced as an attorney for several years in the field of maritime and international trade law. She is currently a junior lecturer in the School of Law, Howard College and acts as an internal moderator and external examiner in business law subjects. She has published in the fields of contract law, insurance and admiralty law. Her current research focus is data privacy and she is under examination for a $\mathrm{PhD}$ study entitled 'Privacy by (re)Design: A comparative study of the protection of personal information in the mobile applications ecosystem under United States, European Union, and South African law. Donnellyd@ukzn.ac.za https://orcid.org/0000-0002-5574-7481

Dr. Rob Elkington Rob Elkington, Ph.D., currently resides in Canada, where he serves as the CEO of Global Leadership Initiatives, Inc., which exists to 'develop excellence in leadership globally'. On this matter, please consult www.globalleader.ca. Rob also serves on the faculty of various uni- 
versities such as: Adjunct Professor at the Ontario Technical University in the Faculty of Education; Senior Lecturer, Stellenbosch University School of Public Leadership; Trent University Master of Management program. These affiliations provide research opportunities and support the development and facilitation of several undergraduate and graduate courses related to leadership. Rob also works with the Ontario Technical University's Continuous Learning Centre to develop and facilitate numerous courses for public and private-sector corporations. Rob is an ICF certified FLOW Business Coach, and MBTI practitioner. He has published a range of books, book chapters, peer-reviewed journal articles, and has facilitated numerous peer-reviewed presentations. rob.elkington@ontariotechu.ca https://orcid.org/0000-0001-7939-6551

Vandanah Gooria is a Programme Manager and Lecturer in Marketing and Management at the Open University of Mauritius. She works voluntarily as part time Executive member for the Down Syndrome Association (Mauritius). She served as Board member and Committee member of Africa Down Syndrome Network (ADSN) for the last two years. She had 13 years of experience in administration, then has over 7 years of professional and academic experience encompassing market research and surveys, development of course materials, authoring courses and university teaching and then over 3 years of experience in social work. She is currently doing her PhD in Special Education Needs Management and published research papers in accredited journals (IEEE Xplore Digital Library, Research Gate) and International Conference proceedings. She has co-authored one book chapter in Technology for Efficient Learner Support Services in Distance Education - Experiences from Developing Countries published in Springer. Her areas of interest are mainly Special education needs, Marketing, Tourism, Management, Open Educational Resources (OER), Technology and Open Distance Learning. v.gooria@open.ac.mu https://orcid.org/0000-0002-1805-6964

Dr. Paul Kauriki holds a PhD in Public Administration from the University of KwaZulu Natal (UKZN). He is an honorary research fellow at the school of Management, IT and Governance, UKZN. He has published several articles in peer reviewed journals as well as book chapters. His research interests are public governance, public participation, citizenship, electronic governance, and monitoring and evaluation in the public sector.

kariukip@ukzn.ac.za; 
Pamirry@gmail.com; https://orcid.org/0000-0001-5758-5343

Ms. Lindiwe Nqobile Kunene is an academic at the University of KwaZulu-Natal. She is a Lecturer in the Discipline of Management and Entrepreneurship. Her research is in Small, Medium, and Micro Enterprises (SMMEs), Entrepreneurship, Business Strategy and Innovation Strategy with an emphasis on the development economics impact for Africa. kunenel3@ukzn.ac.za; https://orcid.org/0000-0002-4284-643X

Professor Sam Lubbe has retired from fulltime academia but is still supervising Doctoral and Masters students in Business Leadership at UNISA in the School of Business Leadership. He is currently helping MUT as a retired research professor. He has a $\mathrm{PhD}$ from Wits and still teaches Research Methodology. He has published widely, attended a large number of international academic conferences where he read academic papers. He has also co-authored some textbooks. sam.lubbe@ gmail.com https://orcid.org/0000-0002-1225-7511

Dr. Thokozani Patmond Mbhele is a lecturer at UKZN, School of MIG (Westville). He teaches and supervises students under the Discipline of Supply Chain Management (Operations, procurement, logistics); has contributed chapters in books and currently serves as reviewer for a number of international journals. mbhelet@ukzn.ac.za https://orcid.org/0000-0003-3124-8781

Professor Jan Meyer is the Deputy Director of the NWU Business School since 2018. He is also an academic board member of numerous private institutions and serves on the board of the AISCR. He holds a PhD from the University of Pretoria (2002), Masters in Business Leadership from UNISA (1995), Certificate in Logistics Management from the University of Pretoria (1991) and a Bachelor's Degree in Political Science (UNISA, 1990). He also completed the Graduate Certificate in Higher Education at Monash (Melbourne, 2006). janmeyer56@gmail.com https://orcid.org/0000-0002-3677-963X

Ms. Portia Sinegugu Mthembu is a UKZN Master of Commerce alumnus. She is a Content and Social Media Manager and Digital Content Strategist. mthembusinegugu@gmail.com 
Mr. Mpho Mzingelwa holds a BSc in Computer Science and International Masters in Business Administration. He is currently pursuing his Doctoral studies. Mpho is a lecturer at the University of KwaZulu-Natal, within the discipline of Information Systems Technology. His research interests include ICT4D (Information and Communications Technologies for Development), Indigenous Knowledge Systems, and the $4^{\text {th }}$ Industrial Revolution Technologies. mzingelwa@ukzn.ac.za; https://orcid.org/0000$\underline{0002-5152-9081}$

Dr. Lizzy Ofusori holds a $\mathrm{PhD}$ in Information Systems and Technology from the University of KwaZulu-Natal, South Africa. She is a postdoctoral research fellow at the University of KwaZulu-Natal. She is also the editorial manager to African Journal of Computing \& ICT and African Journal of Management Information System. Her research interests include information security, BYOD, Mobile security, Big Data and E-governance. ofusoril@ukzn.ac.za; https://orcid.org/0000-0002-6036-619X

Professor Maxwell W. Phiri is an Academic in Marketing and Supply Chain Management in the School of Management, IT \& Governance at the University of KwaZulu-Natal. He is the Academic Leader for the discipline of Marketing, and Supply Chain Management. He holds a doctoral degree from the University of KwaZulu-Natal. He worked in industry for 18 years before becoming an academic after realising the need to blend work experience and academic knowledge in teaching. He worked as a Research Coordinator at the Graduate School of Business and thereafter joined the School of Management in 2005. Prof Phiri lectures in Marketing Management, Strategic Brand Management, Business Strategy, Consumer Behaviour, Advanced Topics in Management, Supply Chain Management, New Product Development, Global Marketing, Marketing Management, Business to Business Marketing, Services Marketing and Business Ethics. at both undergraduate and postgraduate level. His is passionate about postgraduate supervision, especially, at $\mathrm{PhD}$ level. He has contributed immensely in producing $\mathrm{PhD}$ graduates who are now teaching in a number of SADC countries. Prof Phiri is one of the editors for the Retail and Marketing Review, a Bi-annual journal specialising in marketing. He also continues to work in various roles as an academic, supervisor, and researcher. Phirim@ukzn.ac.za; https://orcid.org/0000-0002-9633-6777

Dr. Devika Pillay holds a B.Com (Hons) degree from the former University 
of Natal. Whilst working as a research officer at the Entrepreneurial Research Unit in 1998, Technikon Natal, she received a scholarship to pursue a research Masters in marketing. She was one of ten South Africans selected to attend a course in entrepreneurial development in Nagoya, Japan in 1999. On her return from Japan and on completion of her Master's degree, Dr. Pillay joined the former University of Natal as an academic in the School of Economics and Management. At present, she lectures in the School of Management, Information Technology and Governance at the University of KwaZulu-Natal's, Westville campus. Dr. Pillay is placed within the discipline of Supply Chain and Marketing. Her current areas of teaching are Marketing Research and Strategic Marketing. Dr. Pillay received her $\mathrm{PhD}$ in higher education and curriculum studies from the University of KwaZulu-Natal focusing on the issues of sustainability marketing in the marketing curriculum. Her research interests are in sustainability marketing, marketing education and current trends in marketing. Dr. Pillay extended her role in the capacity of academic leader for teaching and learning from 2018 to January 2020, and is also part of the Joint Expertise Project (JEP), a collaborative effort with the University of Chemnitz in Germany, with a direct involvement in the launching of curriculum modules in sustainability and aerotropolis and smart cities. Dr. Pillay continues to work in her various roles as an academic, supervisor, researcher and external examiner.pillayd6@ukzn.ac.za https://orcid.org/0000-0002-5849-0554

Dr. Anisha Ramsaroop is an academic based at the University of KwaZulu-Natal in the School of Management, Information Technology and Governance in the discipline of Human Resource Management. She has numerous degrees in the field of Human Resource Management including BAdmin, BAdmin (Hons) \& MAdmin and is a registered Industrial Psychologist with the Health Professions Council of South Africa (HPCSA). Her key areas of research include diversity, sexual harassment, career management, training and development and strategic HRM. She has supervised and graduated numerous Honours and Masters students. ramsaroopas@ukzn.ac.za; https://orcid.org/0000-0002-1496-9811

Professor Purshottama Sivanarain Reddy is a Senior Professor and subnational government specialist in the School of Management, IT and Governance at the University of Kwazulu-Natal, in Durban, South Africa. $\mathrm{He}$ is currently Vice-President: Programmes; member of the Board of 
Management and founding Project Director of the Working Group on Subnational Governance and Development of the International Association of Schools and Institutes of Administration (IASIA) (Brussels). He has also served on an IASIA - UNDESA Taskforce for Effective Public Administration at the Local Level for the Achievement of the MDGs. In 2014, he received the Donald Stone Award for being 'A Distinguished International Scholar/ Practitioner' and for his 'Contribution towards Advancing the Wellbeing of IASIA'. Prof. Reddy is also currently the Chairperson of the Policy and Programme Committee (PRAC) of the International Institute of Administrative Sciences (IIAS) (Brussels). He has also served as a member/ alternate associate board member of the Commonwealth Local Government Forum (CLGF) (London), representing universities and research organisations. Prof Reddy is a rated researcher with the National Research Foundation (NRF) in South Africa and previously served on its specialist committee representing the Discipline of Public Administration. He has published extensively nationally and internationally and is the editor/ coeditor of fourteen books. He is on the editorial/ advisory committee of seven journals in South Africa, India, Estonia, United Kingdom and Australia. Prof. Reddy is currently an elected member of the University of KwazuluNatal Council, representing academic staff. Reddyp1@ukzn.ac.za;

https://orcid.org/0000-0001-9237-6272

Dr. Upasana G. Singh is the Academic Leader in the Discipline of Information Systems and Technology at the University of KwaZulu-Natal, Westville Campus, in Durban South Africa. As a Senior Lecturer, she has a keen interest in Educational Technologies. In 2019 she completed her Fellowship in 'Teaching Advancement in Universities' (TAU), from the CHE. Her primary area of research is Digital Teaching and Learning in Higher Education. During the pandemic she has developed 3 conceptual models emerging from her research of the transition to online learning for academics, students and females.singhup@ukzn.ac.za

https://orcid.org/0000-0002-9943-011X

Professor Judith Terblanche is a chartered accountant (CA) and working as an Associated Professor in the Department of Accounting at the University of the Western Cape. She obtained her PhD in Philosophy of Education from Stellenbosch University. Her research interest is focused on the intersection of commerce, theology and education. She is co-author of the book, Cosmopolitan Education and Inclusion: The Self and Others in 
Deliberation (Palgrave-MacMillan, 2020, with Yusef Waghid, Chikumbutso Herbert Manthalu, Faiq Waghid \& Zayd Waghid). jterblanche@uwc.ac.za; https://orcid.org/0000-0002-5649-0083

Professor Yusef Waghid is a Distinguished Professor of Philosophy of Education in the Department of Education Policy Studies at Stellenbosch University in South Africa. He is the author of Towards a Philosophy of Caring in Higher Education: Pedagogy and Nuances of Care (PalgraveMacmillan, 2019) and the co-author of The Thinking University Expanded: On Profanation, Play and Education (Routledge, 2020, with Nuraan Davids). yw@sun.ac.za; https://orcid.org/0000-0003-2565-824X

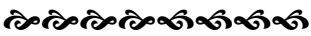




\title{
Editorial: Global Trends in Management, IT and Governance in an E-World (E-MIG 2019 International)
}

\section{Upasana G. Singh}

ORCID iD: https://orcid.org/0000-0002-9943-011X

\author{
Purshottama S. Reddy \\ ORCID iD: https://orcid.org/0000-0001-9237-6272
}

Maxwell W. Phiri

ORCID iD: https://orcid.org/0000-0002-9633-6777

\section{Perienen Appavoo \\ ORCID iD: https://orcid.org/0000000240760739}

This book, Global Trends in Management, IT and Governance in an E-World contains samples of papers delivered, of an extremely successful conference held in Mauritius, from 14 to 15 of May 2019. The Conference was jointly cohosted by the Open University of Mauritius (OU) and the College of Law and Management Studies at the University of KwaZulu-Natal (South Africa) in collaboration with the University of Mauritius; the Amity Institute of Higher Education (Mauritius); the University of Huddersfield (United Kingdom); the Lyallew Khalsa College of Engineering (India); the Shivalik College of Engineering (India) and the Quantum University (India). The principal aim of this multidisciplinary international conference was to secure a gathering of academics from a variety of disciplines and to provide a forum to reflect on and interrogate global trends in an e-world ahead of the Fourth Industrial Revolution. It also provided a platform for promoting academic scholarship and leadership capacity development continentally. All the papers accepted for 


\section{Upasana G. Singh et al.}

publication in this volume of the Alternation African Scholarship Book Series, were subjected to a rigorous review process prior to publication.

Below, we provide a brief overview of the abstracts of each chapter.

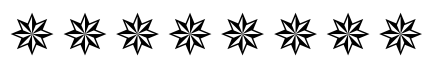

Chapter 1, 'Data Privacy in the Cloud: The Position of Small, Medium and Micro Enterprises Engaged in Mobile Application Development in South Africa', by Dusty-Lee Donnelly, points out that rapid technological development challenges the application of privacy laws. Mobile application (app) development is a new and rapidly growing arena wherein a significant number of developers are small, medium and micro enterprises (SMMEs), lacking the required resources and expertise to respond to privacy issues. Mobile app ecosystems are intricate - characteristically using third-party libraries and cloud-based data storage and back-end services, resulting in uncertainty regarding the authorised responsibilities for lawful data processing and reporting of data breaches. Mobile apps constitute a major risk of privacy infringement, given the large quantity of personal data and meta-data that could be entered by app end-users or collected through on-device sensors, made possible through the mass downloads of apps. This qualitative preliminary pilot study, given the above-mentioned context, explored the levels of knowledge and attitudes, as well as the practices and challenges relative to data privacy of four small app developers and entrepreneurs in South Africa, who are developing mobile apps. This chapter, through the use of semi-structured interviews, provides a descriptive analysis of the findings, including inter alia, an overview of the requirements of the European General Data Protection Regulation (GDPR), of South Africa's Protection of Personal Information Act (POPIA), and the principles of the Privacy by Design theoretical framework.

Mpho Mzingelwa in Chapter 2 believes that the role, impact, acceptance and implementation of Information and Communication Technologies (ICTs) in the South African informal retail sector is not well understood, as it is not officially documented. Consequently, there is little clarity on the extent to which ICTs have been adopted within these microenterprises, particularly in the rural areas. The research focused on rural spaza shops, explored the adoption of ICTs by their managers and is appropriately titled, 
'The Adoption of Information and Communication Technologies (ICTs) by the Managers of Spaza Shops in the Rural Areas of South Africa'. Spaza shops are significant retail outlets, making a substantial contribution to the country's township and rural economy, providing an entry point for persons otherwise excluded from the formal economy. Spaza shops have generated self-employment and have impacted positively on reducing both unemployment and poverty. However, they are understudied, underappreciated and little understood. A questionnaire, with both closed- and open-ended questions was used, to gather data from 80 spaza shop managers in the rural areas of the King Sabata Dalidyebo (KSD) region, Eastern Cape Province, South Africa. Findings revealed that electronic calculators, mobile phones (including SMSes), WhatsApp instant messaging, Speedpoint devices, Facebook social networking, and e-mails were widely used by spaza shop owners. Flash devices were used for selling airtime, data and electricity, and for some DSTV payments and Lotto ticket sales, 'cash back' services, and for accepting payments from customers. The ease of use, affordability and accessibility of mobile phones, and availability of Flash devices and Speedpoint devices, provided benefits to spaza shop owners. Eskom national grid electricity, solar power, and cellular network connectivity (Vodacom, MTN, Cell-C and Telkom) were the necessary facilitating mechanisms enabling the adoption of ICTs. The absence of Automated Teller Machines (ATMs) in the rural areas provided limited opportunities for the spaza shop managers' direct access to cash. Challenges experienced were crime, the high cost of computer equipment and the lack of computer skills, which were found to be the primary barriers to the adoption of computer use by the spaza shop managers. The research findings are beneficial to state institutions, as well as to ICT consultants and vendors who can use the findings to target their interventions and sales efforts towards microenterprises more accurately.

Chapter 3 by Paul Kauriki and Lizzy Ofusori, titled 'E-Citizenship and its Role in Promoting Participatory Governance in South Africa: Durban Metro Case Study', stresses that citizen engagement is a key factor in the successful and sustainable use of electronic platforms. These involve multiple activities ranging from collecting, to processing raw data into useable formats, that can facilitate decision-making towards solving societal problems. The eThekwini City Council as a metropolitan municipality (hereafter referred to as Durban Metro or the Metro) seeks to become an inclusive, liveable city in which citizens are digitally capacitated to engage with it. There is a lack of 
insight into what drives Durban citizenry to engage in local governance processes using various electronic platforms. Consequently, this study sought to identify factors that influence citizens' interest in engaging in these processes using the available digital platforms. The researchers conducted a single case study of citizen engagement in Durban, South Africa, using a cohort of civic education facilitators sampled from a province-wide coalition of civil society organisations. Study participants were purposively selected based on their local participation in civic activities relative to governance promotion in the city, as well as their exposure to various municipal digital platforms used to engage with the citizenry. Age and gender ensured a balanced participation of the respondents. Snowballing was used as a sampling technique to identify individuals who participated as key informants for the study. The research pointed to the citizens' own consciousness as active citizenry in society which was an inherent motivator for engaging with electronic platforms. The quality of information accessed on the various digital platforms used by the Metro did not deter citizens from engaging with the Metro. Citizens felt that they can easily access information about the Metro and this was a strong factor in deepening trust in the Metro's desire to engage with the citizenry. This insight is useful in informing municipal decision makers about stimulating and improving the digital platforms to enhance their engagement with the Metro. Some key lessons for policy makers to enhance e-citizenship in promoting participatory governance at the local government level, are highlighted.

Mylet Ursula Dlamini, Jan Meyer and Sam Lubbe in Chapter 4, investigate service delivery efficiency and electronic government (e-Government) effectiveness at Ngaka Modiri Molema District Municipality. The chapter is titled 'The Evaluation of Municipal Electronic Government Capacity and Service Delivery at Ngaka Modiri Molema District Municipality' and highlights problems relating to municipal incompetency, and service delivery backlogs. Parts of the local communities are economically inactive and it is pointed out that the capacity of the Municipality is key to the process of effective service delivery. The data was collected using a questionnaire and the research sample comprised employees from the Ngaka Modiri Molema District Municipality. The research findings indicated that there was limited capability, and the e-government service provided by the Municipality was ineffective and inefficient, due to incompetence. It was recommended that the municipality should embark on training and development programmes to improve capacity and competency and thereby 
enhance e-government efficiency and effectiveness.

In their study, 'Dimensional Objectives for E-Commerce in Africa: The Case of Company $Z$ ' in Chapter 5, Lindiwe N. Kunene, Thokozani P. Mbhele and Portia Mthembu, explore the objectives that are of importance in forming an e-tailing strategy in the African context. The study used the case of Company Z, an international retail company from South Africa, which investigated how they performed when they entered the rest of Africa. Through an exploratory study designed to understand the decision rationale that management at this organisation followed in conducting their online e-tail business, it was concluded that three objectives lead to success in Africa's etailing industry. While the first two objectives, 'relational and value-based' objectives, which emerged from this study, are similar to those adopted by first world countries, the third objective, 'collaboration', which is a principle that is entrenched in the Ubuntu management principles, is unique to the African context.

Anisha Ramsaroop's study, titled 'The Relationship between Career Plateaus and the Career Stages of the University of KwaZuluNatal Academics' in Chapter 6, concentrates on the linkage between career plateaus and the vocation phases of academics across UKZN's five campuses, with 253 academics across all levels comprising the sample. The study followed a mixed methods approach, with the quantitative aspect, including questionnaires which were either personally or electronically administered to academics. The qualitative component, included interviews with a group of academic leaders. The Protean career orientation provided the theoretical framework for the study, regarding how decisions in one's career is guided by Career Management and Career Choice models. Tenure, promotions, job content, age, personal/ professional/ life plateauing, have impacted on academics at different stages of their careers. Institutional challenges like spates of student unrest, funding issues, increased workloads, research emphasis, and the spill-over between private/ working hours was taken cognisance of. Stringent promotion criteria and an early retirement age has also resulted in low morale, dissatisfaction, frustration, fatigue and increased stress levels. This has also impacted negatively on academic goals pursued. Seeign that an academic's life is determined by academia, the research focused on whether academics are plateaued hierarchically relative to institutional mobility; over their work content which is unchanging; through skills of the job; or on a personal level. The exploration, establishment, maintenance and 
disengagement - in some cases unintentionally - contributed to an increased staff turnover and demotivation, resulting in career plateauing. The results reflected considerable unanimity by respondents on structural plateauing and academic advancement opportunities. A structure was proposed for the operative management of the categories of academic career plateaus spanning stages. It elucidates strategies for applicable stakeholders at different stages of their careers.

The challenge of ecological sustainability, has manifested in a global awareness and concern for the wellbeing of the world population, and earth and environmental care. The 1972 United Nations Conference on the Human Environment, the Brundtland Report (1987), the United Nations Conference on the Environment and Development (UNCED) (1992), the Education for Sustainability Develop-ment (ESD), and the Decade of Education for Sustainability Development (DESD): 2005 - 2014, all, emphasised that world development must go hand in hand with sustainable interventions concerning earth and environmental care. A shared common assumption is that the present generation's use of the earth's resources should not compromise 'the ability of future generations to meet their own needs' (Brundtland Report). Therefore, the plea for a socially responsive curriculum brought in line with a sustainability paradigm and philosophy are key to the transformation of curriculum in tertiary institutions. Against this background, Chapter 7, by Devika Pillay and Manyeruke Josphat, is titled 'Socially Responsive Curriculum: Powerful Knowledge in Marketing Curriculum in South Africa', That there is a growing consciousness of sustainability in relation to the concern for people and the planet. Consequently, the call for a socially responsive curriculum aligned within the paradigm of a sustainability ethos becomes integral to curriculum transformation in higher education institutions. A socially responsible curriculum is explored in the context of the marketing discipline that is entrenched in a dominant social paradigm. This dominant social paradigm is juxtaposed against critical marketing theory that promulgates the need for marketing curriculum transformation. The need for the inclusion of the sustainability marketing approach is interrogated through highlighting the existing historical, powerful and dominant epistemological context of marketing knowledge found in prescribed textbooks of higher education institutions. This becomes the focal point in signalling a departure from a purely performance-based marketing ideology to incorporate new forms of knowledge through curriculum transformation. 
The COVID-19 pandemic outbreak was unexpected and has certainly revolutionised the tertiary education sector, as the innate notion of how, when and where to deliver education is being challenged. It has also signified how yesterday's disruptors can become today's rescuers. Traditional universities providing campus-based instruction have long viewed online education as a threat, or of limited value and poor quality. However, as demonstrated by Upasana Gitanjali Singh and Vandanah Gooria in Chapter 8, titled, 'The COVID-19 Effect on Mauritian Higher Education', it has proven itself as a life-saver in many ways. They investigated how academics at Mauritian higher education institutions (HEIs) have been coping with the effects of the COVID19 pandemic. The impact has been transformative and dramatic as academics have been forced to find workable, fast and effective solutions for moving courses online, to remote teaching and learning, and lifelong learning, using digital platforms, while at the same time maintaining the same depth of engagement with students they could have in a traditional classroom setting. The rising popularity of online education has resulted in educational institutions also seeing an extraordinary potential opportunity of cost savings longitudinally, and the ease of scaling has facilitated ongoing investments in online education by all HEIs. The pandemic and resultant movement to online teaching and learning, have also made academics more adept at managing and valuing the technology devices of the digital era, for lifelong learning, and for assisting students with their tasks in virtual learning processes. Data was collected through an online questionnaire from representatives of four Mauritian HEIs, after obtaining informed consent and ethical clearance. Results indicate that $85.7 \%$ of respondents adopted the contact-based mode prior to the pandemic, and $80 \%$ moved to the online mode during the pandemic. $57.1 \%$ assumed they would move to blended learning post the pandemic. The most popular digital tools adopted by these academics, to support their online teaching and learning processes during COVID-19, were Zoom (66.7\%) and Google Tools (52.4\%). The percentages clearly show that respondents used more than one digital tool. Email (65.2\%) and WhatsApp (72.3\%) were the most popularly adopted communication channels with and among students, during the pandemic. While there were no significant results in respect to challenges faced whilst working from home, the sudden shift caused increased levels of stress and anxiety for respondents.

In Chapter 9, titled 'Emerging Issues in Higher Education Leadership: Results from Round 1 of a Global Delphi Survey', Rob 
Elkington focuses on the emerging issues facing the leadership of Higher Educational Institutions (HEI) globally. The reader is alerted to the fact that many of these issues are emerging in the $21^{\text {st }}$ century due to the impact of the Fourth Industrial Revolution (4IR). A brief description of the 4IR is rendered, to highlight the intersection of HEI leadership and the impact of this emerging new 4IR context. The chapter probes the issues facing the leadership of HEI through a robust literature review and the results of a first round Lockean Delphi survey of HE leaders in several countries such as Canada, the USA, and South Africa. The Delphi survey highlights four issues facing HE leadership, followed by suggestions for the second round Delphi survey to probe these four issues further.

The Chartered Accountancy profession plays a valuable role in the business environment and members often participate in leadership positions. Chartered Accountants also have the authority to make decisions that can impact society and the environment either negatively or positively, unless social justice awareness is cultivated. South Africa seems to be in dire need of transformation through fostering equality and the redress of lived injustices, in which the chartered accountant profession can play a constructive role. However, this will require changes to the status quo. Higher education institutions are an identified space for the cultivation of the full humanity of individuals and this paper reports on some of the recommendations to improve the chartered accountant educational landscape. Titled, 'Cultivating Socially Responsible Chartered Accountant Business Leaders through Education' by Judith Terblanche and Yusuf Waghid, the chapter argues for the enhancement of teaching and learning practices that support the outcomes and aims of democratic citizenship education, the equipping of the chartered accountant educator with the required pedagogical and philosophical knowledge and, incorporating a structured component of experiential learning into the curriculum. Through this research, the focus intentionally shifts from the mere focus on the technical ability of the chartered accountant to that of the required responsibility to lead justly in a transformative society.

Dr. Upasana G. Singh School of Management, IT and Governance University of KwaZulu-Natal Durban

Singhup@ukzn.ac.za 
Prof. Purshottama S. Reddy School of Management, IT and Governance University of KwaZulu-Natal

Durban

$\underline{\text { Reddyp1@ukzn.ac.za }}$

Prof. Maxwell W. Phiri School of Management, IT and Governance University of KwaZulu-Natal

Durban

Phirim@ukzn.ac.za

Dr. Perienen Appavoo Head of Research Open University of Mauritius p.appavoo@open.ac.mu 


\title{
Data Privacy in the Cloud: The Position of Small, Medium and Micro Enterprises Engaged in Mobile Application Development in South Africa
}

\author{
Dusty-Lee Donnelly \\ ORCID iD: https://orcid.org/0000-0002-5574-7481
}

\section{Abstract}

Rapid technological development challenges the application of privacy laws. Mobile applications' development is a new and rapidly growing field in which a high number of developers are Small, Medium and Micro Enterprises (SMMEs) who may lack the resources and expertise to address privacy issues. Mobile application ecosystems are complex - typically involving use of thirdparty libraries and cloud-based data storage and back-end services - so creating uncertainty about legal responsibilities for lawful data processing and reporting of data breaches. Mobile applications present a high risk of privacy infringement given the vast amounts of personal data and meta-data that may be entered by application end-users or collected through on-device sensors and the huge number of application downloads. Against this background, the aim of this qualitative preliminary pilot study was to use semi-structured interviews to explore the levels of knowledge, attitudes, practices and challenges of small mobile application developers and entrepreneurs in South Africa to data privacy. This article describes the findings of the study and provides an overview of the requirements of the European General Data Protection Regulation (GDPR) and South Africa's Protection of Personal Information Act (POPIA), and the principles of privacy by design.

Keywords: mobile applications, data privacy, privacy by design, GDPR, POPIA, SMMEs 


\section{Introduction}

Mobile applications (apps) present a high risk of privacy infringement. Sophisticated on-device sensors and the huge number of app downloads mean that vast amounts of personal data, including content and meta-data, may be collected by apps and transferred to third parties who may use the data in unexpected ways, without the user's awareness or permission (Van der Sype \& Maalej 2014: 25; Breaux et al. 2015; Cortesi et al. 2015; European Network \& Information Security Agency (ENISA) 2018: 12; Razaghpanah et al. 2018: $2)$. The problem has reached public attention through recent data abuse scandals, such as the case of Cambridge Analytica, who used a personality app on Facebook to harvest personal data for voter-profiling and targeted political advertising in Donald Trump's 2016 United States presidential election campaign. The app's privacy policy contained deceptive, false assurances that no personal data was collected, but what truly shocked regulators and the public was the vast scale of the data collection. Approximately 250000 Facebook users directly interacted with the app, but Cambridge Analytica gained access to the profiles of over 50 million Facebook 'friends' in those app users' social networks (Federal Trade Commission (FTC) [US] 2019: 7). A range of empirical studies have shown that many apps pose a high privacy risk as they fail to provide adequate protection of privacy (Papageorgiou et al. 2018: 9391) and users lack adequate understanding of the relative risks associated with the use of these apps (Van Kleek et al. 2017: 5208). The presence of third-party trackers was detected in $90 \%$ of Android apps, with concentrated data flows being directed to big technology companies such as Alphabet and Facebook (Binns et al. 2018: 5).

Mobile app ecosystems are complex - often involving the use of thirdparty libraries, cloud-based data storage and back-end services. There is a need to address how free and informed consent can be obtained from app users, including how app users can be made aware of parties who have access to and process their data (Office of the Privacy Commissioner (OPC [Canada]) 2012: 4). The involvement of multiple parties creates uncertainty about the legal responsibilities for lawful data processing and reporting of data breaches (ENISA 2018:12). A high number of app developers are based in Small, Medium and Micro-sized Enterprises (SMMEs) and cannot adequately address these issues, as they have 'limited resources and security/privacy expertise' (ENISA 2018:12). 
The rapid development of technology and the new uses of personal data are proving a challenge to the application of privacy laws (Organisation for Economic Cooperation and Development (OECD) 2013: 66). This paper adopts the theoretical framework of 'Privacy by Design' (PbD), which is the 'concept of engineering privacy directly into the design of new technologies, business practices and networked infrastructure, in order to achieve the doublyenabled pairing of functionality and privacy' (Cavoukian \& Prosch 2010: 3). Privacy by Design underpins both the General Data Protection Regulation (2016) (GDPR) in the European Union (EU), and the Protection of Personal Information Act (POPIA) (2013) in South Africa.

In the current study, an 'app-developer-centric' approach is taken. Such an approach is described in a recent meta-study, which advocates empirical research to better understand the mobile app ecosystem and how $\mathrm{PbD}$ principles can be implemented in the field of mobile app development (ENISA 2018).

The study is an exploratory, qualitative case study of four SMMEs that have developed mobile app as participants at one stakeholder site, being an accelerator program for mobile app developers at an innovation hub in South Africa. The study focuses on identifying their levels of knowledge and attitudes as well as the practices and challenges, in relation to data privacy. The names of the participants, their company, the app, and the stakeholder site are excluded in order to preserve the anonymity of the participants.

This chapter will first review the requirements of the GDPR and the POPIA as well as the principles of PbD. The chapter will then set out the methodology, and results of the empirical study and present an analysis of findings, a conclusion and recommendations.

\section{The Legal Requirements of GDPR and POPIA}

In this section the key legislative provisions relevant to the objectives in the field of study are considered. The GDPR came into force on 25 May 2018 replacing the Data Protection Directive (1995). The GDPR introduced more stringent privacy protections and large penalties for non-compliance. It has extra-territorial application and every entity processing the personal data of EU residents must ensure compliance. The privacy protection advocated for by the GDPR is thus expected to have a significant global impact (He et al. 2019:2). Mobile app developers in South Africa need to be aware of and to comply with 
its provisions.

In addition, a draft Regulation on Privacy and Electronic Communications (2017) was released on 20 September 2018, with the intention that it will repeal the Privacy and Electronic Communications Directive (2002). The 'e-Privacy' regulation aims to particularise the general principles contained in GDPR by providing specific rules applicable to electronic communications data, which include both the content and metadata processed by mobile applications. However, it has not been adopted and its contents are still being furiously debated.

In South Africa, data privacy is regulated by the POPIA, and from 1 July 2021 app developers must comply fully with its provisions.. At the time of the data collection for this study in 2018, POPIA's commencement date had not been announced. At that time, South African data controllers could voluntarily subscribe to the less onerous privacy principles set out in Chapter VIII of the Electronic Communications and Transactions Act (2002) and only had to provide details on their website of their security procedures and privacy policy when supplying goods or services to consumers by way of an electronic transaction. The interception of the content and metadata relating to communications was (and remains) governed by the Regulation of Interception of Communications (RICA) and Provision of Communication-Related Information Act (2002).

The GDPR was selected for comparison because the legal approach to the right to data privacy is 'broadly similar' in South Africa and in the EU (Roos 2003: 20). Both the POPIA and the GDPR recognise that the protection of data privacy is a fundamental right - enshrined in section 14 of the South African Constitution and article 8 of the European Convention on Human Rights, respectively. The POPIA was drafted after a detailed report by the South African Law Reform Commission (2009) recommended an approach similar to that of the EU (De Bruyn 2014: 1316).

Furthermore, the GDPR has a global reach through its extra-territorial scope (GDPR 2016: art 3.2). Even if an organisation is not a data privacy 'establishment' in the EU (itself a wide concept), it must comply with the GDPR if it processes the 'personal data' of data subjects situated in the EU i.e. not just EU citizens but all EU residents - in one of two contexts: either it is 'offering goods or services' to such persons (even when free) or it is monitoring the behaviour of such persons.

A South African app developer must comply with the GDPR if the app 
will be downloaded by EU residents or will collect the data of EU residents for tracking, profiling or analytics by the developer or a third party. Without an establishment in the EU, such a developer cannot fulfil the provisions for investigation by a single, lead supervisory authority in art. 56 and may thus face multiple investigations by the data protection authorities of various EU member states, subject to sectorial and national legislation (European Data Protection Board (EDPB) 2018:12).

Although, the POPIA has no explicit extra-territorial scope, its provisions apply when personal data are 'entered in a record by or for a responsible party', either if that responsible party is domiciled in South Africa, or if it 'makes use of automated or non-automated means' of processing the data in South Africa (POPIA 2013: sec. 3.1). Arguably, when an app offered by a developer established in the EU is downloaded on a smartphone in South Africa, the processing of personal data by that app constitutes 'automated means' as defined by the POPIA (2013: sec. 3.4). Although the app developer in this instance will be governed by GDPR, the POPIA does not automatically defer to the GDPR, but provides that where other legislation has 'more extensive provisions', those will prevail (POPIA 2013: sec. 3.2.b).

Although similar, the provisions of the POPIA and the GDPR do have some differences that may affect how they are to be interpreted and applied, and this creates an additional layer of complexity in the mobile apps' ecosystem where:

1. legal compliance with the laws of multiple jurisdictions may be required; and

2. the complex architecture of mobile apps typically involves one or more layers of data processing, and cross-border data flows, which must now be contractually managed in a transparent manner.

\section{Legal Responsibility of App Developers}

The study sought to determine the attitude of the participants - in particular whether they regarded themselves as having any responsibility for ensuring that third parties processing data of app users do so lawfully. Although there have been numerous studies of consumer perceptions of privacy, there has been very little research on the awareness of and attitudes toward privacy legislation among data controllers (Mikkonen 2014: 191). Furthermore, although several 
data protection agencies have published privacy guidelines for mobile apps (OPC [Canada] 2012; FTC [US] 2013; Article 29 Data Protection Working Party (Art.29WP) [EU] 2013; California Department of Justice 2013; Information Commissioner's Office [UK] 2014; Office of the Australian Information Commissioner [Australia] 2014), regulators appear to lack awareness of how developers perceive privacy (Hadar et al. 2018: 261). Studies adopting a developer-centric approach (Balebako et al. 2014; Jain \& Lindqvist 2014; Van Der Sype \& Maalej 2014; Hadar et al. 2018; Sy et al. 2018) indicate low levels of knowledge about privacy legislation, suggesting that PbD may not be a 'viable' approach (Martin \& Kung 2018; Hadar et al. 2018:278), without informed interventions to change organisational and software engineering mindsets.

Personal data (referred to in the POPIA as 'personal information') includes any information that identifies, or could be used to identify a living, natural person, who is referred to as the data subject. The POPIA extends protection 'where applicable' to existing juristic persons. Personal data includes direct identifiers such as a person's name, an identification number or contact details and attributes about a person such as gender and race. Any information which alone, or in combination with other information, renders a specific person 'identifiable' (POPIA 2013: sec.1; GDPR 2016: art.4) falls within the scope of the legislation. Certain information such as race, ethnic origin, health status and criminal behaviour of a data subject, are treated as special data to which more stringent requirements apply (POPIA 2013: sec.26; GDPR 2016: art. 9 \&10). Determining whether one is processing personal data can thus require 'elaborate analysis' - taking into account the specific context (ENISA 2018:14). The term 'processing' is also wider than how a software engineer would typically understand the term (ENISA 2018: 51), and includes collection, storage, transmission, use, linking and deletion of data (POPIA 2013: sec. 1; GDPR 2016: art. 4).

The complex relationships in the mobile app ecosystem must be analysed within the legislative framework of a relationship between responsible party/ies (data controller/s) and operator/s (data processor/s). A responsible party is defined in the POPIA to include any entity (public/private $\&$ natural/juristic person), acting alone or jointly, to determine the purpose and means for processing personal information (personal data). In the GDPR, this person is called the data controller. Under both Acts, it is possible that there could be more than one responsible party (data controller). For example, if an 


\section{Dusty-Lee Donnelly}

app integrates with login credentials from a third party or with advertising networks, those parties may also be data controllers (ENISA 2018:16).

An operator (processor) is a person who processes personal information for, or on behalf of, a responsible party. This would include cloud service providers, although it has been argued by Kuan Hon (2016) that to classify the following service providers: Infrastructure as a Service (IaaS), Platform as a Service (PaaS) and pure data storage Software as a Service (SaaS) as processors, is incompatible with the fact that cloud users are not 'instructing' or 'authorising' cloud providers to process data: the cloud service enables the cloud user to access the resources in order to process the data itself.

In accordance with the 'accountability principle', the responsible party (data controller) is responsible for ensuring that processing is carried out lawfully and is required to use contractual means to secure compliance (POPIA 2013: sec.21.1; GDPR 2016: art.28.3). Under the GDPR, a processor is required to take measures to assist the data controller to achieve and demonstrate legislative compliance (GDPR 2016: art.28.2), and to implement 'appropriate technical and organisational measures to ensure a level of security appropriate to the risk' (GDPR 2016: art.32). The data controller must require 'sufficient guarantees' from the processor that such measures are in place (GDPR 2016: art.28.1). Processing must be governed by a contract binding the processor in respect of the controller (GDPR 2016: art.28.1). Under the PbD principle, controllers must engage trusted third parties - but still have to vet privacy compliance. This would require at least reading a processor's terms and conditions, or privacy policy, to ensure that it deals with the minimum requirements as set out in article 28(3)(a) - (h), including the type of data being processed, and the nature, purpose and duration of processing and the rights and obligations of the controller.

Determining the roles of the various parties is a complex exercise and must be undertaken in the context of a particular app. The literature on the implementation of controls over third-party processors is scarce (Kurtz et al. 2018:8). The entity that is developing the app (app provider/app owner) would be the primary responsible party (ENISA 2018: 16). This entity may develop the app in-house, or it may contract an independent app developer to do so. Whether the developer is in that instance a co-responsible party, a processor or not directly regulated, can only be determined in a specific context, having regard to the role that they perform, and whether they are themselves processing any personal data. Nevertheless, the producers of products, services 
and apps that process personal data are 'encouraged to take into account the right to data protection when developing and designing such products, services and applications and, with due regard to the state of the art, to make sure that controllers and processors are able to fulfill their data protection obligations' (GDPR 2016: rec.78). This appears to be applicable to app developers (who are not also the app owners), app stores, operating system (OS) providers, library providers, and hardware manufacturers (ENISA 2018: 16). Privacy of personal data in this multi-party environment requires inter-operable and consistent protections to be applied by all stakeholders (Cavoukian 2012: 15).

\section{The Practice of Privacy by Design Required by Law}

The concept of $\mathrm{PbD}$ comprises seven foundational principles (see Table 1, below). The concept was first developed in Canada in the 1990s (Cavoukian 2012: 16). In 2010, the $32^{\text {nd }}$ International Conference of Data Protection and Privacy Commissioners adopted a unanimous resolution on $\mathrm{PbD}$ (Cavoukian 2011: 6), and the concept has continued to grow in popularity (Martin \& Shilton 2016: 201). It acquires its name from the third principle, that privacy is to be embedded into the design of the system. This in turn reflects a change in approach from reactive measures to enforce legal liability after a breach, to proactive measures that consider privacy from the outset of the design process, built into the default settings of the system.

\section{Table 1: The Seven Foundational Principles of Privacy by Design (PbD)}

\begin{tabular}{|l|l|}
\hline \multicolumn{1}{|c|}{ Principle } & \multicolumn{1}{c|}{ Description } \\
\hline $\begin{array}{l}\text { 1. Proactive not Reactive; } \\
\text { Preventative not Remedial }\end{array}$ & $\begin{array}{l}\text { The PbD approach is characterised by } \\
\text { proactive rather than reactive measures. }\end{array}$ \\
\hline $\begin{array}{l}\text { 2. Privacy as the Default } \\
\text { Setting }\end{array}$ & $\begin{array}{l}\text { No action is required on the part of the } \\
\text { individual to protect their privacy - it is } \\
\text { built into the system, by default. }\end{array}$ \\
\hline $\begin{array}{l}\text { 3. Privacy Embedded into } \\
\text { Design }\end{array}$ & $\begin{array}{l}\text { PbD is embedded into the design and } \\
\text { architecture of IT systems and business } \\
\text { practices. It is not bolted on as an add- } \\
\text { on, after the fact. }\end{array}$ \\
\hline
\end{tabular}




\begin{tabular}{|l|l|}
\hline $\begin{array}{l}\text { 4. Full Functionality - } \\
\text { Positive-Sum, not Zero-Sum }\end{array}$ & $\begin{array}{l}\text { PbD seeks to accommodate all } \\
\text { legitimate interests and objectives in a } \\
\text { positive-sum 'win-win' manner, and not } \\
\text { through a dated, zero-sum approach } \\
\text { where unnecessary trade-offs are made. }\end{array}$ \\
\hline $\begin{array}{l}\text { 5. End-to-End Security - Full } \\
\text { Lifecycle Protection }\end{array}$ & $\begin{array}{l}\text { PbD, having been embedded into the } \\
\text { system prior to the first element of } \\
\text { information being collected, ... ensures } \\
\text { 'cradle to grave', secure lifecycle } \\
\text { management of information, end-to-end. }\end{array}$ \\
\hline $\begin{array}{l}\text { 6. Visibility and } \\
\text { Transparency - Keep it } \text { Open }\end{array}$ & $\begin{array}{l}\text { Its component parts and operations } \\
\text { remain visible and transparent, to both } \\
\text { users and providers alike. }\end{array}$ \\
\hline $\begin{array}{l}\text { 7. Respect for User Privacy - } \\
\text { Keep it User-Centric }\end{array}$ & $\begin{array}{l}\text { Above all, PbD requires architects and } \\
\text { operators to keep the interests of the } \\
\text { individual uppermost, by offering such } \\
\text { measures as strong privacy defaults, } \\
\text { appropriate notice, and empowering } \\
\text { user-friendly options. }\end{array}$ \\
\hline
\end{tabular}

Source: Adapted from Cavoukian and Prosch (2010: 5 - 6 (e.i.o.))

A PbD approach requires app developers to 'design new applications with privacy in mind right from the outset, and throughout the process and prototyping' (Cavoukian \& Prosch 2010: 18). The concept identifies abstract high-level principles, but regulators need specific guidance on expectations in the context of mobile apps (Martin \& Shilton 2016: 201), and app developers need the legal requirements to be 'translated' into concrete, context-specific development goals (ENISA 2018: 47; Hadar et al. 2018, Omoronyia et al. 2013; Sheth et al. 2014; Thomas et al. 2014).

Article 25 of the GDPR now makes explicit reference to PbD. The article requires that the data controller must 'implement appropriate technical and organizational measures such as pseudonymization, which are designed to implement data-protection principles, such as data minimization, in an effective manner ...'. Following a $\mathrm{PbD}$ approach, article 25(1) requires that such measures be implemented not only during processing, but even earlier 
when the means of processing is first determined. Furthermore, article 25(2) requires that such measures must ensure that 'by default, only personal data which are necessary for each specific purpose of the processing are processed'. Senarath and Arachchilage (2018a) observed that in practice, developers face a 'dilemma' between applying the data minimisation principle and collecting more data to create additional app functionality.

Although the POPIA contains no express reference to $\mathrm{PbD}$, it is apparent from a comparative analysis of the legal requirements that compliance with the POPIA also requires a PbD approach. The eight conditions for lawful processing under the POPIA reflect the same data protection principles contained in the GDPR (Botha et al. 2015a: 41). Table 2 (below) presents an analysis by ENISA $(2018: 22)$ of the application of GDPR principles in the context of mobile applications. Table 2 (col. 1) has been inserted to show the close correlation between the GDPR and the POPIA. Table 2 (row 8) has been included to show the accountability principle contained in the legislation.

In terms of the accountability principle in both the POPIA and the GDPR, the responsible party (data controller) is accountable for ensuring data privacy and must ensure that the conditions for lawful processing are complied with. Section 8 of the POPIA expressly records that this duty applies both 'at the time of the determination of the purpose and means of the processing and during the processing itself'. This implies a PbD approach.

Secondly, the data minimisation principle restricts how much personal data are collected, processed, stored and made accessible to third parties. Both the POPIA and the GDPR require that data collection be limited to the data that are adequate, relevant and not excessive; in other words, data that are necessary for the specified purposes of processing. Thus, by default, privacy is protected.

Lastly, both the POPIA and the GDPR require that data must be collected for a specific, explicitly defined and lawful purpose. In other words, there must be a legitimate purpose for the data collection. This requires, firstly, that the user be informed of and freely consents to this purpose, unless it is otherwise permitted by statute (POPIA 2013: sec.11; GDPR 2016: art.6), and, secondly, that further processing of data must be compatible with the purpose for which they were collected (POPIA 2013: sec.14; GDPR 2016: art.5.1.b). Aligned to this processing limitation is a storage limitation, in that data must not be kept in a form which permits identification of the data subject for longer than is necessary for achieving the purpose (POPIA 2013: sec.14; GDPR 2016: art.5.1.e). Data should therefore be deleted, or if this is not possible, de- 
identified (anonymised), or at least pseudonymised as soon as possible (ENISA 2018: 50).

Table 2: An indicative example of assessing risks with regard to GDPR compliance

\begin{tabular}{|c|c|c|c|}
\hline $\begin{array}{c}\text { POPIA } \\
\text { Condition }\end{array}$ & $\begin{array}{c}\text { GDPR } \\
\text { Principles }\end{array}$ & $\begin{array}{c}\text { Indicative } \\
\text { Privacy } \\
\text { Risks }\end{array}$ & $\begin{array}{c}\text { Indicative } \\
\text { Requirements }\end{array}$ \\
\hline $\begin{array}{l}\text { Processing } \\
\text { Limitation } \\
\text { lawful \& } \\
\text { reasonable } \\
\text { Sec.9 } \\
\text { Openness } \\
\text { Sec.17 \& } 18 \\
\text { Data subject } \\
\text { participation } \\
\text { Sec.23-25 }\end{array}$ & $\begin{array}{l}\text { Lawfulness, } \\
\text { fairness and } \\
\text { transparency - } \\
\text { Art.5(1)(a) }\end{array}$ & $\begin{array}{l}\text { Unlawful, } \\
\text { excessive } \\
\text { and incorrect } \\
\text { processing } \\
\text { (e.g. due to } \\
\text { permissions } \\
\text { to unautho- } \\
\text { rised parties } \\
\text { to access } \\
\text { personal data } \\
\text { through the } \\
\text { app). }\end{array}$ & $\begin{array}{l}\text { App providers/developers } \\
\text { should ensure that they } \\
\text { have a legal basis for the } \\
\text { processing of personal } \\
\text { data. } \\
\text { App providers/developers } \\
\text { should inform the data } \\
\text { subjects properly about } \\
\text { their data processing } \\
\text { activities. This may help } \\
\text { the users to understand } \\
\text { what personal data are } \\
\text { collected by them and } \\
\text { why. } \\
\text { App providers/developers } \\
\text { should be aware of data } \\
\text { subject rights such as } \\
\text { rights to access, } \\
\text { rectification, erasure, and } \\
\text { data portability. They } \\
\text { should implement } \\
\text { appropriate processes to } \\
\text { support these rights. } \\
\text { Transparency requires the } \\
\text { documentation of } \\
\text { processing operations. }\end{array}$ \\
\hline
\end{tabular}




\begin{tabular}{|c|c|c|c|}
\hline $\begin{array}{l}\text { Purpose } \\
\text { specification } \\
\text { Sec. } 13 \\
\text { Further } \\
\text { processing } \\
\text { limitation } \\
\text { Sec.15 }\end{array}$ & $\begin{array}{l}\text { Purpose } \\
\text { limitation } \\
\text { Art.5(1)(b) }\end{array}$ & $\begin{array}{l}\text { Excessive } \\
\text { collection } \\
\text { and sharing } \\
\text { of data (e.g. } \\
\text { due to } \\
\text { multiple } \\
\text { sensors of } \\
\text { mobile } \\
\text { devices that } \\
\text { are activated } \\
\text { without } \\
\text { need). }\end{array}$ & $\begin{array}{l}\text { App providers/developers } \\
\text { should use the data for a } \\
\text { specific purpose that the } \\
\text { data subjects have been } \\
\text { made aware of, and no } \\
\text { other without further } \\
\text { consent. If the personal } \\
\text { data are used for purposes } \\
\text { other than the initial } \\
\text { purpose, they should be } \\
\text { anonymised or the data } \\
\text { subjects must be notified } \\
\text { and their consent must be } \\
\text { re-obtained. }\end{array}$ \\
\hline $\begin{array}{l}\text { Processing } \\
\text { Limitation } \\
\text { Minimality } \\
\text { Sec. } 10\end{array}$ & $\begin{array}{l}\text { Data } \\
\text { minimisation } \\
\text { Art.5(1)(c) }\end{array}$ & $\begin{array}{l}\text { Excessive } \\
\text { processing } \\
\text { (e.g. due to } \\
\text { use of third- } \\
\text { party } \\
\text { libraries). }\end{array}$ & $\begin{array}{l}\text { The minimum amount of } \\
\text { data for specific } \\
\text { processing should be } \\
\text { processed by app } \\
\text { providers/developers. For } \\
\text { instance, they should not } \\
\text { store the exact location } \\
\text { point when a generic } \\
\text { location area is sufficient } \\
\text { for their app } \\
\text { functionalities. }\end{array}$ \\
\hline $\begin{array}{l}\text { Information } \\
\text { quality } \\
\text { Sec. } 16\end{array}$ & $\begin{array}{l}\text { Accuracy } \\
\text { Art.5(1)(d) }\end{array}$ & $\begin{array}{l}\text { Outdated } \\
\text { data pose } \\
\text { identity theft } \\
\text { risks. }\end{array}$ & $\begin{array}{l}\text { Rectification processes } \\
\text { into data management } \\
\text { should be embedded in } \\
\text { the app design. }\end{array}$ \\
\hline $\begin{array}{l}\text { Processing } \\
\text { limitation } \\
\text { retention \& } \\
\text { restriction of } \\
\text { records } \\
\text { Sec. } 14\end{array}$ & $\begin{array}{l}\text { Storage } \\
\text { limitation } \\
\text { Art.5(1)(e) }\end{array}$ & $\begin{array}{l}\text { Undue data } \\
\text { disclosure } \\
\text { (e.g. due to } \\
\text { cloud storage } \\
\text { services used } \\
\text { by mobile }\end{array}$ & $\begin{array}{l}\text { Personal data must not be } \\
\text { stored longer than is } \\
\text { necessary. App } \\
\text { providers/developers } \\
\text { should provide the 'right } \\
\text { to be forgotten' to the }\end{array}$ \\
\hline
\end{tabular}




\begin{tabular}{|l|l|l|l|}
\hline & & $\begin{array}{l}\text { app } \\
\text { developers). }\end{array}$ & $\begin{array}{l}\text { data subjects. This data } \\
\text { must be kept only for a } \\
\text { certain period of time for } \\
\text { non-active users. }\end{array}$ \\
\hline $\begin{array}{l}\text { Security } \\
\text { safeguards } \\
\text { Sec.19\& } 20\end{array}$ & $\begin{array}{l}\text { Integrity and } \\
\text { confidentiality } \\
\text { Art.5(1)(f) }\end{array}$ & $\begin{array}{l}\text { Unlawful } \\
\text { data } \\
\text { processing, } \\
\text { data loss, } \\
\text { data } \\
\text { breaches, } \\
\text { data } \\
\text { destruction } \\
\text { or damage. }\end{array}$ & $\begin{array}{l}\text { App providers/developers } \\
\text { should ensure that the } \\
\text { security requirements of } \\
\text { the personal data and the } \\
\text { processing systems are } \\
\text { met. This encompasses } \\
\text { integrity and } \\
\text { confidentiality, as well as } \\
\text { availability and resilience } \\
\text { (Art. 35(1)(b) GDPR). }\end{array}$ \\
$\begin{array}{ll}\text { For instance, the } \\
\text { appropriate control access } \\
\text { mechanisms should be } \\
\text { embedded into the apps } \\
\text { infrastructure, in order to } \\
\text { detect or monitor } \\
\text { unauthorised access to the } \\
\text { data. }\end{array}$ \\
\hline $\begin{array}{l}\text { Accounta- } \\
\text { bility }\end{array}$
\end{tabular}

Source: Col 1. \& row 8 adapted from POPIA (2013), Botha et al. (2015a: 41); Col 2-4, rows 1-7, drawn from ENISA (2018: 22). 
The POPIA and the GDPR are technologically neutral legislation, and refer only to 'appropriate technical and organizational measures' (e.a.) (GDPR 2016: rec.78; POPIA 2013: sec.19.1). The POPIA (2013: sec.19.1) simply states that such measures must be reasonable. However, the GDPR (2016: art.25.2) sets out four factors that must be taken into account in determining and implementing such measures: 'the state of the art, the cost of implementation, the nature, scope, context and purposes of processing and the risks of varying likelihood and severity for rights and freedoms of natural persons posed by the processing'.

Guidelines on best practice for mobile app developers provide examples of how to obtain informed consent (Future of Privacy Forum \& Center for Democracy 2011; National Telecommunications and Information Administration [US] 2013). Vague (blanket) consent does not meet the requirement of purpose specification (FTC [US] 2012: 58). Informed consent requires a 'clear affirmative act' (GDPR 2016: art.4.11) and must be preceded by disclosure of a specific, explicit and legitimate purpose (GDPR 2016: art5.1b). Blanket acceptance of general privacy terms does not meet GDPR requirements (Art.29WP [EU] 2017:16). While the challenges of communicating privacy practices on a small mobile screen are widely acknowledged, consent notifications must still be clear, prominent, and delivered at an appropriate time (FTC [US] 2012: 58; GSM Association 2016: 5).

The ability to develop secondary uses from analysis of very large data sets ('big data') presents challenges as to how core data protection principles are applied in practice (Art.29WP [EU] 2014: 2). Innovation inherently involves extracting insights from data that might lead to new uses that were not anticipated at the time of collection. There is extensive debate in the health ethics literature about the adequacy of broad (wide) consent versus blanket consent for future research use of biomedical specimens (Budin-Ljøsne et al. 2017:2). Dynamic consent, meaning 'personalised, online consent and communication platforms' that facilitates ongoing communication and user control (idem 3) may be informative for privacy researchers in the mobile ecosystem.

Although de-identified (anonymised) data are no longer personal data and thus not subject to data privacy laws (POPIA 2013: sec.6.1.b; GDPR 2016: rec.26), there is a blurred boundary between personally identifiable information (PII) and anonymous data (FTC [US] 2012: 2). Anonymisation is described in the literature as 'a process through which identifying information 
is manipulated (concealed or deleted) to make it difficult to identify data subjects' (Esayas 2015: 4). Data can be anonymised, for example, by aggregation of data or adding 'noise' (ENISA 2018: 48). However, if there is even a possibility that data can be re-identified to link to an individual, then the law applies (Esayas 2015: 10). Data are not de-identified or anonymous if the means of re-identifying an individual by manipulating the data or linking them to other data is 'reasonably foreseeable' (POPIA 2013: sec.1) or 'reasonably likely' (GDPR 2016: rec.26).

The Regulation on Privacy and Electronic Communications (2017: art.6) requires that electronic communications data (both content and metadata) be made anonymous, unless the purpose of processing cannot be fulfilled by processing anonymous data. The POPIA (2013: sec.14.1) requires that 'data must not be kept in a form which permits identification of the data subject for longer than is necessary for achieving the purpose', for which it was collected and processed. This can be achieved by destroying, deleting or de-identifying a data record (POPIA 2013: sec.14.4).

Pseudonymisation, on the other hand, can be achieved 'by substituting direct identifiers with codes and numbers to prevent an individual being identified' (Esayas 2015: 4). Data have been pseudonymised if technical and organisational measures are implemented to ensure that additional information that could be used to attribute the data to a specific data subject is always kept separately (GDPR 2016: art4). Pseudonymisation of data is specifically encouraged under GDPR (2016: art.25.1) as a practice that can protect privacy - although this does not preclude other measures such as encryption.

Although pseudonymisation is not explicitly referred to in the POPIA, it is a $\mathrm{PbD}$ practice that may be used to achieve the privacy objectives of a responsible party. However, parties subject to the POPIA are considerably constrained in their ability to use pseudonymised data, by the requirement in section 14(4) that the data be deleted or de-identified (which by definition requires deletion of any information that could reasonably be used to reidentify an individual) once the responsible party is no longer authorised to retain the data. Consent to retain the data in a pseudonymised form for a longer period, would be required.

\section{Challenges Facing SMMEs in Data Privacy Protection}

Within this already complex field, this empirical study sought to examine the 
challenges experienced by SMMEs. In addition, current legislation was analysed to determine whether there were any provisions that took into account the position of SMMEs.

The GDPR (2016: rec.16) encourages regulators to 'take account of the specific needs' of SMMEs. GDPR also adopts a risk-based approach to exemptions, rather than providing a blanket exemption to all SMMEs:

- An SMME with fewer than 250 employees is exempt from recordkeeping requirements, unless the processing it performs is routine rather than occasional, or concerns special personal data, or is 'likely to result in $a$ risk to the rights and freedoms of data subjects' (GDPR 2016: art.30.5) (e.a.).

- A privacy impact assessment is only required before processing data 'likely to result in a high risk to the rights and freedoms of natural persons' (GDPR 2016: art.35.1) (e.a.).

- Data breaches do not need to be reported to the supervisory authority if the data controller can show that it is 'unlikely to result in a risk to the rights and freedoms of natural persons' (GDPR 2016: art.33.1) (e.a.)

- Data breaches need only be reported to the data subject if it is 'likely to result in a high risk to the rights and freedoms of the natural person in order to enable him/her to take the necessary precautions' (GDPR 2016: art.34.1).

- A data protection officer is only required when the controller's core activities involve 'regular and systematic monitoring of the data subjects on a large scale' or the processing of special personal data 'on a large scale' (GDPR 2016: art.37.1).

Whether these provisions will achieve the desired effect of meeting the needs of SMMEs, is open to doubt. First, the terms 'a risk', 'a high risk' and 'large scale' monitoring are not defined and require expert analysis in any particular context. While presented as a cost-saving measure, in reality owners of small businesses will have to perform the same risk assessments without access to expert knowledge.

In South Africa, the POPIA applies to all entities processing personal information. The Act does not include risk-based exemptions. This makes the debate about developing a regulatory response that accommodates the position of SMMEs particularly relevant in South Africa. 
Although compliance with privacy legislation is recognised as imposing a significant regulatory burden on data controllers, it also provides an opportunity to build consumer trust and thus boost business success (Mikkonen 2014: 192). In one study, apps with missing or inadequate privacy policies were found to be less popular in the Google Play Store (Papageorgiou et al. 2018: 9394).

\section{Methodology}

This was an exploratory (pilot), qualitative case study undertaken with ethical approval and with written gatekeeper's permission and informed consent of participants. The stakeholder site was purposively selected, because their program has had a successful, government-supported program in operation since 2012, providing entrepreneurial support focused specifically on the target population: small app developers and entrepreneurs developing a mobile application.

Using a census approach, all graduates were invited to participate. Semi-structured, in-depth interviews of approximately 60 minutes each were audio-recorded, professionally transcribed and then thematically analysed by the researcher and a co-coder - using Nvivo (version 12) software. An indepth, semi-structured interview was also held with the CEO at the stakeholder site, as being a key informant providing insights into the stakeholder's perspectives and understanding of data privacy.

The findings were triangulated with document analysis of the participants' privacy policies and artefact analysis of the mobile app permission settings. Each app was downloaded on an Android smartphone, and a user account was created. Screenshots were taken to record the permission settings and privacy policy available to the app user. The participants were all either unwilling or unable to supply copies of contracts with third-party cloud service providers for inclusion in the analysis.

To preserve confidentiality and anonymity, the names of the participants, their businesses, and their apps, were excluded from the published findings.

\section{Research Design and Limitations}

The stakeholder site was based in Pretoria, although it accepts participants for 
its accelerator program from throughout South Africa. The site was thus regarded as sufficiently representative of a cross-section of experiences of small, mobile app developers in South Africa. Study participants were based in Pretoria, Johannesburg and Cape Town.

An additional stakeholder site, a technology start-up incubator in Durban, was identified using snowball sampling but was excluded from the research findings. From nine potential participants only two were available for an interview within the study time-frame but did not meet the participation criteria. The first respondent had developed a web-based app only and this study was limited to apps for personal handheld devices such as smartphones, and available for download on the Google Play or Apple App stores. The second respondent was no longer a small business as it had grown to more than 50 employees (National Small Enterprise Act 1996: sch.1) and had moved its registration offshore.

The aim of the study was to sample to redundancy; however, the sample size was limited by a low response rate. The invitation to participate was sent to 47 start-up organisations. Representative from four start-up organisations responded indicating a willingness to participate. The response rate was $8.5 \%$. The study findings are thus not capable of generalisation, but this was undertaken in August 2018 as a preliminary pilot study that formed part of $\mathrm{PhD}$ research. The expansion of the study to additional stakeholder sites, and a follow-up study employing a national survey of app developers met similarly low response rates in 2019 and could not be completed in 2020 due to the national state of emergency in response to COVID-19. A revised followup study is planned for 2022. As further publishable work is some years away, the results of the preliminary pilot study are regarded as important for distribution in the public domain on the eve of the commencement of the POPIA on 1 July 2021, as they highlight a critical lack of awareness around data privacy that merits immediate attention from the Information Regulator, and industry stakeholders.

The use of in-depth interviews was integral to the research design. Although it required a significant time commitment from participants, which may have reduced the response rate, it provided rich data. One-on-one interviews provided an intimate conversational setting to foster maximum trust and encourage frank disclosure by participants.

An inter-disciplinary study which subjected apps to static and dynamic analysis to identify vulnerabilities, detect communications between the app and 
third parties, test the security of data transmissions, and identify the content of data packets, could provide more detailed insight into the privacy and security risks posed by the apps (Papageorgiou et al. 2018: 9393). It could also provide the basis for a follow-up study to determine what app developers could do differently to better protect the privacy of the personal data of app users.

\section{Results and Discussion}

This section first provides a summary of the participant demographics, business profiles and apps encountered in the study. It then presents the results of the qualitative analysis of interview transcripts and discusses those findings.

\section{Participants' Profiles}

In terms of the participation criteria for the study, participants had to be either a mobile app developer or an entrepreneur who owns a company developing a mobile app, or both. All the participants were entrepreneurs, but only one was also a mobile app developer. All were males. Three were black and one was white. Three were aged between 35 to 45 years while the fourth participant was between 25 and 35 years. . All had attained at least an undergraduate degree. However, only one participant had a formal qualification (or training) in app development. He reported that he had not covered data privacy in his studies, that he employed other developers and had not written the code for the app discussed as part of the study.

The study sought to explore the relationships between app developers and companies developing the app. The study revealed an interesting dichotomy between the views of these two types of participants. On the one extreme was an entrepreneur who took the view that the app developer was responsible for data privacy. He had outsourced the app development to an independent developer (whereas all other participants had developers as business employees or partners). He described the situation thus:

Because even on the app when you go to the app store, it says 'this app is developed by [Name of Developer]', So it doesn't say it's developed by [Name of Participant]. So, it means they are responsible for it.

The same participant had almost no knowledge about what data the app was 
actually collecting, saying 'the developer can tell me, I don't know'. Nor had the participant had any discussion with the developer about which third parties might have access to the data or where the data would be stored:

I don't know, it's just a cloud. That's what the developer told me, he said, 'no, we're using [a] cloud'.

When probed about the issue he recalled an email from the developer listing third-party software being used in the app but added that he had 'no idea' who these people were or what their role was. When asked if he had any responsibility to ensure that these parties, if accessing the data, did so lawfully, his response indicated mixed feelings - on the one hand shifting responsibility to the developer and on the other hand expressing doubt about what steps he should take himself.

In contrast, the one participant, who was an app developer, placed responsibility for data privacy with his client, and accepted responsibility only for maintaining confidentiality in respect of data accessed by his company or employees. He did so on the basis that his company was not hosting the data and back-end application. The interview also established that he had no insight into the contracts between the client and other service providers. Nevertheless, as the party responsible for the design of the system, it was notable that when asked if he had any data privacy goals in mind when developing the app, he candidly replied: 'Not at all'. When the issue was probed further, he further added:

We focus on developing solutions and systems. We don't prioritise [the] privacy of our users.

The above examples serve to illustrate the limitations of privacy risk assessments conducted by individual entities, and the need for privacy to be assessed in 'a holistic, ecosystem-wide manner if it is to be both effective and lasting' (Cavoukian 2010: 7).

\section{Business Profiles}

The study was restricted to businesses that are small enterprises, by reference to having less than 50 employees in terms of the Schedule to the National Small 
Enterprise Act 102 of 1996 . The businesses were all formally registered private companies but ranged in size: two employed less than five employees (including the owner), one employed six to nine employees and one employed 10 to 49 employees. In addition, all participant businesses potentially met the criteria as exempt micro enterprises, having an annual turnover of less than R10 million in terms of the amended Information and Communication Technology (ICT) Broad-based Black Economic (B-BEE) Sector Code (RSA 2016)

\section{App Profiles}

The study was further restricted to businesses developing one or more mobile apps for personal handheld devices. The study classified businesses to one of the following stages:

a. Start up - concept successfully pitched to incubator or funder;

b. Pilot - app is currently being piloted/completed pilot testing premarket launch;

c. Commercialised - first sales after successful market launch; less than one year in operation; and

d. Scale - developed further apps, markets, or significantly increased turnover, and more than one year in operation.

All the apps had been commercialised and were available on the Google Play Store for download on Android devices, and one app was also available on the Apple App Store. However, none of the apps had reached a stage of scale having only about 50 to 100 downloads each. The reasons for this were reported as being due to secure business partner or client buy-in.

The study did not focus on one particular app category. The stakeholder site-selected program entrants were based on the potential social impact of the app concept, but the apps involved in the study had diverse classifycations on the app store: education, retail, government services, and social.

All the apps were available as free downloads and thus, unsurprisingly, two of the four participants planned to monetise the data itself (in anonymised form) as a revenue generating mechanism. A third participant's business model was still in its infancy, but he anticipated integrating the app directly with financial services' companies. When probed on this issue, he realised - 
apparently for the first time - that this would raise concerns about whether those companies would also use the data of app users for other purposes, for example for targeted advertising. The fourth app provided government services and collected sensitive data, and for this reason it was hosted on government servers, and the privacy of the app data was controlled by requiring all employees with access to the data to sign confidentiality agreements.

\section{Knowledge about Privacy Laws}

Although all participants claimed knowledge about data privacy with varying degrees of confidence, they had no or very limited knowledge of the specific requirements of data privacy legislation. An empirical study by Botha et al. (2015b: 7) showed that South African SMMEs were not yet compliant with the POPIA, chiefly due to a lack of awareness.

Two participants were unaware of the existence of specific laws governing privacy and could not name the legislation - but displayed markedly different degrees of confidence in their level of knowledge. The first particularly confident response, claimed full awareness:

I am fully aware of it and it's a recent one anyways. But even ... I mean with the recent one, it's just because of the Facebook case [involving Cambridge Analytica]. But other than that, my knowledge when it comes to data is that the guy who develops the app has the data, ok. But I think [The Stakeholder] told me that no, it will be my responsibility eventually, so I'm still trying to figure it out how am I going to own it.

In contrast, another participant expressed considerable doubt about their knowledge of data privacy laws:

Um not really, not much. Not ... just, just ... you know, like for example, what I understand about, about the privacy is that, for example, like you ... like you're not allowed to advertise to kids [minors], right? ... So, I guess I will have to read ... Is there an actual Act that is...?

The other two participants knew about the existence of the legislation and some key data protection principles but claimed a lack of knowledge about the specific provisions. For example, the third participant reported that the 
company intern was tasked with drafting a report on the differences between the POPIA and the GDRP - with the aim of 'trying to see what were the big differences'. However, when probed on this point, the participant admitted that they had not done anything about it:

No, I read quickly the notes, I just filed it for the next time. I am meeting the lawyers, uh, I didn't see anything that was really concerning for the moment; I had a look, but not properly, at it.

Interestingly the participant recorded the rationale for this exercise to be they would implement 'the higher standard', which they assumed to be the European standard. Although there is considerable overlap as the same data privacy principles underpin the legislation, there are also differences. In some respects, the POPIA imposes a higher standard. For example, the POPIA applies to the data of juristic persons as well as natural persons. This participant's response thus brings to the fore the concern raised by several other participants and the key informant - that it is very difficult to comply with different legal standards. The GDPR has extra-territorial application, and thus a South African app developer who is processing the personal data of any resident of the EU would be governed by both the POPIA and the GDPR. This same participant said of his compliance with data privacy laws:

It's very easy for me to say that we [are] compliant because our terms and conditions were written by professional lawyers that know what they are talking about. I have absolutely no clue what are in the terms and conditions; I just make sure that I comply.

What emerged from the interviews was that participants were either unclear about what a privacy policy should contain or were unaware of what their own privacy policy did contain. A document analysis of the privacy policies of the developers revealed that the terms and conditions were generic and did not comply with requirements of the legislation.

\section{Attitudes towards Privacy Laws}

All participants expressed high levels of concern about data privacy compliance and a desire to learn more about how to comply with the law. 
However, their attitudes towards data privacy are best described as mixed. All participants expressed a desire to ensure users gave informed consent and a desire to learn more about how to comply with privacy laws (which were coded as positive attitudes). However, they expressed mixed feelings when discussing the importance of privacy compared with other priorities, principally the need to focus on how the app functions and the need to monetise the app. For example, one participant stated that:

... data is a, or at least the privacy of the data, is a big concern for us and we wanna [want to] make sure that we use it correctly, protecting the privacy of the [identified App user] that [who] are our customers, uhm, but at the same time being able to use the data to have a financially sustainable business model.

I mean data privacy is of course important but the latency is as important, and if my app is uh too slow, no one will use it. So, I won't even have an issue about data privacy, because I won't have any data.

This same user raised the issue again, when discussing different cloud services:

Alibaba[.com] has a kind of radical view on data privacy saying that if they have the same rules as there are in Europe, your [their] service would not exist and there wouldn't be any convenience for the user.

Some participants showed concern about the fact that the legislation may expose them to sanctions and expressed the view that as small businesses they needed to be 'protected' from the legislation. Views expressing the attitude that participants would comply with privacy laws to avoid prosecution, were also coded as mixed. Furthermore, all participants expressed mixed attitudes on the issue of whether the participants had any responsibility to ensure that third parties given access to the data only used the data for a lawful purpose. This is discussed further in relation to the practices employed in relation to privacy (below).

\section{Practices Employed in Relation to Privacy}

Privacy by Design was not a practice implemented by any of the participants. 
Although all participants were already at the stage of commercialisation, the view expressed was that privacy was 'not really a concern right now' and that they could 'sort it out when the time comes'. As one participant put it:

No. All I wanted was to see the app working (laughter). Believe you me, all I wanted to see was the app working.

The same view was expressed in one way or another by all the participants, and none reported undertaking a privacy impact assessment, or mapping data flows and risks of data leakage. None reported having obtained legal advice specifically related to compliance with privacy legislation; this was related to the high cost of quality legal services, which was mentioned by all participants.

The study aimed to explore which third parties might have access to the app data, but three out of the four participants could not explain clearly who would have access to the app data, and in one case, a participant was unaware of who was hosting the app and whether the data was being stored in South Africa. The term 'trust' or variants such as 'believe', were raised by all participants to describe their relationship with third parties, who might have access to app data. One participant expressed it thus:

To be completely honest with you, I trust them to follow the rules .... And that's why we haven't checked ...

Prompted for further disclosure, the participant indicated:

So, basically, I wouldn't like Google Cloud or Alibaba[.com] to access our information and then to sell this information to someone else, because that's what I'm planning to do. ... But my first thought is that they [Google Cloud and Alibaba.com] are compliant with any data privacy rules.

Another participant expressed the view that using Google and other 'big companies' was the best means of protecting app data:

I mean it's something that we think about. We can only hope and obviously, uhm trust that since they're a big company and they are up there with top officials, you know, of any government-uhm, it would 
be used to protect all our data.

When probed as to whether he had ever checked the terms and conditions, he admitted that he had not:

Can I be honest? ... You know we all just click, uh, without reading the terms and conditions. I don't know when the last time was [that] I read privacy policies.

Only one participant reported reading the terms and conditions of the app store but reported that he 'wouldn't know' if app stores were able to process the content of app data, although the terms and conditions stated that the app store simply hosts the 'lining' of the application.

When prompted with the question of whether the development process includes steps to restrict data collection, it appeared that generally the opposite approach is taken. The stakeholder interview also flagged the issue:

We haven't come across directly where it's about the user data being sold, it's about using that data to create a hypothesis or a tool or a utility ... by design, the notion is not what you need for this version, but always collect as much as you can ...

The stakeholder is also aware of the privacy risks, and appropriate privacy practices, but reported the view that this was not how things are generally being done:

... by design should it [personal data] come in and immediately [you] anonymise it and you only work with that data ... But I think what's happening at the moment, people are using that single raw pool of data to do things on top of it. So there's always risk. You've created a door into the data ...

\section{Challenges Experienced in Relation to Privacy}

Three challenges were reported by all participants. First, they reported challenges complying with the requirement of meaningful consent. Second, they reported that it was difficult to obtain affordable and adequate legal 
advice. Last, they reported a need for education and training. The concerns facing the participants in this study related to complex challenges posed by inter-operability of systems through Application Processing Interfaces (APIs) and how to de-identify (anonymise) or pseudonymise data. A study of free education and training resources about the POPIA, which are available online, showed that while they were useful for raising awareness and general education, they did not replace the need for specific, expert advice (Botha 2015a: 49).

The requirement for user consent was experienced as challenging because of the difficulty in explaining how the data were used, and conversely because it might 'scare' users provide the full information. The challenge was linked to the lack of an adequate privacy policy, and in turn to the lack of awareness and lack of access to expert advice. Figure 1 (below) shows that although all participants claimed to have a privacy policy, some were not available to app users, and none adequately complied with the privacy legislation.

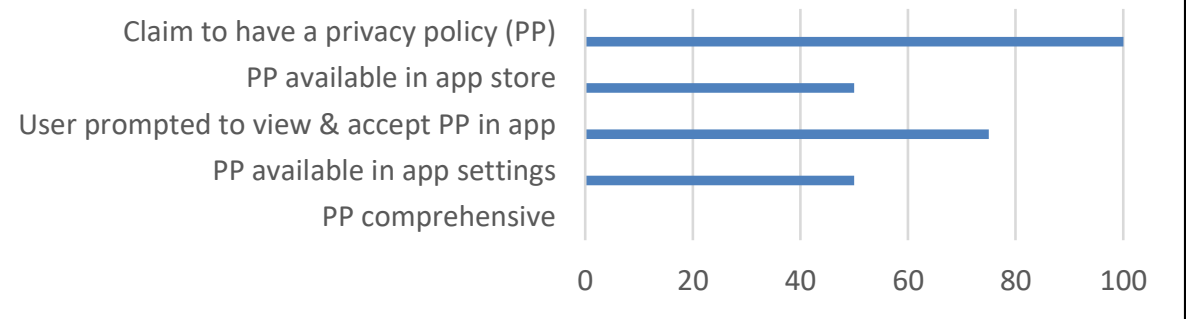

Figure 1: Participant use of privacy policies

\section{Privacy Analysis of App 1}

One participant had already resolved that because of the problems created by users reading his terms and conditions and deciding not to install the app - on the next upgrade he was going to 'hide them with that small print'. He claimed to have terms and conditions that were 'generic', but which had been drafted on a pro bono basis by a law firm in Sandton. Artefact analysis of the app demonstrated that the app user is required to create a profile with their name and surname (but no password) and the terms and conditions are then automatically displayed, requiring the user to scroll through several screens and mark a check box at the end to 'accept'. To complete the sign-up process, 
and before using the app, the user is then required to enter especially sensitive data, including their identity number, date of birth, gender, marital status and information from which the app user's race and ethnicity can be identified.

Upon download, the app asks the app user to deny or allow the app permission to 'access photos, media and files on your device'. The app can still be used without enabling this permission, but some functions will not be available. Additional app permissions in the app info, viewable in the Play Store, indicated that the app can also access contacts, location (approximate and precise GPS location), phone (read phone status and identity, directly call phone numbers) and SMS, which have been flagged in prior research as dangerous permission settings (Papageorgiou et al. 2018: 9394), and should have been explained in the app's privacy policy.

When the terms and conditions of this app were reviewed, it was unsurprising that the participant reported that many potential app users had been deterred from downloading the app. The terms were poorly drafted, containing incomplete sentences, grammatical errors and repetition. To confuse matters further, the developer's privacy policy viewable in the app store had a completely different set of terms and conditions related to a different business.

Analysis of the privacy policy showed it to be completely inadequate, even for bare compliance with the legislation. Two sections referred to in-app purchases and subscriptions respectively, and links after each section for 'full disclosure' were broken and provided no additional information. The interview also clarified that both sections were inapplicable, as the app was a free download with no in-app purchases or subscriptions. The terms then contained a section on content, informing the user 'you are responsible for the content created and shared'. No details were provided of what data were collected by the app and how it was processed.

\section{Privacy Analysis of App 2}

The terms of another app's privacy policy informed the app user:

It is solely the responsibility of the user to protect your privacy.

This is completely at odds with the PbD principle that a user's privacy should be protected by default - even if the app user does nothing. Not only was this statement incorrect according to the law, but the privacy policy was outdated 


\section{Dusty-Lee Donnelly}

as it informed users that they could choose to use the app anonymously. In the interview it was established that version 1 of the app collected the user's telephone number and device details to permit the creation of a permanent identifier that would enable user interaction with the app to be tracked to a particular user - even if they uninstalled the app and downloaded it again. In version 2 of the app, anonymity was impossible as the app required registration with personal details.

This privacy policy informed users that their information might be disclosed to 'internal and external parties for the purpose of the service', but did not identify those parties or purposes. It then sets out a potentially confusing assurance that the app user data will not be sold or shared with third parties, unless requested by the app user.

The primary parties to whom the data are transmitted by the app, and the purpose of the data collection, are set out clearly in the details about the app in the app store but are not repeated in the privacy policy. The permissions listed in the app store indicate that the app has access to the device's camera, contacts, location and calendar, but this is not explained in the privacy policy. Access to the calendar states that it includes permission to read calendar events and confidential information, to modify and add events and send emails to guests without the user's knowledge.

No further information is provided in the privacy policy about further processing, or about how the transmission, storage and privacy of the data are secured. The interview also established that the data were being used for forecasting and analysis - but did not establish whether the data were deidentified. The interview also established that the data were being hosted by an external service provider, in terms of an expired contract. The developer was not privy to any contracts with third-party processors.

\section{Privacy Analysis of App 3}

The privacy policy sets out in clear and understandable language the general types of personal data collected, the purposes of collection, and how the data are secured. The policy indicates the general categories of third parties who may receive personal information, the reasons for this and alerts the user that some processing may take place outside South Africa but does not state where. As the privacy policy is a general policy applicable to the app developer's websites and products, it is a good illustration of the limitations of privacy 
policies in providing specific information about an app. The policy does provide an email point of contact for further queries on the privacy policy.

The app is educational and will be used by children. The privacy policy did not deal with the issue of parental consent - stating only that the developer does 'not publish content that is targeted at children' and will 'not knowingly collect personally identifiable information from children under the age of 13 years'. In South Africa, the age of consent is 18 years (POPIA 2013: sec.1) and processing requires the prior consent of the child's parent or guardian (a 'competent person') (POPIA 2013: sec.35.1). In the EU the general age of consent is 16 years, although the member state law can lower the age of consent but not to below 13 years (GDPR 2016: art8.1). In the app, a year of birth is required to access certain 'parents' only' areas.

Furthermore, app users are assured that the developer will not sell or share their personal details with anyone, but the privacy policy later recorded that 'occasionally' data may be shared with external companies for marketing their products and services by post, unless the user opts out. Users are directed to the developer's website to update their profile and subscriptions, but no website address is provided.

Therefore, this privacy policy was not regarded as dealing comprehensively with all privacy issues.

\section{Privacy Analysis of App 4}

The fourth participant, discussing informed consent, responded that:

My first concern is that I respect my users; I use the data [and would like] that they are fully aware that I'm using [it] and that they feel good about it.

In the same interview, when probed further on how informed consent would be obtained, the participant responded:

I think that won't be a problem because people don't read this type of thing, but I want our users to fully understand that if we give them a service that is cheap for them it's because we use the data. It's because we use the data to sell services to brands and I don't want to hide that from them. I want them to understand that it's a free service because 
we can sell some ads [advertisements] on it and I want them to be fully aware of that, and I want to understand if that's a problem for them or not ... that's mainly our concern - how do we present that to our users [so as] not to scare them? ...

The participant indicated in the interview that their terms and conditions will be freely accessible on their app and that he would have 'no problem' sending them to the researcher. The use of future tense was not probed in the interview, but subsequent analysis of the app indicated that users installing the app must register by supplying a phone number, creating a password and checking a tick box indicating 'I have read and accept the T\&Cs (terms and conditions) of use of XXX app'. However, there was, no link to the terms and conditions. The developer did not list a privacy policy in the relevant app store or anywhere in the app settings. A follow-up email to the participant enquiring about these matters went unanswered.

\section{Conclusion and Recommendations}

Although a technical study such as that by Papageorgiou et al. (2018) would be needed to accurately determine the risk posed by individual apps to the privacy of app users, this study did demonstrate that app developers and entrepreneurs developing mobile apps are neither sufficiently aware of, nor compliant with the legislative requirements of the GDPR and the POPIA. The key findings of the study were that all participants:

1. Had no or very limited knowledge of data privacy legislation;

2. Expressed high levels of concern about data privacy compliance, but responder bias was likely, as low overall participation rates suggest that data privacy is not a high priority for SMMEs engaged in mobile app development;

3. Reported relying on 'trust' of third-party providers and employed no measures to vet privacy compliance; and

4. Reported challenges complying with the requirement of meaningful consent.

While the study sought to investigate specific strategies and tools being employed by app developers to address privacy in the design of their mobile 
apps, the participants did not report any comprehensive information on the available strategies, suggesting that they lacked sufficient knowledge about the existing technology. Likewise, where third parties were involved the participants were not taking steps to identify those third parties, to verify what data those third parties were collecting from the app, and to ensure that contract terms provided sufficient protection of the privacy of app user data. On the contrary, participants reported that they relied upon 'trust' of third parties but did not report using any strategies to verify that their trust was well-placed, such as contractual guarantees, privacy certification, privacy risk assessments or a data management plan. In short, $\mathrm{PbD}$ is not an approach that was being implemented by these developers. On the contrary, privacy is regarded as an issue that can be addressed after successful commercialisation of the app.

Despite all the participants being aware of the need to obtain consent from users, the findings suggest that app developers need to know more, in practical terms, about how to obtain meaningful consent from app users. At the simplest level this involves being in a position to draft appropriate privacy policy terms. However, more complex concerns involve how one deals with sensitive data, data of minors or anonymised data. The findings suggest a need for detailed guidance for app developers on these issues. These findings cannot be generalised due to the small sample size. However, they are consistent with earlier studies in other jurisdictions. The findings point to the need for a wider study of these issues in South Africa, to better understand the awareness, attitudes, practices and challenges of app developers, and to isolate issues that may be unique to SMMEs. As further publishable work will only be publishable in years to come, the results of the preliminary pilot study are important to be shared in the public domain as soon as possible, as they highlight that app developers in South Africa may have a critical lack of awareness around data privacy that merits immediate attention from the Information Regulator and industry stakeholders.

The Information Regulator (2021) published a guideline for the development of Codes of Conduct in terms of sec.65 of the POPIA. However, mobile app developers do not work in a sector with a representative regulatory oversight body that could develop such a code. Based on the findings of this study it is recommended that the Information Regulator in South Africa:

1. Introduces appropriate training and education materials for app developers on privacy requirements; 
2. Develops or endorses suitable guidelines on best practice for app developers;

3. Ensures that such guidelines contain clear, explicit requirements, with steps for evaluation and appropriate software engineering techniques (Senarath \& Arachchilage 2018b); and

4. Engages all stakeholders in the mobile ecosystem, including platform providers, OS providers, hardware manufacturers, advertisers and other third parties, on means to best secure the privacy of app users.

\section{Acknowledgements}

The author gratefully acknowledges the app developers and entrepreneurs who have taken part in the study to date. The financial assistance of the National Research Foundation (NRF) is hereby gratefully acknowledged. Opinions expressed and conclusions arrived at, are those of the author and are not to be attributed to the NRF.

\section{References}

Article 29 Data Protection Working Party (art29WP) [EU] 2013. Opinion 02/2013 on Apps on Smart Devices. WP202. Available at:

https://ec.europa.eu/justice/article-29/documentation/opinionrecommendation/files/2013/wp202_en.pdf (Accessed on 17 May 2021.)

Article 29 Data Protection Working Party (art29WP) [EU] 2014. Statement of the WP29 on the Impact of the Development of Big Data on the Protection of Individuals with Regard to the Processing of their Personal Data in the EU. WP221. Available at: https://www.pdpjournals.com/docs/88352.pdf (Accessed on 17 May 2021.)

Article 29 Data Protection Working Party (art29WP) [EU] 2017. Guidelines on Consent under Regulation 2016/679. WP259. Available at: https://ec.europa.eu/newsroom/article29/itemdetail.cfm?item_id=623051 (Accessed on 17 May 2021.)

Balebako, R. et al 2014. The Privacy and Security Behaviors of Smartphone App Developers. Workshop on Usable Security (USEC 2014), San Diego, 2014. Available at:

https://www.researchgate.net/publication/269197012_The_Privacy_and Security_Behaviors_of_Smartphone_App_Developers (Accessed on 17 May 2021.) 
Binns, R. et al 2018. Third Party Tracking in the Mobile Ecosystem. Paper presented at Proceedings of the 10th ACM Conference on Web Science. Available at: https://arxiv.org/pdf/1804.03603.pdf (Accessed on 17 May 2021.)

Botha, J. et al 2015a. Evaluation of Online Resources on the Implementation of the Protection of Personal Information Act in South Africa. In Zaayman, J. \& L. Leenan (eds.): Proceedings of the $10^{\text {th }}$ International Conference on Cyber Warfare and Security ICCWS-2015. Reading: Academic Conferences. Available at:

https://researchspace.csir.co.za/dspace/handle/10204/8299 (Accessed on 17 May 2021.)

Botha, J. et al 2015b. The Effects of the POPI Act on Small and Medium Enterprises in South Africa. In Venter, H.S., M. Loock \& M. Coetzee et al. (eds.): Proceedings of the Information Security of South Africa (ISSA) 2015 Conference. Johannesburg: ISSA.

Available at: https://doi.org/10.1109/ISSA.2015.7335054

(Accessed on 17 May 2021.)

Breaux, T D. et al 2015. Detecting Repurposing and Over-collection in Multiparty Privacy Requirements Specifications. Paper presented at 2015 IEEE 23rd International Requirements Engineering Conference (RE). Available at: https://doi.org/10.1109/RE.2015.7320419

(Accessed on 17 May 2021.)

Budin-Ljøsne, I. et al 2017. Dynamic Consent: A Potential Solution to Some of the Challenges of Modern Biomedical Research. BMC Medical Ethics 18,4: 1 - 10. Available at: https://doi.org/10.1186/s12910-016-0162-9 (Accessed on 17 May 2021.)

California Department of Justice (CA AG) 2013. Privacy on the Go: Recommendations for the Mobile Ecosystem. Available at: https://oag.ca.gov/sites/all/files/agweb/pdfs/privacy/privacy_on_the_go. pdf (Accessed on 17 May 2021.)

Cavoukian, A 2011. Privacy by Design Strong Privacy Protection-Now, and Well into the Future a Report on the State of PbD to $33^{\text {rd }}$ International Conference of Data Protection and Privacy Commissioners. Toronto, ON, Canada: Office of the Privacy Commissioner, Ontario, Canada. Available at:

https://www.ipc.on.ca/wp-content/uploads/Resources/PbDReport.pdf (Accessed on 17 May 2021.) 
Cavoukian, A 2012. Privacy by Design and the Emerging Personal Data Ecosystem. Toronto, ON, Canada: Office of the Privacy Commissioner, Ontario, Canada. Available at:

https://www.ipc.on.ca/wp-content/uploads/Resources/pbd-pde.pdf (Accessed on 17 May 2021.)

Cavoukian, A. \& M. Prosch 2010. The Roadmap for Privacy by Design in Mobile Communications: A Practical Tool for Developers, Service Providers, and Users. Toronto, ON, Canada: Office of the Privacy Commissioner, Ontario, Canada. Available at: https://www.ipc.on.ca/wpcontent/uploads/Resources/pbd-asu-mobile.pdf (Accessed on 17 May 2021.)

Cortesi, A. et al 2015. Datacentric Semantics for Verification of Privacy Policy Compliance by Mobile Applications. Paper presented at International Workshop on Verification, Model Checking, and Abstract Interpretation. Available at: https://doi.org/10.1007/978-3-662-46081-8_4 (Accessed on 17 May 2021.)

Data Protection Directive. 1995. Directive on the protection of individuals with regard to the processing of personal data and on the free movement of such data. (1995) 95/46/EC. Available at: https://eurlex.europa.eu/legal-content/EN/TXT/?uri=CELEX\%3A31995L0046 (Accessed on 17 May 2021.)

De Bruyn, M 2014. The Protection of Information (POPI) Act - Impact on South Africa. International Business and Economics Research Journal 13,6: 1315 - 1340. Available at: https://doi.org/10.19030/iber.v13i6.8922 (Accessed on 17 May 2021.)

Electronic Communications and Transactions Act (Act 25 of 2002) 2002. Available at: https://www.gov.za/documents/electronic-communicationsand-transactions-act (Accessed on 17 May 2021.)

Esayas, S 2015. The Role of Anonymisation and Pseudonymisation Under the EU Data Privacy Rules: Beyond the 'All or Nothing' Approach. European Journal of Law and Technology 6,2: 1 - 23. Available at: https://ssrn.com/abstract=2746831 (Accessed on 17 May 2021.)

European Data Protection Board (EDPB) 2018. Guidelines 3/2018 on the Territorial Scope of the GDPR (Article 3). Available at: https://edpb.europa.eu/sites/edpb/files/consultation/edpb guidelines 32018 territorial scope en.pdf (Accessed on 17 May 2021.) 
European Network and Information Security Agency (ENISA) 2018. Privacy and Data Protection in Mobile Applications. Heraklion, Greece: ENISA. Available at: https://www.enisa.europa.eu/publications/privacy-and-dataprotection-in-mobile-applications (Accessed on 17 May 2021.)

Federal Trade Commission (FTC) [US] 2012. Protecting Consumer Privacy in an Era of Rapid Change: Recommendations for Businesses and Policymakers. Available at: https://www.ftc.gov/reports/protectingconsumer-privacy-era-rapid-change-recommendations-businessespolicymakers (Accessed on 17 May 2021.)

Federal Trade Commission (FTC) [US] 2013. Mobile Privacy Disclosures Building Trust Through Transparency. Available at:

www.ftc.gov/os/2013/02/130201mobileprivacyreport.pdf (Accessed on 17 May 2021.)

Federal Trade Commission (FTC) [US] 2019. Opinion of the Commission in the matter of Cambridge Analytica, LLC. Available at:

https://www.ftc.gov/system/files/documents/cases/d09389 comm final opinionpublic.pdf (Accessed on 17 May 2021.)

Future of Privacy Forum \& Center for Democracy and Technology 2011. Best Practices for Mobile Applications Developers. Available at:

https://fpf.org/wp-content/uploads/Apps-Best-Practices-v-beta.pdf (Accessed on 17 May 2021.)

General Data Protection Regulation (GDPR) 2016. Regulation (EU) 2016/679 of the European Parliament and of the Council of 27 April 2016 on the Protection of Natural Persons with Regard to the Processing of Personal Data and on the Free Movement of Such Data, and Repealing Directive 95/46/EC. Available at: https://eur-lex.europa.eu/legalcontent/EN/TXT/?uri=celex\%3A32016R0679 (Accessed on 17 May 2021.)

GSM Association 2011. Mobile Privacy Principles: Promoting Consumer Privacy in the Mobile Ecosystem. Available at:

https://www.gsma.com/publicpolicy/wp content/uploads/2016/02/GSMA2016

Guidelines_Mobile_Privacy_Principles.pdf (Accessed on 17 May 2021.)

Hadar, I. et al 2018. Privacy by Designers: Software Developers' Privacy Mindset. Empirical Software Engineering 23,1: 259 - 289. Available at: https://doi.org/10.1007/s10664-017-9517-1 (Accessed on 17 May 2021.) He, L. et al 2019. The Impact of GDPR on Global Technology Development. 
Journal of Global Information Technology Management 22,1: 1 - 6.

Available at: https://doi.org/10.1080/1097198X.2019.1569186

(Accessed on 17 May 2021.)

Information Commissioner's Office (ICO) [UK] 2013. Privacy in Mobile apps: Guidance for app Developers. Available at:

https://ico.org.uk/media/for-organisations/documents/1596/privacy-inmobile-apps-dp-guidance.pdfhttps://ico.org.uk/media/for-

organisations/documents/1596/privacy-in-mobile-apps-dp-guidance.pdf

(Accessed on 17 May 2021.)

Information Regulator [RSA] 2021. Guidelines to Develop Codes of Conduct: Issued Under The Protection Of Personal Information Act 4 Of 2013 (POPIA).

Available at:

https://www.justice.gov.za/inforeg/docs/InfoRegSA-Guidelines-

DevelopCodeOfConduct-22Feb2021.pdf (Accessed on 17 May 2021.)

Jain, S. \& J. Lindqvist 2014. Should I Protect You? Understanding Developers'

Behavior to Privacy-preserving APIs. Workshop on Usable Security (USEC'14). Available at:

https://www.ndss-symposium.org/wp-content/uploads/2017/09/01_1-

paper.pdf (Accessed on 17 May 2021.)

Kuan Hon, W 2016. GDPR: Killing Cloud Quickly? Portsmouth, NH, USA: International Association of Privacy Professionals (IAPP). Available at: https://iapp.org/news/a/gdpr-killing-cloud-quickly/ (Accessed on 17 May 2021.)

Li, H. et al 2019. The Impact of GDPR on Global Technology Development. Journal of Global Information Technology Management 22,1: 1 - 6 . Available at:

https://doi.org/10.1080/1097198X.2019.1569186 (Accessed on 17 May 2021.)

Kurtz, C. \& M. Semmann 2018. Privacy by Design to Comply with GDPR: A Review on Third-Party Data Processors. Available at:

https://aisel.aisnet.org/amcis2018/Security/Presentations/36/ (Accessed on 17 May 2021.)

Martin, K. \& K. Shilton 2016. Putting Mobile Application Privacy in Context: An Empirical Study of User Privacy Expectations for Mobile Devices. The Information Society 32,3: 200 - 216. Available at:

https://www.tandfonline.com/doi/full/10.1080/01972243.2016.1153012 (Accessed on 17 May 2021.) 
Martin, Y-S. \& A. Kung 2018. Methods and Tools for GDPR Compliance Through Privacy and Data Protection Engineering. Paper presented at 2018 IEEE European Symposium on Security and Privacy Workshops (EuroS\&PW). Available at:

https://doi.org/10.1109/EuroSPW.2018.00021

https://ieeexplore.ieee.org/document/8406568

(Accessed on 17 May 2021.)

Mikkonen, T 2014. Perceptions of Controllers on EU Data Protection Reform: A Finnish Perspective. Computer Law and Security Review 30: 190 - 195. Available at:

https://www.sciencedirect.com/science/article/abs/pii/S02673649140002 $\underline{84}$ (Accessed on 17 May 2021.)

National Small Enterprise Act (Act 102 of 1996) 1996. Available at: https://www.gov.za/documents/national-small-business-act (Accessed on 17 May 2021.)

National Telecommunications and Information Administration (NTIA) United States Department of Commerce 2013. Short Form Notice Code of Conduct to Promote Transparency in Mobile App Practices. Available at: https://www.ntia.doc.gov/files/ntia/publications/july 25 code draft.pdf( Accessed on 17 Ma7 2021.)

Office of the Australian Information Commissioner (OAIC) 2014. Mobile Privacy: A Better Practice Guide for Mobile App Developers. Available at: $\quad$ https://www.oaic.gov.au/agencies-and-organisations/guides/guidefor-mobile-app-developers (Accessed on 17 May 2021.)

Office of the Privacy Commissioner (OPC) [Canada] 2012. Seizing Opportunity: Good Privacy Practices for Developing Mobile Apps. Available at: https://www.priv.gc.ca/en/privacy-topics/technology-andprivacy/mobile-devices-and-apps/gd app 201210/ (Accessed on 17 may 2021.)

Omoronyia, I. et al 2013. Engineering Adaptive Privacy: On the Role of Privacy Awareness Requirements. Proceedings of the 2013 International Conference on Software Engineering. IEEE Press, 2013. Available at: https://doi.org/10.1109/ICSE.2013.6606609 (Accessed on 17 May 2021.) Organisation for Economic Cooperation and Development (OECD) 2013. The OECD Privacy Framework. Paris: OECD. Available at: http://www.oecd.org/sti/ieconomy/oecd privacy framework.pdf (Accessed on 17 May 2021.) 
Papageorgiou, A. et al 2018. Security and Privacy Analysis of Mobile Health Applications: The Alarming State of Practice. IEEE Access 6: 9390 9403. Available at: https://doi.org/10.1109/ACCESS.2018.2799522

(Accessed on 17 May 2021.)

Privacy and Electronic Communications Directive 2002. Directive 2002/58/EC of the European Parliament and of the Council of 12 July 2002 Concerning the Processing of Personal Data and the Protection of Privacy in the Electronic Communications Sector 2002/58/EC.

Available at: https://eur-lex.europa.eu/legal-

content/EN/ALL/?uri=celex\%3A32002L0058

(Accessed on 17 May 2021.)

Protection of Personal Information Act (Act 4 of 2013) 2013. Available at: http://www.justice.gov.za/inforeg/docs/InfoRegSA-POPIA-act2013-

004.pdf (Accessed on 17 May 2021.)

Razaghpanah, A. et al 2018. Apps, Trackers, Privacy, and Regulators: A Global Study of the Mobile Tracking Ecosystem. Available at: https://doi.org/10.14722/ndss.2018.23353 (Accessed on 17 May 2021.)

Regulation on Privacy and Electronic Communications 2017. Regulation of the European Parliament and of the Council Concerning the Respect for Private Life and the Protection of Personal Data in Electronic Communications and Repealing Directive 2002/58/EC. Available at: https://eur-lex.europa.eu/legalcontent/EN/TXT/?uri=CELEX\%3A52017PC0010

(Accessed on 17 May 2021.)

Regulation of Interception of Communications and Provision of Communication-Related Information Act (Act 70 of 2002) 2002. Available at:

http://www. gov.za/sites/default/files/gcis_document/201409/a70-02.pdf (Accessed on 17 May 2021.)

Republic of South Africa (RSA) 2016. Information and Communication

Technology (ICT) Broad-based Black Economic (B-BEE) Sector Code (Government Gazette 40407, 7 November 2016).

Roos, A 2003. The Law of Data (Privacy) Protection: A Comparative and Theoretical Study. PhD, Pretoria: UNISA.

Available at:

http://uir.unisa.ac.za/handle/10500/1463 (Accessed on 17 May 2021.)

Senarath, A. \& N.A.G. Arachchilage 2018a. Understanding Software Developers' Approach towards Implementing Data Minimization. arXiv 
preprint. Available at: https://arxiv.org/abs/1808.01479

(Accessed on 17 May 2021.)

Senarath, A. \& N.A.G. Arachchilage 2018b. Why Developers cannot Embed Privacy into Software Systems? An Empirical Investigation. Paper presented at Proceedings of 22nd International Conference on Evaluation and Assessment in Software Engineering 2018, Christchurch, New Zealand. Available at: https://doi.org/10.1145/3210459.3210484;

https://arxiv.org/abs/1805.09485 (Accessed on 17 May 2021.)

Sheth, S. et al 2014. Us and Them: A Study of Privacy Requirements across North America, Asia, and Europe. Proceedings of the 36th International Conference on Software Engineering. ACM, 2014. Available at: https://doi.org/10.1145/2568225.2568244;

https://dl.acm.org/doi/10.1145/2568225.2568244

(Accessed on 17 May 2021.)

South African Law Reform Commission (SALRC) 2009. Project 124 Privacy and Data Protection Report. Pretoria: SALRC. Available at:

http://www.justice.gov.za/salrc/reports/r prj124 privacy\%20and\%20dat a\%20protection2009.pdf

(Accessed on 17 May 2021.)

Sy, E. et al 2018. AppPETs: A Framework for Privacy-preserving Apps. Paper presented at Proceedings of $33^{\text {rd }}$ Annual ACM Symposium on Applied Computing. Available at:

https://doi.org/10.1145/3167132.3167415;

https://dl.acm.org/doi/10.1145/3167132.3167415

(Accessed on 17 May 2021.)

Thomas, K. et al 2014. Distilling Privacy Requirements for Mobile Applications. Proceedings of $36^{\text {th }}$ International Conference on Software Engineering. ACM, 2014. Available at:

https://doi.org/10.1145/2568225.2568240;

https://dl.acm.org/doi/10.1145/2568225.2568240

(Accessed on 17 May 2021.)

Van der Sype, Y. S. \& W. Maalej 2014. On Lawful Disclosure of Personal User Data: What Should App Developers Do? $7^{\text {th }}$ International Workshop on Requirements Engineering and Law (RELAW), IEEE 2014. Available at: https://doi.org/10.1109/RELAW.2014.6893479;

https://ieeexplore.ieee.org/document/6893479

(Accessed on 17 May 2021.) 
Dusty-Lee Donnelly

Van Kleek, M. et al 2017. Better the Devil you Know: Exposing the Data Sharing Practices of Smartphone Apps. Paper presented at Proceedings of 2017 CHI Conference on Human Factors in Computing Systems.

Available at: https://doi.org/10.1145/3025453.3025556;

https://people.csail.mit.edu/ilaria/papers/CHI2017.pdf

(Accessed on 17 May 2021.)

\author{
Dusty-Lee Donnelly \\ Lecturer \\ School of Law \\ University of KwaZulu-Natal \\ Durban \\ donnelly@ukzn.ac.za
}




\title{
The Adoption of Information and Communication Technologies (ICTs) by the Managers of Spaza Shops in Rural South Africa
}

\section{Mpho Mzingelwa \\ ORCID iD: https://orcid.org/0000-0002-5152-9081}

\begin{abstract}
Introduction and Background: In the South African context, a 'spaza shop' is an informal microenterprise retail store with limited floor space where customers purchase basic groceries over a small counter. It is usually set up in a container, a shack or garage, from a free-standing building or small house. Spaza shops are an important retail channel, and they contribute significantly to South Africa's township and rural economy. They provide an entry point for persons otherwise excluded from the formal economy - enabling self-employment and addressing unemployment and poverty. However, spaza shops remain understudied, underappreciated and little understood.
\end{abstract}

Rationale and Aim: The role, impact and adoption of Information and Communication Technologies (ICTs) in the informal retail sector is not well understood because this sector is not officially documented. As a result, there is little clarity on the extent to which ICTs have been adopted within these microenterprises, particularly in the rural areas. This research study therefore focused on rural spaza shops and explored the adoption of ICTs by their managers.

Objectives: The objectives of the research were to determine: (i) the specific types or examples of ICTs used by the managers of spaza shops in the rural areas of South Africa; (ii) how managers of spaza shops use ICTs to run or manage their spaza shops in the rural areas of South Africa; and (iii) the 
perceived benefits and challenges associated with the ICTs used by the managers of spaza shops in the rural areas of South Africa.

Theoretical Framework/ Model: Two models were used as theoretical lenses for the research, namely: (i) The Organisation for Economic Cooperation and Development (OECD) Model Survey on ICT Usage by Businesses; and (ii) the Unified Theory of Acceptance and Use of Technology (UTAUT).

Methodology: The research adopted a descriptive research design. A questionnaire, which included both closed- and open-ended questions, was used to gather data from 80 managers of spaza shops in the rural area of the King Sabata Dalidyebo (KSD) region, Eastern Cape Province, South Africa. Data was analysed using Microsoft Word 2016 and Microsoft Excel 2016.

Results/ Findings: The research findings revealed that electronic calculators, mobile phones (both feature/basic phones and smartphones), Flash devices, and WhatsApp instant messaging were widely used by the managers of spaza shops. Speedpoint devices, Facebook social networking, and e-mail were also used by a few spaza shop managers. They also used mobile phones for phone calls, SMS, WhatsApp, Facebook, and e-mail. Flash devices were used for selling airtime, data and electricity, and for some DSTV payments and LOTTO ticket sales. Retailers also used Speedpoint devices for 'cash back' services, and for accepting payments from the customers. The research findings revealed that ease of use, affordability and accessibility of mobile phones, and availability of Flash devices and Speedpoint devices, provided benefits to the managers of spaza shops. Eskom national grid electricity, solar power, and cellular network connectivity (Vodacom, MTN, Cell-C and Telkom) are the necessary facilitating mechanisms enabling the adoption of ICTs. The absence of Automated Teller Machines (ATMs) in the rural areas provided marketed opportunities for the spaza shops. The research findings also revealed the challenges experienced and, in this regard, crime, the high cost of computers and a lack of computer skills were found to be the primary barriers to the adoption of the use of computers by the managers of spaza shops in these areas.

Contribution and Implications: Since empirical evidence concerning the adoption of ICTs among informal microenterprises in rural areas is limited, 
this research provides a valuable additional insight into the current nature and challenges of ICT adoption by spaza shop managers in South African rural areas. The research thus provides information for government institutions (for example, Ministries of Small Business Development, Trade and Industry, and Rural Development), for ICT consultants, and for ICT vendors who can target their interventions and sales efforts towards these microenterprises more accurately as a result of the information gathered.

Limitations: Not all rural areas of the KSD region were covered in this research - only thirty of more than 200 rural areas were investigated. The sample therefore consisted of eighty managers of spaza shops in one deeply rural region of South Africa, namely KSD. This limits the generalisability of the findings. The study could be strengthened by increasing the sample size.

Conclusions and Future Directions for Research: The research concludes that more research into this informal sector is needed in order to fully understand the role, impact and adoption of ICTs from a broader perspective. More extensive research studies on the role, impact and adoption of ICTs within the context of informal microenterprises including not only spaza shops, but also street vending, and tourism, and covering the entire region of $\mathrm{KSD}$, could be profitably undertaken.

Keywords: spaza shops, ICTs, microenterprises, rural areas, King Sataba Dalindyebo Region.

\section{Introduction and Background}

The research presents empirical findings on the adoption of information and communication technologies (ICTs) by the managers of spaza shops in the rural areas of South Africa. South Africa has a 'dual economy', characterised by a developed formal economy and an underdeveloped informal economy (World Bank 2019; OECD 2015). Spaza shops operate within the informal economy as an informal sector of South Africa`s retail economy (Sustainable Livelihoods Foundation 2016). In the South African context, a 'spaza shop' is an informal microenterprise retail store with limited floor space where customers purchase basic groceries over a small counter. It is usually set up 
in a container, shack or garage from a free-standing building or small house (Mangaung Municipality 2018; Sustainable Livelihoods Foundation 2016; Von Broembsen 2008). Spaza shops are classified as microenterprises, because they usually employ fewer than ten people (Von Broembsen 2008).

Globally, informal microenterprises play a major role in socioeconomic development, being instrumental in employment creation, income generation, skills development, poverty alleviation, social inclusion, the creation of sustainable livelihoods and also self-empowerment (Arnold \& Fadnis 2018; Christopher \& Manoj 2018; World Bank 2018; World Trade Organization (WTO) 2018; WEF 2017). It is estimated that in Africa and Asia, Small and Medium Enterprises (SMEs) and informal microenterprises account for more than $60 \%$ of businesses, more than $50 \%$ of total employment, and more than $40 \%$ of Gross Domestic Product (GDP) output (UNESCAP 2019). Yet informal microenterprises remain understudied, underappreciated and little understood (Al Essa 2018; Sustainable Livelihoods Foundation 2012).

The digital shift brought about by the accelerated growth of ICTs such as the internet, mobile networks, cloud computing, computer technology, the Internet of Things (IoT), and the introduction of tablets and smartphones, has become highly significant for the operation of retail microenterprises, and can influence both their productivity and their competitiveness (ITU 2015). While most owners and managers

of spaza shops have begun to adopt ICTs for managing their microenterprises in the urban areas (Chetty 2016; Afolayan 2014; Matlala et al. 2014; Odendaal 2014; Talnot \& Marsden 2012; Ongori 2009), there is limited empirical research on the adoption of ICTs among the owners/ managers of spaza shops in rural areas. This research therefore attempts to close this research gap by exploring the adoption of ICTs within the context of microenterprises (spaza shops) in the rural areas.

\section{Rationale and Aim of the Research}

The role, impact, use, usage and adoption of ICTs in the informal retail sector is not well understood because the informal retail sector is not officially documented. As a result, there is little clarity as to the extent to which ICTs have been adopted within these microenterprises, particularly in the rural areas. The majority of studies on the role, adoption and impact of ICTs have 
focused on formal SMEs, and while Chetty (2016), Matlala et al. (2014), Odendaal (2014), Makoza and Chigona (2012), and Ongori and Migiro (2010 have conducted research on the adoption of ICTs among the owners/ managers of informal microenterprises, their research was conducted in the urban areas and largely focused on mobile phones. There is therefore still a limited understanding of ICT adoption in rural areas beyond the use of mobile phones, and this is the focus of this study.

\section{Objectives}

The objectives of the research were as follows:

1) To determine the specific types/examples of ICTs used by the managers of spaza shops in the rural areas of South Africa;

2) To determine how managers of spaza shops use ICTs to run/manage their spaza shops in the rural areas of South Africa; and

3) To determine the perceived benefits and challenges associated with the ICTs used by the managers of spaza shops in the rural areas of South Africa.

\section{Spaza Shops in the Context of South Africa 4.1 Historical Background of Spaza Shops}

The history of spaza shops can be traced back to the apartheid era. 'Spaza'" is an isiZulu word meaning 'hidden'. During the apartheid era, black South Africans were restricted from running businesses. In order to hide their retail business practices and also elude the apartheid authorities, black South Africans in the townships and rural areas established spaza shops alongside their homes. Spaza shops eliminated the inconvenience and costs of traveling to formal shopping places in towns, cities, and malls by setting up small retail

1 isiZulu is one of the official languages in South Africa. It is the most commonly spoken language in South Africa's households. It is spoken by roughly $23 \%$ of South Africa's population (Statistics South Africa, 2012). 
outlets close to the customers in the townships and rural areas (Bear et al. 2005; Terblanché 1991). The post-apartheid government has since legalised spaza shops under the Businesses Act 71 of 1991 (Mangaung Municipality 2018).

\subsection{Defining 'Spaza Shop'}

Spaza shops are essentially informal micro-convenience stores with limited floor space which operate within the informal retail sector (Von Broembsen 2008). They are usually set up and run from home in a container, shack or garage, attached to a free-standing building or small house. Customers can purchase basic goods like bread, cool drinks, milk, fruit, vegetables, meat, sweets, cigarettes, soap, and paraffin over a small counter (Mangaung Municipality 2018; Sustainable Livelihoods Foundation 2012; Von Broembsen 2008). Spaza shops predominantly operate in the townships and rural areas, as these are where the majority of the black population live (Piper \& Chairman 2016; Sustainable Livelihoods Foundation 2016).

\subsection{Business Model and Operations of Spaza Shops}

Spaza shops have adopted a retailer-driven model, selling products demanded by consumers at easily accessible locations in the townships and rural areas. According to Osterwalder and Pigneur (2010), the business model of spaza shops is based on a single customer segment (township or rural population), a one-on-one relationship with customers, word-of-mouth marketing, cash payments, buying stock from wholesale retailers, value creation through convenience, customer service and product availability for township and rural residents` needs. Spaza shops can be distinguished from formal SMEs by their pricing strategy, distinctive branding, and daily business operations (Gumbo \& Bokolo 2014; Sustainable Livelihood Foundation 2012; Bear 2005; Terblanché 1991). The pricing strategy of spaza shops is based on a mark-up price. For example, prices of some products sold at spaza shops can be marked up by 30-50\% above wholesale prices (Gumbo \& Bokolo 2014). When it comes to distinctive branding, spaza shops leverage popular brands in the communities where they operate, products often being referred to by their brand names rather than by a product name (Gumbo \& Bokolo 2014; Bear 2005; Terblanché 1991). Unlike the formal SMEs, spaza shops typically 
trade seven days a week and are open from early morning (around 6 am) until about $10 \mathrm{pm}$. In order to ensure repeat purchases and to promote customer loyalty, some spaza shops also allow their customers to buy goods on credit (Gumbo \& Bokolo 2014).

\subsection{The Contribution of Spaza Shops to the South African Economy}

Spaza shops are an important retail channel, and they contribute significantly to South Africa`s township and rural economy (The Sustainable Livelihoods Foundation 2016). A study conducted by Euromonitor International estimated that South African spaza shops generated an annual revenue of R7 billion in 2017 (Booysen 2018), while another study conducted by the University of South Africa (UNISA) in the same year estimated their contribution at closer to R9 billion. Also in 2017, UNISA estimated that there were about 140000 retail outlets including spaza shops in South Africa, and that about 300000 jobs were created by the spaza economy, supporting more than a million people (Tallorder 2018). According to the Sustainable Livelihoods Foundation (2016), more than $30 \%$ of trade in the informal sector comes from the spaza sector. Spaza shops also provide entry points for people otherwise excluded from the formal economy, thus enabling self-employment and addressing unemployment and poverty (Sustainable Livelihoods Foundation 2016).

\subsection{Future Prospects of Spaza Shops}

Banks are currently known to be targeting spaza shops to become 'bank shops' which will be able to offer minimal banking services at lower costs than those charged by full bank branch offices (Fisher-French 2011). Reports also indicate that insurance companies are targeting spaza shops as 'insurance shops' where customers would buy, for instance, funeral cover at a lower cost than would normally be charged (African Unity Life 2017). Also, retail supermarket chain stores such as Pick 'n Pay have launched a 'spaza innovative modernisation programme' which seeks to boost spaza shops by providing support systems (mentoring, training, IT systems, and entrepreneurship development) (Pick ' $n$ Pay 2018). Also, My Spaza Distributions and Consulting Pty (Ltd) (in partnership with Ethekwini Municipality, Ithala Bank, and KwaZulu-Natal Economic Development Ministry) has launched a 
programme called 'MySpaza' which seeks to revitalise the spaza shop economy, streamline customer services among spaza shops, and offer bulk buying solutions and mini distribution centres for spaza shops (My Spaza Distributions and Consulting 2018). Finally, the government of South Africa pays out social grants to more than 17 million South African citizens, and, through a hybrid social grant pay-out model, it is also targeting spaza shops as potential 'social grant pay-out shops' where grant-holders could collect their money (Radebe 2017).

\subsection{Challenges Faced by Spaza Shops}

Owners and managers of spaza shops face a number of significant challenges. These include a lack of business management skills, poor distribution systems, and a lack of the financial skills required to handle financial records effectively and efficiently. There is also a lack of collateral security which would allow them to obtain finance from lenders and thus a lack of sufficient capital required for expansion. In addition, crime, electricity 'load-shedding' (caused by a crisis in electricity provision in the country), a lack of networking/purchasing power to buy in bulk, and the high costs incurred by transportation of stock, along with competition from the growing number of shopping malls now being established in the townships and rural towns, are significant obstacles (Mukwarami 2017; van Scheers 2010).

\section{Literature Review (Related Work) \\ 5.1 An International Perspective}

Empirical research into the adoption of ICTs among SMEs in urban areas has been carried out by Harindranath et al. (2010) in the United Kingdom (UK); by Ahmed et al. (2010) and Ashrafi and Murtaza (2008) in Oman; by Ongori (2010) in Botswana; by Frempong (2009) in Ghana; by Ahmed et al. (2010) in Pakistan; by Melchioly and Saebo (2010) in Tanzania; and by Esselaa et al. (2006) in 13 African countries. In the UK and Oman, a significant number of SMEs were found to have adopted the use of desktop computers, high speed broadband internet, and Enterprise Resource Planning (ERP) systems for stock control, sales, purchasing, marketing, accounting and finance, and document management (Harindranath et al. 2010; Ashrafi \& Murtaza 2008).

In Botswana, the majority of SMEs had adopted landline phones, per- 
sonal computers, cellphones, Microsoft applications, fax-photocopier-printer machines, internet, and e-mail. In Ghana, mobile telephony was the most popular communication technology among the SMEs (Esselar et al. 2006). In Pakistan, computers, word processing, databases and spreadsheets were used widely (Ahmed et al. 2010). In Tanzania, mobile phones were the most widely adopted form of ICT use among SMEs, and the findings also revealed that this use of mobile phones provided additional economic advantages by improving financial transactions, and enhancing wealth gene-ration and distribution (Melchioly \& Saebo 2010). In thirteen African countries, mobile phones were again found to be the most widely adopted form of ICT due to their availability/ accessibility, affordability and ease of use (Esselar et al. 2006). There is therefore considerable international re-search data on the use of ICTs by established SMEs - but still very little research on their adoption among microenterprises, particularly by informal microenterprises in rural areas.

\subsection{A South African Perspective}

Spaza shops operate within the retail sector where ICTs can influence productivity, competitiveness and survival chances in many business functions including communication with customers, suppliers, and business partners. Information Communication Technologies are also important for supporting relations with government, and for financial management. Management of stock/inventory, sales/orders, marketing, and purchasing/ procurement can also be greatly assisted through the implementation of ICTs. The role and relevance of ICTs in the spaza shop economy is highlighted by Biyela et al. (2018); TallOrder (2018); Van Rensburg (2017); Makoza \& Chigona (2017); Mbuyiswa (2015); Matlala et al. (2014); Ngassam et al. (2012); Talbot \& Marden (2011); Perks (2010); van Scheers (2010); Dorflinger et al. (2009); and Bear (2005). These researchers all emphasise the importance and benefits of ICTs through the appropriate use of the internet, mobile phone technology, point of sale systems (POSs), and web-based applications for purchasing/ procurement, stock management, sales management, and communication with customers and suppliers.

Research into the adoption of ICTs by microenterprise owners/ managers in the urban areas of South Africa has been conducted by Biyela et al. (2018); Afolayan (2014); Matlala et al. (2014); Odendaal (2014); Makoza 
and Chigona (2012). The findings by Biyela et al. (2018) revealed that SMEs use ICTs such as mobile phones, spreadsheet applications, mobile banking, social media communications (mostly WhatsApp), and e-mail. The findings by Afolayan (2014) revealed that microenterprises had adopted mobile phones, computers, iPads, cloud services, Customer Relationship Management (CRM) systems, Pastel Accounting packages, internet, e-mail communication, and Microsoft applications. Similar findings were obtained by Matlala et al. (2014), Odendaal (2014), and Makoza and Chigona (2012). All the above research was however undertaken in urban settings of South Africa. There is therefore still only limited empirical research on ICT adoption in relation to microenterprises such as spaza shops in the context of the rural areas of South Africa.

There are a number of ICT initiatives from ICT vendors and software developers targeting spaza shops including Last Mile for BoP (Base of Pyramid) web-based application, SAP SMS based system, Wi-Fi hotspots, and mobile applications such as Vuleka, Spaza, Selpal, and Flash (Makwaiba 2018; Flash 2018; Selpal 2018; BizTechAfrica 2017; Mengistu et al. 2009). The Last Mile BoP web app, Vuleka app, Spaza app, and SAP SMS based systems designed to allow spaza shops to purchase goods in bulk from wholesale retailers (Makwaiba 2018; SpazaApp 2018; BizTechAfrica 2017; Mengistu et al. 2009). Selpal app and Flash app are designed to allow spaza shops to sell airtime, data and electricity to their customers; and also to accept DSTV and LOTTO payments from their customers (Flash 2018; Selpal 2018).

\section{Theoretical Framework/ Model}

Two models were used as theoretical 'lenses' for this research, namely: (i) the Organisation for Economic Co-operation and Development (OECD) Model Survey on ICT Usage by Businesses; and (ii) the Unified Theory of Acceptance and Use of Technology (UTAUT). The OECD Model Survey on ICT Usage by Businesses was used to address the first two objectives of the research. The UTAUT was used to address the third objective of the research.

The OECD Model Survey on ICT Usage by Businesses is a model which was created by OECD in the year 2015. The model is aimed at improving international comparability by encouraging the use of standardised indicators when designing a survey/questionnaire on the use/adoption of ICTs 
by businesses (OECD 2015). The model was found to be appropriate for this research because it has core module indicators which are in line with the objectives of the research. These indicators of the model are: electronic devices (computers, mobile devices, etc); connectivity (wired/fixed broadband, fixed wireless and terrestrial wireless/mobile broadband connections); website and mobile applications; information management tools (such as ERP and CRM); e-commerce; security and privacy; e-government; ICT skills; cloud computing services; open source software; social media; main economic activity of the enterprise; and perceived benefits, barriers and impacts of ICTs (OECD 2015).

The UTAUT is a theory that models how users come to accept and use (adopt) a technology (Venkatesh et al.). The theory was developed by Venkatesh et al. as an extension of the Technology Acceptance Model (TAM). The theory has four key constructs: performance expectancy, effort expectancy, social influence, and facilitating conditions - and four moderators (age, gender, experience, and voluntariness) related to predicting behavioural intention to use a technology, and actual technology use, primarily in organisational contexts (Venkatesh et al. 2003). The UTAUT was found to be relevant for use in this research because the researcher wanted to determine the perceived benefits and challenges associated with the ICTs used by the managers of rural spaza shops.

\section{Research Methodology \\ 7.1 Study Area/Site}

The data for the research was collected in the rural areas of the King Sabata Dalindyebo (KSD) region. The region is situated in the Oliver Tambo District Municipality (ORTDM) of the Eastern Cape Province, South Africa. The region was chosen by the researcher for four reasons: (i) the region is an entirely rural area in terms of socio-economic development, landscape, and cultural/traditional practices; (ii) the majority of the population in the region reside in these rural areas; (iii) the researcher comes from this region and thus understands the language and culture of the region; and (iv) there are many spaza shops in this region.

In 2016 the region had a total population of 494000 (of which 98\% were black African) and covered an area of $3019 \mathrm{~km}^{2}$. There was a total of 116243 households, of which approximately $95 \%$ were in rural areas and 
village settlements. IsiXhosa and English are the most commonly spoken languages in the region. In 2016, regional access to electricity telephone lines, internet and mobile phones were at $85 \%, 1.9 \%, 3.2 \%$ and $93 \%$ respectively. The region had a literacy rate of $62 \%$ at that time. The main economic sectors in the region included community and social services (27\%), government services $(17 \%)$, financial services $(9 \%)$, wholesale and retail trade $(8 \%)$, transport and communication (2\%), manufacturing (4\%), construction (3\%) and agriculture and forestry (1\%) within ORTDM (ECSECC 2017; Statistics South Africa 2016).

The researcher collected data from 30 rural areas out of a population of 200 rural areas (main places and wards) in the region. The principal (main) places that the researcher investigated were: kwaJali, amaHegebe, Gengqe, Darhabe, Mvezo, Buwa, Bijolo, Bityi, Mancam, Ngqungqu, Gogozayo, kwaLindile, Ngweni, Tyolo, Tyumbu, Chris Hani, Xwili, and Mqhekezweni.

\subsection{Population}

The target population for this research was the managers of spaza shops in all the rural spaza shops in the KSD region. The total population of spaza shops in the KSD region is unknown because the informal retail sector is not officially documented in South Africa. Therefore, the total population of the managers of rural spaza shops in the KSD region is unknown.

\subsection{Unit of Analysis (Participants)}

The participants selected for the research were the managers of spaza shops in the rural areas of KSD region. In the context of this research, 'manager' refers to a person who deals with daily routine activities such as sales/orders, transactions, bookkeeping and finance and accounting, purchasing, communication with customers and suppliers, and control of stock/inventory. Because spaza shops are microenterprises, there is usually only one manager and sometimes the owner of the spaza shop is also the manager.

\subsection{Sampling and Sample Size}

The non-probability sampling technique known as 'convenience-purposive sampling' was used. Initially, the targeted sample size was 200 spaza shops; 
but owing to time limitations and the scattered nature of settlements in rural areas, the researcher only managed to collect data from 80 (eighty) managers. Therefore, eighty (80) managers (one for each spaza shop) constituted the sample size for this research.

\subsection{Data Collection Instrument}

The data was gathered using a semi-structured questionnaire, consisting of both open-ended and closed-ended questions. It was designed in line with the OECD Model Survey on ICT Usage by Businesses, and with the UTAUT theoretical framework. The OECD Model's indicators/variables such as connectivity, social media, mobile phones, computers, ICT skills, main economic activity of the enterprise and number of persons employed, were therefore included. The UTAUT constructs and moderating variables such as age, genders, and the highest level of education attained, were also included in the questionnaire.

\subsection{Data Collection Procedure and Ethics}

The questionnaire was administrated face-to-face by the researcher to the 80 managers. The researcher personally visited the spaza shops to administer the questionnaires. Data was collected during the period October 2018 February 2019. The anonymity and privacy of the participants were respected and informed consent was obtained from the managers of the spaza shops prior to administering the questionnaires. Ethical clearance was obtained from the University of KwaZulu-Natal, permitting the researcher to collect the data.

\subsection{Analysis of Data}

Microsoft Word 2016 was used to facilitate the analysis the open-ended responses. Six features of Microsoft Word, namely: 'Find', 'Go To', 'Select', 'Search', 'Highlighting' and 'Comment' were used. The 'Find', 'Go To, 'Select', 'Search' features were used to search for common keywords/phrases related to the research objectives throughout the text of the opened-ended responses. The 'Highlighting', and 'Comment' features were used to group the keywords/phrases into different themes/patterns. The findings from the 
analysis of the open-ended responses are presented using SmartArt graphics and descriptive narratives. Microsoft Excel 2016 was also used to analyse the closed-ended responses. The results from the analysis of closed-ended responses are presented using tabular descriptive statistics (frequencies and percentages) and charts. The interpretation and discussion of the results/ findings is provided in the next section.

\section{Results and Discussions}

\subsection{Demographic Information of Spaza Shop Managers}

Table 1 below shows the demographic information gathered from the spaza shops managers who participated in the research.

\section{Table 1: Demographic Information of Spaza Shop Managers}

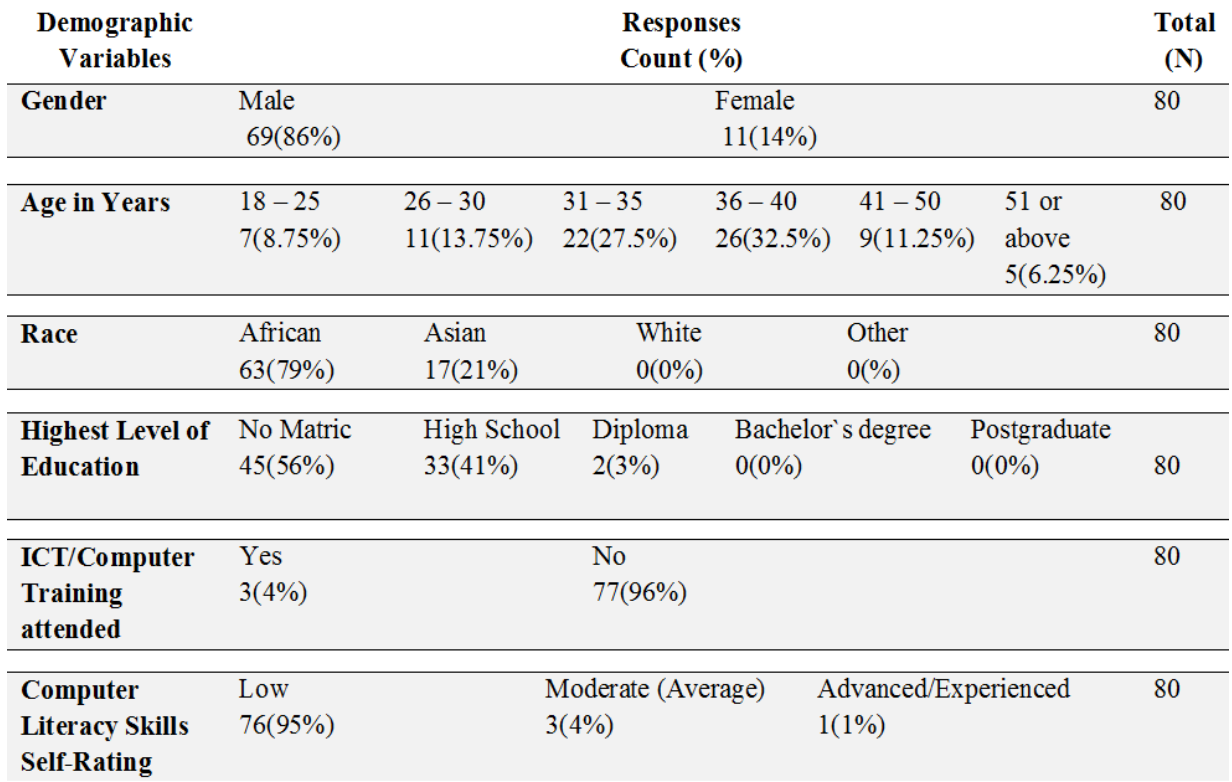

The majority (86\%) of the participants were male and were in the age group 26-50 years. With regards to race, the majority were African (79\%), while Asians constituted the balance. Regarding the highest level of education, the majority $(56 \%)$ of participants indicated that they did not have a matric 
qualification. However, a considerable number (41\%) indicated that they had high school qualifications. Participants were also asked if they had attended/ completed computer/ ICT training. Very few (only 4\%) of the participants indicated that they had. Participants were then asked to rate their computer literacy skills and knowledge as either 'low', 'moderate/average' or 'advanced'; the great majority of participants (95\%) indicated 'low'.

The ratings on gender, level of education, computer/ICT training, and computer literacy skills/knowledge are comparable with findings from other research studies. For instance, a study conducted by Sustainable Livelihood Foundation (2013) also found that the spaza economy is male dominated. Research studies on gender and entrepreneurship in the context of SMMEs by Kepler \& Shane (2007) and Said et al. (2014) suggested that male entrepreneurs showed more effort in search for business opportunities than females. A report by the Cape Digital Foundation (2019) also indicated that many microenterprises, including spaza shops, have an inadequately educated workforce, that they often lack the fundamental skills required to run a business effecttively, and have low ICT skills.

\subsection{Profile of Spaza Shops}

Table 2 below shows the profile of spaza shops. Many (74\%) had two employees, while a few had one or three employees, but not more than three. There were a substantial number of spaza shops which had been operating for 2-4 years (43\%), while $26 \%$ had been operating for 5-7 years, and $16 \%$ had been in operation for 8-10 years. With regards to their source of power, Eskom national grid electricity $(91 \%)$ was the main source of power. A few (10\%) were using solar technology and generators. Regarding their main business activities, all (100\%) were selling food items (e.g. bread and milk) and non-food items such as cigarettes and paraffin. More than three quarters (78\%) were selling pre-paid airtime, while more than half $(55 \%)$ were also selling pre-paid data, with pre-paid electricity also being sold (41\%). Just under a quarter (23\%) were selling home utensils made of plastic such as brooms and washing basins, and also hardware and building materials such as cement and paint. Very few were accepting payments for DSTV (9\%), and Lotto $(3 \%)$. A small number $(8 \%)$ reported that they were allowing their loyal customers to buy on credit. Very few $(6 \%)$ were offering a 'cash back' service. 
Table 2: Profile of Spaza Shops

\begin{tabular}{|c|c|c|c|c|c|c|c|c|c|c|}
\hline $\begin{array}{c}\text { Profile } \\
\text { Variable }\end{array}$ & & & & & $\begin{array}{l}\text { Response } \\
\text { Count (\% }\end{array}$ & & & & & $\begin{array}{l}\text { Total } \\
\text { (N) }\end{array}$ \\
\hline $\begin{array}{l}\text { Number } \\
\text { of } \\
\text { employees }\end{array}$ & $\begin{array}{l}1 \\
15(18.75 \%)\end{array}$ & & $\begin{array}{l}2 \\
59(7\end{array}$ & $3.75 \%)$ & $\begin{array}{l}3 \\
6(7.5 \%)\end{array}$ & $\begin{array}{l}\text { More than } 3 \\
0(0 \%)\end{array}$ & & & & 30 \\
\hline $\begin{array}{l}\text { Years in } \\
\text { Operation }\end{array}$ & $\begin{array}{l}0-1 \\
9(11 \%)\end{array}$ & & $\begin{array}{l}4 \\
43 \%)\end{array}$ & $\begin{array}{l}5-7 \\
21(26 \\
\%)\end{array}$ & $\begin{array}{l}8-10 \\
13(16 \%)\end{array}$ & & $\begin{array}{l}110 \\
3(4 \%\end{array}$ & more & & 80 \\
\hline $\begin{array}{l}\text { Source of } \\
\text { Power/En } \\
\text { ergy }\end{array}$ & $\begin{array}{l}\text { Eskom natio } \\
\text { grid } \\
72(91 \%)\end{array}$ & & $\begin{array}{l}\text { Gen } \\
1(10\end{array}$ & rator & $\begin{array}{l}\text { Solar } \\
7(8 \%)\end{array}$ & $\begin{array}{l}\text { Batteries } \\
0(\%)\end{array}$ & & her & 8 & 0 \\
\hline $\begin{array}{l}\text { Business } \\
\text { Activities } \\
\text { (Products } \\
\text { / Services } \\
\text { Sold) }\end{array}$ & $\begin{array}{l}\text { Food items } \\
\text { (e.g. bread, } \\
\text { milk, etc) } \\
80(100 \%) \\
\\
\text { Non-food } \\
\text { items (e.g. } \\
\text { cigarette, } \\
\text { paraffin, } \\
\text { etc) } \\
80(100 \%)\end{array}$ & $\begin{array}{l}\text { Buil } \\
\text { Mat } \\
\text { (e.g. } \\
\text { Pain } \\
\text { Cem } \\
\text { etc) } \\
18(2\end{array}$ & & $\begin{array}{l}\text { Airtime } \\
62(78 \%)\end{array}$ & $\begin{array}{l}\text { Data } \\
44(55 \%)\end{array}$ & $\begin{array}{l}\text { Electricity } \\
33(41 \%)\end{array}$ & $\begin{array}{l}\text { DSTV } \\
\text { payments } \\
7(9 \%)\end{array}$ & $\begin{array}{l}\text { Lotto } \\
2(3 \%)\end{array}$ & $\begin{array}{l}\text { Credit } \\
6(8 \%)\end{array}$ & $\begin{array}{l}\text { Cash } \\
\text { Back } \\
5(6 \%)\end{array}$ \\
\hline
\end{tabular}

This profile of spaza shops reveals some interesting findings. In 2016, access to electricity in the King Sabata Dalindyebo region was at 85\% (ECSECC 2017) and therefore some rural areas encountered by the researcher, such as kwaJali, maHegebe, and Tyolo, had not been electrified, and hence there were some spaza shops that were using solar power and generators. Some were also using these sources of power as a backup, in case of Eskom electricity load-shedding.

The research findings reveal that the range of merchandise offered by these informal retail microenterprises is expanding, covering not only traditional everyday necessities such as bread and milk but also covering services such as electricity, airtime, mobile data, a 'cash back' service, the opportunity to buy on credit, and DSTV payments and LOTTO tickets. It is because of these service offerings that banks, insurance companies, retail supermarket chain stores, and government are beginning to see market potential in the spaza economy. 


\subsection{Objective 1: Specific Types/Examples of ICTs Used by the Managers of Spaza Shops}

This section addresses the first objective of the research. The relevant section of the questionnaire was based on closed-end questions and was divided into four parts: Devices; Applications; Connectivity; and Storage/Backup. The research sought to establish which technological devices, applications, internet connectivity/ mobile data network, and cloud storage services were used by the managers of spaza shops.

\subsubsection{Technological Devices Used}

Figure 1 shows the responses to the question on 'technological devices' used.

All $(100 \%)$ of the managers indicated that they used an electronic calculator.

Mobile phones (both basic/ feature phones at $63 \%$ and smartphones at $81 \%$ ) were the most commonly used additional technological devices.

A number (41\%) were using a Flash Device ${ }^{2}$ (not to be confused with a USB flash drive).

Very few (6\%) indicated that they were using Speedpoint devices. None were using desktop computers, laptops, tablets, printer machines, fax machines, scanners, game machines, landline telephones, or digital photo/ video cameras in their spaza shops.

These research findings have some interesting implications. For instance, the findings of the research on mobile phones are similar to those established by Ongori (2010), Esselar et al. (2006), Biyela et al. (2018), Afolayan (2014), Maniwick (2014), and Makoza and Chigona (2012) in the urban areas. This is an indication that mobile phones are bridging the digital divide between the

${ }^{2}$ A Flash device is an electronic machine provided by the company called Flash. It allows retail stores to sell airtime, data, and electricity to their customers and also to accept DSTV and Lotto payments. The device has a built-in printer feature for printing receipts. There is also a mobile app version of the Flash device known as Flash app or Trader App (Flash 2018). 
rural areas and urban areas. The use of the Flash device and Speedpoint devices by these managers also shows that they have begun adopting valueadding mobile/portable devices other than mobile phones.

\section{Do you use any of these Technological Devices in the spaza shop?}

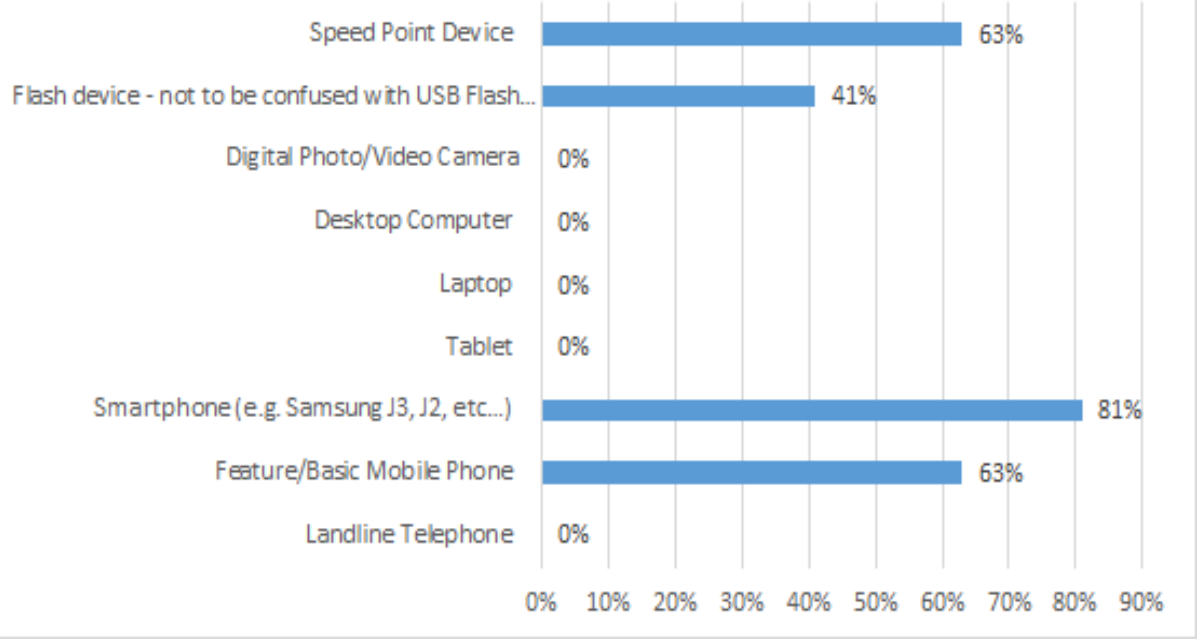

Figure 1: Technological devices used by the managers of spaza shops

\subsubsection{Applications Used by the Managers of Spaza Shops}

Figure 2 shows the responses on 'applications' used by the managers of spaza shops.

WhatsApp (65\%) was the most frequently used application (for instant messaging), followed by Facebook (19\%), and e-mail communication (8\%).

None of the spaza shop managers indicated that they were using a Money Transfer App such as Mpesa.

It is interesting to note also that none were using a bulk buying mobile app such as Vuleka, and MySpaza. Again, none were using ERP applications, computer-based Point of Sale (PoS) systems, database applications, or spreadsheet applications. 


\section{Do you use any of these Applications in the spaza shop?}

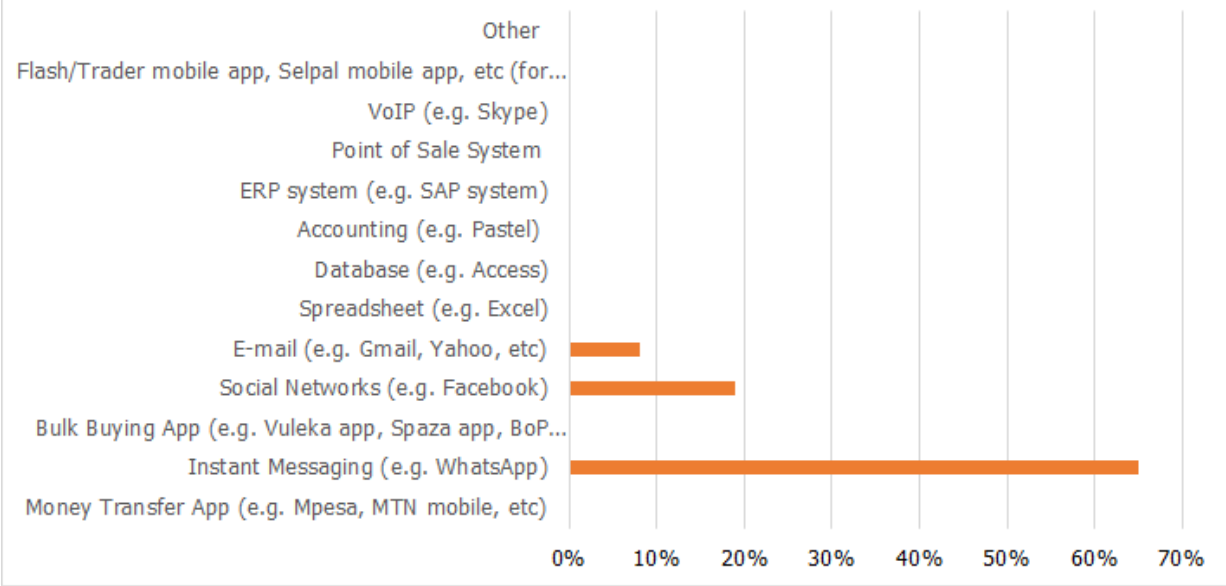

\section{Figure 2: Applications used by the managers of spaza shops}

The above findings show that:

- Managers of rural based spaza shops have not yet adopted web-based systems and mobile app-based systems for bulk buying from their retail wholesale suppliers.

- Managers of rural based spaza shops have not yet adopted ecommerce and m-commerce applications.

- Managers of rural based spaza shops have not yet adopted enterprise systems such as ERP, CRM) systems, POSs, and Pastel accounting packages.

- Managers of rural based spaza shops have not yet adopted Microsoft applications such as Access (Database) and Excel (Spreadsheets).

\subsubsection{Backup Storage Used}

Figure 3 below shows the responses on how the traders backup of critical business data/information. This sub-section of the questionnaire sought to establish whether managers of spaza shops were using a network drive, local drive (for example, a drive on a computer), or cloud services such as 
Dropbox Drive, iCloud Drive, SkyDrive, Samsung Cloud, or Google Drive to back up their critical business data/information (e.g. invoices, financial records, customer details, supplier details). The analysis revealed that none of the spaza shop managers were using these devices to back up their business data/information. All (100\%) the participants indicated they save their customer contact details and supplier contact details on their mobile phones.

\section{Do you use any of these backup storages to store the business data/information?}

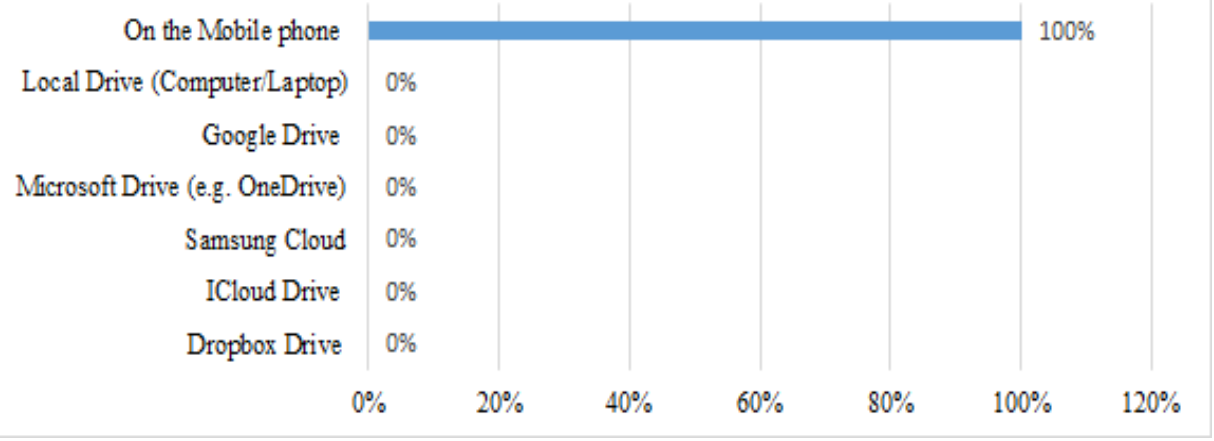

\section{Figure 3: Backup storage used by the managers of spaza shops}

Cloud services provide many benefits including flexibility, efficiency, mobility, collaboration, backup, and a competitive edge. However, the research findings have revealed that managers of spaza shops in the rural areas have not yet leveraged the benefits of the cloud.

\subsubsection{Internet Connectivity/Mobile Data Networks used by the Managers of Spaza Shops}

Figure 4 below shows the responses on 'internet connectivity/mobile data network' used by the managers of spaza shops. MTN mobile data $(45 \%)$ was the dominant form of internet connectivity used while $21 \%, 11 \%$ and $3 \%$ of managers were using Cell-C, Vodacom and Telkom mobile data respectively. None of the managers were using fixed broadband internet such as a Telkom landline/router or Wi-Fi Hotspot. 


\section{What Internet Connectivity or Mobile Data Network do you use in the spaza shop?}

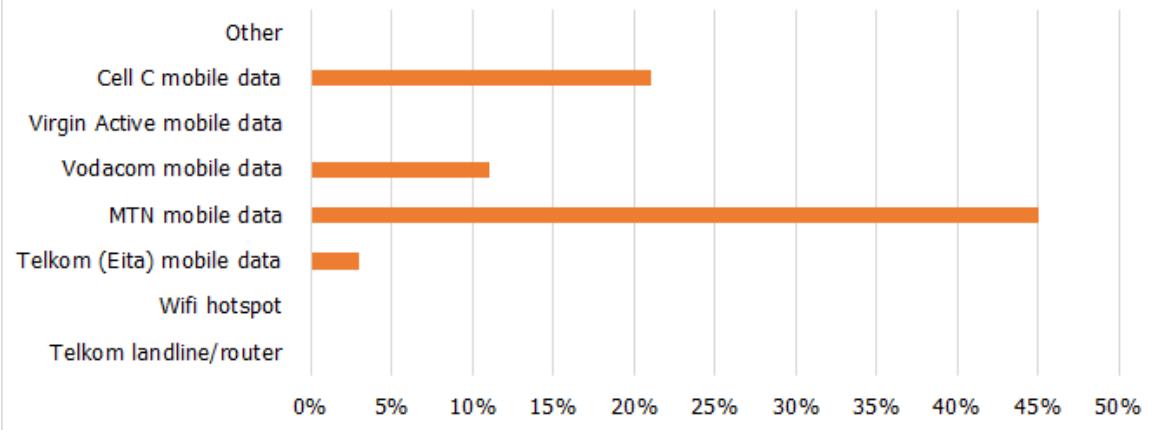

\section{Figure 4: Internet connectivity/ mobile data network used by the managers of spaza shop}

The limited access to fixed internet provision in the rural areas, such as the KSD region has provided market opportunities for mobile network operators such as MTN, Vodacom, Cell C, and Telkom. MTN mobile data, Vodacom data and Cell $\mathrm{C}$ mobile data are providing internet connectivity to the managers who own smartphones.

\subsection{Objective 2: How Managers of Spaza Shops Use ICTs in their Shops}

This section addresses the second objective of the research. Participants were asked open-ended questions about how they use their technological devices and applications.

The use of ICTs by managers of spaza shops revolves around two business functions: communication with suppliers and customers, and customer-sales transactions. There is limited use of ICTs in the business functions such as bulk purchasing from suppliers, stock/ inventory control for demand/ supply analysis, accounting and finance, and strategic marketing. Figure 5 below shows a summarised analysis of the responses from the managers as to how they use ICTs in their shops. 


\section{Basic/Feature Phone:}

Mostly used for phone calls and SMS, and storage of customer/supplier contacts

\section{Smartphone:}

Mostly used for phone calls, SMS and WhatsApp, and storage of customer/supplier contacts

\section{Flash device:}

Mostly used for selling Airtime, Data, Electricity. A few spaza shops managers use it for accepting DSTV payments and LOTTO.

\section{Speedpoint device:}

Mostly used for 'cash back'. Very few spaza shops use it for accepting payments from customers.

\section{Electronic calculator:}

Used for basic calculations when customers are buying. Also used for cash-up calculations, and for calculating stock related items.

\section{(1) Instant Messaging: \\ Used for communication with suppliers and customers}

\section{Email:}

Used for communication with suppliers

\section{Social Networking:}

Used for communication and socializing with friends

Figure 5: A summarized analysis of the responses on how from the managers of spaza shops use ICTs in their businesses

\subsection{Objective 3: The Perceived Benefits and Challenges Associated with the ICTs Used by the Managers of Spaza Shops in the Rural Areas}

This section addresses the third objective of the research. The relevant section of the questionnaire had two general open-ended questions, asking the managers about their perceptions of the benefits and challenges associated with the use of ICTs. 
Many participants asserted that mobile phones have become their daily communication tools. One participant explained that 'When there is a problem with stock, we can communicate with a supplier using a mobile phone'. One participant stated that 'Cellphones are easy, you can always carry it [them] around'. The Speedpoint devices and Flash devices are providing benefits for sales transactions among the spaza shops. One participant mentioned that 'We offer Cash Back services to our customers, there are no ATMs here in the villages. Customers want to buy data and airtime, so we use [the] Flash device'. One participant stated that 'Old age [Elderly] people want to buy from us, they do not want to go to towns. They want cash back'. Another participant mentioned that 'Customers do not want to go to towns to buy electricity, so we use [the] Flash device to sell electricity'. The lack of Wi-Fi networks and fixed landline internet has thus paved the way for mobile data use in the rural areas. One participant mentioned that 'I use MTN data for WhatsApp and Facebook'. Another participant said: 'Mobile Data, Cell C is cheaper'. Figure 6 below shows a summarised analysis of the common words/phrases used concerning the benefits associated with use of ICTs by the managers of spaza shops.

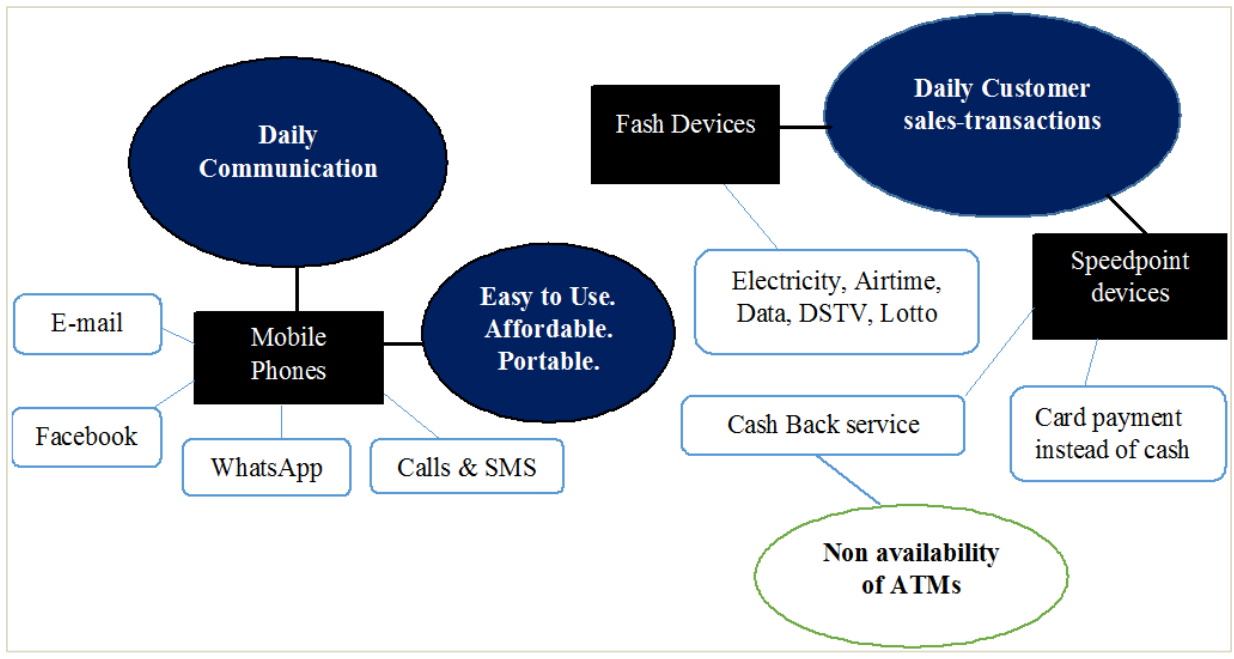

Figure 6: Summarized analysis of the common words/ phrases on the benefits associated with use of ICTs by the managers of spaza shops. 
The above analysis shows that:

- The ease of use and affordability of mobile phones, and the availability of Flash and Speedpoint devices, provides positive performance and effort expectancy to the managers of spaza shops.

- The lack of ATMs in the rural areas has provided market opportunities to spaza shops.

- Their position in rural areas, being far away from towns/cities, also provides market opportunities to the spaza shops.

Despite the acknowledged benefits associated with the use of ICTs by the managers of spaza shops, some participants also pointed out the challenges. Reduced or unreliable access to electricity, crime, mobile network problems, the cost of computers, and a lack of computer skills were some of the problems mentioned. One participant explained that 'Electricity is a problem here in this village, sometimes electricity goes off'. Another agreed that 'Sometimes, the network is not available'. Another participant stated that 'Crime is a problem, people think you have a lot of money when you offer [the] cash back service' and another agreed: 'Robbery [is a problem], criminals can come and rob us if we have computers, laptops and fancy things'. Figure 7 below shows the summarised analysis of the common words/ phrases encountered as to the challenges associated with the use of ICTs by the managers of spaza shops.

\section{Significance/ Relevance of the Research}

The existing empirical evidence on the adoption of ICTs among informal microenterprises in the rural areas is limited. This research therefore provides additional insights into ICT adoption among these microenterprises. The findings of this research may therefore be useful to policy makers, especially those involved in business development interventions supporting microenterprises. The research may also provide useful insights for government institutions (for example, Ministries of Small Business Development, Trade and Industry, and Rural Development), while ICT consultants, and ICT vendors can target their interventions or promotional efforts towards these microenterprises with more assurance. 


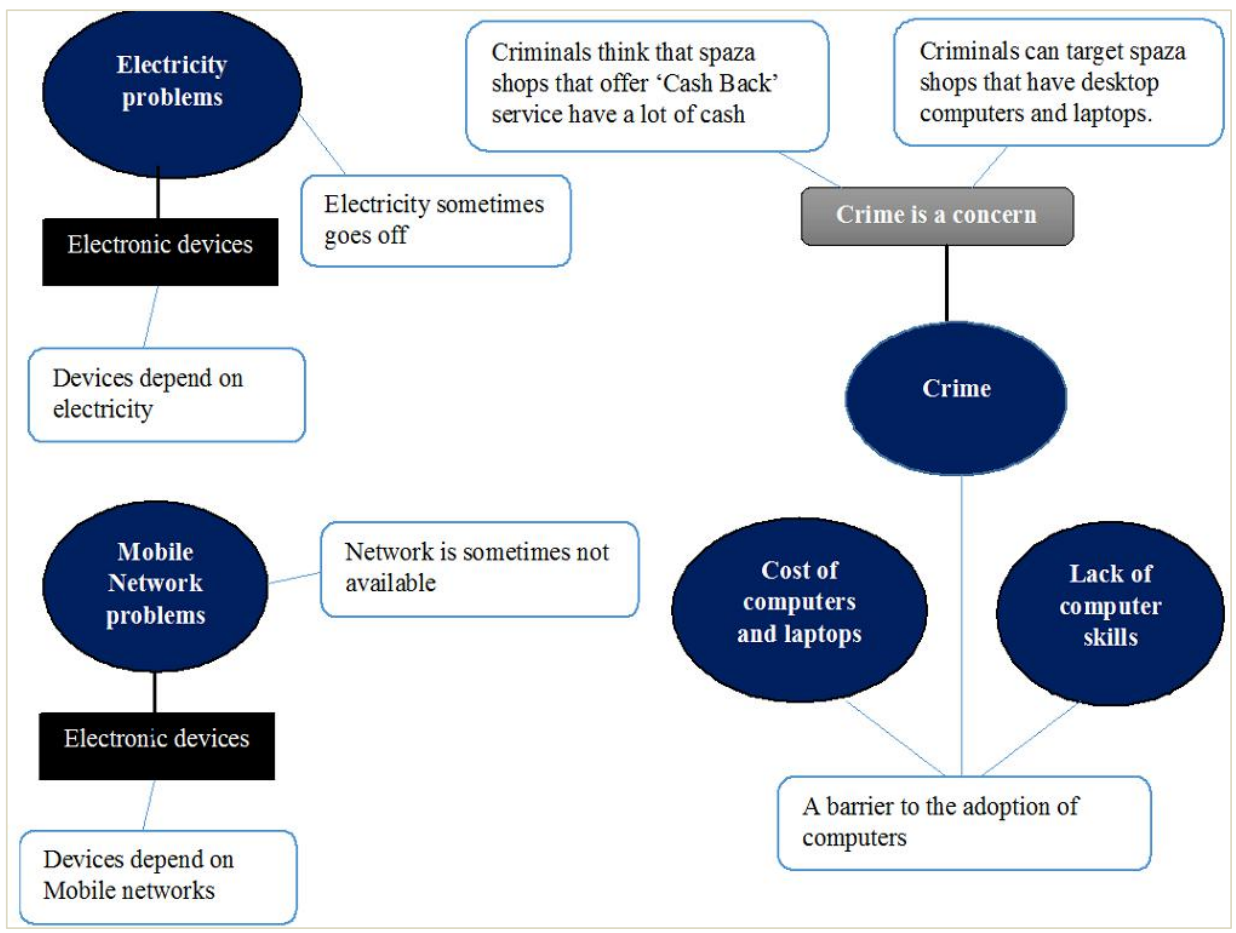

Figure 7: Summarized analysis of the common words/phrases on the challenges associated with use of ICTs by the managers of spaza shops.

\section{Limitations of the Research and Future Directions}

Like other empirical studies, this research is not without its limitations. Not all rural areas (main places and wards) of the KSD region were covered in this research, only 30 out of more than 200 were covered. The sample size consisted of 80 managers of spaza shops in only one deep rural region of South Africa. This limits the generalisability of the findings.

The study could therefore be strengthened by increasing the sample size and including participants from other deep rural regions of South Africa such as the Mbashe region, the Nyadeni region, and the Ngquza Hill region. With an increased sample size, a more detailed empirical analysis among the 
independent variables and the variables that have multiple categories, could be performed. More extensive research studies involving the role, impact and adoption of ICTs within the context of informal microenterprises beyond spaza shops (for instance, street vendors, and tourism guides) covering the entire region of KSD could also be conducted. Potential correlations or associations between some of the demographic variables (for example, the gender, race, and education level of the spaza shop managers) and ICT use variables (devices, connectivity, applications, storage) and other UTUAT variables, could be profitably explored in future research.

\section{Conclusion}

The purpose/aim of this research was to explore the adoption of ICTs by the managers of spaza shops (informal retail microenterprises) in the rural areas of South Africa. The research findings showed that the adoption of ICTs by these managers is largely based on five portable devices: mobile feature phones, smartphones, Flash devices, Speedpoint devices, and electronic calculators. Managers of spaza shops generally use the devices for communication with suppliers/customers, and for customer-sales transactions.

The informal retail sector in South Africa is not documented. ICTbased research on the informal retail sector within the context of rural areas in South Africa is therefore limited. This research has provided new insights into the adoption of ICTs in the spaza economy (that is, the informal retail sector) within the context of South African deep rural areas. However, the research was conducted in only one region, with only 80 participants and therefore further research into this informal sector is needed in order to understand the role, impact and adoption of ICTs for a broader perspective.

\section{References}

Afolayan, A.O. 2014. Adoption of New ICT Innovation by SMMEs in Cape Town. Cape Town: The Cape Peninsula University of Technology (CPUT) Electronic Theses and Dissertations (ETD). Available at: http://etd.cput.ac.za/handle/20.500.11838/1391

(Accessed on 22 August 2018.)

African Unity Life 2017. Mobile Funeral Cover at Your Local Spaza Shop. 
80 De Villiers Way, Glencairn, 7975: African Unity Life (AUL) and Spazapp. Available at: https://www.cover.co.za/mobile-funeral-coverlocal-spaza-shop/ (Accessed on 22 August 2018.)

Ahmed, I., A. Shahzad, M. Umar \& A.B. Khilji 2020. Information Technology and SMEs in Pakistan. Available at:

https://www.researchgate.net/profile/Akmal-

Shahzad/publication/316253413_Information_Technology_and_SMEs_i n_Pakistan/links/58f7a3d1aca272c34c38008b/Information-Technologyand-SMEs-in-Pakistan.pdf (Accessed on 22 August 2018.)

Al Essa, T.S. 2018. This is the Secret of the Most Successful Small Businesses. Available at:

https://www.weforum.org/agenda/2018/01/this-is-the-secret-of-themost-successful-small-businesses/

(Accessed on 02 February 2019.)

Ashrafi, R. \& M. Murtaza 2008. Use and Impact of ICT on SMEs in Oman. Available at: https://www.researchgate.net/profile/Rafi-

Ashrafi/publication/228526881 Use and impact of ICT on SMEs in Oman/links/00b4951d3020ab7648000000/Use-and-impact-of-ICT-onSMEs-in-Oman.pdf (Accessed on 22 August 2018.)

Bear, M. 2005. Spaza Shops in South Africa. Available at: http://www.spazanews.co.za/ (Accessed on 22 August 2018.)

Bear, M., S. Tladi, D. Pedro \& P. Bradnum 2005. Making Retail Markets Work for the Poor - Why and How Triple Trust Organisation Decided to Intervene in the Spaza Market in South Africa. (Case Study. USA: The SEEP Network.) Available at: http://www.valuechains.org/dyn/bds/docs/460/TTO\%20Case\%20Study\%20Final.pdf. (Accessed on 22 August 2018.)

BizTechAfrica 2017. Last Mile for BoP app to Help Spaza Shops Boost their Buying Power 2017. Available at:

https://www.biztechafrica.com/article/last-mile-bop-app-help-spazashops-boost-their-buy/12372/ (Accessed on 22 August 2018.)

Booysen, J. 2018. Spaza Shops Sell up a R 7 Billion Storm in S.A. Available at: https://www.iol.co.za/capeargus/news/spaza-shops-sell-up-a-r7billion-storm-in-sa-14877341 (Accessed on 22 August 2018.) Chetty, N. 2016. The Influence of ICT Interventions on the Performance of Informal Traders in the Sandton Region. Johannesburg: Wits Institutional Repository - Thesis and Dissertations. Available at: 
http://wiredspace.wits.ac.za/ (Accessed on 22 August 2018.)

Christopher, A. \& M. Manoj 2018. Foundation for Economies Worldwide -

Small Business. New York: International Federation of Accountants.

Available at: https://www.ifac.org/global-knowledge-gateway/finance-

leadership-development/discussion/foundation-economies-worldwide

(Accessed on 3 October 2018.)

Dorfling, J, C. Friedland, M. Mengistu, C. Merz, S. Stadtrecher, K. Pabst \&

R. de Louw 2009. Mobile Commerce in Rural South Africa - Proof of

Concept of Mobile Solutions for the Next Billion Mobile Consumers.

IEEE International Symposium on World of Wireless Mobile and Multimedia Networks (WoWMoM). Available at:

https://ieeexplore.ieee.org/abstract/document/5282441?casa_token=Zyur qF71YHUAAAAA:HP-a2V84qCDlvK-

DC8U5Z86a06i5BwBCrEJPbXjX0BnoxgLju0KxAsfRufYo7rRJfEHM

GBnQuA (Accessed on 22 August 2018.)

Eastern Cape Socio Economic Consultative Council (ECSECC) 2017. King

Sabata Dalindyebo Local Municipality Socio-economic Review and

Outlook, 2017. Available at:

https://www.ecsecc.org/documentrepository/informationcentre/king-

sabata-dalindyebo-local-municipality_52786.pdf

(Accessed on 22 August 2018.)

Esselaar, S., C. Stork, A. Ndiwalana \& M. Deen-Swarra 2007. ICT Usage and its Impact on Profitability of SMEs in 13 African Countries. The MIT Press 4,1: 87 - 100. Available at:

https://ieeexplore.ieee.org/abstract/document/4085512/

(Accessed on 22 August 2018.)

Fadnis, M. \& F. Arnold 2018. Foundation for Economies Worldwide $=$ Small Business. New York, USA: International Federation of Accountants.

Available at: https://www.ifac.org/knowledge-gateway/contributingglobal-economy/discussion/foundation-economies-worldwide-smallbusiness (Accessed on 22 August 2018.)

Flash 2018. Buy or Sell Safely and Easily with Flash. Available at:

https://flash.co.za/products/

(Accessed on 22 August 2018.)

Fisher-French, M. 2011. Banking on Spaza Shops. Available at:

https://mg.co.za/article/2011-07-01-banking-on-spaza-shops

(Accessed on 22 August 2018.) 
Frempong, G. 2009. Trends in ICT Usage by Small and Medium Scale Enterprises in Ghana. Ghana: Science and Technology Policy Research Institute. Available at:

http://atdforum.org/IMG/pdf_ICT_use_by_SMEs_in_Africa_Frempong. pdf (Accessed on 22 August 2018.)

Gumbo, T. \& Bokolo, T. 2014. Migrant Spaza Shops: Business Lessons from Soweto. Cape Town: Urban Informality and Migrant Entrepreneurship in Southern African Cities workshop, hosted by the University of Cape Town. Available at:

http://www.hsrc.ac.za/en/review/hsrc-review-july-2014/migrant-spazashops (Accessed on 22 August 2018.)

Harindranath, G., R. Dyerson \& D. Barnes 2010. ICT Adoption and Use in UK SMEs: A Failure of Initiatives? Royal Holloway University of London, UK. Available at: https://www.researchgate.net/profile/DavidBarnes-

22/publication/228858188 ICT adoption and use in UK SMEs a fai lure of initiatives/links/0c960521668510706e000000/ICT-adoptionand-use-in-UK-SMEs-a-failure-of-initiatives.pdf

(Accessed on 22 August 2018.)

ITU, 2016. Accelerating ICT growth together. ITU News Magazine.

Available at: https://www.itu.int/en/itunews/Documents/2016-

06/2016_ITUNews06-en.pdf (Accessed on 22 August 2018.)

Makoza, F. \& W. Chigona 2012. The Livelihood Outcomes of ICT Use in Microenterprises: The Case of South Africa. The Electronic Journal of Information Systems in Developing Countries 53,1: 1 - 16. Available at: https://onlinelibrary.wiley.com/doi/abs/10.1002/j.16814835.2012.tb00374.x (Accessed on 22 August 2018.)

Makwaiba, B. 2018. App Puts Bulk Buying Power into Township Enterprises' Hands. Available at: https://www.tt100.co.za/i-am-emergebrian-makwaiba/ (Accessed on 22 August 2018.)

Matlala, R., R. Shambare \& M. Lebambo 2014. How South African Spaza Shop Owners Utilise Mobile Communication Technologies to Run their Businesses. European Scientific Journal 10,25. Available at:

https://onlinelibrary.wiley.com/doi/abs/10.1002/j.1681-4835.2012.tb00374.x (Accessed on 22 August 2018.)

Mangaung Municipality. 2018. By-Laws Relating to Spaza Shops. Bloemfontein: Mangaung Municipality. Available at: 
http://www.mangaung.co.za/wp-content/uploads/2018/05/Bylaw-SpazaShops-Draft-2018.pdf. (Accessed on October 2018.)

Mbuyiswa, B. 2015. ICT Usage in Small, Medium and Micro Enterprises: A South African Perspective Of its Role and Impact on Poverty Reduction. Theses and Dissertations, University of Pretoria. Available at: https://repository.up.ac.za/handle/2263/61705 (Accessed on 22 August 2018.)

Melchioly, S.R. \& O.M. Saebo 2010. ICTs and Development: Nature of Mobile Phones usage for SMEs Economic Development - An Exploratory Study in Morogoro, Tanzania. Tanzania University of Agder. Available at:

http://citeseerx.ist.psu.edu/viewdoc/download?doi=10.1.1.617.5045\&rep =rep1\&type $=$ pdf (Accessed on 22 August 2018.)

Mukwarami, J. 2017: Factors Affecting the Growth of Locally Owned Spaza Shops in Selected Townships in South Africa. Cape Town: Repository of Theses and Dissertations. Available at:

http://etd.cput.ac.za/bitstream/handle/20.500.11838/2719/208116826Mukwarami-Josephat-MBus-Business-Administration-BUS-

2018.pdf?sequence $=1 \&$ isAllowed=y (Accessed on 22 August 2018.)

My Spaza Distributions and Consulting 2018. My Spaza Programme. Umlazi: My Spaza Distributions and Consulting Pty (Ltd). Available at: https://www.myspaza.store/ (Accessed on 22 August 2018.)

Ngassam, E.K., F. Ntawanga, J.H.P. Elliff. 2012. A Roadmap for Rural Area ICT Solution Deployment: The Case of Kgautswane Community in South Africa. Research Articles, Computer Science, University of Pretoria. Available at: https://repository.up.ac.za/handle/2263/40471 (Accessed on 22 August 2018.)

Notomi, N., M. Tsukamoto, M. Kimura \& S. Yamamoto 2015. ICT and the Future of the Retail Industry - Consumer-Centric Retailing. NEC Technical Journal 10,1. Available at:

https://in.nec.com/en IN/about/technical-journal/latestisse/year/g15/pdf/150107.pdf (Accessed on 22 August 2018.)

Odendaal, N. 2014. Electronic Payment Solutions Moving Informal Retailers into 'Cash-light' Era. South Africa: Creamer Media Engineering News. Available at: https://www.engineeringnews.co.za/article/electronicpayment-solutions-moving-informal-retailers-into-cash-light-era-201404-04-1 (Accessed on 22 August 2018.) 
Ongori, H. \& S.O. Migiro 2009. Information and Communication Technologies Adoption in SMEs: Literature Review. Journal of Chinese Entrepreneurship 2,1: 93 - 104. Available at:

https://doi.org/10.1108/17561391011019041

(Accessed on 22 August 2018.)

Organisation for Economic Co-operation and Development (OECD) 2015. South Africa: OECD. Available at:

http://www.oecd.org/eco/surveys/South-Africa-OECD-economicsurvey-overview.pdf (Accessed on 06 November 2018.)

Osterwalder, A. \& Y. Pigneur 2010. Business Model Generation: A Handbook for Visionaries, Game Changers, and Challengers. Available at:

https://books.google.co.za/books?id=Bjj8G3ttLWUC\&printsec=frontcov er\&dq=osterwalder+and+pigneur $\&$ hl=en $\& s a=X \& v e d=0$ ahUKEwidq_vnPbiAhURtXEKHVcDAhsQ6AEILzAB\#v=onepage $\& \mathrm{q}=$ osterwalder\% 20and\%20pigneur\&f=false. (Accessed on 22 August 2018.)

Perks, S. 2010. Exploring the Management Abilities of Spaza Shop Owners in the Nelson Mandela Metropolitan Municipality. South African Journal of Economics and Management.

http://www.scielo.org.za/scielo.php?pid=S2222-34362010000400006 (Accessed on 22 August 2018.)

Pick 'n Pay 2018. Case Study: From Spaza to Store. Available at: http://picknpayinvestor.co.za/financials/annual-reports/2018/case-studyfrom-spaza-to-store.php (Accessed on 22 August 2018.)

Piper, L. \& A. Charman 2016. Xenophobia, Price Competition and Violence in the Spaza Sector in South Africa. Available at:

https://sihma.org.za/journals/AHMR-Vol-2-No-1-Jan-April-

2016.pdf\#page $=4$ (Accessed on 22 August 2018.)

Radebe, J. 2017. Minister Jeff Radebe: Comprehensive Social Security Report. Available at:

http://www.sassa.gov.za/phocadownload/minister\%20jeff $\% 20 \mathrm{radebe} \% 2$ 0comrehensive\%20social\%20security\%20report.pdf (Accessed on 22 August 2018.)

Sustainable Livelihoods Foundation 2016. South Africa's Informal Economy. Cape Town: Sustainable Livelihoods Foundation. Available at: http://livelihoods.org.za/wp-content/uploads/2018/05/South-AfricasInformal-Economy.pdf (Accessed on 3 October 2018.) 
Sustainable Livelihoods Foundation 2012. Formalising Informal Microenterprises (FIME). Sustainable Livelihoods Foundation. Cape Town, South Africa. Available at: http://livelihoods.org.za/causes/formalisinginformal-micro-enterprises-2/ (Accessed on 22 August 2018.)

Statistics South Africa 2016. King Sabata Dalindyebo. Available at: http://beta2.statssa.gov.za/?page_id=993\&id=king-sabata-dalindyebomunicipality (Accessed on 22 August 2018.)

Selpal 2018. Selpal Gives Store Traders and Street Sellers a Virtual Shop with More Products and More Value. Available at:

https://www.selpal.co.za/products-3/ (Accessed on 22 August 2018.)

Talbot, J. M. \& M. Marsden 2012. SHOP-Net: Moving from Paper to Mobile.

Cape Town: UCT. Available at:

https://pubs.cs.uct.ac.za/id/eprint/709/1/Talbot.pdf

(Accessed on 22 August 2018.)

Van Rensburg, R. 2017. Pick n Pay Offering Township Spaza Shops Convenient Supply Chain Service. Cape Talk Interview Podcast.

Available at: http://www.capetalk.co.za/articles/277611/pick-n-payoffering-township-spaza-shops-convenient-supply-chain-service (Accessed on 22 August 2018.)

TallOrder 2018. Independent Retailers Spaza Shops. What is a Spaza Shop? Available at:

https://www.tallorder.mobi/wp-content/uploads/2018/09/What-is-a-

Spaza-Shop.pdf (Accessed on 22 August 2018.)

Terblanché, N.S. 1991. The Spaza Shop: South Africa's First Own Black Retailing Institution. International Journal of Retail \& Distribution Management 19,5. Available at:

https://doi.org/10.1108/EUM0000000002949

(Accessed on 22 August 2018.)

United Nations Economic and Social Commission for Asia and the Pacific (UNESCAP) 2019. SMEs in Asia and the Pacific. Thailand: UNESCA. Available at:

https://www.unescap.org/sites/default/files/7\%20\%201.\%20SMEs\%20IN\%20ASIA\%20AND\%20THE\%20PACIFIC.pdf. (Accessed on 02 February 2019.)

van Scheers, L. 2010. Challenges of Small Family Groceries Shops in South Africa. World Journal of Entrepreneurship, Management and Sustainable Development 6,3:221-231. 


\section{https://doi.org/10.1108/20425961201000017}

Von Broembsen, M. 2008. Spaza Owners Seek Business Status. South Africa. Mba.co.za. Available at:

http://www.mba.co.za/article!rootid=62subdirectoryid=850

(Accessed on 3 October 2018.)

World Bank 2018. Small and Medium Enterprises (SMEs) Finance

Improving SMEs' Access to Finance and Finding Innovative Solutions to

Unlock Sources of Capital. Washington: World Bank. Available at: https://www.worldbank.org/en/topic/smefinance

(Accessed on 12 September 2018.)

World Bank 2019. The World Bank in South Africa. Pretoria: The World Bank Group. Available at:

https://www.worldbank.org/en/country/southafrica/overview

(Accessed on 02 February 2019.)

World Economic Forum (WEF) 2017. The Africa Competitiveness Report 2017. Geneva: Word Economic Forum. Available at:

http://www3.weforum.org/docs/WEF ACR 2017.pdf

(Accessed on 12 September 2018.)

World Trade Organization (WTO) 2018. Word Trade Report 2018. Geneva:

World Trade Organisation. Available at:

https://www.wto.org/english/res_e/publications_e/world_trade_report18 _e.pdf (Accessed on 2 December 2018.)

Mpho Mzingelwa Department of Information Systems and Technology University of KwaZulu-Natal Durban, South Africa mzingelwa@ukzn.ac.za 


\title{
E-Citizenship and its Role in Promoting Participatory Governance in South Africa: A Durban Metropolitan Municipality Case Study
}

\section{Paul Kariuki}

ORCID iD: https://orcid.org/0000-0001-5758-5343

\section{Lizzy Ofusori \\ ORCID iD: https://orcid.org/0000-0002-6036-619X}

\begin{abstract}
Citizen engagement is a key factor in the successful and sustainable use of electronic platforms. It involves multiple activities ranging from collecting to processing raw data into useable formats that could help solve societal problems. As a metropolitan city, Durban seeks to become a liveable, inclusive city in which citizens are digitally capacitated to engage with it. However, there is a lack of insight into what drives Durban citizens to engage in local governance processes using various electronic platforms. This study aimed to identify factors that influence citizens' interests in engaging in these processes using the platforms.

To attain this objective, the researchers conducted a single case study of citizen engagement in Durban, South Africa, using a cohort of civic education facilitators sampled from a provincial-wide coalition of civil society organizations. Participants of the study were purposively selected based on their participation in local civic activities, in relation to governance promotion in the city as well as their exposure to various digital platforms used by the city to engage with citizens. Age and gender were considered to ensure a balanced participation of the respondents. Snowballing was used as a sampling technique to identify individuals who participated as key informants for the study.
\end{abstract}

The research found that citizens' own consciousness as active citizens 
in society was an intrinsic motivator for engaging with the electronic platforms. The quality of information accessed on the various digital platforms used by the Durban Metropolitan Municipality did not deter citizens from engaging with it. Moreover, the fact that citizens felt that they could easily access information about the city was a strong factor towards deepening trust in the Metro's desire to engage with citizens. This insight is useful in informing decision makers at the Metro on how to stimulate and improve the digital platforms as a way of enhancing the engagement experience. Furthermore, the research draws some key lessons for policy makers to enhance e-citizenship by promoting participatory governance at the local government level.

Keywords: e-citizenship, participatory governance, South Africa, Durban Metropolitan Municipality, eThekwini City Council

\section{Introduction}

E-Citizenship or digital citizenship is an emerging concept of Information and Communication Technologies (ICTs) that is gaining global momentum. This concept helps citizens to understand how technology can be used to create new statuses, privileges or rights that did not previously exist (Roots \& Dumbrava 2016). According to Roots and Dumbrava (2016), e-citizenship is more than just an engagement tool; it is a way to prepare citizens for a technology-based society. In this emerging era of digital technology, governments are looking for approaches to revamp their open administration services to citizens, utilising the potential offered by ICTs (Lips 2006). Other than the paper-based public service delivery, governments are now creating ecitizenship service delivery in order to better serve the citizenry (Lips 2006). Governments are supporting all efforts to prepare skilful citizens who are capable of functioning efficiently in this digital age to express themselves in a wide range of situations; acquire, develop and implement solutions in different contexts; and utilise a broad range of tools and applications developed in the digital context (Lips 2006). These digital technologies not only provide ways to connect with others across the globe but also enable broader e-citizenship participation in democratic processes and in civil society action (Mossberger et al. 2007). e-Voting, petition platforms, blogs, crowdfunding sites and other online tools and forums offer new opportunities for citizens to contribute to 
shaping political debate and driving 'real world' change (Kleinhans et al. 2015). Furthermore, it has,

the potential to reinvigorate a more 'citizen-powered' democracy; such a democracy might see citizens having a more direct determining influence on democratic processes, underpinned by closer and more responsive citizen-state interactions, and broader public representation in these processes (Dubow 2017: 4).

However, the level to which digital technologies can strengthen ecitizenship participation in democratic processes depends on the ability of the technology to mobilise advanced levels of engagement and action from citizens across a wider range of society (Dubow 2017). Citizen involvement in democratic processes can be enhanced through specific digital tools which include platforms that involve citizen inputs and views regarding policy formulation, or that seeks citizens' opinions in the allocation of the local government budget. Dubow (2017) argues that at present these tools are not widely used and that their impacts on democratic processes are still uncertain.

\section{Definition of Key Concepts}

\section{E-Citizenship}

E-Citizenship or digital citizenship can be defined as a way in which people use Information Technology (IT) to engage the government, politics and society (Mossberger et al. 2007).

\section{Participatory Governance}

Participatory governance is a process and structure designed to engage citizens and the government through institutional arrangements and political networks that facilitate supportive, collaborative-based discursive relationships among the citizens and government (Chen et al. 2009). Fischer (2015) describes participatory governance as a subset of governance theory which emphasises democratic engagement, particularly through deliberative practices. It is a concept that is increasingly gaining popularity. Gustafson and Hertting (2017) argue that there are three types of public governance: political, civic and development. Political and civic governance focus on issues that relate to human rights, while development governance deals with planning, budgeting, monitoring and 
accountability of socio-economic development policies and programmes.

\section{Active Citizenship}

It is important to first understand the definition of citizenship. Turner (1997) describes citizenship as a formal legal identity that a person inherits through a collection of lawful rights and commitments, controlling access to the scarce economic, political and social resources of society. Citizenship can be divided into social, civil and political citizenship. Social citizenship refers to the ability of citizens to have access to the right resources needed to live a civilized life in accordance with the prevailing standards of the society. Civil citizenship refers to the necessary rights needed to protect the liberty of individuals, which includes freedom of speech (Epstein et al. 2006). Political citizenship embodies the claim that citizens ought to participate in the democratic exercise, either as an elected individual (i.e. a politician) or as a member of a political community (i.e. a voter). Hence, Brannan et al. (2006) described active citizenship as the willingness to contribute to civil or political debate as well as to social action.

\section{Participatory Democracy}

Participatory democracy can be defined as a process of mutual decision making that combines components from both direct and representative democracy (Pateman 2012). Alarcón et al. (2018) refer to participatory democracy as the responsibility of citizens to be involved in the decisions made by the representatives of the government that can impact the lives of the citizens. It can also be defined as a political system that allows citizens to participate in decision making, either by developing policy or holding a political position (Kaufman 2017). Alarcón et al. (2018) argued that, while the citizens have the ability or power to make decisions on policy proposals, the politicians assume the role of policy implementation. Similarly, Mutz (2006) described participatory democracy as a form of movement which may include the women's suffrage movement or civil rights movement that assemble a group of people to democratically make decisions for the group. A typical example of a participatory democracy is a town meeting where citizens vote or deliberate on major issues (Pateman 2012).

\section{Accountability}

While Thomas (1998) defined accountability as the prevention of potential 
abuse of power, Flinders (2017) described it as control with the ultimate aim of accountability systems. In a democratic society, accountability ensures that actions and decisions taken by public officials are suitable and transparent. According to Carothers and Brechenmacher (2014), accountability requires that the organisation's systems of reporting and controls are appropriate and made visible in the public domain. This is to ensure that the government administration meets the needs of the community which is in accordance with their stated objectives, thereby contributing to better governance and poverty reduction. Accountability implies that the actions of individuals and organisations should be explained to others in a transparent and justifiable manner (Ngulube 2004).

\section{Good Governance}

Lipchak (2002) refers to good governance as the procedure the government uses to undertake functions and activities in a transparent, responsive and efficient manner and in which citizens engage the government in the quest for their mutually economic, social and political objectives. In other words, good governance refers to the values and standards that a government considers as it governs. Hence, good governance implies open, accountable, inclusive, and effective public organisations (Mungiu-Pippidi 2015).

\section{Citizen Engagement}

According to Berger (2009: 340), ' ...engagement means activity and attention, an investment of energy and a consciousness of purpose'. In other words, engagement is a way of finding solutions to problems. Hence, Siebers, Gradus and Grotens (2018) define citizen engagement as a means of achieving a range of developmental goals which include increased social capital, improved public services and reduced poverty. Using such initiatives can bring about greater accountability, transparency and social inclusion, resulting in tangible improvements in people's lives (Bee \& Kaya 2017).

\section{Metropolitan Council}

In South Africa, a metropolitan council or municipality is a municipality that implements all the functions of local government for a city or metropolis. This is in contrast to areas which are primarily rural, where the local government is divided into district municipalities and local municipalities. In the Local Government: Municipal Structures Act, no. 17 of 1998, it is laid out that this 
type of local government is to be used for conurbations, 'centre of economic activity', areas 'for which integrated development planning is desirable', and areas with 'strong interdependent social and economic linkages' (VyasDoorgapersad 2014).

\section{Legal Framework for E-Citizenship in South Africa}

According to Naidoo (2012), '... there are several legal instruments in [the] forms of acts, regulations and policies that guides the use of electronic devices and electronic services in South Africa', for instance, the Electronic Communications Bill Act 36 of 2002, that transformed the South African Telecommunication and the Promotion of Access to Information Act, that endows constitutional right to information access (Naidoo 2012). Other policy measures include the Electronic Communications Transaction Act, the Minimum Information Security Standards, the Law Commission Issue Paper on Privacy Public Service Act, the Handbook on Minimum Interoperability Standards (MIOS) and the Open Source Software Strategy and Policy of 2006 (Mutula \& Mostert 2010).

However, the citizens have encountered negative experiences which discourage the usage of e-citizenship in engaging the government owing to the inability of the South African government to effectively leverage the existing legal and infrastructural framework to improve the standard of living. Some of these negative experiences include poverty, insecurity and illiteracy (Mutula $\&$ Mostert 2010; Naidoo 2012). Consequently, citizens are dissatisfied with the success level in accessing services (Mutula \& Mostert 2010).

However, according to the United Nations Conference on Trade and Development, in their, 'Promoting Entrepreneurship for Development' (UNCTAD 2015),

... some progress in e-government implementation in South Africa is noted as indicated by the UN e-government development rankings, from being 101 out of 192 countries in 2012 to $68^{\text {th }}$ position out of 193 countries in 2018.

With such progress it becomes imperative then to assess whether this progress has also improved citizens' experience with e-government services at local and municipal levels. 


\section{Conceptual Framework for E-Citizenship}

Several models are frequently used to provide insight into the success of citizen adoption of e-government new technology. These models are used to study user acceptance of technology or information systems. However, empirical studies have shown that factors from the Technology Acceptance Model (TAM) and the Diffusion Of Innovation (DOI) model play a major role in user acceptance of e-government services (Gefen, Karahanna \& Straub 2003; Pavlou 2003). The TAM was developed by Davis, Bagozzi and Warshaw (1989). This theory is widely used to better understand end users' intention when using new technologies (Davids 2011). The TAM has been found to provide a consistent prediction of people's behaviour in relation to perceived ease of use and perceived usefulness of new technologies' (Venkatesh \& Davis 2000).
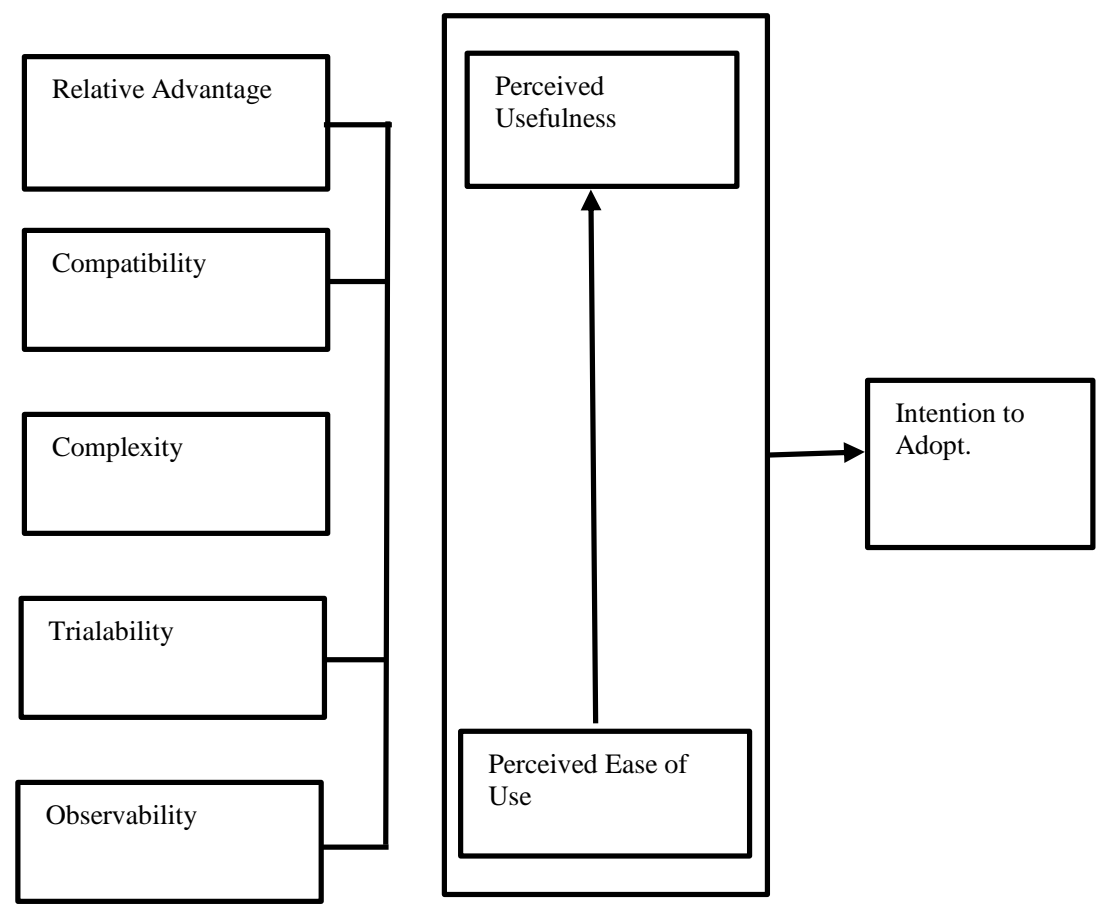

Figure 1: Factors for e-citizenship adoption of e-government new technology (Authors own) 
When the TAM model was empirically analysed; the results showed that the individual behaviour of accepting to use an electronic system is associated with the quality of services (Venkatesh \& Davis 2000). According to Pavlou (2003), measuring the quality of electronic services provides a clear insight into citizen behaviour when using them. In a similar view, the DOI theory is used to explain how new ideas and technologies spread among groups of people (Rogers 1995). It uses five innovative factors which include 'relative advantage', 'compatibility', 'complexity', 'trialability' and 'observability'. Drawing upon these theories, this study conceptualizes a framework for ecitizenship as shown in Figure 1.

The conceptual framework takes into consideration the citizens' decisions in adopting new technology. The framework integrates its constructs from the TAM and DOI model. It further describes the interconnection between the various components. The arrows between the components describe their relationships. The conceptual framework will promote ecitizenship adoption of e-government new technology and sustainability.

\section{E-Citizenship and Participatory Governance in South Africa}

E-Citizenship participation in governance is generally recognised as part of democracy and governance in South Africa. It can be described as the use of ICT tools by the citizens to engage the government. e-Participation is therefore closely related to e-governance participation. It is enshrined in the 1996 Constitution and applies to various law-making processes, policies and institutions as well as to structures, statutory bodies and programmes. An example of a past e-participation project is discussed below.

In 2012, the Local Government ICT Network launched a model eparticipation project together with a number of selected local authorities. They were given SMS credits and a direct call number. Citizens could then use these numbers to submit their proposals or complaints, and to report incidents such as power failures, burst pipes and potholes. Equally, the local authority could use the system to inform residents about scheduled council meetings, festivals or anticipated restrictions. The system is integrated into the local authority's normal email system and is entirely voluntary.

This project is showing early signs of success. In Emakhazeni, 
a rural authority in the province of Mpumalanga, there has been a significant fall in the number of complaints about poor services, and public attendance at council meetings has increased dramatically over the same period (Human Sciences Research Council 2013).

Dubow (2017) affirms that digital technologies have the potential to transform e-citizenship participation in democratic processes through the introduction of new mechanisms and practices, for example, by mobilising greater participation from people whose political engagement has traditionally been lower, by strengthening the voice of citizens in the public sphere, by enabling more direct participation in democratic decision making and by facilitating community support and cohesion. However, Modise (2017) argues that participatory democracy in South Africa is a great challenge for democratic processes due to the lack of adequate knowledge by citizens regarding political operation locally and internationally. The service delivery protests and marches are a clear indication that participatory democracy is a great challenge in democratic South Africa. Citizens carry out these protests to ensure the government listens to and considers their requests. Mawela et al. (2017) maintain that significant changes that can impact the lives of the community can only be initiated at the local government level. Similarly, Abrahams and Newton-Reid (2007) support that e-government programmes can be triggered by South African municipalities to enable citizens to interact with government using the full range of electronic media, through Integrated Development Plans (IDP) and incorporating relevant measures in growth and development strategies (Abrahams \& Newton-Reid 2007). Hence, the local governments which are closest to the communities are best poised to deliver on a vision of e-government. Furthermore, the provincial and national governments need to offer supervision, support, mentorship and assistance where necessary (Modise 2017).

\section{E-Citizenship Experiences in South Africa: Challenges and Possibilities}

According to Ochara and Mawela (2015), the key benefits of e-citizenship include strengthening citizen voices, facilitating social cohesion, sharing and interpreting data and supporting direct citizen participation in democratic processes. The government has established different technological-driven platforms through which citizens can engage with their government. However, 
... the degree to which digital technologies can strengthen citizen participation in democratic processes was felt to depend on the ability of digital technologies to mobilise higher levels of engagement and action from citizens across a broader spectrum of society (Dubow 2017: 6).

Similarly, e-citizen participation in democratic processes undoubtedly faces various challenges which include,

slow response rates to citizens' requests, lack of customer service orientation from public sector staff, limited and inconvenient hours offered by government institutions and long distances to reach government offices (particularly in rural areas) (Nkosi \& Mekuria 2010: 149).

Moreover, sometimes government services are inaccessible owing to network failures, resulting in abrupt shut down of service provision which displeases citizens (Dubow 2017). In addition, some municipalities do not budget adequately for aging IT infrastructure which complicates efficient accessibility of municipal services electronically. As a result, citizens struggle to submit their information relating to services rendered to them by the municipalities, especially where payment for the services is concerned.

These challenges threaten the effectiveness of e-citizen participation and widen the exclusion gap, especially along socio-economic lines. It is argued that local government is at the forefront of understanding citizens' needs and is the 'delivery arm' of government. It is the obligation of municipalities to ensure that there is an improvement in services for underdeveloped communities. This will ensure that there is an equitable provision of services to all citizens (South African Local Government Association 2014). Furthermore, there is a need for a better understanding of how civic engagement and participation can be mobilised through digital technologies (Dubow 2017). Hence, it is essential that government addresses any challenges that need urgent responses in order to minimise citizens' disenfranchisement.

Drawing upon these opportunities of e-citizenship and the challenges that must be addressed to harness this potential, it is imperative to build wellnetworked communities, ensure transparency and trust in democratic pro- 
cesses, and improve the information environment. By strengthening community networks and ensuring transparency and trust in democratic processes, digital technologies can enable citizens to make their voices heard effectively and effect positive social change in the public sphere (Dubow 2017). Furthermore, it will enable a digitally enabled citizenry to participate in the democratic processes, both at the local and the national level. Similarly, the digital provision of robust and tailored empirical data and citizen inputs can enable policymakers to make more evidence-based decisions for the greater social good (Dubow 2017).

\section{Methodology}

This study followed a qualitative approach to collect data which was conducted in 2018 for 6 months. The qualitative approach was chosen to understand better the experiences of citizens as they engage with the municipality. To achieve this objective, the researchers used a cohort of civic education facilitators sampled from a provincial-wide coalition of civil society organisations. They were purposively selected based on their participation in local civic activities in relation to governance promotion in the city as well as their exposure to various digital platforms used by the city to engage with citizens. Age and gender were considered to ensure a balanced participation. Twenty civic educators were selected to participate in the study. Snowballing was used as a technique to identify individuals who participated as key informants for the study from the municipality. Five senior officials from the municipality were involved in the study. Data was collected through semi-structured and keyinformant interviews telephonically. Thereafter, data was transcribed in preparation for analysis, which was done thematically. All interviews were conducted in English. These themes were identified based on the emerging dominant ideas that the researchers identified while analysing the data thematically.

\section{Limitation}

The study focused on the Durban Metro owing to time and financial constraints. Moreover, some key municipal functionaries involved in policy development with regard to e-governance in the municipality were not available to be interviewed for the study. Thus, some crucial information that could have provided some key insights was not captured by the study. 
Furthermore, the study did not focus on the rural areas because of the time constraints.

\section{Findings and Discussion}

This section presents the findings of the study, followed by a brief discussion of the salient points for clarity. The emerged themes from the interview are summarised (Table 1).

Table 1: Major themes that emerged in the qualitative analysis.

\begin{tabular}{|l|l|}
\hline S/n & Major themes \\
\hline 1 & Inaccessible information portals in the metro websites \\
\hline 2 & Use of one language on the website of the metro \\
\hline 3 & ICT-related human resource capacity challenges in the metro \\
\hline 4 & Limited citizen participation in online metro processes \\
\hline 5 & Limited citizen digital literacy \\
\hline 6 & Public-private partnership to enhance citizen digital literacy \\
\hline
\end{tabular}

\section{Inaccessible Information Portals in the Metro Websites}

The municipality has an extensive information sharing system on its website, but most respondents reported that it is inaccessible owing to its elaborate architecture. The respondents claimed that it is a challenge to navigate through the website in search of information. As one respondent claimed:

The Metro has a good website ... however, it is so extensive in its layout and design that it takes some time to actually find the information that one really is looking for...one wishes it was simpler, especially for most of citizens who have limited knowledge about websites.

As a result of the above, some respondents reported that it is challenging to make any input to any policy or programme documents, thereby limiting their interaction with the Metro:

Our municipality is constantly working on projects and programmes that we as citizens should make an input [in].... but it is challenging 
when one cannot navigate through its elaborate website ... we collect information continuously in our communities and we would like to share with the municipality through its website as it is easier... [We citizens] are always gathering information from our various interventions in communities across the Metro....... I'm sure that information would help the Metro in developing their own policies and projects.

\section{Use of One Language on the Website of the Metro}

Additionally, the Metro uses English as the only language of communication on its website. This has limited the extent to which citizens can engage with the Metro effectively. As one respondent reported:

The Metro's website is presented in English language .... whilst I understand that English is the language of business ... but ordinary citizens in this province [meaning KwaZulu--Natal] are isiZulu language speakers ... surely, some sections of the website should be in the local language so everybody can engage with the information and participate in any aspects of the Metro's work ... personally I feel limited to share information .... I have views .... but I cannot express myself powerfully like I would do in my own language [isiZulu] ...

The Metro should consider dual language presentation on its website, so it can maximise its interaction with citizens. As one municipal official claimed:

The Metro is able to re-design its website using dual language to cater for the demographics in the city...just like it does with its weekly newsletter ... which is presented in dual language and therefore everybody can engage with its content and explore further any possibilities of sharing their views ... this way the metro increases citizen participation in all its affairs and maximises its accountability to the citizenry ....

\section{ICT-related Human Resource Capacity Challenges in the Metro}

Even though the municipality has an elaborate and functional website and information system, the respondents claimed that some municipal officials faced 
challenges in using the ICT mechanisms to engage with citizens. One municipal official claimed:

There are challenges [ICT-capacity challenges]...that we are experiencing ... most of them relate to technical capacities such as using technology to communicate information with the public ... some of our staff are not tech-savvy ... sometimes they struggle using our various platforms to gather data and interpret it ....

Moreover, there is no allocated capacity development budget for human resources assigned for ensuring that staff receive ICT-related training to sharpen their skills. As one municipal official claimed:

Rarely do we attend training [ICT-related training] as there is no budget for such opportunities ... unless one self-funds to enhance one's own technical capacities, one might remain at the same level of knowledge and experience whilst things keep changing .... and without keeping pace with the times, we will not be able to improve on our capacity to deliver online-related services to the public efficiently and sustainably ....

\section{Limited Citizen Participation in Online Metro Processes}

Furthermore, public participation in the Metro online processes remains ad hoc and uncoordinated. This is partly owing to low digital literacy levels prevailing among most citizens and also because of the absence of feedback portals on most of the Metro's online platforms. Citizens cannot relay any of their views through the Metro's online platforms because there is no provision for it. This limits the extent to which citizens participate in a system that is primarily aimed at sharing information and eliciting engagement from the public. As one respondent reported:

Our Metro should consider setting [up] a section on its online platforms where we [citizens] can share our views and ideas on any aspect of its work ... at the moment it is impossible as there is not portal where we can make input ... but it is disheartening when one cannot find a way of sharing ideas and thoughts .... 
This scenario can often lead to the exclusion of the public from the broader decision-making processes such as those that relate to local development planning processes. Limited public participation in such processes may result in the Metro imposing its plans on communities and ultimately any of its interventions.

\section{Limited Citizen Digital Literacy}

Digital literacy is a critical factor in enabling effective e-citizenship. eParticipation is highly dependent upon an individual's capacity to interact via online digital platforms. In circumstances where digital literacy levels are low, citizens lack confidence to engage online with the government. As one respondent reported:

Most of us [citizens] are not well acquainted with internet or anything related to online [activities]...personally I struggle with using the internet, I was never exposed to it until recently where I got an opportunity to attend a community-based training offered by a local $N G O$ (non-governmental organisation), then I got some skills but still it [the training] is not sufficient [for me] to make use of the internet as effectively as I should ...

It is important to note that digital literacy is much more than the skill of using technology to engage via a technology-based platform. It also includes the ability to read and write. Stated differently, this contextual understanding of digital literacy is critical because without using this inclusive meaning of digital literacy, an important aspect of learning which includes problemsolving, critical thinking and creativity will be left out. Therefore, digital literacy is an empowering process whereby an individual not only acquires skills and competency but also gains insights on how to take advantage of positive aspects of using technology whilst at the same time learning to avoid the negative aspects associated with it.

\section{Public-Private Partnership to Enhance Citizen Digital Literacy}

In relation to the above point, it is critical that the Metro explore public-private partnerships that would help in addressing digital illiteracy which presently 
impedes effective e-citizen participation. As one municipal official contended:

The government should do something about it...it should encourage the private sector and civil society to assist in training ordinary citizens to be more digitally-literate so they can engage with the Metro via its online platforms ....

Undoubtedly, partnerships are important in addressing any gaps that limit the efforts of the government in enhancing effective citizen engagement. Therefore, it is imperative that the Metro explores opportunities where such partnerships can be identified, nurtured and leveraged to the extent that they can be mutually beneficial to ordinary citizens' e-literacy.

\section{Discussion}

Citizens' participation is a key indicator of a thriving democracy. The use of technology has made it easier for citizens to participate actively in government processes at all levels of governance. Technology has made it possible to bring the government to the people, thereby mobilising them to participate in its programmes and processes. The main objective is to deepen engagement between the state and the citizenry.

Given the long and painful past of South Africa under the apartheid regime which was characterised by the politics of exclusion, the post-1994 democratic government has been working tirelessly to ensure that every citizen has an opportunity to participate in its plans aimed at improving engagement, even at the local governance level. However, this ideal has been met by postapartheid reconstruction challenges of re-building a fragmented society faced by multiple socio-economic and political complexities. It is in addressing these challenges that the use of technology becomes a critical mechanism for bridging the gap between the state and her people.

Technological advancement has enabled governments to improve public administration as well as developing mechanisms of providing citizencentred public services. The government has established different technologically-driven platforms through which citizens engage with their government. As the study revealed, there are various challenges at multiple levels, ranging from digital illiteracy among citizens to inaccessible information portals of government sites. Whilst this chasm is enormous, it needs an 


\section{Paul Kariuki \& Lizzy Ofusori}

urgent response to close it and minimise the disenfranchisement that comes with it as it further widens the exclusion gap, especially along socio-economic lines. It is therefore imperative that government addresses any challenges that threaten effective e-citizenship. The following section suggests some pragmatic recommendations for consideration.

\section{Recommendations}

The study makes the following recommendations based on its findings:

- The municipality must address citizens' digital literacy so that citizens are empowered to effectively interact with the municipality and allow the citizens access public services. Customer service experiences are critical in a competitive business environment and municipalities are not immune to this competition;

- Connected to the above point, the Metro should explore possibilities of forming public-private partnerships so that joint interventions related to equipping citizens with relevant digital knowledge can fast track digital literacy levels among the public. The partnership could involve the private sector, academia and civil society as stakeholders to work together in tackling digital illiteracy;

- The Metro should work harder to enhance the digital capabilities of its human resource base. As indicated by the findings, some of the municipal functionaries assigned to manage municipal information portals lack the essential digital skills of engaging online with citizens. Improving its human resource ICT-related capabilities will go a long way in enhancing citizens' experience of government services at the Metro level;

- The Metro should also consider improving its information portals so that citizens can engage with these with minimum challenges. Accessing information via online platforms was noted as an ongoing challenge experienced by most citizens and this needs to be improved so the citizens can access government information and services. Moreover, it is critical that all the Metro's services and information are 
presented in a coherent way in formats that are easily digestible by its citizenry, a critical aspect of ensuring sustained participatory governance; and

- The Metro could consider establishing community-based digital hubs that make it possible for citizens living outside of the Metro to have an opportunity to access government information and its services. Most peri-urban areas are under-served as far as digital services are concerned. There is a need for the Metro to invest in these communities and enhance their accessibility to its services, thereby improving their participation in local governance processes through enhanced access to information. Additionally, citizens can provide useful feedback about the Metro's services, information that can be used to improve government policy. By way of giving feedback, citizens are able to enhance their own capabilities to review government project and programme proposals available online and contribute towards shaping their direction.

\section{Conclusion}

E-Citizenship is still in its infancy in South Africa and certainly in its formative stages of development in the Durban Metro. It has a significant role in promoting participatory governance in the country and at the local level. However, with advances in technology coupled with the commitment from government to fully utilise technology in enhancing its engagement with citizens, it is necessary that participatory governance is improved. This improvement will depend on enhancing citizens digital literacy so that they are able to interact with the metro's online service delivery platform. This way participatory governance will be enhanced as citizens engage with government for any of its public services.

\section{References}

Abrahams, L. \& L. Newton-Reid 2007. eGovernance for Social and Local Economic Development. LOG-IN Africa Third Technical Progress Report. Alarcón, P., C. Galais, J. Font \& G. Smith 2018. The Effects of Economic Crises on Participatory Democracy. Policy \& Politics 47,2: 265 - 286. 
https://doi.org/10.1332/030557318X15407316045688

Bee, C. \& A. Kaya 2017. Youth and Active Citizenship in Turkey: Engagement, Participation and Emancipation. Southeast European and Black Sea Studies 17,1: 129 - 143.

https://doi.org/10.1080/14683857.2016.1232893

Berger, B. 2009. Political Theory, Political Science and the End of Civic Engagement. Perspectives on Politics 7,2: 335 - 350.

https://doi.org/10.1017/S153759270909080X

Brannan, T., P. John, \& G. Stoker 2006. Active Citizenship and Effective

Public Services and Programmes: How Can we Know What Really

Works? Urban Studies 43,5-6: 993 - 1008.

https://doi.org/10.1080/00420980600676626

Carothers, T., \& S. Brechenmacher 2014. Accountability, Transparency, Participation, and Inclusion: A New Development Consensus? Available at: https://carnegieendowment.org/2014/10/20/accountability-

transparency-participation-and-inclusion-new-development-consensuspub-56968

Chen, D.-y., T.-y Huang, N. Hsiao, T.-L Lin \& C.-p Lee 2009. Experimental e-Deliberation in Taiwan: A Comparison of Online and Face-to-Face Citizens' Conferences in Beitou, Taipei. In Reddick, C.G. (ed.); Handbook of Research on Strategies for Local e-Government Adoption and Implementation: Comparative Studies. IGI Global.

https://doi.org/10.4018/978-1-60566-282-4.ch017

Davids, G. J 2011. Local Government Capacity Challenges in Post-apartheid

South Africa: Lessons Learnt. African Journal of Business Management 5,9: 3570 - 3576. https://doi.org/10.1287/mnsc.35.8.982

Davis, F.D., R.P. Bagozzi \& P.R Warshaw 1989. User Acceptance of Computer Technology: A Comparison of Two Theoretical Models. Management Science 35,8: 982 - 1003.

Dubow, T 2017. Civic Engagement: How Can Digital Technologies Underpin Citizen-Powered Democracy? RAND.

Epstein, P., L. Wray \& C. Harding 2006. Citizens as Partners in Performance Management. Public Management 88,10: 18 - 22.

Fischer, F. 2015. From Theory to Practice. Readings in Planning Theory 348. https://doi.org/10.1002/9781119084679.ch17

Flinders, M. 2017. The Politics of Accountability in the Modern State: Routledge. https://doi.org/10.4324/9781315206950 
Gefen, D., E. Karahanna, \& D.W. Straub 2003. Trust and TAM in Online Shopping: An Integrated Model. MIS Quarterly 27,1: 51 - 90.

https://doi.org/10.2307/30036519

Gustafson, P., \& N. Hertting 2017. Understanding Participatory Governance: An Analysis of Participants' Motives for Participation. The American Review of Public Administration 47,5: 538 - 549.

https://doi.org/10.1177/0275074015626298

Human Sciences Research Council 2013. Ehancing Digital Citizen

Engagement: Lessons from South Africa. HSRC Review 12,1: 9 - 10.

http://hdl.handle.net/20.500.11910/2522

Kaufman, A. S 2017. Human Nature and Participatory Democracy. In Connolly, W. (ed.): Pluralism in Political Analysis. Routledge.

Kleinhans, R., M. van Ham, \& J. Evans-Cowley 2015. Using Social Media and Mobile Technologies to Foster Engagement and Self-organization in Participatory Urban Planning and Neighbourhood Governance. Planning Practice \& Research 30,3: 237 - 247.

https://doi.org/10.1080/02697459.2015.1051320

Lipchak, A 2002. Information Management to Support Evidence-based Governance in the Electronic Age. Paper presented at the A Public Policy Forum Discussion Paper. Executive summary. Available at:

http://www.ppforum.ca/common/assets/publications/en/ow_p_11_2002b _es.pdf (Accessed 10 March 2007).

Lips, M 2006. e-Government under Construction: Challenging Traditional Conceptions of Citizenship. In Nixon, P.G. \& V.N. Koutrakou (eds.): EGovernment in Europe: Re-booting the State. Routledge. https://doi.org/10.4324/9780203962381-14

PMid:16373526 PMCid:PMC2563273

Mawela, T., N.M Ochara, \& H. Twinomurinzi 2017. E-Government Implementation: A Reflection on South African Municipalities. South African Computer Journal 29,1: 147 - 171.

https://doi.org/10.18489/sacj.v29i1.444

Modise, L. J 2017. The Notion of Participatory Democracy in Relation to Local Ward Committees: The Distribution of Power. In die Skriflig 51,1: 1 - 8. https://doi.org/10.4102/ids.v51i1.2248

Mossberger, K., C.J. Tolbert \& R.S. McNeal 2007. Digital Citizenship: The Internet, Society, and Participation. Cambridge and London: MIT Press. 
https://doi.org/10.7551/mitpress/7428.001.0001

PMid:17489696

Mungiu-Pippidi, A. 2015. The Quest for Good Governance: How Societies

Develop Control of Corruption. Cambridge: Cambridge University Press. https://doi.org/10.1017/CBO9781316286937

PMid:25693546

Mutula, S.M. \& J. Mostert 2010. Challenges and Opportunities of EGovernment in South Africa. The Electronic Library 28,1: 38 - 53.

https://doi.org/10.1108/02640471011023360

Mutz, D. C 2006. Hearing the Other Side: Deliberative versus Participatory

Democracy. Cambrdge: Cambridge University Press.

https://doi.org/10.1017/CBO9780511617201

Naidoo, G. 2012. Implementation of E-Government in South Africa: Successes and Challenges. The Way Forward. International Journal of Advances in Computing Management 1,1: 62 - 66.

Ngulube, P. 2004. Fostering Accountability and Justice: Opportunities for Records Managers in Changing Societies. ESARBICA Journal 23: 23.

https://doi.org/10.4314/esarjo.v23i1.30961

Nkosi, M., \& F. Mekuria 2010. Mobile Government for Improved Public Service Provision in South Africa. Paper presented at the 2010 ISTAfrica.

Ochara, N.M. \& T. Mawela 2015. Enabling Social Sustainability of EParticipation through Mobile Technology. Information Technology for Development 21,2: 205 - 228.

https://doi.org/10.1080/02681102.2013.833888

Pateman, C. 2012. Participatory Democracy Revisited. Perspectives on Politics 10,1: 7 - 19. https://doi.org/10.1017/S1537592711004877

Pavlou, P.A. 2003. Consumer Acceptance of Electronic Commerce: Integrating Trust and Risk with the Technology Acceptance Model.

International Journal of Electronic Commerce 7,3: 101 - 134.

https://doi.org/10.1080/10864415.2003.11044275

Rogers, E.M. 1995. Lessons for Guidelines from the Diffusion of Innovations. Joint Commission Journal on Quality and Patient Safety 21,7: 324 - 328. https://doi.org/10.1016/S1070-3241(16)30155-9

Roots, L. \& C. Dumbrava 2016. E-Citizenship Opportunities in the Changing Technological Environment. The Future of Law and eTechnologies 4556. https://doi.org/10.1007/978-3-319-26896-5_3 
Siebers, V., R. Gradus \& R. Grotens 2018. Citizen Engagement and Trust: A Study among Citizen Panel Members in Three Dutch Municipalities. The

Social Science Journal. https://doi.org/10.1016/j.soscij.2018.09.010

South African Local Government Association 2014. About Municipalities.

Available at: www.nationalgovernment.co.za/units/view/171/southafrican-local-government-association-salga

Thomas, P.G. 1998. The Changing Nature of Accountability. Taking Stock: Assessing Public Sector Reforms 2: 348 - 393.

Turner, B.S. 1997. Citizenship Studies: A General Theory. Citizenship Studies 1,1: 5 - 18. https://doi.org/10.1080/13621029708420644

United Nations Conference on Trade and Development (UNCTAD) 2015.

Promoting Entrepreneurship for Development. Available at: http://unctad.org/meetings/en/SessionalDocuments/ciid29_en.pdf

Venkatesh, V. \& F.D. Davis 2000. A Theoretical Extension of the Technology Acceptance Model: Four Longitudinal Field Studies. Management

Science 46,2: 186 - 204. https://doi.org/10.1287/mnsc.46.2.186.11926

Vyas-Doorgapersad, S. 2014. Gender Equality, Pro-poor Growth and MDG

Goal 1 in South African Municipal Governance: The Case of Sedibeng District Municipality. Mediterranean Journal of Social Sciences 5,21: 327. https://doi.org/10.5901/mjss.2014.v5n21p327

Paul Kariuki

School of Management, IT and Governance University of KwaZulu-Natal pamirry@gmail.com

Lizzy Ofusori School of Management, IT and Governance University of KwaZulu-Natal lizzyofusori@yahoo.co.uk 


\title{
The Evaluation of Municipal Electronic Government Capacity and Service Delivery at Ngaka Modiri Molema District Municipality
}

\author{
Mylet Ursula Dlamini
}

Jan Meyer

ORCID iD: $\underline{\text { http://orcid.org/0000-0002-3677-963X }}$

\section{Sam Lubbe}

ORCID iD: http://orcid.org/0000-0002-1225-7511

\begin{abstract}
This study investigated the efficiency of municipal service delivery experienced by the community and the e-Government effectiveness in Ngaka Modiri Molema District Municipality. It highlights problems relating to municipal incompetency, and service delivery backlogs. Segments of the community remain economically inactive and municipal capacity is the catalyst of the whole scenario. The sample consisted of Ngaka Modiri Molema District Municipality employees and the data was collected using questionnaires. The findings of this study provide a point of departure for the evaluation of municipal e-Government service delivery at the municipality and indicate that there is a lack of competence by staff members and ineffectiveness in the e-Government service. The District Municipality management should explore opportunities that ensure that training and development are provided to municipal staff to improve capacity and competency and also explore the opportunity to increase e-Government efficiency and effectiveness.
\end{abstract}

Keywords: effectiveness, electronic government capacity, lack of competency, service delivery, municipal incompetency 


\section{Introduction}

Section 151 of the Republic of South Africa Constitution Act 1996 (Act 108 of 1996), provides for the establishment of municipalities, with the executive and legislative authority vested in its council. A municipality governs the affairs of the community. The ability of a municipality to perform its functions may not be compromised or impeded by the national or provincial governments as part of affirmative action (Smith 2005: 16 - 17, - unreviewed).

According to Kaisara and Pather (2011: 1), the Internet has become an integral part of the information society with an ever-increasing role in areas of education, professional sectors, recreation, social networking and in myriad other areas of life. As a result, the capacity of modern organisation is influenced by the way in which it is able to harness the benefits of the Internet.

\section{Problem Statement}

The study aims to determine by what means e-government capacity will assist in the improvement of municipal service delivery. Blom-Hansen et al. (2016) show that recurring episodes of local protests are testimony to the shortcomings of municipal services. Local government constraints are as a result of a scarcity of technical skills, recruitment and retaining of staff, eGovernment inefficiency and inappropriate handling of resources.

Research conducted by Alcayna et al. (2016) indicate that in general most national and provincial departments with supervisory and regulatory responsibilities over municipalities are not playing their role of ensuring that standards and processes for monitoring and supervision are implemented.

\section{Research Questions}

The research questions to be investigated are:

i. What determines efficiency and deficiency in municipal service delivery?

ii. To what extent is the municipality capable and competent?

iii. What determines good quality municipal service delivery?

iv. What determines the efficiency and effectiveness of electronic Government (e-Government) system? 


\section{Literature Review}

\section{Local Government and Capacity Building}

Simmons et al. (2011: 4) highlight that to define capacity building invites statements, definitions, theory and practice ranging from technical skills development to institutional development. Renfors (2019) defines competency as a combination of training, knowledge, skills and effectiveness.

\section{E-Government}

Panayiotou and Stavrou (2019) define e-Government as government's use of technology, particularly web-based Internet applications, to enhance the access and delivery of government information and service to citizens, business partners, employees, and government entities.

\section{Capacity and Competency}

Jitsing et al. (2019: 21) highlight that the positive progress and success of the local government system in South Africa is being overwhelmed by a range of factors. Van der Waldt et al. (2018: 173) state that the capacity in local government is demonstrated by a lack of financial resources to meet service delivery and staff vacancies, and municipalities have to be competent.

Van der Waldt et al. (2018) mentions that the National Capacity Building Framework identified capacity constraints within local government as a lack of competency. This can lead to the inability to do tasks, poorly defined job descriptions, recruitment and selection of staff not in line with job descriptions and an inadequate knowledge and information base within municipalities and behaviour.

Johnstone and Blenkinsopp (2017) state that existing government training institutions are overburdened with the rising demand in terms of capacity and capability. A study conducted by Mohr et al. (2012: 895) revealed that rural governments were run by volunteers and a small staff of employees. Mohr et al. (2010: 894-895) further highlight that units of governments have difficulty negotiating, monitoring, and enforcing contracts. This capacity in turn, is linked to organisational performance.

\section{Skills in Local Government}

Damasceno Cunho et al. (2018) forecasted that the nation was poised for a 
workforce crisis and that the government was likely to feel the crisis because of the high proportion of older employees leaving the workplace and demand for knowledge by workers. According to Jindal et al. (2016), various organisations build skills in diverse areas, including leadership, financial management, local economic development, participatory planning, budgeting and conflict management to impact performance and effectiveness.

Van der Waldt et al. (2018: 5-43) highlight that there is a large increase in the demand for skills due to the transformation and restructuring agenda of the local government sector, increased focus on the sector as an implementation agent for national policies, necessity to eradicate service delivery backlogs and high staff turnover, the transformation of human resource management practices, and employment equity considerations. Furthermore, Van der Waldt et al. (2018) note that despite problems with the attraction and retention of high-level skills, very little evidence is found on strategies to address problems across the local government sector.

\section{Learning and Training}

According to Kachali et al. (2018), acknowledging that the learning process is important when building capacity to handle crises. Kachali et al. (2018) went on to state that a response to a crisis is benefited by individuals having adequate skills and knowledge of resources, actors and relations needed to solve the specific crisis situation.

Van der Waldt et al. (2018) indicated that there is a weakness in the overall management of training, as demonstrated by the little consideration given to workplace training and the development of policies and procedures. In addition, although trainings do take place in the local government sector, much of this training is piecemeal, ad hoc and does not lead to full qualifications.

\section{Efficiency and Performance}

There is a need to ensure that municipalities are responsive, efficient, and effective and provide value for money with the allocated public resources (CoGTA 2009:6). According to Van der Waldt et al. (2018) performance areas are governance and democracy, municipal transformation and institutional development, municipal financial viability and management, etc. The public 
choice approach is often characterized by a 'leviathan' view of government, which argues that government monopoly over the people leads to overproduction and inefficiency (Mohr et al. 2010: 894).

\section{Service Quality and Delivery}

In terms of Act 32, Section 73, (RSA 2000), Local Government: Municipal Systems, the municipality must give effect to the provision of the Constitution and give priority to the basic needs. Therefore, municipalities must be accessible, provided with economic, efficient and effective resources, financially sustainable, environmentally sustainable, and regularly reviewed with a view to upgrading, extension and improvement.

Service delivery is hampered not only by staff vacancies, but also by the lack of standards guiding the appointment of staff, the allocation of numbers and types of posts against service delivery standards and targets (Van der Waldt et al. 2018). The South African Constitution stipulates that the local government is the agent that must promote social and economic development in their community.

Local government needs to understand the perceptions of performance on service quality dimensions and its influence on satisfaction levels (Nishant et al. 2019). Customer orientation is one of the important ways in which governments attempt to improve the quality of services (Lal et al. 2018: 95).

The Auditing Standards specify that the evidence of service quality should be covered by measuring stakeholder or customer perception (eye of the customer) and technical quality (measures that reflect the eye of the expert) (Brusca \& Montesinos 2016). Lee et al. (2011: 2) further explain that eGovernment service depends on the perceived quality of services provided through on-line channels, because the business user's prior interactions with government through off-line service channels.

\section{Cost and Financial Resources}

Damasceno et al. (2018) indicate that turnover without planning can lead to increased costs, lack of continuity, and immediate negative effects on organisations. Kaisara and Pather (2011: 2) assert that long term cost-saving and improved service quality are the benefits that could be accrued by implementing e-Government. 
Meyer and Meyer (2016) highlight that the financial aspects of municipal services primarily concern the revenues and expenditures of service providers. Expenditures include costs incurred in the process of producing services and delivering them to customers, while revenues entail the different sources of income tariffs and other user charges, loans, bonds, equity investment, municipal subsidies, and intergovernmental transfers that are used to cover costs (Meyer \& Meyer 2016).

Furthermore, poor financial management, lack of control and accountability systems impact negatively on service delivery for communities (Jitsing et al. 2019: 54-55). Local government has considerable financial powers, including the right to raise income through property taxes and user charges for services (Van der Waldt et al. 2018: 6). One of the objectives of e-Government is to make the government and its policies more efficient, providing citizens with quicker and better access to public information and the ability to use services in a more personal and cost-effective manner (Ibrahim et al. 2016).

\section{E-Government}

E-Government initiatives can refocus attention to a number of issues such as to collaborate more effectively across agencies and tiers of public administration, and to enhance customer focus. Lal et al. (2018: 90) state that the eGovernment has the opportunity to develop comprehensive and more effective policies and implementing strategies.

Government can use Information Technology (IT) to improve efficiency and streamline its operations, and that it is with urgency that government should adopt and use IT to modernize services, improve administration and efficiency (Kaisara \& Pather 2011: 3). e-Government provides services to business, government employees and citizens (Saleh et al. 2019). Lal et al. (2018) assert that e-Government is a catalyst or tool for government administrative reform. Proponents often promise the outcome of better govern-ment, including improved quality of services, reduced costs, wider political participation or more effective policies and programs.

New possibilities offered by IT give government an opportunity to think of ways to work and provide services to citizens and businesses (Ibrahim et al. 2016). Lee et al. (2011: 1) argue that e-Government primarily using Web technology is rapidly being adopted by governments at all levels, but the adoption by citizens and businesses has been relatively slow. 
Lee et al. (2011: 3-7) argue that e-Government provides better benefits than off-line services. Local governments need to confront the demanding challenges related to their ability to provide next generation e-Government services. The shortage of IT workers is ranked as the number one barrier to eGovernment (Lee et al. 2011: 3-7). Kaisara and Pather (2011: 7-9) assert that failure to understand citizens' concerns risks alienating citizens who might not be satisfied with -Government services. Furthermore, e-Government requires a concomitant set of on-line service delivery principles.

Lal et al. (2018:95) highlight that e-Government is not just about designing smart IT policies or functional systems; it is also about coordination between projects active at all levels. Furthermore, Lal et al. (2018) state that eGovernment is a broad concept encompassing service delivery and transforming government and democratic opportunities. Kaisara and Pather (2011: 7) found that e-Government websites have invalid e-mail addresses, notably do not respond to queries as received, nor are automated responses used.

\section{Research Methodology}

Ngaka Modiri Molema District Municipality is the municipality in the North West province in South Africa of which Mafikeng is the capital of the province

https://en.wikipedia.org/wiki/Ngaka_Modiri_Molema_District_Municipality.

This municipality was selected as this district has ongoing problems with service delivery and the researcher was grated the opportunity to assist in determining opportunities for improvement.

Saunders et al. (2007) argue that quantitative research is predominately used as a synonym for any data collection technique (such as a questionnaire) or data analysis procedure (such as graphs or statistics) that generates or uses numerical data. The study will use a quantitative research method to obtain the respondent's perspective (Frey \& Dishi 1995: 4). SPSS and descriptive statistics will be applied to analyse the data.

The researchers used questionnaires to collect data from 165 respondents selected from Ngaka Modiri Molema District Municipal office, using simple random sampling. The data will be gathered by using face-to-face interviews after obtaining the required permissions and ethical clearance from all parties concerned. 


\section{Discussion of the Results}

The purpose of this study was to seek ways to improve the quality and efficiency of the municipal services, contribute to e-Government service and enhance capacity of service delivery implementation.

A sample of 165 representing the senior and middle management and aspects of the work force of the municipality, was approached (population of 2000 ), and only 160 responded (response rate 80\%), 52\% were males, this is not representative and results should be checked if this research were to be used in future. The sample breakdown is considered as representative of Ngaka Modiri Molema District Municipality.

Of the 160 respondents, $42(26 \%)$ were aged $21-30$ years, $40(25 \%)$ were aged $31-40$ years, 35 (22\%) were aged $41-50$ years, while $30(19 \%)$ were aged 51-60 years, $10(6 \%)$ were above 60 years of age. The differences in ages assumes a balance of skills, knowledge and work experience, which in this case, can be regarded as an appropriate mixture. Out of the total sample of 160 approached, $83(52 \%)$ were males and $48 \%$ were females. Preference was not given according to gender. The almost equal balance of genders may be due to the application of employment equity legislation as shown in the theory.

The research data showed that most of the respondents were occupying supervisory or managerial positions. Out of 160 respondents, the majority of respondents were qualified (in accordance with government regulations). However, education cannot be used as a differentiating factor; working for the municipality should require a higher level of education (figure 4). The data illustrates that $91 \%$ of the respondents were satisfied with the municipal service delivery. Bush and Glover (2016) assert that effectiveness means acquiring necessary knowledge, skills and attitudes that can be applied to the job situation.

The majority of the respondents $(91 \%)$, indicate that the municipality has the ability to provide service to the community. This suggests that the respondents are satisfied with the municipal ability to render service to the local community. According to the relevant Sector Skills Plan (2010: 18-19), the capacity constraints within local government are due to a lack of competency which may lead to an inability to perform municipal functions.

Out of the total sample of 160 approached, 85 (53\%) of the respondents indicated being satisfied with the adequacy of training and development provided by the municipality. The research suggests there may be a short-coming 
in municipality training that requires attention. van der Waldt et al. (2018) highlighted that the problem with acquiring skills in municipalities is the lack of experience within local government. A study conducted by Blom-Hansen et al. (2016) indicates that the lack of competence is one of local constraints.

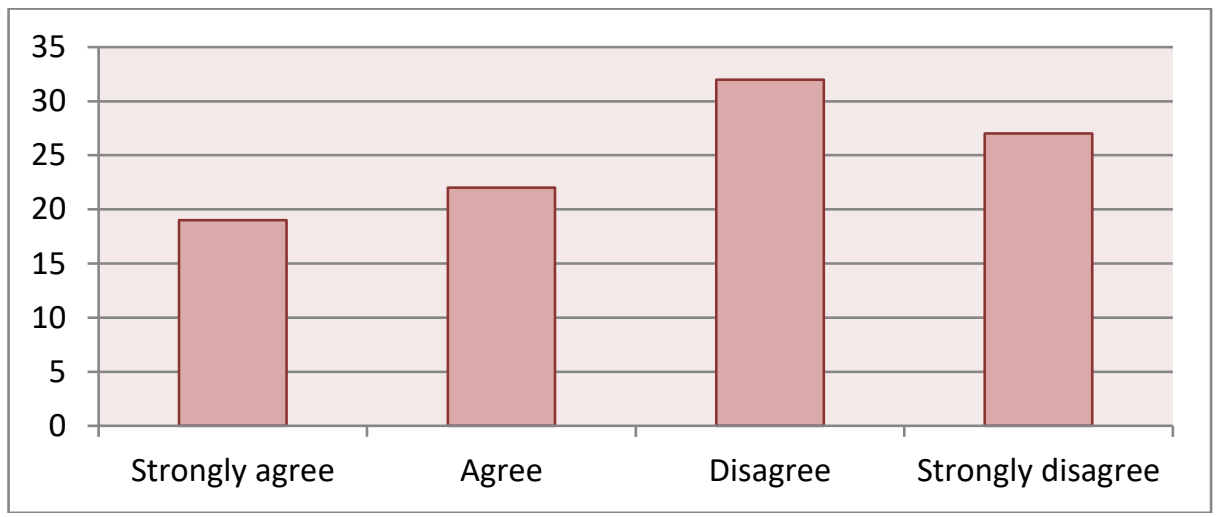

Figure 1: Recruitment and selection process application in the local government under investigation (question on questionnaire)

Figure 1 (y axis- number of respondents and $\mathrm{x}$-axis their reaction to recruitment) shows that 95 (59\%) were dissatisfied with the way recruitment and selection are applied and conducted. The research suggests that recruitment and selection is limited within the Ngaka Modiri Molema Municipality thus external, more appropriately suited candidates are not sourced. Van der Waldt et al. (2010: 17) highlight that service delivery is hampered by staff vacancies and the lack of norms and standards guiding the appointment of staff within municipalities. Jitsing et al. (2019: 66) assert that political influence in the appointment of employees, at the expense of technical competence is not conducive to attracting and retaining talented professionals.

The data indicates that a number of respondents were completely dissatisfied with the municipal staff's knowledge and skills in providing the required service. The research explicates that there is a shortage of skills to provide services to the community. Kachali et al. (2018) state that a wellfunctioning response to a crisis is benefited by individuals having adequate skills and knowledge of resources. 
Figure 2 (y axis- number of respondents and $\mathrm{x}$-axis their reaction to of upholding the principle of service delivery) shows that the respondents were satisfied with the municipal culture of upholding the principle of service delivery. The study interprets that municipal culture has limitations in upholding the principle of service delivery. The Sector Skills Plan (2010: 1819) identifies certain constraints in local government such as a lack of service orientated attitude and behaviour and an organisational culture that does not uphold the principles of service delivery. Ibrahim et al. (2016) assert that service delivery must provide greater satisfaction with higher efficiency. The data indicates that the $69 \%$ of respondents were happy about the output of service delivery to the community. The authors therefore suggest that the quality of service delivered by the municipality is lacking. This is in line with Ibrahim et al. 's (2016) finding that user dissatisfaction with the low quality of service provision has become a political issue.

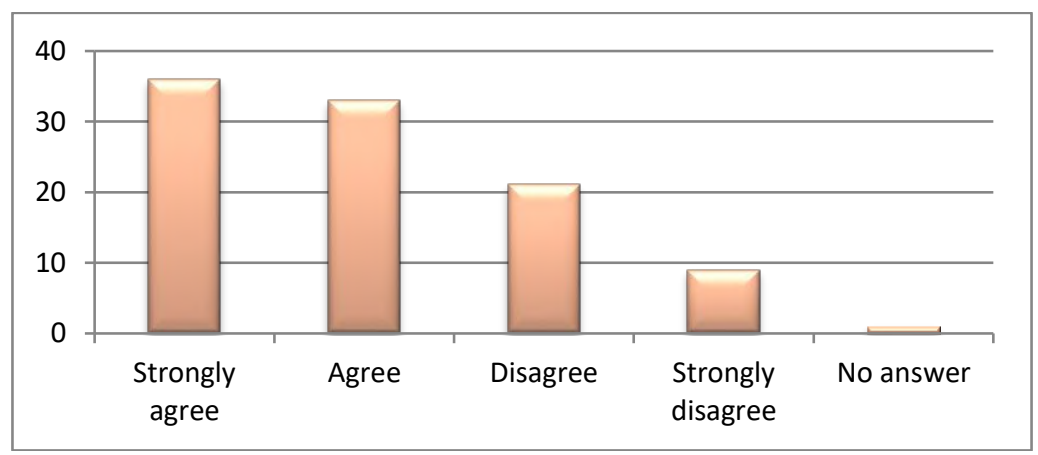

Figure 2: Municipal organisational culture of upholding the principle of service delivery (question on questionnaire)

Figure 3 (y axis- number of respondents and $\mathrm{x}$-axis their reaction to better service in terms of quality [strongly agree and agree added together] indicates that $61 \%$ of the respondents are satisfied with e-Government system in terms of the quality of service delivery. The research explicates that eGovernment is effective in ensuring service delivery to the community. Ibrahim et al. (2016) indicate that enhanced quality of service provision is a major component of public administration, and the use of IT to generate improvements is a primary driver for e-Government activity. 


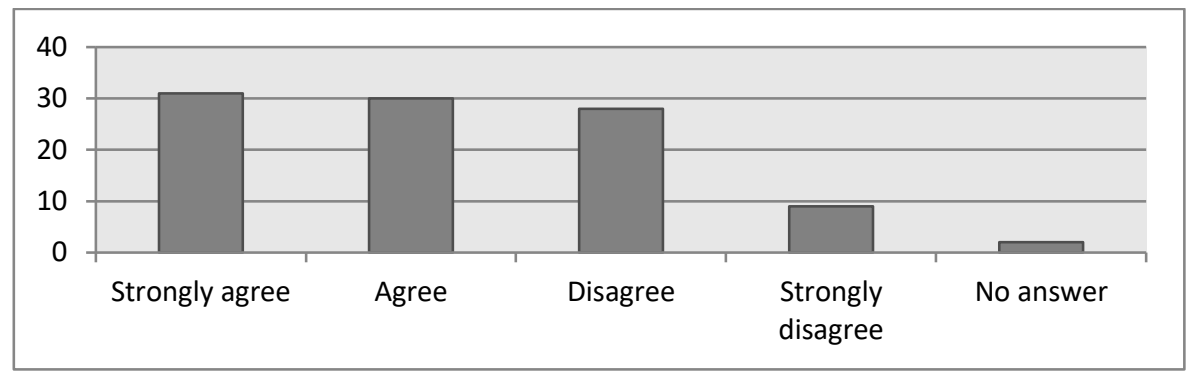

Figure 3: e-Government ensuring better quality when they deliver a service (a research question)

Also, out of the sample of 160 respondents, $82 \%$ presume that eGovernment service enhances access and service delivery during the analysis of the questionnaires. This indicates that e-Government has some freedom towards improving access and service delivery. Kaisara and Pather (2011: 7 9) assert that failure to understand citizens' concerns risks alienating citizens who might not be satisfied with e-Government services, and that e-Government requires a concomitant set of online service delivery principles.

The data show that $68 \%$ of the respondents presume e-Government service to be efficient. The Department of Communications (2010) highlight that the role of IT is to improve efficiency and streamline operations and that government should adopt and use IT in order to modernise services, improve administration and efficiency.

\section{Associative Statistics}

The Spearman correlation between age and number of years at the municipality was 0.961 . This can be interpreted that age and length of service does not impact on municipal service delivery. The correlation between age and gender is 0.928 . The interpretation could be done that gender has no impact on municipal service delivery as the study is dealing with this aspect. The correlation between age and qualifications is 0.947 . This implies that the respondents perceive no barrier in relation to age and qualifications to deliver services.

The correlation between age and provision of high-level expertise by staff in delivering services is 0.941 . This could be interpreted that the respondents perceive municipal staff as being good at service delivery. The corre- 
lation between age and organisational culture upholding principle of service delivery is 0.935 . This implies that upholding culture has no impact on service delivery.

The correlation between age and community understanding the role of service is 0.927 . The authors looked at assoiciation, cause and effect while interpreting the data. This impact of this implies that the respondents are satisfied with the community awareness of service delivery. The correlation between number of years at municipality and qualification is 0.961 . This implies that the respondents are satisfied with the level of education of the municipal staff as it does not impact service delivery. The correlation between number of years at the municipality and sufficiency and competency of municipal leaders to fulfil their roles is 0.945 . This implies that the respondents consider the municipality capable of delivering good service.

The correlation between number of years at the municipality and municipal organisational culture is 0.936 . This could be interpreted as the respondents' perception that municipal organisational culture does not impact service delivery. The correlation between number of years at the municipality and e-Government service is 0.93 . This could be interpreted that respondents perceive e-Government to be efficient and it does not have an impact on municipal service delivery.

The correlation between sufficiency and competence of municipality leaders to fulfil their roles and age is 0.929 . This could be interpreted that the respondents view municipal leaders to have the relevant skills and capability to fulfil their roles. The correlation between sufficiency and competence of municipality leaders to fulfil their roles and the number of years at the municipality is 0.945 . This implies that the competence of municipality leaders to fulfil their roles has no impact on municipal service delivery. The correlation between the recruitment and selection process is appropriately applied and the number of years at the municipality is 0.936 . This suggests that the respondents perceived the recruitment process as being adequately applied and that it impacts service delivery.

The correlation between the recruitment and selection process is appropriately applied and municipal staff providing high level of expertise in delivering the required services to the community is 0.922 . This could be interpreted that the recruitment and selection is properly followed and staff have the skills to provide service to the community. The correlation between the recruitment and selection process is applied and community satisfaction is 
0.928. This implies that the respondents were satisfied with the recruitment and selection process and the degree of service provided.

The correlation between the recruitment and selection process is applied and municipality have sufficiently trained IT personnel is 0.941 . This implies that the recruitment and selection process is applied and that the IT personnel are trained to execute their duties. The correlation between the age of respondents and municipal staff providing expertise in delivering the required services to the community is 0.941 . This suggests that the municipal staff providing expertise in delivering the required services to the community and age has an impact on service delivery.

The correlation between the municipal staff providing a high level of expertise in delivering the required services to the community and municipal organisational culture upholds the principle of service delivery is 0.984 . This can be interpreted that the municipal staff are competent and knowledgeable in providing the municipal service delivery and that the organisational culture is upheld at the same time.

The correlation between 'the staff has the required knowledge and skills to provide the required services to the community' and 'the municipality has sufficiently trained IT personnel' is 0.924 . This could be interpreted that the respondents perceive the municipal staff as sufficiently trained to provide the required services. The correlation between municipal organisational cultures upholding the principle of service delivery and age is 0.935 . This suggests that the municipal culture is upheld by the municipality and age has no impact on municipal service delivery.

The correlation between 'the municipal organisational culture upholds the principle of service delivery' and 'municipal staff providing high level of expertise in delivering the required services to the community is 0.984 '. This implies that the respondents are satisfied by the municipal organisational culture to provide service delivery to the community.

The correlation between community understanding the role of IT service and community satisfaction to the quality of service delivery is 0.924 . This suggests that the respondents perceive the community understanding the role of IT. The correlation between community understands the role of IT service and municipality have sufficiently trained IT personnel is 0.950 . This implies that the respondents presume the community understanding the role of IT service and that the municipal IT personnel are competent and qualified.

The correlation between 'e-Government services are efficient' and 
'municipal staff provide high level of expertise in delivering the required services to the community' is 0.974 . This could be interpreted to mean that the respondents presume e-Government to be sufficient and relevant and that the municipal staff are qualified to execute their functions. The correlation between 'e-Government services are efficient' and 'municipal organisational culture upholds the principle of service delivery' is 0.971 . This suggests that the respondents perceive the e-Government service as efficient and the municipality as upholding service delivery.

\section{Conclusion and Recommendations Response to Research Questions}

The main findings of this research in relation to each research question will now be discussed.

\section{What determines efficiency and deficiency in municipal service delivery?}

Local government struggles to provide services to citizens, and the provision of poor services erodes trust (Meyer \& Meyer 2016). It was found that the most frequent response on determining factors of efficiency and deficiency in municipal service delivery was that the municipal service delivery was adequate and efficient. The notion is supported by data that the respondents perceived municipal staff as possessing the required expertise to provide community service and perceived e-Government as efficient. This is contrary to findings (above) that highlighted that most of the respondents were unhappy with the output of service from the municipality.

An analysis of the data found that most of the respondents perceive the municipality as being capable of providing the required services to the local community. The analysis reveals that the majority of respondents perceive the municipal staff having the required expertise to provide service. Furthermore, it was found that the majority of the respondents were happy with training and development, while $47 \%$ were highly dissatisfied with the training and development within the municipality. However, the analysis of data illustrated that the majority of respondents were dissatisfied with the municipal knowledge and skills, and perceive the IT personnel to be inadequately trained. 
According to the Sector Skill Plan (2010: 18-19) the National Capacity Building Framework identified the capacity constraints within local government as having inadequate technical skills and knowledge in functional areas and an inadequate information base within municipalities.

Lastly, it was found that most of the respondents suggested that the municipal leaders were sufficiently and competently skilled to provide service delivery. The correlation between the sufficiency and competence of municipality leaders to fulfil their roles and age was 0.929 . This implies that the respondents perceive the municipality as being capable; however, they are not satisfied with training and development provided by the municipality.

The research concludes that respondents are satisfied with the municipal service delivery and consider the municipality as being capable and efficient. Management should explore the opportunity to ensure further training and development of municipal staff to ensure that they are competent to deliver high quality services to the community.

\section{To what extent is the municipality capable and competent?}

Research conducted by Jitsing et al. (2019: 21) further highlights that the overall positive progress and success of the local government system in South Africa is increasingly overwhelmed by a range of factors and negative practices both internal and external to municipalities. These factors apply to poor governance, service delivery failures and their capacity and performance.

Figures support the notion that respondents perceived the municipal service delivery as being both adequate and efficient. This capacity, in turn, is linked to overall organisational performance.

It was found that the majority of respondents perceived the municipal staff as having the required expertise to provide service to the community, while a small number of respondents did not concur Furthermore, it was found that the majority of respondents were dissatisfied with the municipal staff knowledge and skills to provide the required service to the community, while a few respondents were satisfied with the municipal staff knowledge and skills.

Zhu et al. (2017) concur that the problem with skills shortages is that it is actually a systematic industry problem. The correlation between the staff having the necessary knowledge and skills to provide the required services to the community, and the municipality having sufficiently trained IT personnel was 0.924 . In a study conducted by Blom-Hansen et al. (2016) in Pretoria the 
authors highlighted that effective municipality is a function of a combination of technical skills, material resources and civic engagement.

Results from the study showed that the majority of respondents were satisfied with the municipal organisational culture of upholding the principle of service delivery, while a small but significant number of respondents was dissatisfied with the municipal organisational culture. Of the respondents, $83 \%$ were satisfied with the municipal service delivery. However, 69\% of respondents were dissatisfied with the service delivery quality. The correlation between municipal organisational culture upholding the principle of service delivery and the municipal staff providing high level of expertise in delivering the required services to the community was 0.984 .

This implies that the respondents were dissatisfied with the capacity and competency of the Ngaka Modiri Molema District Municipality. The research concludes that respondents were not satisfied with the municipal capability and competency. The management should explore ways of ensuring improvement in capacity and competency, to provide the required service to the community.

\section{What determines good quality municipal service delivery?}

Municipalities struggle with strategies of providing affordable services to citizens in a sustainable way (Meyer \& Meyer 2016: 1-3). The present study found that $69 \%$ of respondents were dissatisfied with the service delivery, while $30 \%$ were satisfied with the quality of service provided. Most of the respondents were dissatisfied with the level of awareness provided to the community by the Municipality's IT service. However, the majority of respondents were satisfied with the training and development provided at the municipality and perceived municipal leaders as sufficiently skilled and competent.

Kaisara and Pather (2011:7-9) assert that failure to understand citizens' concerns risks alienating citizens who might not be satisfied with eGovernment services. Furthermore, e-Government requires a concomitant set of on-line service delivery principles. It was found that $61 \%$ of the respondents are satisfied with e-Government system in terms of quality and ensuring service delivery. The majority of respondents suggested that the e-Government was efficient and enhanced access and service delivery.

Of the respondents, $83 \%$ were satisfied with the municipal staff's 
understanding of the legal framework. The correlation between staff understanding the local government legal framework and sufficiency, and the competency of municipal leaders to fulfil their roles was 0.928 , a positive correlation between the two variables. Alcayna et al. (2016) indicate that the mandate, motivation, and means to provide the services required and needed by local citizens in a manner that is responsive to changes in requirements and needs over time, must be responsive to the differing requirements and needs of groups of citizens within the community.

This implies that the respondents perceived the municipality as providing good quality service, despite some limitation in the service quality. The research concludes that the respondents were happy with the quality of service that was being rendered to the community, despite certain constraints in the delivery of high quality service. The management should ensure a continued and sustained improvement in the quality of service rendered to the community.

\section{What determines the efficiency and effectiveness of the electronic Government (E-Government) system?}

Panayiotou and Stavrou (2019: 209) assert that e-Government is enabling organisations to provide better services to their constituents. It was found that the majority of respondents (69\%) perceived e-Government service as enhancing access and service delivery, and a small number of respondents were dissatisfied with e-Government's inability to improve access and service delivery. Thomas (2017) states that e-Government is the use of technology to enhance the access to, and delivery of government services to benefit citizens, business partners and employees.

An analysis found that the majority of respondents were not satisfied with the level of awareness by the community and the role of IT services. This implies that there is a barrier to IT service awareness. Most of the respondents were also unhappy with the output and quality of service delivery. The correlation between e-Government ensuring better services in terms of quality and the municipality having sufficiently trained IT personnel was 0.943 .

It was found that the majority of respondents perceived e-Government service as being efficient, while a small number perceived that it as inefficient. It was found that the majority of respondents were happy with training and development provided by the municipality. The correlation between the municipality having sufficiently trained IT personnel and e-Government service 
being efficient was 0.950 . Ibrahim et al. (2016) assert that new possibilities offered by IT give governments opportunities to think of ways to work and provide services to citizens and businesses.

This implies that the respondents were not satisfied with efficiency of the e-Government system. The research concludes that the respondents were dissatisfied with the e-Government efficiency and effectiveness. The management should focus on raising awareness of e-Government and ensure that the IT personnel are adequately trained to improve service delivery.

\section{Recommendations}

The recommendations, based on the discussions are as follows.

Millar and Doherty (2016) state that capacity building should be promoted as a way to enhance effectiveness and sustainability. Capacity building has become an important tool in supporting local government. According to Act 209 of 1993, Local Government Transition Act, which is the statutory legislation, local government is the form of government that is closest to the people, and necessary to ensure that the needs of its community are adequately provided for, through the provision of services such as health, water, housing, sanitation and electricity, classed as essential services.

On the discussion of capacity and competency, the municipality should explore opportunities to improve their recruitment and selection process and ensure that it is appropriately applied to ensure fairness.

On the discussion of skills in local government, the municipality should explore opportunity to improve training and development to increase knowledge and skills of the municipal staff. It was found that $47 \%$ of the respondents were unhappy with the training and development provided by the municipality. This implies that there are serious constraints associated training and development and this requires attention. Ndevu and Muller (2017) assert that it is imperative for municipalities to constantly change and review the way services are rendered, in order to remain relevant and effective. An institutional culture of learning should be developed to any process change. Employees should be empowered through continuous learning, training and development. Training systems within local government are poorly developed and training committees are often poorly capacitated. The analyses found that the majority of the respondents were dissatisfied with the municipal staff knowledge and 
skills in providing the service to the community. This implies that there is a shortage of skills within the municipality.

The municipality should explore opportunities to improve municipal systems and operations to enhance the delivery of quality of service to the community. Smith (2005:3) argues that in order for municipalities to deliver services effectively and efficiently, they have to build partnerships with the private sector, especially where municipalities deliver a wide range of diversified municipal services to their local communities within their area of jurisdiction. Meyer and Meyer (2016: 1-3) provides that quality municipal services support the economic development of municipalities, while poor levels of service, interruptions, low coverage levels, and other problems undermine quality of life in municipalities, retard economic growth, and erode trust between citizens and local governments.

Singhal et al. (2017) state that service quality is considered a critical measure of organisational performance. It was found that the majority of the respondents were satisfied with the municipal leader's sufficiency and competency, while the minority of respondents were unhappy with the municipal leader's sufficiency and competence. The majority of respondents were happy with the municipal organisational culture of upholding the principle of service delivery, and the difference in the percentage of the respondents that were discontent was less. It was also found that $69 \%$ of the respondents were unhappy with the quality of service being rendered to the community which makes for a dissatisfied community.

. Panayiotou and Stavrou (2019) argue that e-Government does not simply have to be the application of new technologies but has the potential to be a strategy for delivering more effective and efficient services.

Saleh et al. (2019) assert that technology helps governments to achieve some important goals through websites that provide convenient and accessible information to citizens. Lal et al. (2018: 89) highlight that e-Government is a catalyst or tool for government administrative reform. Proponents often promise the outcome of better government, and improved quality of services, cost savings, wider political participation or more effective policies and programs. For Saleh et al. (2019), providing quality e-Government services to citizens makes interactions between citizens and government agencies smoother, easier, and more efficient. Lee et al. (2011: 1) argue that e-Government primarily using Web technologies has been rapidly adopted by governments at all levels, but the adoption by citizens and businesses has been relatively slow. 


\section{Conclusion}

Local government face stress of economic downturn or stagnation and are struggling to maintain service levels. Furthermore, they must cope with population growth and additional service demands. In-order to enable municipalities to carry out their responsibilities, local government need to transform the service delivery through a process of restructuring. eGovernment is critical for meeting expectations for interaction with administration and enables agencies to align efforts as needed, to significantly improve service.

The findings of this study provide a point of departure for the evaluation of municipal e-Government capacity and service delivery at Ngaka Modiri Molema District Municipality.

The findings support the notion that local government is poised for a workforce crisis. Also, that skills and knowledge is critical to provide quality services. The findings further support the fact that service quality has been proven to be a suitable indicator of IT effectiveness, the assessment of service quality in the public sector has been less studied. The findings allude to the raising awareness about e-Government as being crucial and many citizens do not know which services actually exist. Lack of awareness of services prevents citizens from becoming familiar with the added value that electronic public services could offer in their everyday lives.

A final conclusion can be made that e-Government capacity and municipal service delivery can be identified as municipal incapacity and incompetency, and inefficiency of e-Government system. The results highlight the need for Ngaka Modiri Molema District Municipality management to explore opportunities that ensure that training and development is provided to municipal staff to improve capacity and competency.

\section{References}

Alcayna, T., V. Bollettino, P. Dy \& P. Vinck 2016. Resilience and Disaster Trends in the Philippines: Opportunities for National and Local Capacity Building. PLoS Currents 8.

https://doi.org/10.1371/currents.dis.4a0bc960866e53bd6357ac135d7408 46 PMid:27790382 PMCid:PMC5061578.

Bakunzibake, P., G.O. Klein \& S.M. Islam 2019. E-government Implementa- 
tion and Monitoring: The Case of Rwanda's 'One-stop' E-Government. The Electronic Journal of Information Systems in Developing Countries 85,5: p.e12086,. https://doi.org/10.1002/isd2.12086.

Blom-Hansen, J., K. Houlberg, S. Serritzlew \& D. Treisman 2016. Jurisdiction

Size and Local Government Policy Expenditure: Assessing the Effect of

Municipal Amalgamation. American Political Science Review 110,4:

812-831. https://doi.org/10.1017/S0003055416000320.

Brusca, I. \& V. Montesinos 2016. Implementing Performance Reporting in

Local Government: A Cross-countries Comparison. Public Performance \& Management Review 39,3: 506 - 534.

https://doi.org/10.1080/15309576.2015.1137768.

Bush, T. \& D. Glover 2016. School Leadership and Management in South Africa: Findings from a Systematic Literature Review. International Journal of Educational Management 30,2: 211 - 231,

https://doi.org/10.1108/IJEM-07-2014-0101.

CoGTA 2009/2010 Annual Report. 2010. Available at:

https://cogta.mpg.gov.za/documents/AnnualReport09-10.pdf

Damasceno Cunha, R., A.L.M. Serrano, V.R. Franco \& P. Guarnieri 2018. Staff Sizing as a Mechanism of Efficiency: An Application of a Nonparametric Method. Cogent Business \& Management 5,1: p.1463835. https://doi.org/10.1080/23311975.2018.1463835.

Department of Communications 2010. Annual Report of the Department of

Communications in Terms of the Public Finance Management Act, 1999, Republic of South Africa.

Frey, J.H. \& S.M. Dishi 1995. How to Conduct Interviews by Telephone and in Person. London: Sage.

Ibrahim, R., S.M. Hilles, S.M. Adam, M.M. Jamous \& W.M. Yafooz 2016. Theoretical Framework Formation for E-Government Services Evaluation: Case Study of Federal Republic of Nigeria. Indian Journal of Science and Technology 9,37.

https://doi.org/10.17485/ijst/2016/v9i37/94575.

Jindal, N., A. Sehrawat \& Y. Medury 2016. An Analysis of India's Need of Capacity Building for E-Governance. Prabandhan: Indian Journal of Management 9,6: 47-59.

https://doi.org/10.17010/pijom/2016/v9i6/95022.

Jitsing, A., Z. Brey, K. Wall, S. Craig, M. Thosago \& S. Munro 2019. State of Municipal Finance Management: An Overview of Capacity and 
Challenges. Civil Engineering = Siviele Ingenieurswese 27,v27i1: 39 - 45. Johnstone, L. \& J. Blenkinsopp 2017. Challenges for Civil Society Involvement in Civic Entrepreneurship: A Case Study of Local Enterprise Partnerships. Public Money \& Management 37,2 89 - 96,

https://doi.org/10.1002/ncr.4100860208

Kachali, H., I. Storsjö, I. Haavisto \& G. Kovács 2018. Inter-sectoral Preparedness and Mitigation for Networked Risks and Cascading Effects. International Journal of Disaster Risk Reduction 30: 281 - 291.

https://doi.org/10.1016/j.ijdrr.2018.01.029.

Kaisara, G. \& S. Pather 2011. The E-Government Evaluation Challenges: South African Batho Pele-aligned Service Approach. Government Information Quarterly 30: 1 - 11. http://dx.doi.org/10.1016/j.giq.2010.07.008

Lal, B., Y.K. Dwivedi, N.P. Rana, D. Frost \& S. Chirara 2018, Understanding Development from the Perspective of E-Government, Digital Divide and ICT4D Literature: A Research Agenda. In Proceedings of the $19^{\text {th }}$ Annual International Conference on Digital Government Research: Governance in the Data Age. ACM. https://doi.org/10.1145/3209281.3209369.

Lee, J., H.J. Kim \& M.J. Ahn 2011. The Willingness of E-Government Service Adoption by Business Users: The Role of Offline Service Quality and Trust in Technology. Government Information Quarterly 30: 1 - 9.

Meyer, N. \& D.F. Meyer 2016. The Relationship between the Creation of an Enabling Environment and Economic Development: A Comparative Analysis of Management in the Local Government Sphere. Polish Journal of Management Studies 14,2: 150 - 160.

https://doi.org/10.17512/pjms.2016.14.2.14.

Millar, P. \& A. Doherty 2016. Capacity Building in Non-profit Sport Organizations: Development of a Process Model. Sport Management Review 19,4: 365 - 377. https://doi.org/10.1016/j.smr.2016.01.002

Mohr P.J., B.N. Taylor \& D.B. Newell 2012. CODATA Recommended Values of the Fundamental Physical Constants: 2010. Journal of Physical and Chemistry Reference Data 41,4.

Ndevu, Z. \& K. Muller 2017. A Conceptual Framework for Improving Service Delivery at Local Government in South Africa, African Journal of Public Affairs 9,7: 13 - 24.

Nishant, R., S.C. Srivastava \& T.S. Teo 2019. Using Polynomial Modelling to Understand Service Quality in E-Government Websites. MIS Quarterly 43,3: 807 - 826. https://doi.org/10.25300/MISQ/2019/12349 
Panayiotou, N. \& V. Stavrou 2019. A Proposed Maturity Assessment Framework of the Greek Local Government Web Electronic Services. Transforming Government: People, Process and Policy. Available at:

https://doi.org/10.1108/TG-03-2019-0018.

Renfors, S.M. 2019. Identification of Ecopreneurs' Business Competencies for Training Program Development. Journal of Education for Business 1 - 9. https://doi.org/10.3390/su9040492.

Republic of South Africa 2001. E-Govemment Policy, 2001. Pretoria: Government Printer.

Republic of South Africa 1996. The Constitution of the Republic of South Africa Act, 1996 (Act 106 of 1996). Pretoria: Government Printer.

Republic of South Africa 1998. Skills Development Act, 1998 (Act 97 of 1998).

Pretoria: Government Printer.

Republic of South Africa 2000. The Local Government Municipal Systems Act, 2000, (Act 32 of 2000). Pretoria: Government Printer.

Saleh, S.M., A.H. Zolait, M.M. Ali \& E.A. Wali 2019, Investigating the Role of Information System Quality and Managerial Competency on the Organization's Performance. In 2019 International Conference on Innovation and Intelligence for Informatics, Computing, and Technologies (3ICT).

https://doi.org/10.1109/3ICT.2019.8910283 PMCid:PMC6323851

Saunders, L.A., R.V. Lewis, C. Thornhill 2007. Research Methods for Business Students. New York: Prentice Hall.

Sector Skill Plan 2010. Available at:

https://gseta.co.za/publications/sectorSkillsPlan

Simmons, J.P., L.D. Nelson, \& U. Simonsohn 2011. False-positive Psychology: Undisclosed Flexibility in Data Collection and Analysis allows Presenting Anything as Significant. Psychological Science 22,11: 1359 - 1366.

Singhal, A., A.K. Agariya \& J. Tikoria 2017. Service Quality Scales: A Literature Review. Evidence Based Management 84. Available at: https://doi.org/10.1016/j.jretconser.2010.06.003.

Smith, A. 2005. Regstel-aksie Kelder Rade. Rapport 18 September 2005. (Not Peer-reviewed.)

South Africa 1998. Local Government: Municipal Structures Act, 1998 (Act 117 of 1998). Pretoria: Government Printers. 
South Africa 2000. The White Paper on Local Government Service Partnerships. 2000. Government Gazette, No. 21126. Pretoria: Government Printers.

Thomas, J.C. 2017. Citizen, Customer, Partner: Engaging the Public in Public Management: Engaging the Public in Public Management. London \& New York: Routledge.

Van der Waldt, G., D. Fourie, J. Jordaan \& M. Chitiga-Mabugu 2018. Skills Profile of Technical Staff in the South African Local Government Sector: An Empirical Survey. Problems and Perspectives in Management 16,1: 173. https://doi.org/10.21511/ppm.16(1).2018.17.

Zhu, S., J. Pickles \& C. He 2017. Global and Local Governance, and Industrial and Geographical Dynamics: A Tale of Two Clusters. In Geographical Dynamics and Firm Spatial Strategy in China. Berlin \& Heidelberg: Springer. https://doi.org/10.1177/0263774X15621760

Mylet Ursula Dlamini NWU Business School North West University Mafikeng South Africa ursula@ncd-hrd.co.za

Jan Meyer North West University Business School North West University South Africa Jan.meyer@nwu.ac.za

Sam Lubbe Faculty of Management Science Mangosuthu University of Technology Umlazi

South Africa Lubbe.samuel@mut.ac.za 


\title{
Dimensional Objectives for E-Commerce in Africa: The Case of Company $Z$
}

Lindiwe N. Kunene

ORCID iD: http://orcid.org/0000-0002-4284-643X

\section{Thokozani P. Mbhele}

ORCID iD: $\underline{\text { http://orcid.org/0000-0003-3124-8781 }}$

\section{P.S. Mthembu}

\begin{abstract}
Failure to understand the varied dynamics of business in different African countries in Africa has been a huge barrier to international businesses trying to enter the African market. With the advent of e-commerce, it has become critical to find the best solutions for online business activities on the continent. The objective of this study was to identify objectives that are of importance in forming an e-tailing strategy in the African context. The study used the case of Company Z, an international retail company from South Africa, which has entered various African markets. This paper investigated how they performed when they entered the rest of Africa. It was essential to learn from both their successes and failures. The study was exploratory in nature, designed to understand the decision rationale that management at this organisation followed in conducting their online e-tail business. Interviews were analysed using thematic analysis and conclusions found that three objectives that lead to success in Africa's e-tailing industry. The first two objectives were similar to those adopted by first world countries, however the third objective was different. This objective was 'collaboration' whose principle is entrenched in the Ubuntu management principles.
\end{abstract}

Keywords: retail, e-business, business strategy, technology, innovation \& developing country 


\section{Introduction}

Researchers and authors of e-business models have made several attempts to classify online business models, with no common classification reached. Lam and Harrison-Walker (2003) thoroughly analysed business models adopted by online companies and narrowed them down to a two-dimensional business model, consisting of value-based objectives and relational objectives. From a strategic viewpoint, their e-business model attempts to respond to the question that asks why businesses develop online and e-business strategies (Matook 2012). Rapid advancements in e-commerce have made it essential to find robust typology, which relates to the strategic objectives of e-business models. Businesses cannot afford to constantly enter various African markets, and fail. For many businesses, being present in different African countries has become reactionary, they do it because it seems that many other businesses are also doing it. This has had dire consequences. It is important that African-designed models are developed, in Africa and by Africans to ease the way of doing ebusiness in Africa. This paper probes how an African-designed model for ecommerce and more specifically e-tailing should look.

In developing economies, not all e-business models are equally attractive. In his adaptation of the e-business typology, Kshetri (2007) asserts that e-business models which are developed-country focused need to be adapted to fit the varied environments in the developing world. Kshetri (2007) analysed environmental factors in Nepal, which defined the relational and value-based dimensions of e-commerce business models there. Based on their work, this study was able to determine characteristics that underlie adoption and use of e-business models in Africa. Completing such a study identifies relevant objectives for e-tailing in the continent.

\section{Background}

Company $\mathrm{Z}$ has its offices in Cape Town, South Africa, where it is part of a bigger media conglomerate, with an electronic footprint across the country. They are part of an international Media Holding Group from South Africa. Part of this group is Company $\mathrm{X}$, which provides well-known fashion and lifestyle magazines, on which Company $\mathrm{Z}$ was founded. Through their fashion and clothing retail, they expanded to offer their services beyond South Africa. They began to offer their fashion online merchandise to the rest of Africa. Pseudo- 
nyms have been used to protect the identities of the parties involved, as per their request and general ethical guidelines pertaining to research.

\section{Literature Review}

Since the late 1990s, when many traditional brick-and-mortar organisations became completely internet-based; e-commerce promised to become the key to business development and economic growth (Hughes \& Beukes 2012). It was believed that e-commerce would offer substantial changes in the way that firms buy and sell products, and that this would mean major reductions in costs associated with trading internationally (Fredriksson 2010). The Internet has brought rapid changes in the business environment and enabled new and diverse ways of trading (Cunningham \& Fröschl 2013). The success of a business is now measured in the ability of a workforce to absorb change, whilst also exploiting new and emerging technologies (Chesher \& Kaura 2012). Organisations that have been quick to realise and adopt business practices associated with Information and Communication Technology (ICT) are even more globalised and have secured a competitive advantage (Bigliardi, Dormio \& Galati 2012). e-Commerce could result in cost reductions, timely dissemination of information, consistency in information distribution, an enhanced emphasis on quality, significantly improved customer service, customisation of products, convenience of doing business (Makame et al. 2014) and improved financial margins (Chester \& Kaura 2012). e-Commerce reflected the anticipated growth in the business-to-business (B2B) market sector, which included other forms of electronic interaction between businesses (Chester, Kaura \& Linton 2013). Çelik and Yılmaz (2011) suggest that e-commerce can be defined from a communications, business, service and/or online perspective. Carsten, Al-Taitoon, Kietzmann, Pica, Wiredu, Elaluf-Calderwood, Boateng, Kakihara, and Gibson (2008: 564) defined e-commerce as the 'sharing of business information, maintaining business relationships, and conducting business transactions by means of telecommunications networks'. As e-commerce forms part of electronic business (e-business), it should also involve pre-sale and post-sale activities, where the commercial exchange of products, goods and services takes place (Mahajan \& Agarwal 2015). The nature of suppliers and recipients of e-commerce is such that it leads to two well-known categories, namely business-to-business (B2B) and business-to-consumer (B2C) activities (Hande, Debleena, \& Atingovil 2015). 


\section{Nature of E-Tailing}

'Retailing refers to the buying of products in bulk from manufacturers and selling them in smaller quantities or individual units to the end consumer. Etailers are defined as transactional websites which make products available for purchase online' (Koch \& van Brakel 2012: 5). In essence, e-tailers (online retailers) purchase products in bulk from manufacturers and offer them for sale to end consumers in smaller quantities or individual units. One main difference between e-tailers and retailers is that the physical traditional store is replaced by a website, application, or any other electronic platform. The fundamental difference is that unlike traditional retailers, e-tailers do not keep stock. Products are shipped straight from the warehouse or manufacturer to the end consumer (Koch \& van Brakel 2012). The internet's scope, interactivity and power has provided e-tailers with the potential to transform their customers' shopping experience, and by doing so, improve their competitive position (Kataria, Ritu $\&$ Hasan 2014). Through the internet's capability to provide information, facilitate dual communication between the customer and business, collect market research data, promote goods and services and ultimately support the online ordering of merchandise, retailers have been provided with an extremely powerful and flexible channel. The internet offers retailers a mechanism for expanding target markets, cultivating customer communica-tions, extending product lines, improving cost efficiency, strengthening cus-tomer relationships and delivering offers tailored to customers' needs (Doherty \& Ellis-Chadwick 2015). However, purchasing apparel online represents a new form of consumer behaviour and e-tailers selling apparel are faced with high levels of competetion. E-commerce is expensive. In order to cover the costs incurred and make profits, e-tailers need to find ways to attract the consumers who are most likely to purchase their products. Liao et al. (2014) maintained that customer loyalty is of utmost importance for retailers who operate in a competitive market.

When compared to non-loyal customers, loyal customers contribute a higher share of profits and customer retention costs are less than the costs associated with attracting new customers. Given the advantages of customer loyalty, retailers and researchers have examined the factors influencing customer's intention to make repeat purchases (Liao et al. 2014).

\section{Theoretical Framework}

When making a decision on e-business models, two prominent questions arise. 
The first question relates to the relational objective and attempts to find out what purpose a company's website will serve, while the second question is value-driven which attempts to establish how an e-business can add value to a company (Lam \& Harrison-Walker 2003).

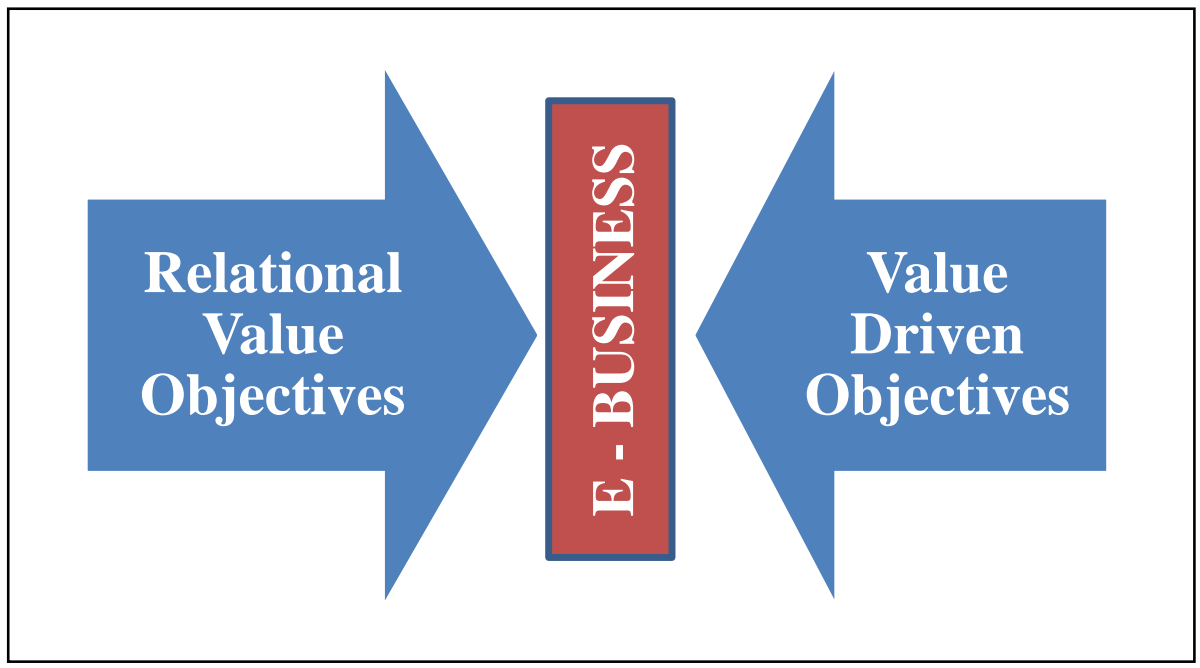

Figure One: Two Dimensional eBusiness Model Source: Author's Own

\section{Relational Objectives}

The relational objectives dimension classifies e-commerce models based on the internet's connectivity characteristic; the internet gives companies the ability to reach any consumer regardless of distance. It is further divided into three categories, namely, corporate communications, network development and direct access (Lam \& Harrison Walker 2003). Corporate communications serves as a media and communications tool so that companies can connect with their existing and potential customers. In other words, companies in this category will develop an e-business strategy to disseminate information related to the company and its offerings in order to create demand for a product category or brand (Zumpe \& Madlberger 2007). 
Table 1: An objective-based typology of e-business models

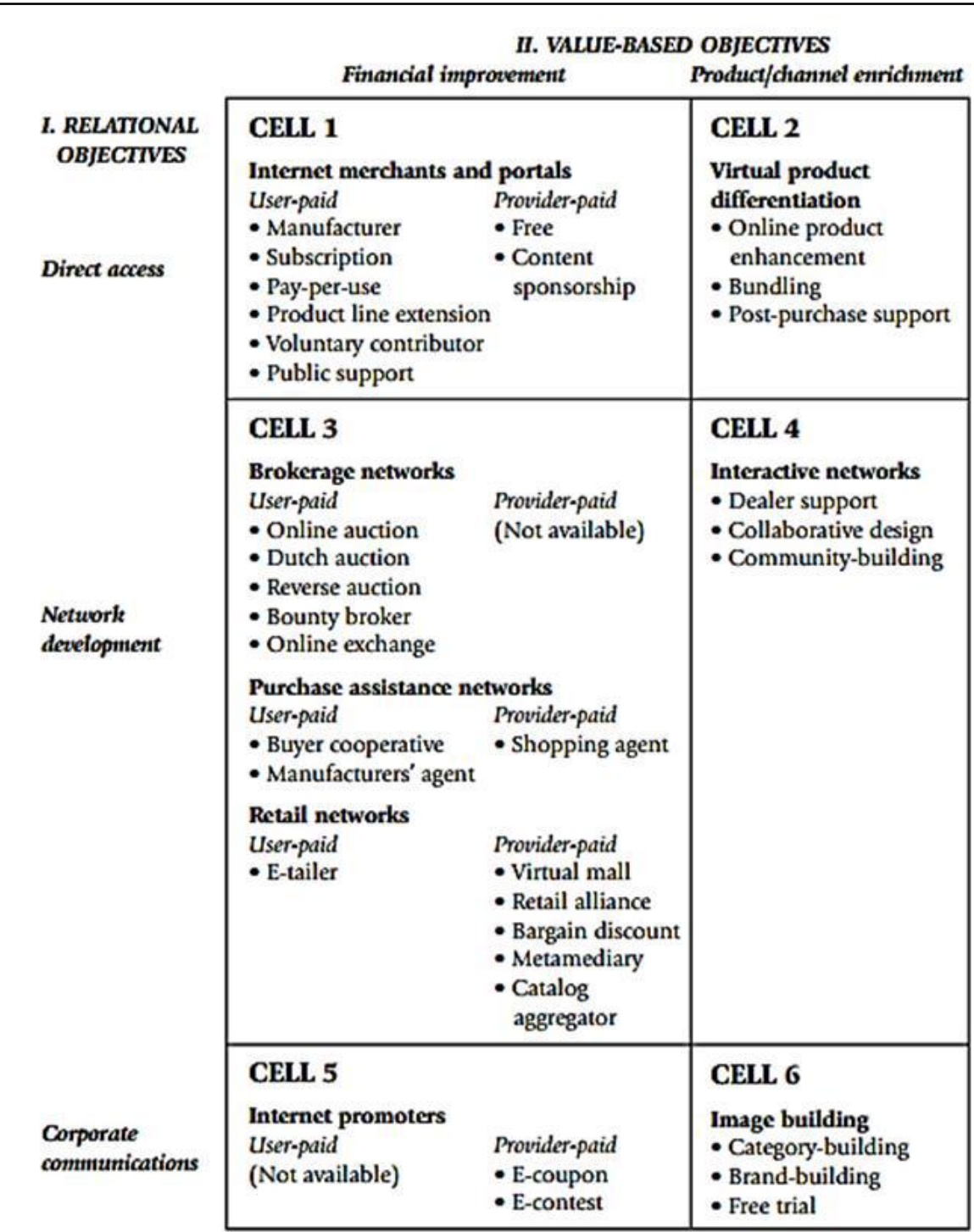

Source: Lam and Harrison-Walker (2003: 17 - 26) 
Network development aims to develop more efficient and effective links among external stakeholders. In this category, commercial websites may also be built to establish supplier networks for industrial products (Lam \& Harrison-Walker 2003). Lastly, direct access eliminates wholesalers and retailers to create direct access to existing and potential consumers. The main benefit to direct access is that companies have the opportunity to customise their products to their consumers' needs, usually at a lower cost than traditional distribution channels allow (Remané, Hanelt, Tesch \& Kolbe 2019).

\section{Value-Driven Objectives Dimensions}

Value-based objectives are concerned with establishing what value e-commerce business models add to an organisation. These values can include, but are not limited to revenue, increased marketing effectiveness, and/or improvement in consumer attitudes (Hedman \& Kalling 2003). Financial rewards, the first dimension, directly adds monetary benefits through mechanisms such as user fees, merchandise sales, advertising and so forth. These revenue streams can be further divided into user-paid, where users are charged directly for website content, products or services; and provider-paid, where revenue is acquired through advertising fees, market research fees and sales commissions (Lam \& Harrison-Walker 2003). The second dimension, product and channel enrichment, generates revenue indirectly. Models that are carefully designed can improve customer loyalty, create and raise brand awareness, decrease operating costs, decrease time to market or build synergy among brands that support new product acceptance. By focusing on customer loyalty, companies can protect themselves against competition (Lam \& Harrison-Walker 2003). From these two dimensions, e-business models can be classified into six cells, namely: Internet merchants and portals; virtual product differentiation; brokerage networks; interactive networks; Internet promoters; and image building (Lam \& Harrison Walker 2003), as depicted in Figure 2 above.

\section{Dynamism of African Market Environment}

E-commerce has created a significant change in the way business is carried out. It is the primary reason that businesses now have opportunities for expansion and an ability to reach far-flung areas of the world without incurring additional costs (Agarwal \& Wu 2015). More importantly, developing 
countries that were previously excluded from international markets and global activities have the opportunity to participate in international trade (Oluyinka Shamsuddin \& Wahab 2013). In order to reap the benefits offered by ecommerce, organisations in developing countries need to understand environmental factors that characterise adopting the online trading system (Nabareseh $\&$ Osakwe 2014). The adoption of technological business practices has a positive correlation on the level of economic development in a country ( $\mathrm{Li} \&$ Xie 2012), which in turn is determined by the availability of infrastructural, economic, social and cognitive factors. When adopters have the financial capacity and the technological infrastructure to adopt technology, they are in a position to adopt e-commerce (Lin \& Chen 2012). In today's global economy, markets on the African continent have shown much more dynamism (Moriarty et al. 2015) than in previous years, as well as major potential which in relative terms has been unexplored (Rossi, Murugesan \& Godbole 2012). The African market is rapidly growing and presents opportunities to reach people living in rural areas. This is a huge benefit which is driving e-commerce growth on the continent. In areas where it is difficult for people to access traditional brickand-mortar stores, both local and global companies use websites to make sales that facilitate the purchase and delivery of high quality, domestic and international products right to the doorsteps of consumers.

\section{Dimensional Business Models}

With all the various challenges facing African e-commerce companies, it is evident that organisations in developing countries cannot simply adopt business models used in the developed market (Hubbard 2015). What works for international e-commerce companies such as Amazon and eBay, for example, will not work in Africa, which is significantly different in terms of infrastructure and economic growth (Murray 2012). E-commerce companies that view Africa through a continent-wide perspective will miss the numerous opportunities and challenges that a continent with 54 countries and more than 2000 language dialects presents (Hattingh et al. 2013). Which of these opportunities a company will choose, depends on its product or service offering. A good place for retail companies to start is by understanding the local markets and their competitive advantages. In this way, companies can align their offering by working off their strengths and customising where necessary, in order to be successful. Figure 2 illustrates three main categories 
that African markets primarily fall under, namely, the basic, developing or the mature stage (ARDI 2015).

Stage 1: Basic. Little to no formal shopping exists in these markets. The key factor for buyers in these markets is thus price. For retailers entering basic markets, the discount 'value for money' format may offer a firm proposition and opportunities for scaling and growth (ARDI 2015).

Stage 2: Developing. Mainstream retailers may prove the most logical entrypoints for these markets. In this stage, retailers can follow one of two expansion opportunities - they can move upwards by developing more targeted or larger varieties, or downwards with smaller varieties. Both paths offer retailers unexplored growth potential with a steadily improving infrastructure (ARDI 2015).

Stage 3: Mature. If retailers entering at this point are not primarily concerned with scaling, entering Africa's mature markets remains a solid point of entry. These markets offer established shopping cultures, relatively high wealth levels and well-established infrastructure. Retailers in this stage have the option to move downwards to test basic versions of their current formats. With more demanding consumers and stiff competition in these markets, differentiation is a key factor (ARDI 2015). 


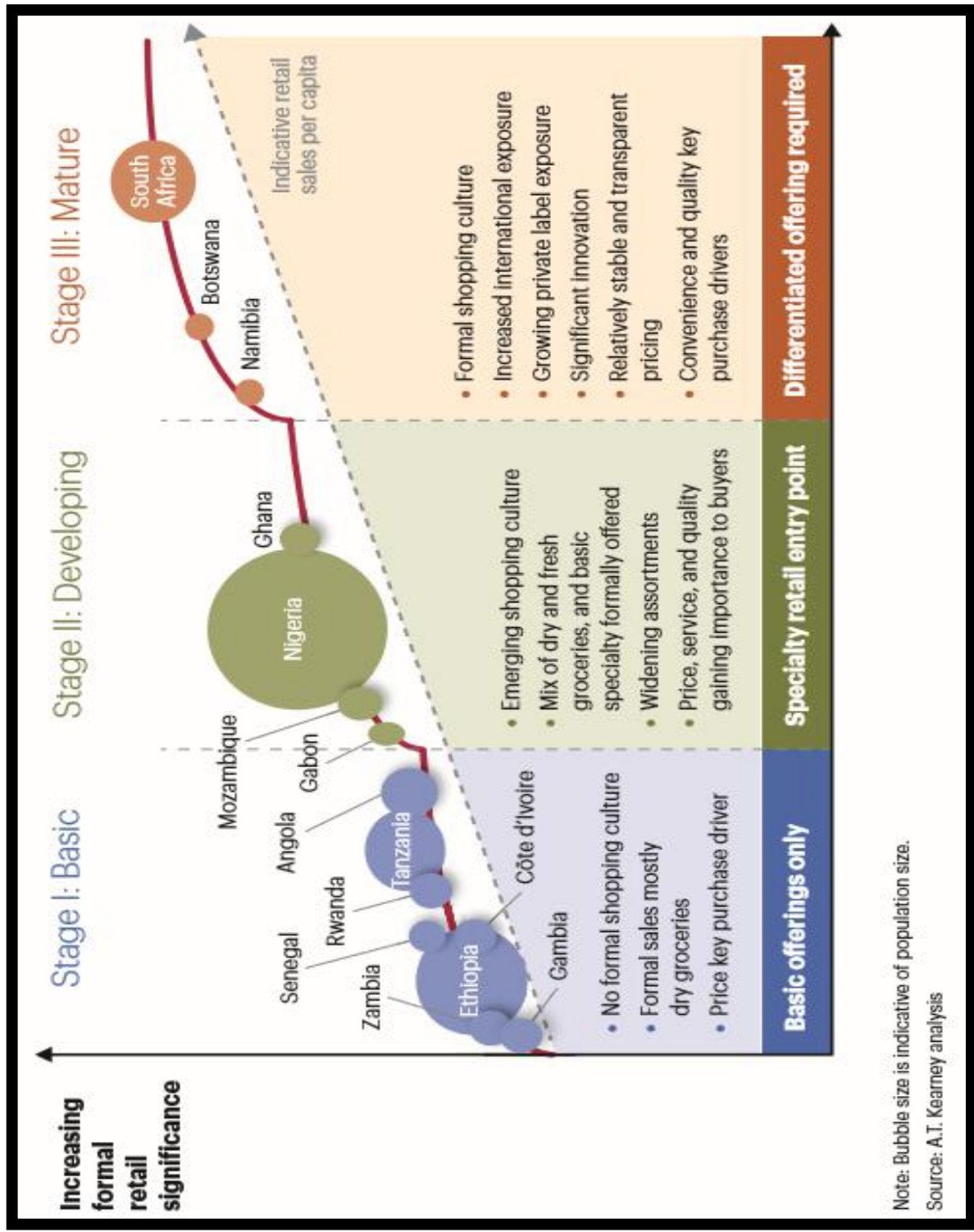

Figure 2: African Retail Proposition Stages. A.T. Kearney's 2015 African Retail Development Index (ARDI) Source: African Development Retail Index (2015) 
E-tailers should embrace what the African Institution of Technology calls a 'city-centric' approach, i.e. they should look at the African e-commerce sector in terms of the opportunities that specific cities can offer (Hubbard 2015). For instance, while it may be too early for smaller, more basic towns in Nigeria to trade online, Lagos is ready due to its affluent and highly population density (Apulu et al. 2011). Therefore, even within a country, it is important for e-tailers to look at opportunities' city by city due to a lack of adequate infrastructure in some cities and this can assist with scaling (Hubbard 2015). Further, e-tailers may need to share some resources, at least until there are significant improvements in infrastructure. If they do not reduce costs related to logistics, e-tailers may be unable to out-compete traditional stores on price. Another major element shaping e-commerce in Africa is the rise in web traffic coming from mobile devices; so it is important for e-tailers to build a responsive website experience that is compatible across all devices (Hubbard 2015).

\section{Research Methodology}

This study followed an inductive approach as there are currently questionable theories that inform the value-based objectives for e-tailing in Africa. The qualitative research was therefore exploratory in its design as there was limited information in this area (Sekeran \& Bougie 2011). Data collected in this research could be used as a basis for further studies in the e-tailing phenomenon in Africa. The aim of this research was to gain a deeper understanding of the topic under investigation (Banister et al. 2011).

The target population of this study comprised the 64 employees at Company Z in 2016. The population is geographically based in Company Z's head office in Cape Town in the Western Cape Province, South Africa. The sample size used was twelve middle and top management employees, which made up the census of middle and top management cohort in Company Z. To collect data for the study, semi-structured, individual face to face interviews were administered. The questions asked were based on existing literature and the constructs it provided. In addition, this data collection process gave the researcher the opportunity to deeply investigate the social matters of the study (DiCicco \& Crabtree 2006).

Transferability was critical for this research. The research was designed to provide lessons that could be transferred to other similar contexts. External validity is 'concerned with the extent to which the finding of one study 
can be applied to other situations' (Shenton 2004: 69). This was paramount in this study. However, many researchers argue that the findings in qualitative research cannot be applied to other populations, as they relate to a small number of specific environments or individuals. Nonetheless, contrary to this argument, Stake (1999) suggests that while the case in a qualitative study may be unique, it is a case within a broader group, and thus the potential for transferability should not be completely ruled out. In seminal works on achieving data quality for qualitative research, Lincoln and Guba (1985) offer the same argument, suggesting that the researcher has a responsibility to ensure that sufficient contextual information about the fieldwork is provided in order for the reader to make a transfer. It is important for the researcher to also provide a thorough description of the phenomenon being investigated in order for the reader to have a good understanding. This also enables the reader to compare the occurrences in the study with broader situations.

The qualitative data was analysed using thematic analysis, which is a form of content analysis. The data was processed using NVivo data analysis software (Version 10). To conduct the data analysis, the data collected was transcribed verbatim in order to capture all the important information. Using the NVivo programme, the researcher reviewed and reduced the research data by identifying and noting down relevant concepts, textual phrases and quotes by the participants which were related to the major elements of the research objective. The textual phrases of each participant were laid out under each participant's name, coded according to relevant themes, grouped according to each concept, and presented in a tabular format. The textual phrases were then analysed, and key concepts, themes and patterns were identified. Interpretations were made and the results were presented.

\section{Presentation of Results}

Not all the targeted sample respondents were reached. The study was therefore based on eleven of the twelve that were targeted. Results showed how Company $\mathrm{Z}$ fits its business model to meet its e-commerce business strategy.

Financial rewards: The majority of the participants revealed that Company $\mathrm{Z}$ adds monetary value directly to the company by selling fashion online.

It (the online business strategy)is to get people to visit our website and buy our product offerings. (Participant 3) 
Product and channel enrichment: It was found that Company $\mathrm{Z}$ also adds value indirectly through 'brand promotion' and 'brand loyalty'. A number of participants added that when Company $\mathrm{Z}$ was first established, value was created through 'brand awareness'.

When we started out, our initial barrier was to try and start an online retail store from a company that is [was] purely focused on media. To achieve this, we had to be aggressive in our strategy in order to make ourselves known. (Participant 6)

Now that the brand is established and has a presence in the market, it is focused on building 'brand loyalty' through digital marketing efforts and customer service. In terms of marketing, the business intelligence department provides the marketing team with data it can use to communicate with the customer.

Within our product offering we receive statistics from the business intelligence team and from those we can see what our customer is buying, and then try and gauge [develop] a customer profile. (Participant 9)

The 'customer profile' enables the e-tailer to 'keep track of customer shopping habits', and from there 'meet customer demands'.

The more the business intelligence division knows about the shopper, the more information we can give to the marketing team who can tailor [target] marketing strategies more appropriately. (Participant 8)

A majority of the participants suggested that the marketing department should use Integrated Marketing Communications (IMC) channels to 'target the right customers' and 'communicate with the customer'. From a marketing point of view, one of the participants commented that:

... when we look at brand acquisition and retention, as a marketer you know which channels are relevant to what, and then you plug in the channels, then from there you have a mix of channels that you take to market. (Participant 4) 
In terms of customer service, it is vital for Company $\mathrm{Z}$ to provide a positive experience in order to build and improve brand loyalty. Participants revealed that Company $\mathrm{Z}$ aimed to provide their customers with a 'seamless experience'. A customer's experience during their interaction with the website is vital for Company $\mathrm{Z}$ in order to establish and maintain trust.

Building trust is largely the result of the customer's first interaction with the website. Does the website look secure? Has the customer been referred to the website by a friend? Has the friend used the website in the past? (Participant 7)

From a customer service point of view, the participants discussed the importance of Company $\mathrm{Z}$ dealing with customer complaints, some of which may be the result of a bad experience with a courier.

We view every complaint as an opportunity to win the customer over so that they become promoters of our brand. (Participant 10)

The participants added that building trust through customer service also means building a strong 'relationship with couriers' who control the last mile, and subsequently, are responsible for the last engagement with the customer.

Lastly, being affiliated with a company such as their Holding Group Company, which has a large presence in Africa and internationally, assists Company $\mathrm{Z}$ in building customer trust.

It really helps that we are part of the Holding Group Company and part of Company $X$ (which is within the Group) which are already hugely trusted brands in South Africa. (Participant 4)

Decreasing operating costs: Resource sharing is beneficial in decreasing operating costs. At Company $\mathrm{Z}$ resource sharing is evident in two themes. The first theme is revealed through the opportunity that the magazine titles owned by Company X presented for the establishment of an e-tailer like Company Z.

Company $Z$ was set up to leverage off Company $X$ 's magazines business. So it made sense to build an e-commerce company off the strong magazine titles. (Participant 3) 
The second theme is the use of Company X's internal logistics company, which Company $\mathrm{Z}$ uses to deliver products to its customers. Participants revealed that it was important for Company $\mathrm{Z}$ to constantly work towards improving 'speedto-market' in order to improve customer satisfaction.

\section{Discussion of Results}

Company Z's e-business model adds value to the company both directly through the sale of merchandise and indirectly through product and channel enrichment, decreasing operating costs and improving logistics. According to Hedman and Kalling (2003), when a company's activities result in revenue, products and/ or reduced operating costs, value is created and added to the company. This fulfils the value-based objectives of the two-dimensional business model. During the start-up phase of the company, the aim of the business was to generate revenue through the development of an e-business model that would service a latent customer base in the fashion industry. The company aimed to achieve this by placing products online that would enable online shoppers to purchase these items. Through their hardcopy magazines, they identified a gap in the market that turned offline readers to online fashion buyers.

Hubbard (2015) maintained that e-commerce companies operating in the African market cannot adopt business models that have been used by companies in international markets because Africa faces numerous challenges and is developing differently in terms of infrastructure and economic growth (Murray 2012). When entering the African market, it is important for companies to understand the different local markets and their competitive advantages (ARDI 2015). For Company Z, having an affiliation with Company $X$ 's magazine titles, provided the e-tailer with a competitive advantage. The etailer leveraged off the company's magazines and several other magazines that already had a presence in the South African media industry and are associated with Company $\mathrm{X}$ and the Media Holding Company, both which are trusted multi-national companies in Africa.

In terms of product and channel enrichment, Company $\mathrm{Z}$ initially engaged in aggressive marketing campaigns. Durrant (2015) indicated that marketing strategies of this nature enable e-commerce companies to gain significant returns in terms of brand awareness. With an established brand, the e-tailer continues to add value by focusing its digital marketing and customer service efforts on building and maintaining brand loyalty. In a competitive 
market, maintaining customer loyalty is vital in ensuring a higher share of profits and decreasing the costs of attracting new customers (Liao et al. 2014). E-commerce is expensive, so in order to cover the costs incurred and make profits, e-tailers need to find ways to attract consumers who are most likely to purchase their products (Liao et al. 2014). In the study, it was established that Company $\mathrm{Z}$ uses the statistics received from its business intelligence team to create a customer profile that gives the company an understanding of its customer segment.

The statistics also enable the marketing team to gain a better understanding of Company Z's consumer buyer behaviour, and in that way, the e-tailer can tailor its communication efforts to meet the customer expectations. This information provides Company $\mathrm{Z}$ with the opportunity to meet demand. This builds brand loyalty such that the e-tailer will be able to drive repeat purchases. Furthermore, various channels are used to communicate the right message to the right customer.

We look at brand acquisition and retention to see which channels are relevant to what. We then plug into the relevant channels, and from there, you have a mix of channels that you can take to market. (Participant 4)

The company also builds and maintains brand loyalty through its customer service department.

An indirect way of generating income is by always aiming to retain our customers. We want to win customers over so that they keep coming back to us. It is more expensive to get a new customer in than to keep an old one. Therefore, our aim is to win customers for life. (Participant 10)

Building brand loyalty and customer trust are achieved by maintaining a strong relationship with the courier services that the e-tailer relies on for deliveries. In reality, to do business well, one is required to create long term mutually beneficial relationships with a network of different stakeholders; it cannot be done alone. You are, because of others, in business. This is an African way of doing business and it is embedded in Mbigi's African business practice identified as Ubuntu Management Principles (Machi \& Kunene 2018). 
The last dimension in which Company Z's e-business model adds value to the company is by decreasing operating costs. Hubbard (2015) asserted that in order for e-tailers to reduce the costs related to logistics they need to share some resources, at least until there are significant improvements in infrastructure. If they do not, they may be unable to out-compete traditional stores on price. Resource sharing at Company $\mathrm{Z}$ is demonstrated through the use of Company X's internal logistics company, which the e-tailer uses for some of its customer orders.

\section{Conclusions \& Recommendations}

The study found that there was a third objective that businesses with e-tailing strategy need to consider in the African context, this was a collaboration objective. These are depicted in the conceptual framework below.

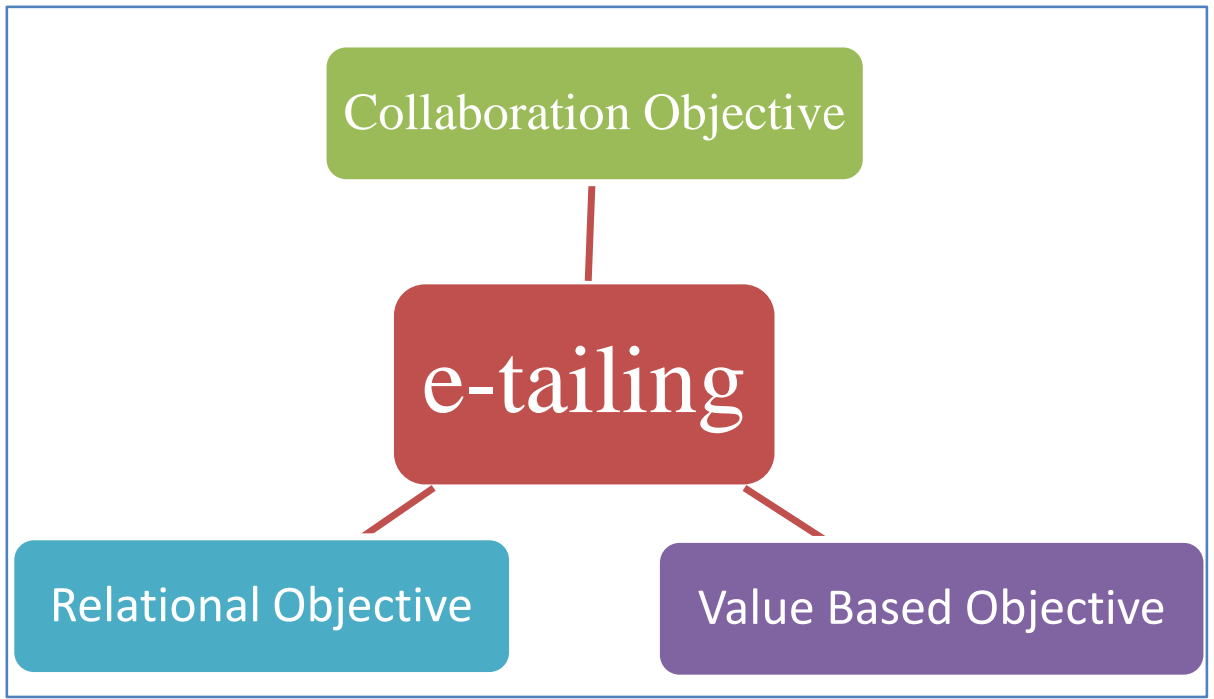

Figure 3: Three Dimensional Business Model to e-tailing Source: Author's Own

\section{Relational Objective}

This objective is concerned with the sale of merchandise. It is essential for people who visit the website to make apparel purchases; this is the core reason for the online existence of any e-business. 


\section{Value-Based Objective}

This objective is concerned with product, channel enrichment as well as reduction of operational costs.

A strong brand strategy with an emphasis on brand loyalty is important. But most importantly, there is a need to become aggressive when building a brand initially as a new e-tailer. This will lead to building and maintaining customer trust. The second factor in defining value based objective links to the next objective. A network of companies and/or a parent company that has existing infrastructure, can be beneficial in reducing operating costs.

\section{Collaboration Objective}

Where there is a parent company already in existence, it is critical for the parent company to share its resources in delivering products to customers. This is especially critical in places where infrastructure is not in existence or has not been fully developed. Where there are no parent companies, it requires that a company finds partners with a shared vision, that they can share resources with and help one another in promoting their brands.

This research reveals a third objective in conducting e-tailing business in the African context. Businesses need to be cognisant of the fact that different African countries will present different environments. It is therefore imperative to customise the city-centric strategy guided by the three value-based objectives, which are embedded in strong network creations, especially via linkages with networks that are already present in each city.

\section{References}

ARDI 2015. African Retail Development Index. African Business Central. Available at: https://www.africanbusinesscentral.com/2015/09/13/the2015-african-retail-development-index-infographics-video-report-atkearney/ (Accessed on 09 September 2018).

Agarwal, J. \& J. Wu 2015. Factors Influencing Growth Potential of E-

Commerce in Emerging Economies: An Institution-based N-OLI Framework and Research Propositions. Thunderbird International Business Review 57,3: 197 - 215.

Apulu, I., A. Latham \& R. Moreton 2011. Factors Affecting the Effective 
Utilisation and Adoption of Sophisticated ICT Solutions: Case Studies of SMEs in Lagos, Nigeria. Journal of Systems and Information Technology 13,2: 125 - 143. https://doi.org/10.1108/13287261111135972 (Accessed on 09 September 2018.)

Banister, P., G. Bunn, E. Burman \& J. Daniels 2011. Qualitative Methods in Psychology: A Research Guide. London: McGraw-Hill International. Bigliardi, B. \& A.I. Dormio \& F. Galati 2012. The Adoption of Open Innovation within the Telecommunication Industry. European Journal of Innovation Management 15,1: 27 - 54.

https://doi.org/10.1108/14601061211192825

Carsten, S., A. Al-Taitoon, J. Kietzmann, D. Pica, G. Wiredu, S. ElalufCalderwood, K. Boateng, M. Kakihara \& D. Gibson. 2008. Exploring Enterprise Mobility: Lessons from the Field. Information Knowledge Systems Management 7,1/2: 243 - 271.

Çelik, H.E. \& V. Y1lmaz 2011. Extending the Technology Acceptance Model for Adoption of E-Shopping by Consumers in Turkey. Journal of Electronic Commerce Research 12,2: 152 - 164.

Chester, M. \& R. Kaura 2012. Electronic Commerce and Business Communication. Harboruogh: Springer.

Chester, M., R. Kaura \& P. Linton 2013. Electronic Business \& Commerce. London: Springer Verlag.

Creswell, J.W. 2003. Research Design: Qualitative, Quantitative, and Mixed Method Approaches. California: SAGE Publications Inc.

Cunningham, P. \& P. Fröschl 2013. Electronic Business RevolutionOpportunities and Challenges in the $21^{\text {st }}$ Century. New York: Springer.

Dicicco-Bloom, B. \& B.F. Crabtree 2006. The Qualitative Research Interview.

Medical Education 40: 314 - 321. https://doi.org/10.1111/j.1365-

2929.2006.02418.x PMid:16573666

Doherty, N.F. \& F. Ellis-Chadwick 2010. Internet Retailing: The Past, the Present and the Future. International Journal of Retail \& Distribution Management 38,11/12: 943 - 965.

Durrant, N. 2015. The Real State of E-Commerce in South Africa: 9 Things you Need to Know Today. Available at: https://ventureburn.com/2015/04/real-state-ecommerce-south-africa-9things-need-know-today/ (Accessed on 09 September 2018).

Feilzer, M.Y. 2010. Doing Mixed Methods Research Pragmatically: Implications for the Rediscovery of Pragmatism as a Research Paradigm. 
Journal of Mixed Methods Research 4,1: 6 - 16.

https://doi.org/10.1177/1558689809349691

Hande, P.V., G. Debleena \& A. Govil. 2015. A Comparative Study on Factors

Shaping Buying Behaviour on B2B and B2C E-Commerce Platforms

in India. International Journal of Multidisciplinary Management Studies 5,3: 1 - 10.

Hattingh, D., B. Russo \& A. Sun-Basorun 2013. Betting on Africa's Potential. McKinsey Quarterly 2: $12-15$.

Hedman, J. \& T. Kalling 2003. The Business Model Concept: Theoretical Underpinnings and Empirical Illustrations. European Journal of Information Systems 12, 1: 49 - 59.

https://doi.org/10.1057/palgrave.ejis.3000446

Hubbard, J. 2015. Is Local E-Commerce Growing Up? Available at: https://www.moneyweb.co.za/news/economy/is-local-e-commercegrowing-up// (Accessed on 28 February 2016).

Hughes, S. \& C. Beukes 2012. Growth and Implications of Social ECommerce and Group Buying Daily Deal Sites: The Case of Groupon and Livingsocial. International Business \& Economics Research Journal 11,8: 921 - 934.

Koch, A. \& P.A. van Brakel (eds.). 2012. Proceedings of the $14^{\text {th }}$ Annual Conference on World Wide Web Applications, 7-9 November 2012, Durban, South Africa: Annual Conference on World Wide Applications. Cape Town: Cape Peninsula University of Technology. https://citeseerx.ist.psu.edu/viewdoc/download?doi=10.1.1.891.4663\&re $\mathrm{p}=\mathrm{rep} 1 \&$ type $=\mathrm{pdf}$

Kataria, A., A. Ritu \& A. Hasan 2014. Conceptual Study on E-Tailing \& Mobile Retailing in Retail Environment. International Journal of Retailing \& Rural Business Perspectives 3,1: 808 - 813.

Kshetri, N. 2007. Barriers to E-Commerce and Competitive Business Models in Developing Countries: A Case Study. Electronic Commerce Research and Applications 6,4: 443 - 452. https://doi.org/10.1016/j.elerap.2007.02.004

Lam, L.W. \& L.J. Harrison-Walker 2003. Toward an Objective Based Typology of E-Business Models. Business Horizons 46,6: 17. https://doi.org/10.1016/S0007-6813(03)00084-3

Liao, Y., Y. Wang \& C. Yeh 2014. Exploring the Relationship between Intentional and Behavioural Loyalty in the Context of E-Tailing. Internet 
Research 24,5: 668 - 686. https://doi.org/10.1108/IntR-08-2013-0181

Li, P. \& W. Xie 2012. A Strategic Framework for Determining E-Commerce Adaptation. Journal of Technology Management in China 7,1: 22 - 35. https://doi.org/10.1108/17468771211207321

Lin, A. \& N.C. Chen 2012. Cloud Computing as an Innovation: Perception, Attitude, and Adoption. International Journal of Information Management 32,6: 533 - 540.

Lincoln, Y.S. \& E.G. Guba 1985. Naturalistic Inquiry. Beverly Hills: Sage.

Machi, S.P.G. \& L.N. Kunene 2018. Use of Ubuntu Principles of Management to Successfully Operate Informal Entrepreneurial Businesses in uMlazi Township (South Africa). International Conference on Innovation and Entrepreneurship. Academic Conferences International Limited.

Makame, W.H., H.J. Kang \& S. Park 2014. Factors Influencing Electronic Commerce Adoption in Developing Countries: The Case of Tanzania. South African Journal of Business Management 45,2: 83 - 96.

https://doi.org/10.4102/sajbm.v45i2.126

Mahajan P. \& M. Argwal 2015. Exploring the Potential of E-Commerce in the Digital Age: Challenges and Opportunities for Commerce Education. Journal of Information Technology 11,4: 46 - 56.

Matook, S. 2012. Measuring the Performance of Electronic Marketplaces: An External Goal Approach Study. Decision Support Systems 54: 1065 1075. https://doi.org/10.1016/j.dss.2012.10.032

Murray, C. 2012. The Challenges of E-Commerce in Africa. Available at: http://memeburn.com/2012/11/the-challenges-of-ecommerce-in-africatech4africa/ (Accessed on 28 February 2016).

Moriarty, M., B. van Dijk, M. Warschun, J. Prinlsoo, E. Savona \& M. Witjes 2015. Retail in Africa: Still the Next Big Thing. A.T Kearney Global Consumer Institute.

http://www.marketpulse.co.ke/images/publications/Retail-in-Africa--Still-the-Next-Big-Thing-by-ATKearney.pdf

Nabareseh, S. \& C.N. Osakwe 2014. Can Business-to-consumer Electronic Commerce be a Game-changer in Anglophone West African Countries? Insights from Secondary Data and Consumers' Perspectives. World Applied Sciences Journal 30,11: 1515 - 1525.

Oluyinka, S., A. Shamsuddin \& E. Wahab 2013. A Study of Electronic Commerce Adoption Factors in Nigeria. International Journal of Information Systems and Change Management 6,4: 293 - 315. 
https://doi.org/10.1504/IJISCM.2013.060974

Remané, G., A. Hanelt, J.F. Tesch \& L.M. Kolbe 2019. The Business Model Pattern Database: A Tool for Systematic BMI. In Tesch, J.F. (ed): Business Model Innovation in the Era of the Internet of Things. Cham, Switzerland: Springer.

Sekaran, U. \& R. Bougie 2011. Research Methods for Business: A Skill Building Approach. $5^{\text {th }}$ Edition. West Sussex: John Wiley \& Sons Ltd.

Shenton, A. 2004. Strategies for Ensuring Trustworthiness in Qualitative Research Projects. Education for Information 22: 63 - 75.

Stake, R.E. 1999. Case Studies. In Denzin, N.K. \& Y.S. Lincoln (eds): Handbook of Qualitative Research. Thousand Oaks: Sage.

Zumpe, S. \& M. Madlberger 2007. A Transaction-based Framework for Business Models in Electronic Commerce. $11^{\text {th }}$ Pacific - Asia Conference on Information Systems. 4 - 6 July 2007, Auckland, New Zeeland. https://www.researchgate.net/publication/221228903_A_transactionbased Framework for Business Models in Electronic Commerce

Lindiwe, N. Kunene University of KwaZulu-Natal School of Management, Information \& Governance Discipline of Management \& Entrepreneurship +27312607152 KuneneL3@ukzn.ac.za

P.S. Mthembu University of KwaZulu-Natal School of Management, Information \& Governance Discipline of Supply Chain \& Marketing mthembusinegugu@gmail.com

T.P Mbhele

University of KwaZulu-Natal School of Management, Information \& Governance Discipline of Supply Chain \& Marketing mbhelet@ukzn.ac.za 


\section{The Relationship between Career Plateaus and the Career Stages of the University of KwaZulu-Natal Academics}

\section{Anisha Ramsaroop \\ ORCID iD: http://orcid.org/0000-0002-1496-9811}

\section{Abstract}

The study focused on the association between career plateaus and vocation stages of the University of KwaZulu-Natal's (UKZN) academic staff across the Westville, Howard College, Edgewood, Medical School and Pietermaritzburg campus sites. The sample consisted of 253 academics across all levels from tutors, senior tutors, developmental lecturers, lecturers, senior lecturers, associate professors and research fellows. Through a mixed methods approach, the quantitative aspect included questionnaires electronically and personally administered to academics, and the qualitative component was undertaken by interviewing a cohort of academic leaders across campuses. The study was theorised through the Protean career. The Career Choice and Career Management models further located the framework of the study regarding decisions in one's career. Various dynamics such as promotion, tenure in a specific position, age, job content, personal plateauing, professional plateauing, and most recently life plateauing have impacted on academics at various career stages. Various issues encountered at the institution include student unrest, funding issues, academic discontent in respect of higher workloads, a greater emphasis on research and an overspill between private and working hours. Stringent criteria for promotion and an early retirement age has also left many academics with low morale, dissatisfaction, frustration, fatigue and elevated levels of stress. Some of these challenges have derailed the realisation and pursuance of academic goals. Against this background, the research aimed to determine if academics are plateaued hierarchically in respect of mobility in the institution; over their invariable work content; through job skills and or personally (where academia controls all domains of an academic's life to the marginalisation of any additional activity). These challenges are inherent at the exploration, esta- 
blishment, maintenance and disengagement career stages. A negative impact on academics in some instances inadvertently contributed to employee turnover and demotivation, hence plateauing.

Hypotheses of the study highlighted a noteworthy association between both dimensions and sub-dimensions (structural/ hierarchical, content/ job content, personal, professional and life) and career stages (exploration, establishment, maintenance and disengagement), significant differences in the opinions of academics differing on each of the respective biographical variables (age, marital status, job status, tenure, race, gender, education level) and their individual career stages (exploration, establishment, maintenance and disengagement) with the career plateau construct and the variance in career stages significantly expounded by the career plateau status. Results of the study reflected a high level of agreement from respondents regarding structural plateauing and limited opportunities for advancement at the University, amongst other key findings. Furthermore, a framework for the effective management of the types of career plateaus across career stages in an academic environment was advocated. The framework illustrates strategies for relevant stakeholders in academia at various career stages.

Keywords: career, plateaus, stages, model, exploration, establishment, maintenance, disengagement, structural, hierarchical, structural, job content

\section{Introduction}

The unpredictable influences of globalisation compelled states to reorganise their markets. Organisations reacted by levelling their organisations, decreasing staff, downscaling, reshuffling, introducing productivity enhancements and avoiding expenditures by controlling advancement (Shaw \& Chayes 2011). Jung and Tak (2008) endorses that as organisational configurations develop horizontally, vocation progression in as far as vertical advancement is concerned has become competitive and often tough to implement. This has been the case at the institution under study. Stringent criteria for promotion at the institution was a key contributor of discontent amongst academics. Career plateaus denote a sense of frustration and psychosomatic anguish workers encounter ensuing an enduring or impermanent 'dead end' or a standstill in their vocations. A widespread meaning of career plateaus recognises career 
plateaus as a juncture where the possibility of ranked preferment is minimal (Sthapit 2010).

A drastic change in the academic landscape has had a profound effect on academic staff at institutions of higher learning. Challenges include higher workloads, work-life imbalance, academic instability and the low likelihood of advancing in careers. These are some of the reasons why academics are leaving institutions whereas others choose to uphold the position for the remainder of their tenure (Mafenya 2014; HESA 2014). The researcher, an academic, undertook the study to gain greater insights into the complexity of issues that affect academics in higher learning, using the University of KwaZulu-Natal (UKZN) as a case study. Many academics have left the institution for other tertiary bodies. The rationale of the study was to identify and comprehend the various encounters experienced by academics in the current era, thereby crafting a more favourable environment for the effective functioning and utilisation of academic skills, hence avoiding a 'brain drain' of scarce, highly qualified academics.

\section{Challenges Facing Academics in Higher Education}

Post-1994 changes have compelled tertiary institutions to transform their medium of instruction, student composition and numbers, and organisational structures, to name a few challenges (Condy 2015). All aspects have affected and influenced almost all sectors of tertiary domains, inclusive of academic vocations and the fulfilment of academics in general, argues Jansen (2004). This is highlighted by knowing that the educational fraternity is viewed as a demanding vocation (Barkhuizen et al. 2004; Bellamy et al. 2003). In order to ensure sustained existence, tertiary organisations should make use of competent and committed academic personnel. If the South African and international tertiary institutions want to harness, keep, grow and use their academics while promising career acceleration and its related value, there is then a dire necessity to recognise what is hampering academic careers (Zeffane \& Mayo 1994; Cuthbert 1996; Islam et al. 2015). Internationally, a study of Portuguese academics identified various career barriers affecting academics. These barriers included collegiality and career blockages and workplace politics. Furthermore, a lack of supervisory support, lack of research collaboration and peer rivalry and competition; barriers associated with career progression standards and expectations (such as dissatisfaction with publication metrics, inequities 
with performance management weightings for career progression and limited vacancies for rank advancement) were identified. Barriers related to inadequate organisational support and employment precariousness (which included aspects such as job insecurity, shortage of monetary support for research, huge administrative workloads and a dearth of administrative support and huge teaching workloads) were highlighted. Wessels (2008) recognised that the surge in student enrolments has resulted in heavier workloads, and academics needed to enhance their abilities to manage the growing increase in the volume of students.

The respondents identified these as key issues they faced at the institution. The insufficient monetary resource for tertiary teaching is a key obstacle encountered by all South African academes. The dearth of sufficient finance influences the capability to propose ample compensation, and furthermore bounds institutions' capacity to capitalise in structure, amenities and paraphernalia, thereby restricting research competences. According to the Department of Education (DoE) White Paper (DoE 1997: 7) it is the duty of the government's Department of Higher Education and Training (DHET) to ensure elevated research ability which can guarantee the continuance of individual-driven, open-ended intelligent examination, and the persistent solicitation of research accomplishments to high-tech enhancement and communal improvement (Mafenya 2014). Other barriers identified related to finding a balance (which included concerns such as competing proficient roles and work-life balance) and barriers pertaining to gender structure (including issues such as unfriendly work-family culture, feelings of insecurity and having to prove one's competence, personal prejudice regarding motherhood and alienation from social networks) maintains Santos (2016).

\section{Career Plateau}

Career plateaus have been viewed as positions in a vocation that highlight the possibility of upward advancement as being an unlikely event, submits Warren et al. (1977) who introduced a managerial model classifying careers in respect of recent performance and the possibility of forthcoming advancement (Gale 2006). A renewed focus emerged on career plateaus for two key purposes:Firstly, to ensure competitive advantage, downsizing and restructuring was prioritised hence limiting promotion. Secondly, the interest in research associated with the effects and antecedents of career plateaus (Chao 1990). With the 
obscuring of skills boundaries, several personnel were exposed to scarcer prospects for vocation flexibility and impending employability. Considering the changing landscape of work, organisations were constantly under pressure to deal with scarce resources, higher competitiveness, inadequate fiscal progression, advanced expertise and mergers and acquisitions, which all have a cascading effect on downsizing (Choy et al. 1998). As organisations become flatter, career mobility in terms of vertical mobility is unattainable (Jung \& Tak 2008). Kelly (1985), cited in Cable (1999) viewed plateauing as a juncture that heralds no further prospects of advancement which could be attributed to a number of reasons.

\section{Types of Plateaus}

Badiane (2016); Tabarsa and Nazari (2016); and Nwovuhoma and Malik (2016) tried to extend the career plateau phenomenon utilising three diverse groups: structural or hierarchical, content, and life plateauing. Alivand and Ebrahimpour (2015) distinguished types of plateaus as personal, structural and content plateauing. According to Bardwick (1987) cited in Miles (2010), this distinction is vital, given that plateaus have unique precursors and consequences.

\section{Hierarchical/ Structural Plateauing}

A career plateau is commonly defined as a structural plateau. This occurs when promotion is halted in a hierarchical organisation (Bardwick 1987 cited in Miles (2010); Joseph 1996) due to a 'pyramid-like structure' of organisations. In comparison, personal plateauing is seen within the organisation as a lack of want of an individual to occupy a senior position. In this instance, insufficient competencies, or lack of disfavour for a senior position may add to a person's lack of promotion (Warren et al. 1976; Cable 1999). Structural plateauing is also attributed to a combined effect of the original structure and birth rate variations over which the employee has no control (Nwovuhoma \& Malik 2016; Tan \& Salomane 1994).

Other factors include reorganisation of organisations, rationalising of jobs and abolition of middle management (Cable 1999). Alivand and Ebrahimpour (2015) view structural plateauing as occurring when an employee reaches the highest levels of the organisation due to limitations in the hierarchical 
organisational structure. Of significance, is that these plateaued individuals take their final step in their career and reach the final rung of promotion ladders (Cable 1999).

\section{Job Content Plateauing}

Content plateauing relates to a juncture in a person's vocation, wherein the inherent features of the job are low and there is a low likelihood of an improvement in the status quo (Lapalme et al. 2009). Such a plateau features when there is no challenge in work or work accountabilities (Feldman \& Weitz 1988; Salami 2010), since the individuals are conversant with their jobs and become uninterested (Smith-Ruig 2009). Strategies which encompass job design techniques such as career expansion, job rotation, job enhancement and work restructuring, should be implemented to make the job more challenging, as suggested by Joseph (1996) and Bardwick (1987) cited in Cable (1999).

Content plateauing compels able employees to stay in identical positions for several years deprived of a key change in work accountabilities (Weiner et al. 1992), hence the non-appearance of novel, varied and challenging jobs meaning employees are not given room to develop (Allen et al. 1999; Bardwick 1983). Personnel experiencing content plateauing are deprived of rewards and are of the belief that the organisation is not supportive (Lapalme et al. 2009). Bardwick (1987) is of the view that those experiencing hierarchical and content plateauing get ignored by organisations. This aspect, the author believes, sends a message to the worker of not being appreciated and valued, hence resulting in undesirable consequences for both workers and institutions. In this regard, Alivand and Ebrahimpour (2015) are of the view that some people can stay happy in this situation and may utilise situations to resist change with a mandate to maintain a sense of sanctuary.

Bardwick (1987) cited in Duffy (2000) stated that this category of plateau is manipulated by the employee, therefore the employee is in a position to take charge over the changing tasks instead of changing events structurally. Previous research undertaken on job content plateauing was significantly viewed to be interrelated to job dissatisfaction, poor organisational commitment, and elevated stages of turnover (Allen et al. 1999; Milliman 1992). McCleese and Eby (2006), on the other hand, identified circumstances where job content plateauing is concomitant through some undesirable work out-looks, role 
uncertainty in terms of one's duties and responsibilities, and low possibility of advancements as mediators of job content-work attitude connection.

\section{Life Plateauing}

Hierarchical plateauing has dominated literature on career plateauing with not much emphasis on job content and life plateauing (McCleese \& Eby 2006). Life plateauing pertains to a person's state of mind of being locked in their characters outside of work (Allen et al. 1999; Bardwick 1987 cited in Miles (2010). This type of plateauing is viewed as an inner position, to deliver on past obligations (Tabarsa \& Nazari 2016). A life plateau is more philosophical and could be a midlife calamity due to offspring, for instance becoming the most central part of their lives, as well as their individuality and self-respect. This situation could be fine, as long as one is of the view that they are successful, but if they become targets for rationalising or being sidestepped for advancement prospects or the effects of the 'empty nest', they could struggle to glue together the 'parts' of their lives (Brooks 1994).

A study carried out by Smith-Ruig (2009) indicated that most participants acknowledged the need for a good work-life balance because it is instrumental to career success. Participants felt there was a disparity between work-life balance and career success thereby presenting feelings of being unsuccessful, which culminated in 'life plateauing'. This concurs with Heslin (2005), cited in Smith-Ruig (2009), where immense job fulfilment need not fundamentally lead to subjective career achievement when it has an impact on the employees' wellbeing, family or other personal values.

\section{Personal Plateauing}

With personal plateauing the person shows no desire for mutual labour and non-labour accomplishments (Bardwick 1987) cited in Miles (2010). Tan and Salomane (1994) view personal plateauing as concentrating on a person's private domain. Choudray et al. (2013) are of the view that personal plateauing happens when the employee's capability does not correspond with the occupational requirements or when the employee is unmotivated or lacks career ambition. Burke (1989) recognises personal plateauing in two ways: where the employee has no interest in advancing to an elevated occupation and when the company determines a person's lack of talent to achieve adequately at a high- 
ranking point due to particular inadequacies, despite the availability of jobs. Duffy (2000) views personal plateauing as the most dangerous kind of plateau. The person does not desire any bearing and zeal for both labour and non-workrelated activities and avoids additional responsibility (Alivand \& Ebrahimpour 2015). Feldman and Weitz (1988) cited in Coetzee \& Schreuder (2015) recognised numerous dimensions of career plateau, the initial one being, unsuitable skills and capabilities, as a focal point of the discussion that follows.

\section{Job Skill Plateauing}

Feldman and Weitz (1988) attributed job skill plateauing to 'reduced entrylevel performance' in conjunction with inappropriate training, reduced freedom of movement needs, non-existence of inherent inspiration, strain and fatigue, the absence of extrinsic motivators poor organisation progression and stagnation in a vocation attributable to one's own limitations. A different concept that provides justification for those in non-traditional careers is that of a professional plateau (Smith-Ruig 2009).

\section{Professional Plateauing}

Professional plateauing is a juncture at which employees discover that their jobs are unchallenging rendering scarce prospects for proficient growth and forthcoming absorption (Lee 1999). Lee (1999) further cited in Ruig-Smith (2009) refers to a professional plateau as being associated with progression in a profession, as opposed to traditionally associating progression in a career. The author attributes importance to this type of plateauing to an appearance of 'fresh' patterns of the Protean career, and a process which individuals steer and is determined by their own criteria.

\section{Career Stages}

Career stages denote evolutionary phases such as exploration, establishment, maintenance and disengagement of a person's working life. These phases are shaped by critical occurrences and modifications, which individuals can clearly see in their professions. Plateauing contributes to unwanted labour consequences such as low gratification, reduced enthusiasm, higher levels of anxiety, poor performance and heightened turnover intentions. 
During an individual's lifecycle, persons go through foreseeable periods or phases in their lives and vocations. Every life or vocation phase is moulded by situations that require attention. In this regard, Super $(1957 ; 1984)$ cited in Kaur and Sandhu (2010), suggested a philosophy that individuals encounter precise vocation periods in their lifetime. Life-cycle phases are recognised by numerous salient undertakings and modifications, which are visible, notwithstanding their professions.

Career stages are therefore, encountered with age and the stages employees encounter, at different phases of their lives. They come across a course of transformation that may be summarised as an arrangement of lifetime phases, namely exploration, establishment, maintenance and disengagement (Stead \& Watson 1999). Transformational events are the backgrounds in which employees exist, comprising biological, psychological, social, spiritual, cultural, economic and historical settings (Schreuder \& Coetzee 2015). Furthermore, the employee and the work background are bound to adjust. Career stages are broken up into three distinct stages/phases:

(i) Early adulthood, namely the novice, transitional and settling down phases;

(ii) The midlife/ career stage (self-related factors); and

(iii) The late life/ career stage (self-related factors) (Murchinsky, Kriek \& Schreuder 2005).

According to Super's theory of vocation growth (Super 1957; Savickas 2002, cited in Hess \& Jepsen 2008), persons undergo four components of vocation anxiety throughout the expansion of their vocations, which involve clarifying career interests, consolidating career choices, maintaining what they have and lastly a decline in occupational interest. Super (1957) cited in Hess and Jepsen (2008) state that personnel will reprocess through the phases, and therefore vocation periods should not be ascertained via linear measurements of age and tenure but concluded by assessment of trepidations related to vocation periods. The linear career pattern was characterised by aspects such as power, competence, achievement, recognition and self-development (Schreuder \& Coetzee 2015).

It is said that the linear career patterns faced many challenges in the contemporary working world due to limited opportunities for progress, hence promoting the concept of non-linear careers where progression is not guaran- 
teed due to various challenges such as mergers and acquisitions and the flattening of organisational structures which have eliminated many manage-ment positions. Conway (2004) cited in Hess and Jepsen (2008), suggested that the managing of worker encounters through vocation phases could be practice-ally deliberated by companies. If contrary to this, organisations are exposed to unproductivity, poor competitive advantage, a drop in self-esteem and zest due to the influences of plateauing.

\section{Alignment with the National Development Plan (2030)}

Vision 2030, which is encapsulated in the National Development Plan (NDP) has two key principles: firstly the abolition of poverty, and secondly the advancement of equivalence. The NDP's methodological approach to tertiary learning is to deduce the general development stance to make explicit recommendations for every sector. Higher education (HE) is not recognised in the Diagnostic Overview (2011a) as one of the 'key' challenges, but 'public services' are, and under 'developing and upgrading capabilities' (2011b: 5), 'improving education and training' (ibid) is seen as one of the nine domains necessitating concentrated consideration to achieve the 2030 vision. The Plan further highlights three key 'functions' tertiary education achieves 'to develop a nation' (ibid): Equip people with requisite high level skills; be a dominant producer of new knowledge; offer prospects for social movement (National Development Plan 2030). Tertiary institutions are instrumental in driving these two principles through quality teaching and learning, teaching professionalism, research technology support, education and increased outputs pertaining to research and graduate throughput (National Development Plan 2030). Higher Education, specifically at university level needs to show their unique contributions. Institutions of HE should be efficient in this regard. This should be characterised by increased throughput and participation, as well as higher levels of innovation and of publication output. By 2030, 75\% of academics should have PhDs. Women and black people should make up more than 50\% of research and training staff. Programmes and initiatives should concentrate on national urgencies, comprising African vernaculars and native knowledge structures. There should be a comprehensible state strategy for HE, promoting innovation and the development of knowledge. HE should respond to scarce skills with closer links between economic and education planning. The school, college and HE systems need to be better articulated. There needs to be a 
healthier connection with the diverse segments of the education system, and improved academic mobility for learners and staff (National Science and Technology Forum 2019).

Academics are key 'instruments' driving this process and realising this vision. This cannot be envisaged without suitably competent, skilled and dedicated academic personnel. The HE domain is totally reliant on the calibre and commitment of these personnel, concedes Robyn and Du Preez (2013). Research and advancement by tertiary institutions, science councils, units, NGOs and private entities has a pivotal obligation in enhancing South Africa's international competitiveness.

In contextualising the National Development Plan (NDP) 2030, emphasis is on promoting the need for research and development. With regard to HE, the NDP 2030 stipulates that Higher Education Institutions (HEIs) must be engaged in continuous quality improvement, and the need for better performance. In so doing, HEIs would contribute to enhancing their strategic focus. Further to this, there is a need to ensure 'synchronised attention on research and growth on the stature of education and adequate human capacity, compelling universities to become hubs of distinction in technology. In raising the professional profile and cadre of academia, this would in turn, provide an invaluable and quality service to the teaching and learning ambit and the research agenda of tertiary learning in South Africa.

Other benefits of career development include the ability of the employee to search and discover future career paths; managers can advance productivity, employee capability is increased, workers' attitudes improve, and occupation gratification allow for the efficient distribution of employees and the promotion of greater employee loyalty (Vermeulen 2015). Employees feel gratified knowing that the employer has fulfilled their part of the psychological contract when career development is valued and promoted (Saleem \& Amin 2013). The need for ongoing career development is warranted due to the greater flexibility and versatile skills needed by employees (Vermeulen 2015). Public universities can back academics' vocation growth initiatives via confirmative governance, formation of prospects for planned learning, providing financial resources for vocation expansion programmes and make provision for rewards to individuals who endeavour vocation growth. Such initiatives include advancement upon accomplishment of development initiatives, granting employees study leave and organising forums such as sessions, workshops and symposiums. Such initiatives allow them to disseminate new knowledge and 
inventions (Saleem \& Amin 2013: 197).

Badat (2008) cited in Robyn and Du Preez (2013), highlights three challenges for South African tertiary institutions: the sector is aligning itself to become competitive with industry to retain accomplished academics; the ability of future academics to have the competencies to generate high calibre graduates and to foster equivalent opportunities for learners, and lastly to be able to bring transformation in institutional cultures in the historically white institutions. Higher education institutions need administrators and graduates who are diversity conversant as enablers to the transformation process, suggests (Cody 2015). Inequities in remuneration in public and private entities are contributing to the existing challenges. This is a contributing factor to younger, talented academics being difficult to retain in the current dispensation. The retention of talented young academics, the Generation $\mathrm{Y}$, is currently a demanding global issue across all sectors and more so amongst staff at tertiary institutions. Senior South African academics are better remunerated than lower ranked or junior academics, according to research conducted by the Vice Chancellors' Association of Higher Education (HESA 2014). Whilst this is good news for high-ranking academics, it unfortunately has the direct opposite effect for the next generation of academics, suggests MacGregor (2015).

\section{Research Design and Methodology Objectives of the Study}

The research aimed to:

- Establish the career plateau status of the participants in terms of structural/ hierarchical, job content, personal and job skill plateauing;

- Ascertain the career stage of the participants in terms of exploration, establishment, maintenance, and disengagement;

- Ascertain if there is a valid association between career plateaus and career stages;

- Determine whether the variance in career stages is due to the career plateau status;

- Examine the influence of the biographical variables on the career plateau status and career stages respectively; and

- Make appropriate recommendations arising from the study. 


\subsection{Research Design}

The study encompassed a combination of descriptive and explanatory research. Justification for utilising descriptive research was attributed to the researcher wanting to describe the characteristics of the phenomena, that is, to establish the career plateau status of the participants in relation to structural/ hierarchical, job content, personal and job skill plateauing, and ascertain the career stage of the participants in terms of exploration, establishment, maintenance, and disengagement.

The rationale for utilising explanatory research enabled the researcher to make inferences and to find solutions pertinent to the research. This kind of research was used firstly to clarify the phenomena such as human behaviour by indicating how the variables (career plateaus and career stages) are related to one another; and how one variable affects another (for example, whether the variance in career stages was due to the career plateau status). Hence, by explaining and predicting human behaviour, the researcher was in a position to change or control that behaviour. For example, the researcher established if a significant affiliation occurred between key variables, that is, career plateaus and career stages. Another reason for its usage was attributed to the utilisation of the mixed research methods, which permitted the researcher to cross check the outcomes from the quantitative segment with the qualitative segment. In this methodology, the investigator collected both quantitative (close-ended) and qualitative inputs (open-ended) data, incorporated the two, and then drew explanations centred on the mutual strengths of both sets of data to better comprehend research problems (Creswell 2015).

Greene (2015: 607) maintains that, mixed methods scholarships, at least initially, offered prospects to participate 'meaningfully' by joining data at diverse levels. Teddie and Tashakkori (2010: 11) quantified mixed methods research as 'research strategies using qualitative and quantitative data gathering and enquiry methods in any corresponding or chronological segments'. Bearing in mind the key characteristics of mixed methods research as described by these writers, such designs should eventually offer academics more vigorous opportunities and direct the planning of work. Not only is data at diverse levels correlated. The significance of specific corresponding or chronological data segments that interact at the different levels, is also described.

A fundamental conjecture of this approach is that when a researcher fuses statistical developments (quantitative data) with stories and 
personal understandings (qualitative data), this collective strength provides a better understanding of the research problem than either form of data alone (Creswell 2015: 1).

\section{Sampling \& Sample Design}

A total of 1347 academics across all five UKZN campuses comprised the population of the study. The academic staff complement of the entire university entailed: 135 professors, 135 associate professors, 208 senior lecturers, 745 lecturers, 21 junior lecturers, 85 below junior lecturers and 18 academic employees under the category 'other' such as developmental lecturers and research fellows (UKZN - 2015). Two hundred and fifty-three (253) academics were utilised as the sample. This sample is viewed as a reliable and valid sample that allowed the researcher to apply the outcomes from the identified respondents to the population under study (Sekaran \& Bougie 2010). In addition, the researcher needed to safeguard against non-responses and therefore increased the sample size.

Stratified random sampling was utilised, where participants were randomly chosen from each stratum listed above. Stratified sampling is a way for ensuring good alignment by reducing possible sampling inaccuracy (Babbie 2014). In addition, this sampling design includes assurance of the sample's representativeness irrespective of sample size due to its use in the sampling strategy from the start. In addition, stratified random sampling involves a reduced sample, hence requires less time and financial resources than simple random sampling (Welman, Kruger and Mitchell 2008).

\section{Data Collection}

Data in this study was collected both quantitatively and qualitatively.

\section{Data Collection Methods}

Interviews and questionnaires (primary data) and secondary data (UKZN 2015) were utilised in the study. The questionnaire was made up of three (3) sections. Section A collected the biographical information of the participants, for example, age, marital status, job status, campus site, tenure, race, gender and educational level. Section B concentrated on career plateaus, which was 
adapted from Joseph (1996) and Lee (1999). Career plateaus was made up of four dimensions, hierarchical/structural plateauing; content plateauing, job skill plateauing and personal plateauing. Section $\mathrm{C}$ focused on career stages (exploration, establishment, maintenance and disengagement) adapted from The Adult Career Concerns Inventory (ACCI) by Smart (1994). The researcher identified the ACCI as an appropriate instrument, since it is a measure of attitudes deemed essential to career and vocational adaptability. The ACCI was designed to assess an individual's ability to plan and give forethought to watching and thinking ahead about one's work and working life' (Super et al. 1988, cited in Smart 1994).

Questionnaires were uploaded onto the University intranet, and also personally administered, as per instructions from the UKZN Registrar. Interviews were conducted with 23 academic leaders across all five campuses to gauge their perspectives on career stages and career plateaus as line managers. Thereafter, a comparison was made with the responses from the questionnaires of academics. Generic information was covered on both variables. Face-to-face, semi-structured interviews were done since flexibility was required in order to extract important information (Dawson 2002). Each interview was audio recorded and transcribed. Notes taken during the interviews augmented the verbatim transcriptions

\section{Data Analysis}

Data was analysed quantitatively and qualitatively. Descriptive and inferential statistics were utilised to scrutinise the statistics and are discussed in detail below.

The Pearson Product Moment Correlation was used in the study to ascertain if career plateaus and career stages are associated with each other. In the study, the t-test was utilised to ascertain whether the variances in reactions of respondents were attributed to the effect of one of the variables (for example, career plateaus) or if these occurred coincidentally. In the study, the ANOVA was utilised to ascertain statistically significant dissimilarities in the perception of the study dimensions (career plateaus and their sub-dimensions and the career stages and their sub-dimensions) among the participant groups (professors, associate professors, senior lecturers, lecturers, junior lecturers, below junior lecturers). Multiple regression analysis was utilised to establish which career plateau dimensions are the best predictors of each career stage. 
The researcher utilised thematic analysis for interpreting the qualitative data. This is widely utilised in qualitative data analysis methods (Bryman $\&$ Bell 2014). The purpose of thematic analysis is to recognise, consider and describe configurations or themes, across a dataset (Bryman \& Bell 2014:305). Factor Analysis was utilised to ascertain the validity of the questionnaire. The Kaiser-Meyer-Olkin Measure of Sampling Adequacy and Bartlett's Test of Sphericity was used to establish if factor analysis could be performed.

\section{Reliability}

Two segments surpassed the recommended Cronbach's Alpha value, thus specifying an extent of adequate, consistent scoring for these units of the study. Cronbach Alpha values of the research for the three structural items was 0.827; for three content items was 0.704 ; two personal choice items was 0.443 and three job skill items was 0.275 . There were thirteen career plateau items. The lower scores $(0.342$ and 0.569$)$ are attributed to the interpretation by the different categories of respondents to the statements in these sections. The low scores were attributed to a degree of non-acceptance of some of the aforementioned aspects of the research. The matrix tables were preceded by a summarised table revealing the outcomes of the Kaiser-Meyer-Olkin (KMO Measure) and Bartlett's Test. The requirement is that KMO of Sampling Adequacy should be more than 0.50 and Bartlett's Test of Sphericity less than 0.05 . In all illustrations, the conditions were fulfilled which permits for the factor analysis process. Factor analysis was undertaken for the Likert scale dimensions.

\section{TABLE 1: KMO AND BARTLETT'S TEST}

\begin{tabular}{|l|l|l|l|l|}
\hline & \multicolumn{3}{|l|}{$\begin{array}{l}\text { Kaiser-Meyer- } \\
\text { Olkin Measure of } \\
\text { Sampling } \\
\text { Adequacy }\end{array}$} & \multicolumn{3}{|l|}{ Bartlett's Test of Sphericity } \\
\cline { 3 - 6 } & $\begin{array}{l}\text { Approx. Chi- } \\
\text { Square }\end{array}$ & 203.074 & 1 & $\begin{array}{l}0.00 \\
0\end{array}$ \\
\hline $\begin{array}{l}\text { Hierarchical/Struc } \\
\text { tural }\end{array}$ & 0.500 & 1.207 & 1 & $\begin{array}{l}0.27 \\
2\end{array}$ \\
\hline Content & 0.500 & & & Sig. \\
\hline
\end{tabular}




\begin{tabular}{|l|l|l|l|l|}
\hline Job skills & 0.632 & 91.085 & 6 & $\begin{array}{l}0.00 \\
0\end{array}$ \\
\hline Personal & 0.683 & 200.335 & 3 & $\begin{array}{l}0.00 \\
0\end{array}$ \\
\hline Exploration & 0.918 & 1315.774 & 28 & $\begin{array}{l}0.00 \\
0\end{array}$ \\
\hline Establishment & 0.878 & 1070.496 & 28 & $\begin{array}{l}0.00 \\
0\end{array}$ \\
\hline Maintenance & 0.871 & 1222.423 & 21 & $\begin{array}{l}0.00 \\
0\end{array}$ \\
\hline Disengagement & 0.757 & 409.625 & 10 & $\begin{array}{l}0.00 \\
0\end{array}$ \\
\hline
\end{tabular}

\section{Biographical Data}

Overall, the ration of men to women was approximately 1:1 (53.4\%: 46.6\%). The above statistics in terms of gender reflect that there were additional male participants in the sample in the following age categories 30-39 (14.5\%); 40$49(20.5 \%)$ and $50-59(7.2 \%)$. This also reflects that more male respondents were in their mid-career stages, maintenance and on the border of their late career stages respectively. In the 60 and over 60 age category, (in the late career stage), there were more female respondents (4.8\%) as compared to males. This could be attributed to more females nearing retirement age than the male counterparts. This occurrence could be linked to females joining the University at a later age as opposed to men, which could be associated with family responsibilities or a late start in their careers due to discrimination females experienced at the workplace prior to the new political dispensation.

There was higher probability that females be categorized as hierarchical or job content plateauing than males. In this regard, Gallos (1989) identified a higher number of women who anticipated there were less progression chances available to them in contrast to males. This was reiterated by a respondent:

As a female we do feel that there is definitely a ceiling for females and with one of my friends, we have often discussed how difficult it is for us to progress or to feel that we are being encouraged in that direction. 
Results from the study reflect about $43 \%$ of females agreed and strongly agreed that they found their academic jobs challenging, as opposed to approximately $26 \%$ males. In addition, many of the responses were gained from the 30-39 and 40-49 age groups regarding their levels of agreement.

Almost half of the respondents were lecturers $(47.0 \%)$ with similar levels across the remaining categories $(\mathrm{p}<0.001)$. Other respondents were made up of: $4.7 \%$ professors $8.7 \%$, associate professors, $11.9 \%$ senior lecturers, $9.1 \%$ junior lecturers, $5.5 \%$ below junior lecturers and $13 \%$ which were constituted as 'other'. Other respondents were made up of: $4.7 \%$ professors $8.7 \%$, associate professors, $11.9 \%$ senior lecturers, $9.1 \%$ junior lecturers, $5.5 \%$ below junior lecturers and $13 \%$ which were constituted as 'other'. The statistics is in keeping with university demographics, with particular reference to lecturers which is the largest complement of 745 academics. In terms of the following, there are 135 Professors; 135 Associate Professors; 208 Senior Lecturers, 745 lecturers, 21 Junior Lecturers, 85 Below Junior Lecturers and 18 constituted under 'other', which reflects the overall staff profile at the university. Taking into account the highest staff profile, which are lecturers (745), there is a likelihood that some of the lecturers may have reached a plateau.

Subsequent conversations with lecturers in the interviews confirmed this and their responses are as follows:

If I am a lecturer and I enjoy teaching, I could consider that I am actually at my plateau, this is where I want to be.

Obviously, systematically the lower the levels, the more a plateau can happen, as you have got more people in those levels and fewer positions for them to go up but is systematic because if somebody is motivated and does show that they are worthy of the next stage, then that is not going to be a plateau.

Career plateau is I assume, when you have achieved a level that you are not going to pass, you are not going to be able to move on to another level.

I suppose when you reach a point and you do not want to go further and cannot go further. 
Ok I would see plateaus as reaching the top so in a way and then becoming stabilised for a period of time or for some reason where the staff have reached their peak and are not moving or does not want to move.

I did not meet the criteria for academic leadership and that is, because the criteria requires you to be a senior lecturer to be an academic leader .... However, I have a PhD, and it was an alternate criterium, where you can serve as an academic leader; however, you cannot be appointed as one .... so even though you have the skills and you have the eagerness to actually participate in the administration of the university, you have everything going for you but you do not have the rank to be appointed as an academic leader.

Almost all of the respondents had a postgraduate qualification. The majority of respondents $(91.0 \%)$ had a minimum of a Master's Degree, whilst $2.0 \%$ of the respondents possessed an undergraduate degree, with $4.0 \%$ of the academics possessing a Honours degree, 49\% having a $\mathrm{PhD}$ and $2.8 \%$ possessed a qualification referred to as 'other'. This is a valuable indicator as it designates that a reasonable amount of the participants have a higher qualification. This indicates that the responses gathered would have been from an informed (learned) source. Educational levels may feature as a key aspect when identifying candidates for stimulating assignments maintains Allen, et al., (1998). Therefore, individuals who do not attain a higher level of education may be disadvantaged when contending for fewer advancement opportunities in an organisation. This concurs with Tremblay and Roger (1993), who explain that experiencing success in the early career stage may significantly highlight the potential of the person and the know-how, which is needed for ultimate promotions in the organisational promotional scheme.

Furthermore, the higher score in relation to $\mathrm{PhD}$ qualifications reflects that the University has set a minimum condition for academics regarding the acquisition of a doctorate. This is also in keeping with the Vision of the National Development Plan 2030. The attainment of this qualification could be attributed to individuals wanting to advance their careers. Although this is the case, some respondents indicated the $\mathrm{PhD}$ was being 'thrust' upon them and they were unable to commence with the qualification due to heavy teaching 
workloads. Respondents also mentioned that they were aware that the $\mathrm{PhD}$ was the instrument by which they could attain career progression (and possibly exit the career plateau status they are encountering at their particular career stage). Alignment to these sentiments from the respondents included:

So one would be where the qualifications sometimes limit people .... in other words, they are expected to have their PhD to become senior lecturers. The person is doing the work, teaching loads and the research to some extent, but does not have a PhD so that is the limitation in that sense.

They do not see the fact that I don't have a PhD as a limitation. They feel I can do the job they want me to do.

I personally don't feel that I have plateaued but I know the university looks at me and says you have plateaued from a research perspective because they keep telling me when are you going to do your PhD?

In addition, the acquisition of the $\mathrm{PhD}$ resonates in the results of the hypothesis testing, when examining the relationship between 'level of education' and 'making specific plans to achieve my current career goals'. Results indicate respondents with Masters' degrees particularly, were keen on tailoring plans to attain their current career goals.

The respondents' race groups were as follows: $41 \%$ black African, $4.0 \%$ coloured, $21.7 \%$ white, $30.9 \%$ Indian and $2.4 \%$ described as 'other'. The scores are in keeping with the University's demographics, with the largest academic complement being Blacks, followed by Indians, Whites and Coloureds. Although the racial composition is a significant influential factor in the study, the percentages reveal another significant aspect within the University as an institution of higher learning which has focused on transformation regarding equity. In this regard, this is also in line with the University's equity plan and compliance with the Employment Equity Act 2014. An excerpt confirming this sentiment came from one respondent:

We will never see a White Dean at this school again .... no White employee here will ever aspire to be a Dean, whether they have the right qualifications or not; it might even extend as far as Indians, 
where the university is at the moment, unless they review their transformation strategy. The transformation has plateaued many people who have the potential to go further.

Furthermore, the bulk of the responses emanated from the African race groups in terms of their levels of agreement (agree and strongly agree).

Almost two-thirds of the participants were married (64.0\%). Single people accounted for $31.6 \%$ while $3.2 \%$ were either divorced or separated. Lastly, $1.2 \%$ constituted those categorised as 'other'. Mid-career, married respondents in the study indicated they were impacted upon by various responsibilities on the home-front. This most likely could allow such respondents to plateau in their mid-career. A married respondent stated:

Plateauing as you say is also about your personal life. My personal life I would say is probably sitting there in terms of my plateau and in terms of my achievements, with children, with marriage, all of that, so which plateaus do you value more? For me, I would think that my personal life is more valuable to me.

\section{Discussion of Results}

Analysis of the data was generated quantitatively and qualitatively.

\section{CORRELATIONS}

Bivariate correlation was performed on the (ordinal) data. The results feature in the annexures.

Positive values indicate a directly proportional relationship between the variables and a negative value indicates an inverse relationship. All signifycant relationships are indicated by a $*$ or $* *$.

For example, the correlation value between 'I am technically current and updated in my academic skills through seminars and extra training' and 'My job skills are transferable to other institutions of higher learning' is 0.301 . This is a directly related proportionality. Participants' show that the more updated they are with their skills, the more transferable these skills become, and vice versa.

Due to the vast amount of significant relationships, the excel spreadsheet (correlations) has been attached in ANNEXURE 1 . 
Some relationships are presented below:-

- There is a significant relationship between 'Promotions are limited at the university due to the university's structure' and hierarchical plateauing, job skill plateauing and the exploratory, establishment, maintenance and disengagement career stages respectively.

- There is a noteworthy relationship between 'I am advancing in my academic career' and job skill plateauing and the four career stages.

- There is an important relationship with 'I know everything about my academic job' and job content, job skill and personal plateauing and the establishment and disengagement career stages.

- There is an important association between 'My academic job has remained the same over time' and job skill and personal plateauing and the four career stages.

- There is an important association with 'My job skills are transferable to other institutions of higher learning' and job skills and personal plateauing and the disengagement career stage respectively.

- There is an important relationship between 'I opt not to advance at the university due to family considerations' and personal plateauing and the exploration and the establishment career stages.

- There is a significant relationship between 'I do not desire promotion because of additional responsibilities' and personal plateauing and the establishment and maintenance career stages.

- There is a significant relationship between 'Identifying the skills required for this academic job that interests me' and the exploration, establishment, maintenance and the disengagement career stages.

- An important relationship between 'Achieving stability in my academic occupation' and the establishment, maintenance and disengagement career stages.

- A noteworthy relationship exists between ' Getting established in my academic work' and the establishment, maintenance and the disengagement career stages.

- A significant relationship exists between 'Improving my chance of advancement in my current academic occupation' and the establishment, maintenance and disengagement career stages.

- There is a substantial relationship between 'Developing a reputation 
in my academic line of work' and the establishment, maintenance and disengagement career stages.

- There is a significant relationship between 'Advancing to a more responsible position in academia' and the establishment, maintenance and the disengagement career stages.

- An important correlation exists between 'Developing new skills to cope' and the maintenance and disengagement career stages.

- An important link exists between 'Developing new knowledge and/ or skills to help me improve in my academic work' and the maintenance and disengagement career stages.

- There is a substantial connection between 'Avoiding academic occupational pressures I formerly handled more easily' and the disengagement career stage.

Negative values imply an inverse relationship which implies that the variables have an opposite effect on each other. As one increases, the other decreases.

For instance, the correlation value between 'Promotional opportunities have been limited at the university' and 'I am advancing in my academic career' is -0.286 . It can be said that, irrespective of what academic advancements are made by respondents, the opportunities for promotion are limited.

Due to the volume of inverse relationships to report on, the excel spreadsheet features in ANNEXURE 1 for easy reference.

A few inverse relationships are as follows:-

- An inverse relationship exists between 'Promotional opportunities have been limited at the university' and job skill plateauing and personal plateauing.

- An inverse relationship exists between ' $\mathbf{I}$ am advancing in my academic career' and job content plateauing, personal plateauing and the exploration, establishment, maintenance and the disengagement career stages.

- An inverse relationship exists between 'My academic job is challenging' and job content plateauing, personal plateauing and the exploration, establishment and maintenance career stages.

- An inverse relationship exists between 'My academic job has remained the same over time' and job skill plateauing and personal plateauing. 
- An inverse relationship exists between 'I am technically current and updated in my academic skills through seminars and extra training' and personal plateauing and the exploration, maintenance and disengagement career stages.

- An inverse relationship exists between 'I am constantly learning new things on my job' and personal plateauing and the four career stages.

- An opposite association exists amongst 'I like the contents of my job' and the establishment and disengagement career stages.

- An inverse relationship exists between 'I choose not to advance at the university in order to avoid relocating to another UKZN campus site' and the exploratory, establishment, maintenance and the disengagement career stages.

- An inverse relationship exists between 'Choosing a job (in academia) that will really satisfy me' and the disengagement career stage.

\section{CORRELATIONS BY DIMENSIONS}

The following dimensions correlated (ANNEXURE 2) with each other and are as follows:-

\section{- Content and Hierarchical}

The correlation between 'content' items and 'hierarchical' items is 0,169 . This is directly related proportionally. Respondents indicates a significant relationship between 'content' items and 'hierarchical' items.

\section{- Job skills and Content}

The correlation between 'job skill' items and 'content' items is 0,128 . This is directly related proportionally. An important relationship between 'job skills' items and 'content' items exists.

\section{- Personal and Job skill}

The correlation between 'personal' items and 'job skill' items is 0,268 . This is directly related proportionally. At hand, therefore, a valid affiliation between 'personal' items and 'job skills items' exists.

- Establishment and Exploration

The correlation between 'establishment' items and 'exploration' items is 0,658 . This is directly related proportionally. There is therefore a significant relationship between 'establishment' items and 'exploration' items. 


\section{- Maintenance and Exploration}

The correlation between 'maintenance' items and 'exploration' items is 0,636 . This is directly related proportionally. There is therefore a significant relationship between 'maintenance' items and 'exploration' items.

\section{- Maintenance and Establishment}

The correlation between 'maintenance' items and 'establishment' items is 0,632 . This is directly related proportionally. There is therefore a significant relationship between 'maintenance' items and 'establishment' items.

\section{- Disengagement and Exploration}

The correlation between 'disengagement' items and 'exploration' items is 0,308 . This is directly related proportionally. There is therefore a significant relationship between 'disengagement' items and 'exploration' items.

\section{- Disengagement and Establishment}

The correlation between 'disengagement' items and 'establishment' items is 0,387 . This is directly related proportionally. There is therefore a significant relationship between 'disengagement' items and 'establishment' items.

\section{- Disengagement and Maintenance}

The correlation between 'disengagement' items and 'maintenance' items is 0,334 . This is directly related proportionally. There is therefore a significant relationship between 'disengagement' items and 'maintenance' items.

\section{HYPOTHESES}

Hence, it can be concluded the hypotheses of the study have been confirmed:-

Hypothesis 1: There is a significant relationship between career plateau dimensions (structural/hierarchical, job content, job skill and personal/life) and career stages (exploration, establishment, maintenance and disengagement).

Hypothesis 2: There is a significant difference in the perceptions of employees differing on each of the respective biographical variables (age, marital status, job status, tenure, race, gender, education level) and the respective career stages (exploration, establishment, maintenance and disengagement) and the career plateau construct.

The outcomes reflect a significant difference in the perceptions of employees differing on each of the respective biographical variables (age, marital status, 
job status, tenure, race, gender, education level) and the respective career stages (exploration, establishment, maintenance and disengagement) and the career plateau construct.

The results of the study concurs with other research. Research reflects plateaued employees tend to be older compared with non-plateaued employees (Near, 1983; Savery, 1989; Tremblay and Roger, 1993; Tremblay, Roger and Toulouse, 1995). In terms of job occupancy, plateaued employees were more senior than un-plateaued employees (Gould and Penley, 1984; Tremblay and Roger, 1993). Further to this, many studies identified more Blacks than Whites who experience a career plateau (Greenhaus, Callanan \& Godshalk 2007), Milliman 1992).

Organisational sources such as competition (where a person is viewed as lesser competent than someone from the outside); age (an older employee seen as less desirable compared to a younger employee) and organisational need (where an employee is too valued in an individual's present job and cannot be released for an advanced position) are also viewed by Ference et al., (1977) as reasons for plateauing.

A study in schools of education, conducted by Patterson, Sutton, and Schuttenberg (1987) identified an individual's perception of having vocational advancement (that is, not being plateaued) interrelated positively with productivity and career satisfaction. Further, they stated that full or tenured professors (irrespective of status), were in a stronger position than the Professors' junior colleagues to understand plateaued jobs and did not view career plateauing with a reduced output or satisfaction with career accolades. Both plateaued, as well as non-plateaued (those with career mobility) individuals were in a position to attain productivity and work satisfaction. Hypothesis 2 is therefore accepted.

Hypothesis 3: There is a significant variance in career stages due to the career plateau status.

Evidence from the study revealed the variance in career stages was signifycantly expounded by the career plateau status. The results of the study highlighted the various career stages (such as exploration, establishment, maintenance and disengagement) significantly account for the variance in the career plateau status of the respondents.

Previous research concurs in that research comparing plateaued and 
non-plateaued employees displayed key dissimilarities in career concerns pertaining to career phases (Slocum et al., 1988; Stout, 1988). Career stages are experienced with age and the phases the individuals find themselves in, at various stages of their life. They encountered a process of change which may be summarised as the exploration, establishment, maintenance and disengagement life stages (Stead and Watson, 1999). The sources of change are contextualised in the domains individuals exist in, such as biotic, psychosomatic, social, mystical, cultural, fiscal and historical (Schreuder and Theron, 2006). In addition, the person and the location are subject to variation. Hypothesis 3 is therefore accepted.

\section{Conclusion and Recommendations}

The recommendations highlight the themes that have materialised from the study.

- There is a salient relationship with career plateau dimensions (structural/ hierarchical, job content, job skill and personal/ life) and career stages (exploration, establishment, maintenance and disengage ment).

- There is a noteworthy difference in the perceptions of academics differing on each of the respective biographical variables (age, marital status, job status, tenure, race, gender, education level) and the respect ive career stages and the career plateau construct.

- The variance in career stages was meaningfully clarified by the career plateau status. The outcomes of the study highlighted the various ca reer stages (such as exploration, establishment, maintenance and disengagement) that significantly accounted for the variance in the career plateau status of the respondents.

\section{Recommendations}

Key recommendations have been generated from the model (Figure 1) from the study, for the various stakeholders. Recommendations include amongst others, the following. 


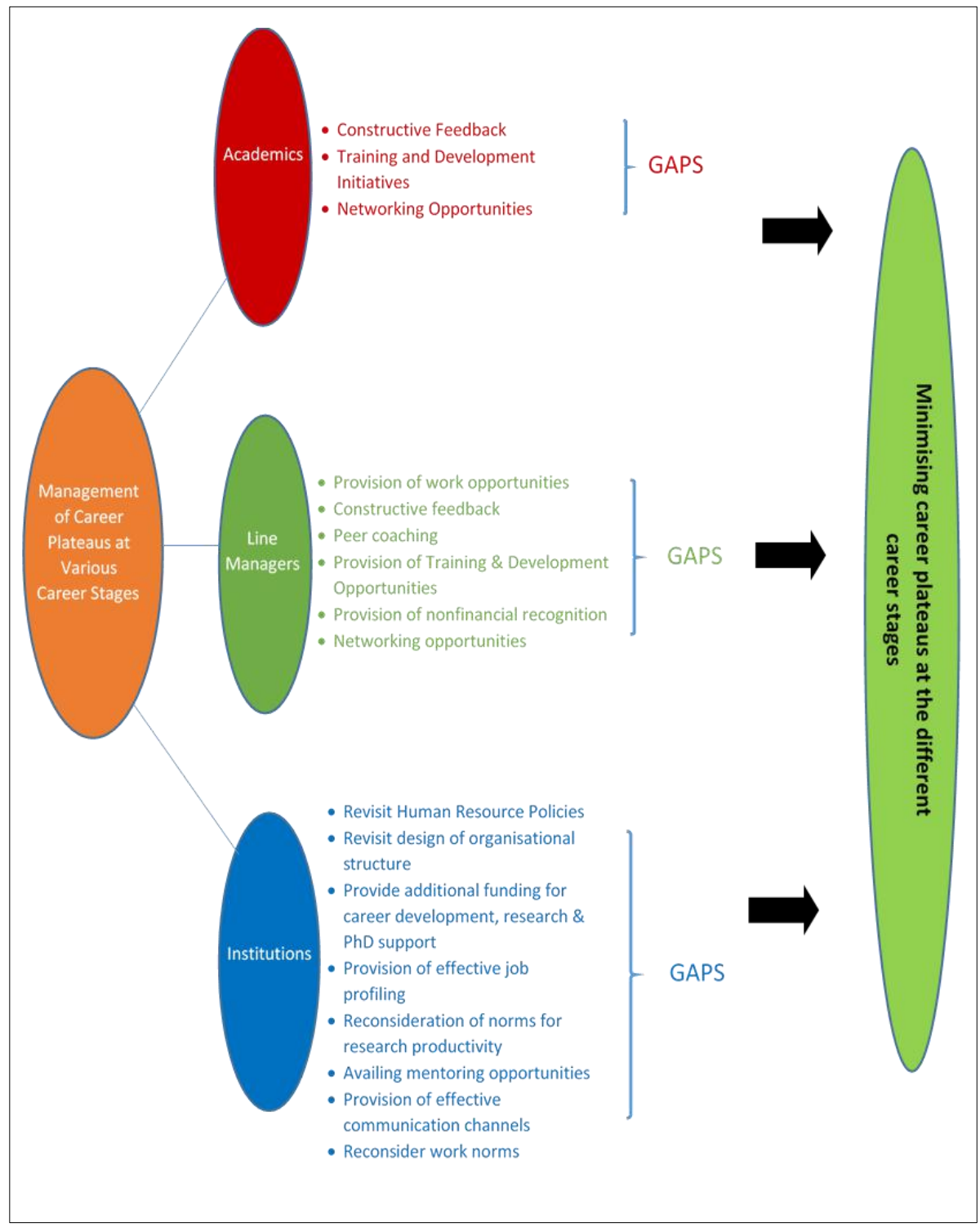

Figure 1: Model of career plateau strategies for relevant stakeholders in academia at various career stages 


\section{Recommendations for Academics \\ Development of Specialised Skills}

Considering the vast changes in $\mathrm{HE}$, more specifically the emphasis on research and publications, academics should become more proactive in terms of acquiring key research skills such as research writing skills and making innovative decisions regarding their careers.

Preceding studies by Tremblay, Roger, and Toulouse (1995) (Lemire, Saba \& Gagnon 1999); Tan and Salomone (1994) concur with the above by stating knowledge of the initial detection of plateauing can prepare employees and therapists to engage in proactive activities (for example, upskilling and expanding interests) and for 'out of the box' strategies associated with vocational planning.

\section{Recommendations for Line Managers Offer Increased Training and Upskilling Opportunities}

The performance management process within the institution provides an avenue for adequate and relevant training and skills development programmes through the personal development plan. The line manager is in a strong position to ascertain the deficiencies identified in the performance management process, in which the academic may require assistance, for example, a statistical package such as SPSS for researchers or a key area of concern as highlighted in the study, that of article/manuscript writing skills.

\section{Provide Exposure for All Your People, Not Merely for the 'Stars'} At the institution, there are high profile academics who contribute significantly to the research output of UKZN. What has been noticed however, as per responses, was the preference of many higher status academics to lecture only at the post-graduate level, thereby leaving the larger, undergraduate classes to junior academics who are still trying to stabilise themselves in research, and as such, need more time to do so.

\section{Recommendations for the Institution} Adjustment of the Promotion Policy

At the institution, despite a uniform and normative set of university-wide criteria for all colleges as a performance rubric for measurement of deliverables 
for promotion, respondents of the study resonated with stringent promotion policy guidelines as a reason for plateauing.

\section{Reduced Workload}

Academics stated unequivocally that they needed more support from the university with regard to their workload, as it was overwhelming. Some responses with regards to this issue include,

Other people often get plateaued because of workload and because they are primarily teaching at undergraduate level - because of the numbers and lack of resources.

From a research perspective, I am sure I have plateaued for 10 years and it is purely because I have no time to actually spend on that because I have an extremely busy work week .... They are always trying to increase our lecture load and I don't just understand why.

Furthermore, credentialing academics also echoed sentiments in terms of wanting a lower/ reduced workload:

It is not that I don't want to do my $\mathrm{PhD}$, I do want to do it but I need to have the time to actually do it properly and I do not want to rush through it and I want to enjoy it.

\section{Recommendations for Future Research}

- A comparative study of national and international HEIs on career plateaus would be interesting, to gauge if similar plateaus were experienced in different countries; and

- More research in the local context is advocated for, since minimal studies have been carried out nationally.

The strategies for the stakeholders are identified as the current gaps. The emphasis in this paper is primarily on the academic domain. The model thus provides a pertinent summary from an academic perspective. 


\section{References}

Allen, T.D., J.E.A. Russel, M.L. Poteet \& G.H. Dobbins 1999. Learning and Development Factors Related to Perceptions of Job Content and Hierarchical Plateauing. Journal of Organisational Behaviour 20,7: 11131137.

\section{https://doi.org/10.1002/(SICI)1099-1379(199912)20:7<1113::AID-} JOB944>3.0.CO;2-7

Alivand, H. \& H. Ebrahimpour 2015. Effects of Career Plateau to the Desire for Professional Development of Staff. Journal of Novel Applied Sciences 4,4: 414 - 417.

Anguera, M.T., A. Blanco-Villasen, J.L. Losada, P. Sa'nchez-Algarra \& A.J. Onwuegbuzie 2018. Revisiting the Difference between Mixed Methods and Multimethods: Is it all in the Name? Springer Nature 52: 2757-2770. https://doi.org/10.1007/s11135-018-0700-2

Badiane, K. 2016. A Study on Career Plateauing, Organisational Commitment and Organizational Citizenship Behaviour of Taiwan-based Expatriates: A Holistic Approach to International Mobility. International Journal of Human Resources Studies 6,2: 134 - 167.

Babbie, E. 2014. The Basics of Social Research. $6^{\text {th }}$ Edition. Wadsworth: Cengage Learning. https://doi.org/10.5296/ijhrs.v6i2.9254

Bardwick, J.M. 1987. How Executives Can Help 'Plateaued' Employees. New York: American Management Review 76,1: 40 - 46.

Barkhuizen, E.N., S. Rothmann \& M.Y. Tytherleigh 2004. A Model of Workrelated Health of Academic Staff in a South African Higher Education Institution. Manuscript submitted for publication.

Bellamy, S., C. Morley \& K. Watty 2003. Why Business Academics Remain in Australian Universities Despite Deteriorating Working Conditions and Reduced Job Satisfaction: An Intellectual Puzzle. Journal of Higher Education Policy and Management 25,1: 13 - 28. https://doi.org/10.1080/13600800305740

Brooks, D.K. 1994. Measuring Career Stage. Human Resources Management Review 4,4 .

Bryman, A. \& E. Bell 2014. Research Methodology: Business \& Management Context. UK: Oxford University Press.

Burke, R.J. 1989. Examining the Career Plateau: Some Preliminary Findings. Psychological Report 65: 295 - 306.

https://doi.org/10.2466/pr0.1989.65.1.295 
Cable, D.A.J. 1999. Plateau and Transition: Career Dynamics in a Changing World. Masters dissertation. Massey University.

Chao, G.T. 1990. Exploration of the Conceptualisation and Measurement of Career Plateau: A Comparative Analysis. Journal of Management 16,1: 181-193. https://doi.org/10.1177/014920639001600113

Chetty, R. \& S. Pather 2015. Challenges in Higher Education in South Africa. In Condy, J. (ed.): Telling Stories Differently: Engaging $21^{\text {st }}$ Century Students through Digital Story Telling. Stellenbosch: SUN MeDIA.

Choudray, S.A., M. Ramzan \& A. Riaz 2013. Strategies for Career Plateaus: An Empirical Investigation of Organisations in Pakistan. Interdisciplinary Journal of Contemporary Research in Business 4,9: 712 - 726.

Choy, R., M. Savery \& K. Lawson 1998. Employee Plateauing: Some Workplace Attitudes. Journal of Management Development 17,5: 1-8. https://doi.org/10.1108/02621719810210983

Coetzee, M. 2015. Employees' Psychosocial Career Preoccupations in Relation to their Work-related Commitment. South African Business Review 19,3: 30 - 47.

Coetzee, M. \& A.M.G. Schreuder 2015. Careers - An Organisational Perspective. $5^{\text {th }}$ Edition. Cape Town: Juta Legal and Academic Publishers. Condy, J. 2015. Telling Stories Differently. Engaging $21^{\text {st }}$ Century Students through Digital Story Telling. Stellenbosch: SUN MeDIA.

https://doi.org/10.18820/9781920689865

PMid:25672915 PMCid:PMC4699670

Cook, S.L. 2015. Redirection: An Extension of Career During Retirement. The Geontologist 55,3: 360 - 373,

Cuthbert, P.F. 1996. Managing Service Quality in Higher Education: Is SERVQUAL the Answer? Managing Service Quality: An International Journal Part 1,6,2: 11 - 16. https://doi.org/10.1108/09604529610109701 Crawshaw, J.R., R. van Dick \& F. Brodbeck 2012. Opportunity, Fair Process and Relationship Value: Career Development as a Driver of Proactive Work Behaviour. Human Resource Management Journal 22,1: 4 - 20.

Creswell, J.W. 2015. A Concise Introduction to Mixed Methods Research. Thousand Oaks: Sage.

Dawson, C. 2002. Practical Research Methods: A User-friendly Guide to Mastering Research Techniques \& Projects. Oxford: How to Books Ltd. Department of Education (DoE) White Paper 1997. Government Gazette. 15 August 1997. 
Duffy, J.A. 2000. The Application of Chaos Theory to the Career-Plateaued Worker. Journal of Employment Counselling 37,4: 229-236.

https://doi.org/10.1002/j.2161-1920.2000.tb01029.x

Feldman, D.C. \& B.A. Weitz 1988. Career Plateaus in the Salesforce: Understanding and Removing Blockages to Employee Growth. Journal of Personal Selling and Sales Management 8: 23-32.

Greene, J.C. 2015. Preserving Distinctions within the Multimethod and Mixed Methods Research Merger. In Hesse-Biber, S.N., R.B. Johnson (eds.): The Oxford Handbook of Multimethod and Mixed Methods Research Inquiry. Oxford: Oxford University Press.

https://doi.org/10.1093/oxfordhb/9780199933624.013.37

PMCid PMC5675203

Greenhaus, J.H., G.A. Callanan \& V.M. Godshalk 2007. Career Management. USA: Thomson-South Western.

Heslin, P.A. 2005. Conceptualizing and Evaluating Career Success. Journal of Organizational Behavior 26:113 - 136. https://doi.org/10.1002/job.270

Hess, N. \& D.M. Jepsen 2008. The Psychological Contract: Investigation and

Career Stage differences. Academy of Management Annual Meeting Proceedings 1-6. https://doi.org/10.5465/ambpp.2008.33716874

Higher Education South Africa's Office Response to the National Development Plan Vision for 2030. https://www.usaf.ac.za/wpcontent/uploads/2017/08/2012_HESA_Response-to-National-

Development-Plan_-May.pdf

Islam, N., M. de Beer, F. Slack 2015. E-Learning Challenges Faced by Academics in Higher Education: A Literature Review. Sheffield Hallam University. https://doi.org/10.11114/jets.v3i5.947

Hess, N. \& D.M. Jepsen 2008. The Psychological Contract: Investigation of Generational and Career Stage Differences. Academy of Management Proceedings 2008,1: 2151 - 6561.

HESA. Higher Education Challenges: Presented by Higher Education South Africa (HESA) 2014. Higher Education and Training (Accessed 24 May 2019).

https://doi.org/10.1044/leader.PPL.24052019.24

Jansen, J.D. 2004. Autonomy and Accountability in the Regulation of the Teaching Profession: A South African Case Study. Pretoria: University of Pretoria, South Africa.

Joseph, J. 1996. An Exploratory Look at the Plateauism Construct. Journal of 
Psychology 130: 237-244.

https://doi.org/10.1080/00223980.1996.9915005

Jung, J. \& J. Tak 2008. The Effects of Perceived Career Plateau on Employee Attitudes Moderating Effects of Career Motivation and Perceived Supervisor Support with Korean Employees. Journal of Career Development 35,2: 187 - 201. https://doi.org/10.1177/0894845308325648 Kaur, K. \& H.S. Sandhu 2010. Career Stage Effect on Organisational Commitment: Empirical Evidence from the Indian Banking Industry. International Journal of Business and Management 5,12: 141 - 152. https://doi.org/10.5539/ijbm.v5n12p141

Koivisto, P. 2010. Preparing for Work Life: Effects of Group Counselling on Adolescents' Career Development and Mental Health. People \& Work 92: $14-25$.

Lam, S.S.K., T.W.H. Ng, \& D.C. Feldman 2012. The Relationship between External Job Mobility \& Salary Attainment Across Career Stages. Journal of Vocational Behaviour 80,1: 129-136.

https://doi.org/10.1016/j.jvb.2011.05.002

Lapalme, M.E., M. Tremblay \& G. Simard 2009. The Relationship between Career Plateau, Employment Commitment and Psychological Distress: the Role of Organisational Supervisor Support. International Journal of HRM 20,5: 1132 - 1145. https://doi.org/10.1080/09585190902850323

Lee, P.C.B. 1999. Career Plateaus and Professional Plateaus: Impact on Work Outcomes of Information Technology Professionals. AMC SIGCPR Computer Personnel 20,4: 25 - 38.

https://doi.org/10.1145/571475.571478

Lemire, L., T. Saba, Y.C. Gagnon. 1999. Managing Career Plateauing in the Quebec Public Sector 1999. Public Personnel Management 28,3: 375 391. https://doi.org/10.1177/009102609902800305

MacGregor, K. 2015. 50\% Higher Education Participation in 50 Years Summit. University World News Global Edition 358: 1 - 8.

Mafenya, P.N. 2014. Challenges Faced by Higher Education Institutions in Research Skills Development: A South African Open and Distance Learning Case Study. Mediterranean Journal of Social Sciences 5,4: 436 - 442. (Institute for Open and Distance Learning, University of South Africa.)

Makki, B.I., R. Salleh, M.A Memon \& H. Harun 2015. The Relationship Between Work Readiness Skills, Career Self-efficacy and Career 
Exploration among Engineering Graduates: A Proposed Framework. Research Journal of Applied Sciences, Engineering and Technology 10,9: 1007-1011. https://doi.org/10.19026/rjaset.10.1867

McCleese, C.S. \& L.T. Eby 2006. Reactions to Job Content Plateaus: Examining Role Ambiguity and Hierarchical Plateaus as Moderators. The Career Development Quarterly 55,1: 64 - 76. https://doi.org/10.1002/j.2161-0045.2006.tb00005.x

McKernan, J.A. 2008. Curriculum and Imagination: Process Theory, Pedagogy and Action Research. London: Routledge.

https://doi.org/10.4324/9780203946930 PMCid:PMC2013908

Miao, C.F., D.J. Lund \& K.R. Evans 2009. Re-examining the Influence of

Career Stages on Salesperson Motivation: A Cognitive and Affective Perspective. Journal of Personal Selling \& Sales Management 29,3: 243 - 255. https://doi.org/10.2753/PSS0885-3134290303

Miles, S. 2010. Job Satisfaction, Perceived Career Plateau, and the Perception of Promotability: A Correlational Study in Television Media. Doctoral dissertation. Walden University.

Milliman, J.F. 1992. Causes, Consequences and Moderating Factors of Career Plateauing, Unpublished Doctoral Dissertation, University of Southern California

Murchinsky, P.M., H.J. Kriek \& D. Schreuder 2005. Personnel Psychology. South Africa: Oxford University Press.

National Planning Commission 2012. National Development Plan 2030 - Our

Future: Make it Work. Pretoria: Government Printers. Available at:

http://www.dac.gov.za/sites/default/files/NDP\%202030\%20-

\%200ur\%20future\%20-\%20make\%20it\%20work 0.pdf

National Planning Commission 2012. Improving Education, Training and Innovation. Available at:

https://nationalplanningcommission.wordpress.com/improvingeducation-training-and-innovation/

Near, J.P. 1985. A Discriminant Analysis of Plateaued Vs Non-Plateaued Managers. Journal of Vocational Behaviour 26: 74-91.

https://doi.org/10.1016/0001-8791(85)90017-X

Nwovuhoma, I.L. \& M.A. Malik 2016. Career Plateau and Teacher Productivity in Rivers State Secondary Schools. Indian Journal of Applied Research 6,3: 644 - 648. 
Patterson, L.E., R.E. Sutton \& E.M. Schuttenberg 1987. Plateaued Careers, Productivity, and Career Satisfaction of College of Education Faculty. The Career Development Quarterly 35,3: 197 - 205.

Philippou, J. 2014. Employers' and Employees' Views on Responsibilities for Career Management in Nursing: A Cross-sectional Survey. Journal of Advanced Nursing 71,1: 78-89.

https://doi.org/10.1111/jan.12473 PMid:24996050

Robyn, A. and R. Du Preez. 2013. Intention to Quit amongst Generation Y Academics in Higher Education. SA Journal of Industrial Psychology/ SA Tydskrif vir Bedryfsielkunde 39,1: a1106.

https://doi.org/10.4102/sajip.v39i1.1106

Saleem, S., and Amin, S. 2013. The Impact of Organisational Support for Career Development and Supervisory Support on Employee Performance: An Empirical Study from Pakistani Academic Sector. European Journal of Business and Management 5,5: 194-207.

Salami, S.O. 2010. Career Plateauing and Work Attitudes: Effects of Mentoring with Nigerian Employees. Europe's Journal of Psychology 6,4: 499 - 508. https://doi.org/10.5964/ejop.v6i4.224

Santos, G.G. 2016. Career Barriers Influencing Career Success: A Focus on Academics' Perceptions and Experiences. Career Development International 21,1: 60 - 84

Sekaran, U. and Bougie, R. 2010. Research Methods for Business: A Skill Building Approach. USA: John Wiley \& Sons.

Schreuder, A.M.G. \& A.L. Theron 2006. Careers: An Organisational Perspective. South Africa: Juta \& Co.

Shaw, R.B. \& M.M. Chayes 2011. Moving Up: Ten Questions for Leaders in Transition. Leader to Leader 59: 39 - 45.

Smart, R.M. 1994. Super's Stages and the Four Factor Structure of the Adult Career Concerns Inventory in an Australian Sample. Measurement \& Evaluation Counselling \& Development. (American Counseling Association) 26,4: 1 - 21.

Smith, T. 2006. Climbing the Corporate Ladder: What Happens after you have Reached the Top? Australia - New Zealand Academy of Management Conference 1 - 11.

Smith-Ruig, T. 2009. Exploring Career Plateau as a Multi-faceted Phenomenon: Understanding the Types of Career Plateaux Experienced 
by Accounting Professionals. British Journal of Management 20,4: 610 622. https://doi.org/10.1111/j.1467-8551.2008.00608.x

Sorizehi, Z., A. Samadi, R. Sohrabi \& N. Kamalipoor 2013. Studying the

Relationship between Plateauing in Career Progression Path with Personnel Burnout. Interdisciplinary Journal of Contemporary Research in Business 5,3: 627 - 638.

Slocum, J.W. Cron, W.L. and Hansen, RW. 1985. Business Strategy and the

Management of Plateaued Employees. Academy of Management Journal 28,1: 133-154. https://doi.org/10.2307/256065

Stead \& Watson 1999 Stead, G.B \& Watson, M.B. 1996 (a). Career research

in South Africa: Challenges for the future. Journal of Vocational Behaviour, 52,289-299

Sthapit, A. 2010. Managing Career Plateaus and Burnouts: A Strategic

Measure. SSRN Electronic Journal 1,1: 1 - 4.

https://doi.org/10.2139/ssrn.2916640

Sturges, J. 2008. All in a day's work? Career Self-management and the Management of the Boundary between Work and Non-work. Human Resource Management Journal 18,2: 118 - 134.

https://doi.org/10.1111/j.1748-8583.2007.00054.x

Tabarsa, G. and Nazari, A. J. 2016. Examining the Moderating Role of Mentoring Relationship in between Content Plateauing with Job Satisfaction and Willingness to Leave the Organization. (Case Study: Iran Ministry of Industry, Mines \& Trade.) Indian Journal of Science \& Technology 9,7: 1 - 8. https://doi.org/10.17485/ijst/2016/v9i7/87858

Tan, C.S. \& P.R. Salomone 1994. Understanding Career Plateauing: Implications for Counselling. The Career Development Quarterly, 42,4: 291 - 301. https://doi.org/10.1002/j.2161-0045.1994.tb00513.x

Tashakkori, A., C. Teddie 2010. Putting the Human Back in 'Human Research Methodology': The Researcher in Mixed Methods Research. Journal of Mixed Methods Research 4,4: 271 - 277.

https://doi.org/10.1177/1558689810382532

Themba, M.A. 2012. Exploring Sociodemographic Differences in Career Maturity in the South African Military. Masters Dissertation. South Africa: University of South Africa.

Themba, M.A., R.M. Oosthuizen \& M. Coetzee 2012. Exploring Sociodemographic Differences in Career Maturity in the South African Military. South African Journal of Labour Relations 36,1: 8-30. 
Tremblay, M. \& A. Roger 2004. Career Plateauing Reactions: The Moderating Role of Job Scope, Role Ambiguity and Participation among Canadian Managers. Journal of Human Resource Management 15,6: 996 - 1017. https://doi.org/10.1080/09585190410001677287

The National Science and Technology Forum. www.nstf.org.za

(Accessed on 23 May 2019.)

UKZN. Vice Chancellor's Communique. 8 August 2017.

Vermeulen, L. 2015. Career Anchors and Work Behavioural Style for Career

Management in the South African Public Service. European Scientific Journal 11,14: 1857 - 7881.

Vice Chancellor's Communique. September 2017. University of KwaZuluNatal.

Warren, E.K., T.P. Ference \& J.A.F. Stoner 1977. Managing the Career

Plateau. Academy of Management Review 2,4: 602 - 612.

https://doi.org/10.5465/amr.1977.4406740

Weiner, A., R. Remer \& P. Remer 1992. Career Plateauing: Implications for

Career Development Specialists. Journal of Career Development 19,1: 37

- 48. https://doi.org/10.1177/089484539201900104

Welman, J.C., S.J. Kruger \& B. Mitchell 2008. Research Methodology. South Africa: Oxford University Press.

Wessels, J.S. 2008, Transforming the Public Service to Serve a Diverse Society: Can Comprehensiveness be the Most Decisive Criterion? Politeia - Journal for Political Science and Public Administration 27,3: $21-36$.

Zeffane, R. \& G. Mayo 1994. Planning for Human Resources in the 1990s: Development of an Operational Model. International Journal of Manpower 15,6: 36 - 56. https://doi.org/10.1108/01437729410065335 
Anisha Ramsaroop

\section{ANNEXURE 1 \\ CORRELATIONS}

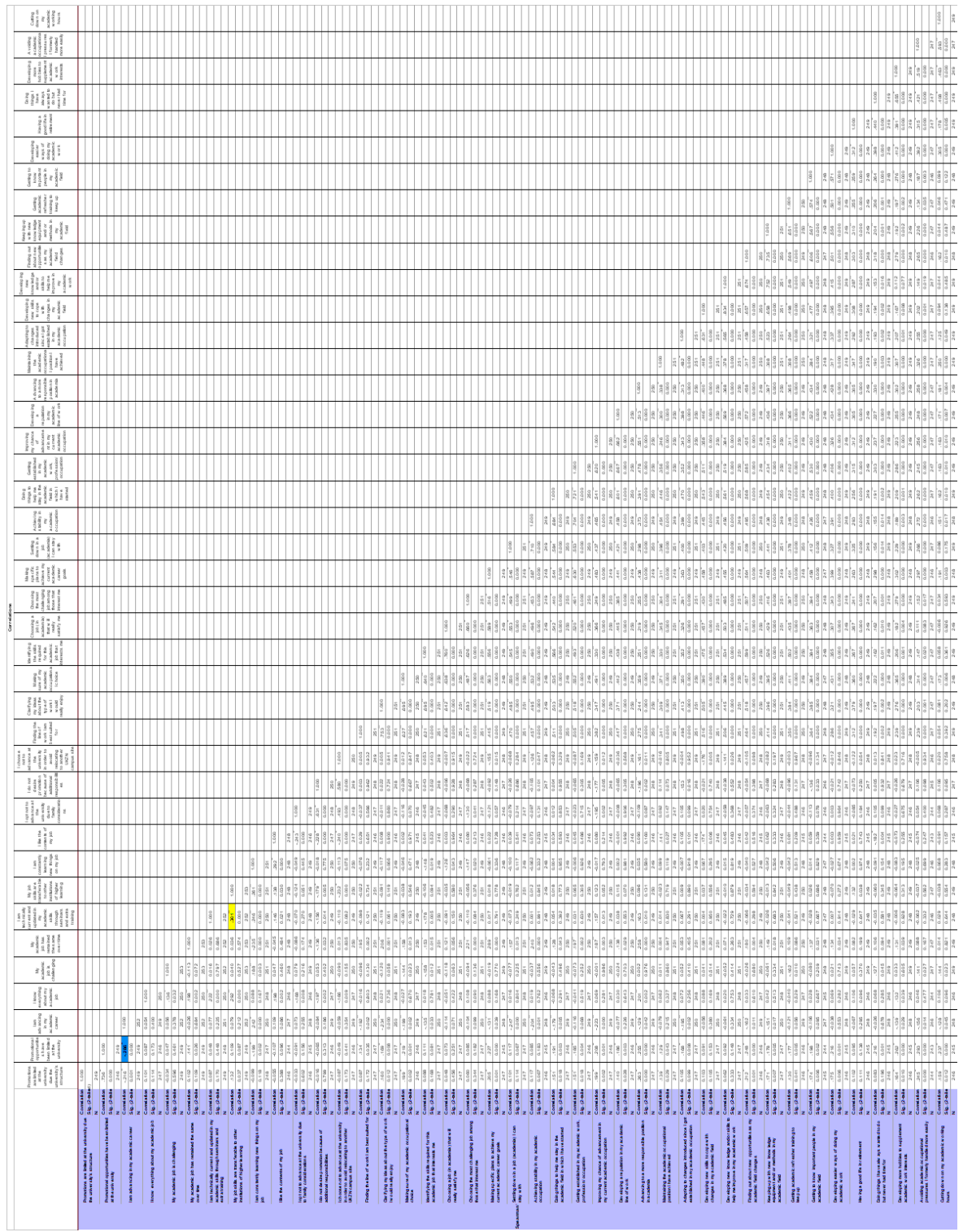


Career Plateaus and Career Stages at University

ANNEXURE 2

\section{CORRELATIONS BY DIMENSIONS}

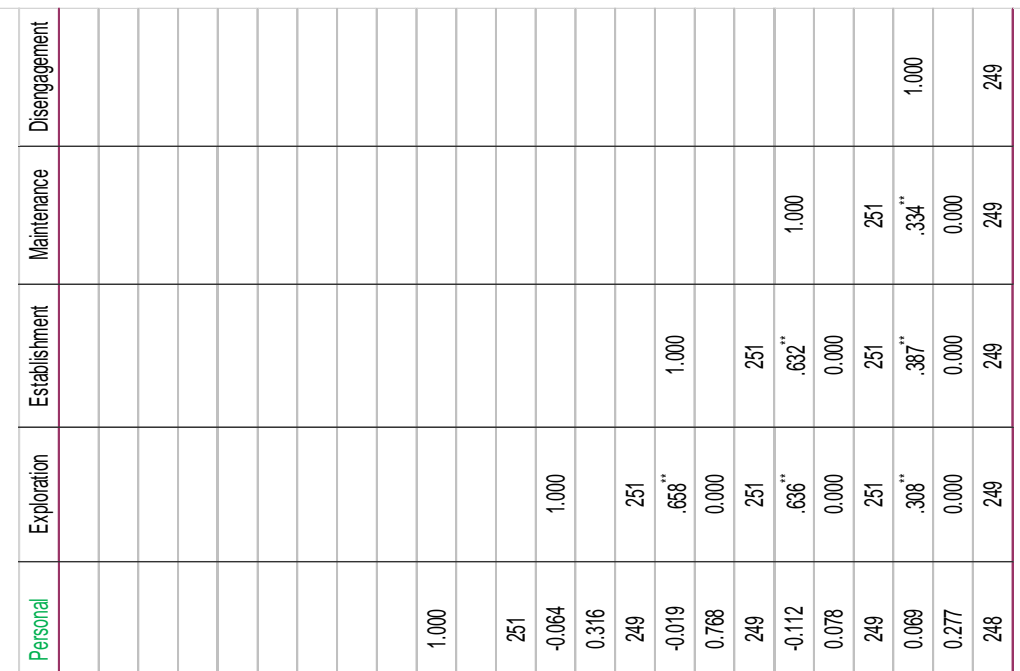

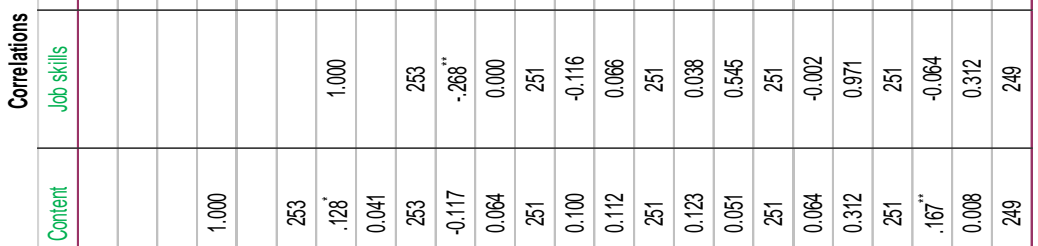

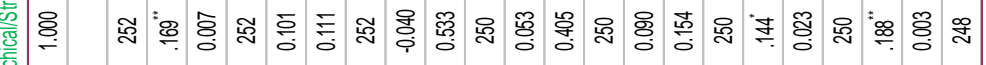

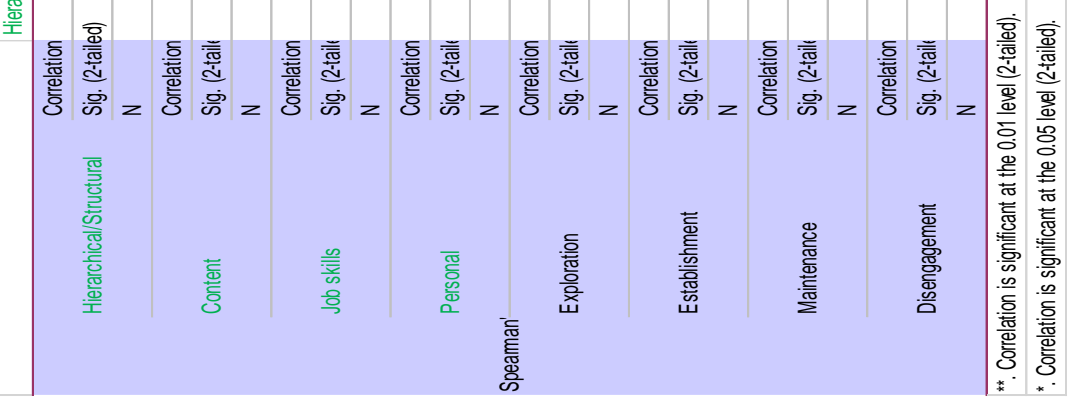


Anisha Ramsaroop

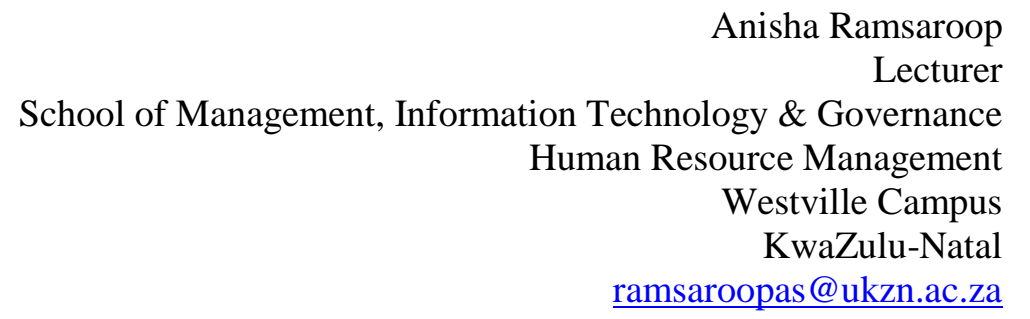




\title{
Socially Responsive Curriculum: Powerful Knowledge in the Marketing Curriculum in South Africa
}

\section{Devika Pillay \\ ORCID iD: https://orcid.org/0000-0002-5849-0554}

\begin{abstract}
There is a growing consciousness of sustainability in relation to the concern for people and the planet. Consequently, the call for a socially responsive curriculum aligned within the paradigm of a sustainability ethos becomes integral to curriculum transformation in higher education institutions. A socially responsible curriculum is explored in the context of the marketing discipline that is entrenched in a dominant social paradigm. This dominant social paradigm is juxtaposed against Critical Marketing Theory that promulgates the need for marketing curriculum transformation. The need for the inclusion of the sustainability marketing approach is interrogated through highlighting the existing historical, powerful and dominant epistemological context of marketing knowledge found in prescribed textbooks of higher education institutions. This becomes the focal point in signalling a departure from a purely performance-based marketing ideology to incorporate new forms of knowledge through curriculum transformation.
\end{abstract}

Keywords: Critical Marketing Theory, curriculum transformation, dominant social paradigm, marketing sustainability, performance-based ideology, socially responsive curriculum

\section{Introduction}

Within the backdrop of a growing sustainability consciousness, the marketing ideology would require fundamental transformation. 
This would be a compelling case to understand the existing ideological context of the Marketing Theory and to interrogate what transformation should occur in the Marketing Theory. The 'marketing concept' derived from neoclassical economics, is founded on the principle that all decisions in marketing are guided by demand, thereby providing economic and social validity for a firm to exist (Varey 2010). The marketing concept is, therefore, a representation of the Marketing Theory which is founded primarily on the promotion of consumer needs.

Within the context of the marketing concept, the 'Dominant Social Paradigm (DSP)' characterised by political, technological, and economic dimensions (among others) has dominated Marketing Theory (Kilbourne \& Carlson 2008; Kilbourne et al, 2002). This resulted in consumer purchase behaviour being associated with individual growth within an economic system of exchange that ironically benefitted the firm's interest. This was supported by Stubbs and Cocklin (2008), who highlighted that the DSP served to legitimise a performance-based ideology of marketing to encourage economic growth (within a neoclassical dominant worldview) for firm success through purchaser consumption.

However, there have been challenges made to mainstream marketing and consumer theory through locating phenomena in social, political and historical contexts to expose embedded power relations and ideologies (Cova et al. 2013). These challenges can be considered criticisms levelled at the limited (economic) theoretical foundation of the discipline. In response to these criticisms, Critical Marketing Theory emerged as an ideological defence of the Marketing Theory. Critical Marketing Theory was an attempt to make visible, power relations that characterised the dominant social paradigm of the marketing theory and to diminish the focus on satisfying consumer needs (Tadajewski 2010a; Tadajewski 2010b; Tadajewski 2008; Tadajewski \& Brownlie 2008; Brownlie 2006).

However, from the Critical Marketing Theory background, the marketing discourse that discovers the impact of power relations, and social, political and historical contexts in relation to academics and the marketing curriculum, is an area for further investigation. The problem highlighted here, reflects on the interplay of power with regard to the existing marketing curriculum and the role of academics in the marketing curriculum transformation in a socially responsive context. The marketing curriculum offers an example of the ways in which the authority (power) of the curriculum 
'deagentises' academics and makes them technocrats or implementers. This is an area where the issue of the marketing ideology can be debated, contested, or even harmonised.

\section{Literature Review}

Foucault (1981), as cited in (Fougère \& Skålén 2012), views power as discursive and embedded within scientific forms of knowledge that are considered to be the truth. The marketing discourse would therefore be subject to such embedded power, and marketing knowledge would be considered the truth. Whilst sovereign power is exhibited visibly, discursive power and knowledge power is not readily observed. Foucault (1981) as cited in (Fougère \& Skålén 2012), has also linked discourses with subjectivity, which is not reduced to the individual itself, but is based on discourse. Therefore, the power/knowledge that would reside in discourses such as marketing managerialism is not just enduring beliefs of power holders, but is reproduced by universities that are actors in the form of power and knowledge, hence upholding avenues of viewing the world (Fougère \& Skålén 2012).

In trying to encapsulate the dominant social paradigm of the marketing discipline, underpinned by the 'marketing concept', academics in the marketing discipline have been very efficient in promoting theoretical concepts such as the 4Ps, namely product, price, place and promotion. There has been limited consideration within the marketing curriculum given to issues such as theimpacts of marketing on the planet, the influence of marketing on consumption ideology or even sustainability. Difficult issues such as race, class, gender, as well as sources and consequences of social objectification, are issues to consider in a classroom, to highlight democracy as praxis (Pautz 2010).

Greene's (1978) emphasis on 'transcendence' in Landscapes of Learning, highlights the importance of understanding one's experiences within their landscapes and to use this as a way of creating social change and connecting to a moral life. Perhaps, in this regard, the marketing curriculum has emphasised the importance of profiteering and taken for granted how the discipline emphasises customer satisfaction built through the mechanism of purchasing products and promoting the need for ownership. This is the message that is communicated to customers and it is what is taught to students as part of their marketing curriculum. 
There is a growing sense of powerlessness that leads to numbness with regards to moral and ethical issues (Pautz 2010). Being powerless contributes to a failure in understanding how the impact on a broader social and ecological level has not been considered in the landscapes of the marketing discipline, including marketing practice. Hence, the nature of knowledge and how this may have influenced the development of a socially responsive marketing curriculum is important and would need to be explored though understanding marketing in a historical context.

\section{The Historical Context of the Marketing Theory: ' 4 Eras of Marketing Thought'}

Historically, marketing as a discipline has moved through various phases that have impacted on its academic discourse. Consequently, understanding the characteristics of these phases may provide insight into the choices academics make in adopting a marketing curriculum orientation. Wilkie and Moore (2012) refer to the '4 Eras of Marketing Thought' that they developed in 2003, to provide a historical context for marketing. These 'Eras' are represented in Table 1 below.

\section{Table 1: The '4 Eras of marketing thought'}

\begin{tabular}{|c|c|}
\hline Era & Distinctive characteristics \\
\hline $\begin{array}{l}\text { (Before 1900) 'Pre- } \\
\text { Marketing' }\end{array}$ & $\begin{array}{l}\text { - There exists no field of study to distinguish } \\
\text { it, as the issues related to it are entrenched in } \\
\text { the field of economics. }\end{array}$ \\
\hline $\begin{array}{l}\text { I. 'Founding the field } \\
\text { of marketing' } \\
(1900-1920)\end{array}$ & $\begin{array}{l}\text { - Marketing is emphasised as distribution } \\
\text { - Emphasis is on defining the purview of } \\
\text { marketing's activities as an economic } \\
\text { institution (derived from the field of } \\
\text { economics). } \\
\text { - First courses are developed with the title } \\
\text { 'marketing'. }\end{array}$ \\
\hline $\begin{array}{l}\text { II. 'Formalising the } \\
\text { field' }(1920-1950)\end{array}$ & $\begin{array}{l}\text { - There is general acceptance and } \\
\text { development of the 'foundations' or } \\
\text { 'principles of marketing'. }\end{array}$ \\
\hline
\end{tabular}




\begin{tabular}{|c|c|}
\hline & $\begin{array}{l}\text { Knowledge development infrastructure is } \\
\text { established for the field: professional } \\
\text { association (American Association of } \\
\text { Marketing ), conferences, journals (Journal } \\
\text { of Retailing and Journal of Marketing). }\end{array}$ \\
\hline $\begin{array}{l}\text { III. 'A paradigm Shift } \\
\text {.. Marketing, } \\
\text { Management and the } \\
\text { Sciences' (1950- } \\
\text { 1980) }\end{array}$ & $\begin{array}{l}\text { - USA experiences mass market growth and } \\
\text { an expanded marketing body of thought. } \\
\text { Two standpoints are developed to dominate } \\
\text { the marketing mainstream: } \\
\text { (1) The 'managerial viewpoint' } \\
\text { (2) The behavioural and quantitative } \\
\text { sciences as avenues to future knowledge } \\
\text { development. } \\
\text { Knowledge infrastructure is expanded and } \\
\text { evolves in line with these changes Journal } \\
\text { of the Academy of Marketing Sciences } \\
\text { begins in 1973). }\end{array}$ \\
\hline $\begin{array}{l}\text { IV. 'The Shift } \\
\text { Intensifies: A } \\
\text { Fragmentation of the } \\
\text { Mainstream' (1980 } \\
\text { - present) }\end{array}$ & $\begin{array}{l}\text { - New tasks emerge in the business world: } \\
\text { short-term financial focus, downsizing, } \\
\text { globalisation, re-engineering. } \\
\text { The main perspectives are criticised in the } \\
\text { philosophy of science debates. } \\
\text { 'Publish or perish' mindset exists, } \\
\text { academics are pressurised. } \\
\text { - Expansion and diversification of knowledge } \\
\text { infrastructure is seen in specialised interest } \\
\text { areas. }\end{array}$ \\
\hline
\end{tabular}

\section{Source: Wilkie and Moore (2012: 55)}

In Table 1, the names of the four eras are represented in the first column; however, the 'Pre-Marketing' era should be noted. This period signified the absence of marketing as a disciplinary field of study. The American Association of Marketing (AMA) and the Journal of the Academy of Marketing Science (JAMS), are represented only by their acronyms in Table 1. Each of 
the four eras is also described in the table in terms of the defining characteristics of marketing during that period.

The contribution of the ' 4 eras of marketing thought' is the proposed link it made to the role of marketing beyond existing Marketing Theory. Specifically, Wilkie and Moore (2012) extended the role of marketing scholarship to include societal concerns. The major contributions to the Marketing Theory are outlined through the descriptions offered in Table 1.

\section{A Characteristics of the 'Eras'}

The movement of marketing from an unknown discipline in the 'premarketing' era to becoming a discipline moulded according to economic principles in the first era is significant. This characterised the theoretical foundations of the marketing discipline as an economic discourse and marketing activities as economic functions. A position which is supported by Wilkie and Moore's (2012; 2006), assertion that knowledge generation of marketing through economics journals gave rise to the commodity approach (all marketing actions engaged in a certain category), the institutional approach (operations of specialised marketing agency such as wholesaler or broker), and the functional approach (focused on the purpose served by several marketing events).

The movements to the second era signalled the development of marketing as an academic discipline. This period was heralded by the development of marketing knowledge and marketing research. This justified the impetus for the professional representation of marketing through institutions and journals.

The third era placed emphasis on the marketing concept, as population growth increased. The managerial concept of marketing depends on the importance of behavioural and quantitative approaches to the Marketing Theory. The fourth era highlighted the shifts in marketing thought that questioned existing dominant perspectives. The discipline was expanded into specialised areas. This era emphasised the pressure placed on academics to publish marketing knowledge.

The role of societal concerns in marketing scholarship proffered by Wilkie and Moore (2012), offered an extension to the existing academic marketing discourse. The actual link between the movement through the phases and the specific response of academics to include this as part of the 
marketing curriculum is unclear. Specifically, the movements through various phases does not account for how power and academic agency evolved as the marketing academic discourse evolved.

The inclusion of societal concerns in the marketing curriculum should be further interrogated through a deeper understanding of power and the manage-rialistic ideology of the academic marketing discourse that is seen to be dominant in the eras of the marketing academic discourse.

\section{B Power and Managerialism}

The managerialistic ideology of the Marketing Theory in Fougère and Skålén (2012) is problematised in the context of Foucalt's work on power. Managerialism is ideologically underpinned by the marketing concept or 'customerism' in the case of Skålén et al. (2008) and is consequently reproduced in the academic marketing discourse. Customerism relates to the organisational context for serving customers and the obligation of organisation members to do so. This provided an interesting perspective as the ideology of marketing presented in critical marketing literature is often based on the standpoint of the consumer. Marketing Theory has been admonished for promoting consumption as a way of life through various examples of Critical Marketing Theory.

Consumer culture theory (CCT), proposed by Arnould and Thompson (2005), is a form of consumer research that highlights the cultural elements of consumption. Another example is the macromarketing perspectives that criticised the DSP for promoting individual self-interest (Kilbourne et al. 1997). Stakeholder theory placed value on relationships that a firm has with its external stakeholders in pursuing Corporate Social Responsibility (CSR) goals (Brower \& Mahajan 2012) and anti-globalisation movements which drew largely from Marxist ideas, critiqued marketing as usually not serving the requests of poor people, countries and indigenous cultures (Witowski 2005). The ideology of marketing is viewed differently in the case of Fougère and Skålén (2012) whose focus has been on schools of academic marketing thought that have shaped the managerial Marketing Theory and developed the subjectifying power of the marketing ideology in organisations. This is linked directly to their conceptualisation of the term 'customerism' that referred to the organisation and the organisation's members.

In addition, Foucault's theories of power are used to understand 
ideology, managerialism and subjectification in the Marketing Theory. This is an important departure, because it is focused on the organisational context and the organisational marketer (Fougère \& Skålén 2012). The extension being made here is that academics are members of a university and it would follow that, as marketing academics they would represent the 'marketers' of interpretation (Fougère \& Skålén 2012). Also, the university can be considered the 'organisation' to which they belong. The academics are therefore subjectified by power in curriculum development. The subjectifying power of the managerialist ideology is thereby embedded in the marketing curriculum.

\section{Curriculum and Knowledge}

Young (2013) and Muller (2009), highlighted the epistemological issues relating to truth questions and the reliability of different forms of knowledge and how these problems have philosophical and sociological dimensions. This has also been emphasised by Barnett (2009) who epistemologically focused on the process of knowing and ontologically, on what knowing is.

Luckett (2010) also emphasised the importance of knowledge in curriculum from a social realist tradition and highlights caution in the consideration of Africanisation and contextualisation of the curriculum in higher education. She considered the idea of redefining knowledge in a powerful, decontextualized and abstract way. A focus on what knowledge is important, is inherent in these views about curriculum.

Young (2013) made a case for 'powerful knowledge' in disciplines that fall outside the natural sciences where rules about the concepts of the discipline are debated but have an extent to which the range of meanings can be recognised and made fallible. Such knowledge cannot be considered as general knowledge and is often focused on a discipline. Following on from this, it can be suggested that the specialisations that occur in a university curriculum, such as those that may be found in the marketing curriculum, are based on powerful knowledge that is defined by rules about its content and transmission. This can be seen in the inclusion of specific topics that form part of the official and enacted marketing curriculum. However, what knowledge is important for marketing may be subject to scrutiny in terms of whether the existing powerful knowledge should remain by itself and not include socially responsive knowledge content. This is considered in the next section, in terms of how marketing knowledge occurs within a social context. 


\section{Social Context for Curriculum: Engaging Social Responsiveness}

The idea of questioning what counts as valid knowledge within a changing South African context, has been extended to consider 'social responsiveness' and how this may impact and influence change in teaching and research (Favish \& McMillan). The South African Higher Education White Paper of 1997 and the Ministry of Education's National Plan for Higher Education (2001) highlight the role of education in developing citizenship, as well as that of highly skilled professional and knowledge workers who contribute towards the country's social transformation agenda through social responsibility.

This created the impetus to lean towards a 'scholarship of engagement' that is not purely dedicated to the development of academic theory. At present, universities are committed to providing knowledge and skills to a new generation of scientists in support of government and industry (Gibbons 2006). He further added that the focus placed by universities on disseminating research results in a one directional manner in academic journals does little to change the universities existing role in higher education. They may appear isolated from other stakeholders around them. Hence, Gibbons (2006) calls for a redefining of the social contract between university and society that produces knowledge in multiple ways within what he calls an 'agora' or a 'transactional space'. It is in these spaces that stakeholders external to the university and academics can all collaborate in the valuable exchange of learning in an environment of problem generating and problem-solving (Gibbons 2006).

Considering the deeply divided, impoverished society bequeathed to South Africa by apartheid (Ensor 2004), this placed responsibility on universities to consider the type of graduates they produce and what pedagogical practices can help in also providing indigenous knowledge "1 that is contextually relevant. Therefore, the significance of social responsiveness in the consideration of what knowledge is produced and how it can be engaged in marketing curriculum transformation needs to be considered. Hence, the four themes of social responsiveness in curriculum as espoused by Favish and McMillan (2009: 173) decided the theoretical and conceptual framing of this study.

${ }^{1}$ African countries often stress the importance of their own knowledge in contrast to the knowledge that is commonly based on Western ideologies (Paden 2007). 
These themes include:

1. Contextualising the curriculum in relation to an obligation to produce graduates with the knowledge and competencies to face the issues in the South African society.

2. The leading epistemologies and practising models of knowledge generation that propagates from local knowledge, and university-local community collaboration.

3. Facilitating the interface between theory and practice.

4. Transforming the curriculum to reflect new notions of professional practice.

The interesting components of the social responsiveness approach lies in its participatory approach to developing theoretical knowledge that defines academic scholarship beyond unilateral dimensions of existing knowledge. Most noteworthy, are its actionable elements of practice that are linked not only to academic theory but also to professional practice. This may serve the marketing discipline well, given the strong practice-oriented component of marketing in a professional context.

The issue of power can be seen to influence the academic marketing discourse in various ways. The implication of this is that it influenced a customer centred view of marketing, whereby marketers were obligated, and in this context academics too, to pursue a managerialist marketing ideology within the marketing curriculum. Through its historical movement, the discipline has maintained this orientation and in the broader context of socially pressing issues this may signal a need for transformation and greater levels of agency on the part of academics to move the discipline forward.

\section{Research Methodology}

A critical approach to research focuses on the context, conflicts and contradicttions in modern society and seeks to be emancipatory, eliminating the reasons for alienation and domination (Maree 2007: 62). These issues when considered in the context of the marketing curriculum would question within its social context, the nature of power. The power dimension would consider how a socially constructed marketing curriculum might result in emancipatory outcomes for students and lecturers. Hence, whose interests are served by the 
curriculum, what type of curriculum would allow for emancipation and social justice, and how power influences the teaching and learning process (Grundy 1987), is inherent in these critical approaches. These sentiments are also echoed by Cohen et al. (2011), who suggest that the justification for a selection of knowledge reveals the ideologies and power in decision making in society and the curriculum and shows how the powerful retain their power through the curriculum. The critical approach will therefore question the ontological assumptions of what constitutes marketing knowledge, as it is represented in the official marketing curriculum.

Against this backdrop, the initial research analysis was done by evaluating prescribed marketing textbooks. The list of prescribed textbooks collected from various higher education institutions in South Africa, which included, the University of South Africa (UNISA); University of Pretoria (UP); University of KwaZulu- Natal (UKZN); Durban University of Technology (DUT); Management College of Southern Africa (MANCOSA); Regent Business School; Oval International Higher Education; University of Cape Town (UCT); University of Stellenbosch (SU) and the University of the Free State (UFS) were evaluated. Tables were used to list prescribed textbooks against the dominant themes that emerged. These themes were derived from reviewing the chapter content lists of the textbooks as well as reviewing the actual chapter contents of these textbooks. Textbooks from each university and higher education institution were obtained via Google Scholar or the University of KwaZulu- Natal's library. It should be noted that some higher education institutions prescribed the same textbooks within their marketing curriculum. Also, the evaluation of textbooks were done for both undergraduate and postgraduate marketing curricula, however, it should be noted that the prescription of textbooks at the post graduate level was not commonplace. Additionally, not all textbooks were obtainable for review and hence, these were excluded.

\section{Research Findings}

A content analysis was done of 74 textbooks utilised in the marketing curriculum of South African higher education institutions. The delineation of the textbooks into undergraduate and post graduate was not the focal point, instead, the emphasis was placed on the content specific aspects of marketing knowledge. The number of textbooks utilised at these various institutions are 
summarised in Table 2. This table revealed that the University of South Africa, the University of Pretoria and The University of Kwazulu-Natal prescribed the highest number of textbooks. However, this should be viewed cautiously, because factors such as larger student populations, more academic marketing offerings in some institutions and the ability to access all textbooks would be limiting factors. However, despite these limitations, a significant number of 74 textbooks were included in the study, and would still provide adequate representation of the actual content of marketing curricula.

\section{Table 2: Summary of textbooks used in South African of Higher Education Institutions}

\begin{tabular}{|l|c|}
\hline $\begin{array}{l}\text { Universities/ Higher Education } \\
\text { Institutions }\end{array}$ & $\begin{array}{c}\text { Number } \\
\text { of } \\
\text { textbooks }\end{array}$ \\
\hline University of South Africa & 25 \\
\hline University of Pretoria & 18 \\
\hline University of KwaZulu-Natal & 12 \\
\hline Durban University of Technology & 4 \\
\hline $\begin{array}{l}\text { Management College of Southern } \\
\text { Africa }\end{array}$ & 1 \\
\hline Regent Business School & 2 \\
\hline $\begin{array}{l}\text { Oval International Higher } \\
\text { Education }\end{array}$ & 2 \\
\hline University of Cape Town & 2 \\
\hline University of Stellenbosch & 1 \\
\hline University of Free State & 7 \\
\hline Total & 74 \\
\hline
\end{tabular}

In the next section, the various themes that emerged from a review of these textbooks are presented.

\section{Thematic Categories of the Textbook Review}

In this analysis 74 textbooks were evaluated. Many textbooks are prescribed at more than one university or higher education institution. The six main themes that emerged included: 


\begin{tabular}{|l|l|}
\hline & Theme 1 - Marketing mix/4Ps of marketing \\
\hline$\square$ & Theme 2 - Sustainability marketing \& ethics \\
\hline$\square$ & Theme 3 - Marketing communications mix \\
\hline$\square$ & Theme 4 - Marketing environments \\
\hline$\square$ & Theme 5 - Market research \\
\hline$\square$ & Theme 6 - Consumer behaviour \\
\hline
\end{tabular}

\section{A Theme 1 -Marketing Mix/ 4Ps of Marketing}

The marketing mix also known as the 4Ps of marketing consisted of product, place, price, and promotion. Product decisions included packaging, labelling, new product development, product types such as convenience, shopping, and speciality products. Place or distribution referred to distribution costs and channels of distribution, namely retailing and wholesaling. Pricing included strategies such as market skimming, penetration, price adjustment, and pricing products based on demand and supply. The last $\mathrm{P}$, promotion, is related to marketing communications. This formed a new theme for this study.

The marketing mix for service marketing differs from the product marketing mix. It includes pricing strategy and distribution such as franchises, agents, and intermediaries. Promotion is not included.

Business to business products have a different marketing mix. It relates to managing products and services, brands in $\mathrm{B} 2 \mathrm{~B}$, and distribution channels which are direct and indirect.

International products follow the traditional marketing mix, product policy differs from country to country. Pricing also differs around the world. International distribution is more complicated as it involves exporting, licensing, strategic alliance, and wholly owned subsidies.

\section{B Theme 2 - Sustainability Marketing \& Ethics}

Sustainability marketing is the behaviour of consumers with regards to sustainable practices. Sustainability marketing has a different set of values, objectives and strategies from traditional marketing. The sustainability marketing mix differs from the traditional marketing mix as it related to consumer solutions, consumer cost, communication, and convenience known as the $4 \mathrm{Cs}$ of marketing. Sustainability branding, sustainability product development, sustainable product life cycle, marketing communications, and 
delivering sustainability is part of sustainability marketing. This needs to be incorporated into marketing, reframing marketing curriculum towards sustainability marketing.

Socially responsible marketing is a new type of marketing that relates to social criticisms of marketing, the target market and the marketing influence on consumers and society. It encompasses enlightened marketing, cause-related marketing, social benefit causes, consumer ethics, corporate social responsibility, and the social marketing mix.

Environmental management includes green marketing and green consumerism, environmentalism, promoting sustainable farming and raising awareness of socio-ecological problems. The physical environment such as natural resources, climate change, energy, pollution, and environmental hazards are foregrounded, with awareness of scarce resources being raised and recycling, non-wasteful packaging, and the use environmentally friendly ingredients being promoted.

Another aspect of this theme relates to ethics in general, ethics in advertising and regulation in advertising. Advertising is often touted as being untruthful, deceptive, offensive and done in bad taste. This being the case, it is unsurprising that marketing has gained a reputation for having targeted and manipulated vulnerable groups such as children in particular and consumers in general. Advertising has utilised stereotypes, offensive messages, subliminal advertising, misleading claims, and over aggressive promotions that inspire overeating and overspending. Consequently, this has influenced social behaviours. Another issue that emerged related to the regulation of nutritional labelling of products. The regulation of nutritional labelling is directly linked with ethical and regulatory issues pertaining to the communication of factual information regarding products.

\section{Theme 3 - Marketing Communications Mix}

The marketing communications mix consisted of tools used to promote and provide information about products, service, organisations, and brands. There are many different tools used, depending on the product and the target market. These tools included advertising such as radio, television and magazines, sales promotion, personal selling, digital marketing, internet marketing, direct marketing, publicity, public relations, support media, trade shows, sponsorships, one-on-one marketing, e-marketing, celebrity endorsements, search en- 
gine optimisation for marketing, social media marketing, mobile marketing such as via short message service (SMS); word-of-mouth referrals, event marketing, and outdoor marketing. There were also online communication tools such as email; viral marketing, public relations, blogging and affiliated marketing. The communication process referred to choices marketers made about what media to use. A choice between mass media, also known as nonpersonal or traditional media, and personal media must be made. This also involved choices made between verbal and non-verbal communications and interpersonal communication.

\section{Theme 4-Marketing Environments}

The marketing environments consisted of the micro (internal) environment and the macro (external) environment. The micro or internal environment referred to the organisation's mission statement, resources, objectives, customers, government, international market, industries, competitors, intermediaries and suppliers, resource-based analysis, performance analysis, value chain analysis, and functional analysis. The macro or external environment refers to external factors that affect the organisation such as demographic, economic, ecological, technological, political and legal, international, cultural, and social factors, as well as those relating to the physical environment.

\section{E Theme 5-Market Research}

The process of market research started with the problem definition; the research objectives stated, followed by the research plan. The research design must be decided: either qualitative, quantitative, or mixed methods could be used. Secondary or primary data and the methods which are exploratory, descriptive or causal must also be decided on. The identification and collection of information is also emphasised. Emphasis is placed on sampling, which can either be non-probability or probability. The design of questionnaires, types of interviews, for example, personal, telephonic and mail, as well as other methods of collecting information are also important. These include observations, experiments, or online market research. Processing information referred to validating, editing and coding raw data, capturing data for display in tables and graphs. Statistical techniques include Chi-square, co-variance, ANOVA, t-test, correlation, covariance, correlation, regression, factor analysis, SPSS and 
scaling techniques, which are used to analyse data. Hence, analysing data, interpreting results, presenting findings (reporting) and planning research projects and budgets are important.

\section{F Theme 6-Consumer Behaviour}

This theme focused on market segmentation which referred to choosing and developing attractive segments. Markets can be divided, based on the geographic location, demographics and lifestyle factors such as age, gender, families, and households, on economic, psychographic, behavioural and sociocultural factors such as social class, on ethnicity; and on cultures and subcultures, which are other segments. Included in this theme is targeting that referred to undifferentiated, differentiated, concentrated, niche, mass customisation and multi-segmentation. Linked to this was positioning which most organisations traditionally use. If similar or the same products are sold across the globe, then marketers use global positioning. This theme also emphasised the consumer decision-making process or decision-making model. This mode highlights the five steps in the process of consumer decision making: recognising the problem, searching for the information, alternative evaluations, purchase and post-purchase evaluation.

Consumer behaviour in service marketing also forms part of this theme. Hence, consumers progress through five different steps when purchasing the kinds of products mentioned previously. The factors affecting consumer behaviour such as consumer perception; consumer learning, attitude formation, diffusion, innovations, social life, personality, and psychological characteristics are also considered important.

Therefore, these themes that have been discussed thus far are what predominates the marketing curriculum within the South African HEIs. Hence, these themes constitute the powerful knowledge that is found in the scholastic epistemologies of marketing curriculum. In the next section, these themes will be interrogated further in the context of their relevance to HEIs.

\section{Prominent Themes at Higher Education Institutions}

The most prominent theme found at UNISA was the marketing communication process and the least were sustainability marketing and ethics, macro and 
micro environment, and market research. At the University of Pretoria (UP) and the UKZN the theme that appeared the most was sustainability marketing and ethics; the least was macro and micro environment.

At the Durban University of Technology (DUT), the least prominent theme was also the macro and micro environment and the most were the marketing mix and sustainability marketing and ethics. At the Management University of South Africa (MANCOSA) and the University of Stellenbosch (SU), all themes were equally represented.

At Regent Business School, the macro and micro environment were not represented. At the University of Cape Town (UCT) sustainability marketing and ethics, marketing communications and the macro and micro environment were not represented. At Oval International Higher Education, the most prominent themes were the marketing mix; sustainability marketing and ethics and market research; the other three themes were underrepresented. At the University of the Free State (UFS) marketing communications was most prominent and the least prominent was the macro and micro environment.

In operationalising the research design, it was considered important to review the content of marketing curricula across Higher Education Institutions (HEI)to identify what constituted the official curriculum and the planned curriculum. Also, in reviewing the official and planned curriculum, the extent to which socially responsive content were included, silenced, or absent from the official and planned marketing curricula, would be established.

The findings were that the courses offered at undergraduate level have a predominantly marketing management focused perspective. There was a strong emphasis on the foundational aspects of marketing, in particular the 4Ps. The importance of branding and global marketing was also evident. There were few institutions that featured modules with an ethical or societal context. These modules were specifically related to social marketing, ethics, governance, consumerism and ethical behaviour.

At the postgraduate level, the marketing management perspective featured predominantly as well. Again, similarities were seen with the undergraduate modules where subjects such as Strategic Marketing, Consumer Behaviour, Advertising, Branding, and Global Marketing are offered. In the case of postgraduate modules, there were few institutions that included societal 
marketing, ethics in business as well as social and cultural issues. Consumer behaviour featured strongly at both undergraduate and postgraduate levels. As a subject area, it does consider some issues related to ethical and societal contexts. However, the focus on those areas was minimal. The summation of the data in this the study made it necessary for further probing regarding the dynamics that dictate curricula content and what this may mean for the discipline of marketing. The findings suggest that socially responsive content in marketing was absent or silenced from the official and planned marketing curriculum.

\section{Conclusions}

This article has acknowledged the absence of the sustainability marketing discourse, as evidenced in the research findings. There exists a general inertia surrounding knowing about sustainability marketing and hence, not including it as a part of powerful knowledge. These scholastic epistemologies placed emphasis on the maintenance of the dominant social paradigm of marketing. This was evidenced in the dominant themes found in the textbooks considered appropriate for the marketing curriculum. However, in order to move the marketing discipline from rhetoric to actualisation of sustainability marketing in the marketing curriculum, this would require academics and marketers to view the sustainability discourse of marketing as theoretically relevant to the academic and business context of marketing. Essentially, the business context for sustainability cannot be contained as the only actionable component of marketing through initiatives such as green marketing. This would make marketing sustainability a superficial discourse with no theoretical foundation.

Therefore, the move to actualisation would require the engagement between business and academia to develop the discipline beyond a practicebased ideology and a skilling rhetoric. This could be achieved through curriculum redesign, which would engage the discipline and its constituents (students) through the introduction of critical thinking and by offering students the option to debate and contest what is presented to them in the form of the curriculum.

Academics remain powerful in the choices made for curriculum content and the continuous representation of marketing in its existing curriculum format would offer students limited opportunity to engage with a socially responsive content. Hence, the questioning of who would benefit from this type of curriculum would be foregrounded. 
The 'silo' mentality in which academics engage does not make visible what others may engage in, in the field of sustainability generally and sustainability marketing specifically. The fact that sustainability marketing is a global megatrend that is minimally represented in the curriculum is a testament to this. The marketing curriculum requires redesign; however, this can only be achieved through the broader engagement of how marketing sustainability is relevant to the marketing curriculum.

Traditionally, a sustainability discourse would be located in the 'hard' sciences discipline such as environmental sciences. However, the inclusion of a sustainability marketing discourse in marketing curriculum would displace an older and historical tradition of the Marketing Theory and make visible the nuances of socially responsive curricula.

This being the case, the sustainability megatrend needs integration within the mainstream academic disciplines of business and marketing domains. This would infer that universities (management and academics) would have to take on the call for sustainability discourses to be mainstreamed across disciplines. Subsequently, this could be filtered into individual departments and academic disciplines.

This predisposition toward such social agencies could be considered as moves toward greater levels of sustainability marketing awareness. This would form the basis of sustainability actualisation and serve as a catalyst to speed up the marketing curriculum redesign process. Consequently, those with knowledge of sustainability marketing could offer their input in developing sustainability marketing curriculum and those without this knowledge would be engaged in discussion to consider these issues. Ultimately, such impetus for discussion around belief systems would offer the opportunity for academics and stakeholders alike to consider how the future of marketing might be represented.

The South African higher education context has made a case for developing socially responsive curriculum. However, it remained at the level of rhetoric for the business and marketing disciplines. Henceforth, it is suggested that higher levels of marketing sustainability consciousness would lead to the ideological disruption of the Marketing Theory and therefore effect curriculum redesign. 


\section{References}

Arnould, E.J., C.J. Thompson 2005. Consumer Culture Theory: Twenty Years of Research. Journal of Consumer Research 31,4: 868 - 882. https://doi.org/10.1086/426626

Barnett, R. 2009. Knowing and Becoming in the Higher Education Curriculum. Studies in Higher Education 34,4: 429 - 440. https://doi.org/10.1080/03075070902771978

Brower, B. \& V. Mahajan 2012. Driven to be Good: A Stakeholder Theory Perspective on the Drivers of Corporate Social Performance. Journal of Business Ethics 117,2: 313 - 331.

https://doi.org/10.1007/s10551-012-1523-z

Brownlie, D. 2006. Emancipation, Epiphany and Resistance: On the Underimagined and Overdetermined in Critical Marketing. Journal of Marketing Management 22: 505 - 528.

https://doi.org/10.1362/026725706777978712

Cohen, L., L. Manion \& K. Morrison 2011. Research Methods in Education. $7^{\text {th }}$ Edition. New York: Routledge.

Cova, B., O. Maclaran \& A. Bradshaw 2013. Rethinking Consumer Culture

Theory from the Postmodern to the Communist Horizon. Marketing Theory 13,2: 213 - 225. https://doi.org/10.1177/1470593113477890

Ensor, P. 2004. Contesting Discourses in Higher Education Curriculum Restructuring in South Africa. Higher Education 48: 339 - 359.

https://doi.org/10.1023/B:HIGH.0000035544.96309.f1

Favish, J. \& J. McMillan 2009. The University and Social Responsiveness in the Curriculum: A New Form of Scholarship. London Review of Education 7,2: 169 - 179. https://doi.org/10.1080/14748460902990351

Foucault, M. 1981. The Will to Knowledge: The History of Sexuality. Volume 1. London, UK: Penguin.

Fougère, M. \& P. Skålén 2012. Extension in the Subjectifying Power of Marketing Ideology in Organisations: A Foucauldian Analysis of Academic Marketing. Journal of Macromarketing 33,1: 13 - 28. https://doi.org/10.1177/0276146712461507

Gibbons, M. 2006. Engagement as a Core Value in a Mode 2 Society. Paper presented at the CHESP-HEQC/ JET-CHESP Conference on Community Engagement in Higher Education, September 3-5, Cape Town, South Africa. 
Greene, M. 1978. Landscapes of Learning. New York: Teachers College Press: Grundy, S. 1987. Curriculum: Product or Praxis. Studies in Curriculum History. USA: Falmer Press.

Kilbourne, W., P. McDonagh \& A. Prothero 1997. Sustainable Consumption and the Quality of Life: A Macromarketing Challenge to the Dominant Social Paradigm. Journal of Macromarketing 17,4: 4 - 24.

https://doi.org/10.1177/027614679701700103

Kilbourne, W.E. \& L. Carlson 2008. The Dominant Social Paradigm, Consumption, and Environmental Attitudes: Can Macromarketing Education Help? Journal of Macromarketing 28,2: 106 - 121.

https://doi.org/10.1177/0276146708314586

Kilbourne, W.E., S.C. Beckmann \& E. Thelen 2002. The Role of the Dominant Social Paradigm in Environmental Attitudes: A Multinational Examination. Journal of Business Research 55: 193 - 204.

https://doi.org/10.1016/S0148-2963(00)00141-7

Luckett, K. 2010. Knowledge Claims and Codes of Legitimation: Implications for Curriculum Re-contextualisation in Southern African Higher Education. Africanus 40,1: 6 - 20.

Maree, J.G. 2007. First Steps in Research. $1^{\text {st }}$ Edition. South Africa: Van Schaik Publishers.

Ministry of Education 2001. National Plan for Higher Education. Pretoria: Ministry of Education.

Muller, J. 2009. Forms of Knowledge and Curriculum Coherence. Journal of Education and Work 22,3: 205 - 226.

https://doi.org/10.1080/13639080902957905

Paden, M. 2007. Strategy for ESD in Sub-Saharan Africa. Journal of Education for Sustainable Development 1,1: 127 - 132.

https://doi.org/10.1177/097340820700100121

Pautz, A. 2010. Do Theories of Consciousness Rest on Mistake? Philosophical Issues 20,1: 333 - 367.

https://doi.org/10.1111/j.1533-6077.2010.00189.x

Stubbs, W. \& C. Cocklin 2008. Teaching Sustainability to Business Students: Shifting Mindsets. International Journal of Sustainability in Higher Education 9,3: 206 - 221. https://doi.org/10.1108/14676370810885844

Tadajewski, M. 2008. Incommensurable Paradigms, Cognitive Bias and the Politics of Marketing Theory. Marketing Theory 8,3: 273 - 297. https://doi.org/10.1177/1470593108093557 
Tadajewski, M. 2010a. Critical Marketing Studies: Logical Empiricism, 'Critical Performativity' and Marketing Practice. Marketing Theory 10,2: 210 - 222. https://doi.org/10.1177/1470593110366671

Tadajewski, M. 2010b. Towards a History of Critical Marketing Studies. Journal of Marketing Management 26,9-10: 773 - 824.

https://doi.org/10.1080/02672571003668954

Tadajewski, M. \& D. Brownlie 2008. Critical Marketing: A Limit Attitude. In Tadajewski, M. \& D. Brownlie (eds.): Critical Marketing: Issues in Contemporary Marketing. Chichester: Wiley.

Varey, R.J. 2010. Marketing Means and Ends for a Sustainable Society: A Welfare Agenda for Transformative Change. Journal of Macromarketing 30,2: 112 - 126. https://doi.org/10.1177/0276146710361931

Wilkie, W.L. \& E.S. Moore 2006. Macromarketing as a Pillar of Marketing Thought. Journal of Macromarketing 26,2: 224 - 232. https://doi.org/10.1177/0276146706291067

Wilkie, W.L. \& E.S. Moore 2012. Expanding our Understanding of Marketing in Society. Journal of the Academy of Marketing Science 40: 53 - 73. https://doi.org/10.1007/s11747-011-0277-y https://doi.org/10.1080/15313220.2013.786337

Witowski, T.H. 2005. Antiglobal Challenges to Marketing in Developing Countries: Exploring the Ideological Divide. Journal of Public Policy and Marketing 24,1: 7 - 23. https://doi.org/10.1509/jppm.24.1.7.63902

Young, M. 2013. Overcoming the Crisis in Curriculum Theory: A Knowledgebased Approach. Journal of Curriculum Studies 45,2: 101 - 118. https://doi.org/10.1080/00220272.2013.764505

Devika Pillay School of Management, Information Technology and Governance Supply Chain and Marketing Westville Campus University of KwaZulu-Natal's pillayd6@ukzn.ac.za 


\title{
The COVID-19 Effect on Mauritian Higher Education
}

\author{
Upasana G. Singh \\ ORCID iD: https://orcid.org/0000-0002-9943-011X
}

\section{Vandanah Gooria \\ ORCID iD: https://orcid.org/0000-0002-1805-6964}

\section{Abstract}

The outbreak of the COVID-19 pandemic was unexpected and has utterly revolutionised the education system. More fundamentally, COVID-19 is causing all higher education institutions (HEIs) to challenge the deep-rooted conception of how, when and where to deliver education and proving how yesterday's disruptors can become today's lifeguards. While many traditional or campus-based institutions once viewed online education as a threat or as valueless and of poor quality, it has come to their rescue. The impact has been transformative and dramatic as academics are forced to find workable, fast and effective solutions for online movement, remote teaching, and lifelong learning using digital platforms while at the same time, maintaining the same depth of engagement they had with students in a classroom setting. The rising popularity of online education has resulted in educational institutions having an extraordinary potential for long-term cost saving and the ease of scaling fuels ongoing investments in online education by all HEIs. During the pandemic, the online movement has made academics more adept at handling the technology and digital age devices for lifelong learning and can now help students learn virtually. This study investigates how academic staff at Mauritian HEIs are coping during the COVID-19 pandemic. The data was collected using online questionnaires distributed to academic staff of four HEIs. Results indicate that $85.7 \%$ of respondents adopted the contact-based mode prior to the pandemic, and $80 \%$ moved to the online mode during the pandemic and $57.1 \%$ assumed they would move to blended learning post the pandemic. The most 
popular digital tools adopted by these academics, to support their online teaching and learning process during COVID-19 were Zoom (66.7\%) and Google Tools (52.4\%) The percentages clearly show that respondents used more than one digital tool. Email (65.2\%) and WhatsApp (72.3\%) were the most popularly adopted communication channels with and among students, during the pandemic. While there were no significant results in respect to challenges faced whilst working from home, the sudden shift caused increased levels of stress and anxiety stress for respondents.

Keywords: online education, digital learning, higher education, academic perceptions, transition, Mauritius

\section{Background}

COVID-19 is a new infectious virus, detected in December 2019 in Wuhan, China. World Health Organisation (WHO) declared the Coronavirus outbreak a Public Health Emergency of International Concern in January 2020 and a pandemic in March 2020. (WHO 2020) In the first instance, Asia was the centre of the initial outbreak of COVID-19 and spread in Europe and North America and other countries. (Johns Hopkins University 2021). US, India and Brazil have confirmed the highest number of cases of COVID-19, followed by France, Turkey, Russia and the UK. (BBC News 2021) As at 13 May 2021, it is reported that there were around 161,328,826 million confirmed cases of COVID-19, including 3,349,171 million deaths globally and 139,129,669 recovered (Worldometers 2021). The global trend at the beginning of Covid19 pandemics and the impact on education are depicted in Table 1. Africa has recorded more than 4.6 million cases and more than 120,000 deaths. South Africa is worst affected with nearly 1.6 million cases on the continent. (BBC News 2021). From March 2020 to May 2021 (between two different waves), the island of Mauritius recorded 1,274 coronavirus cases with 17 deaths and 1130 recovered cases (Worldometers 2021). The Coronavirus crisis has affected nearly every sector of the global economy (The Economist 2020) and Blin (2020) suggesting that the pandemic is gaining momentum in Africa. Mauritius, although only a dot on the world map, has not been spared from this pandemic. The island was (at the time of the study) under national confinement since 20th March 2020 followed soon after by the imposition of a curfew on 
24th March 2020. The impact on the country has been serious with notable effects. In Mauritius, the higher education institutions (HEIs) have shown dedication to supporting students during COVID-19, thus shaping the 'new normal' in education. The golden rule for any Mauritian university during the pandemic, was to continuously empower and transfer knowledge, but how so during a period marked by lockdowns and social distancing? Thus, the Mauritian HEIs have been continuously striving to educate students on how to use modern Information and Communication Technologies (ICT) to support their learning process during lockdown and travel bans. In some of the institutions, campus life is unlikely to return to normal but with the aid of technology, these institutions have almost instantly adapted in order to survive and meet students' needs, despite facing many challenges in the distance learning environment.

The global crisis is forcing HEIs around the world to confront longstanding challenges in higher education (HE). Teachers have a duty to educate students and to this end, several global initiatives by HEIs were adopted to sustain the teaching and learning process during this unique and unprecedented period. Digital learning, Open Educational Resources (OER) and online education has provided a way out for the education sector.

This urgent study into the understanding and experiences of academics and learners in the context of the COVID-19 pandemic is significant and unique. This pandemic has ironically facilitated the promulgation of webinars, online courses, online tutoring, e-assessment and has transformed the modes of learning in the education sector. Now, it is a reality that advances in technology have helped HEIs to further enhance the provision of open and distance learning (Appavoo et al. 2018).

\section{Table 1: Global Trend of Covid-19 and Education Impact}

\begin{tabular}{|l|l|}
\hline Timeline Covid-19 & Impact on Education \\
\hline 26 January 2020 & $\begin{array}{l}\text { China, first country, instituted measures to contain the } \\
\text { Covid-19 outbreak. China extended spring festival } \\
\text { holiday and became first to close all schools and } \\
\text { universities. }\end{array}$ \\
\hline 4 March 2020 & $\begin{array}{l}\text { 22 countries on 3 continents had enacted preventive } \\
\text { measures. Temporary closure of schools and } \\
\text { universities. 290.5M students were globally affected and } \\
\text { supported with distance learning programmes. }\end{array}$ \\
\hline
\end{tabular}




\begin{tabular}{|c|c|}
\hline 5 March 2020 & $\begin{array}{l}\text { Around } 233 \mathrm{M} \text { students affected, followed by } 16.5 \mathrm{M} \text { in } \\
\text { Japan and } 14.5 \mathrm{M} \text { in Iran. This means that majority of } \\
\text { students were affected. }\end{array}$ \\
\hline 10 March 2020 & $\begin{array}{l}1 \text { in } 5 \text { students worldwide staying away from school } \\
\text { while another } 1 \text { in } 4 \text { was barred from HEIs. }\end{array}$ \\
\hline 13 March 2020 & $\begin{array}{l}49 \text { countries closed schools. By } 16 \text { March 20, this figure } \\
\text { has increased to } 73 \text { countries. }\end{array}$ \\
\hline 19 March 2020 & $\begin{array}{l}50 \% \text { of students worldwide affected by school closures, } \\
\text { corresponding in } 102 \text { countries and } 850 \mathrm{M} \text { children and } \\
\text { youth }\end{array}$ \\
\hline 20 March 2020 & $\begin{array}{l}\text { Over } 70 \% \text { of global students impacted by school } \\
\text { closures, } 124 \text { countries (including Mauritius, } 504 \text { cases, } \\
456 \text { recovered, } 10 \text { deaths in the first wave) }\end{array}$ \\
\hline 27 March 2020 & $\begin{array}{l}\text { Nearly } 90 \% \text { of the world's student population was out of } \\
\text { class. }\end{array}$ \\
\hline 29 March 2020 & $\begin{array}{l}\text { More than } 1.5 \text { billion students globally affected } \\
\text { (representing 90\%) }\end{array}$ \\
\hline Mid-April 2020 & $\begin{array}{l}\text { Around } 1,725 \text { billion students affected across } 192 \\
\text { countries (representing 99\% world's student population) }\end{array}$ \\
\hline 30 September 2020 & $\begin{array}{l}1.077 \text { billion students affected (representing 61.6\%), } 72 \\
\text { countries re-opened schools and universities. }\end{array}$ \\
\hline 10 May 2021 & $\begin{array}{l}\text { More than } 158 \text { million confirmed cases and } 3.2 \text { million } \\
\text { deaths across nearly } 200 \text { countries }\end{array}$ \\
\hline
\end{tabular}

Sources: UNESCO (2020), Covid-19 Educational Disruption and response World-wide statistics (2020); World Health Organisation (2020) WHO Coronavirus Diseases; Johns Hopkins University, National Public Health Agencies as at 10.05.21.

\section{Study Aim}

This immediate and dynamic change brought about by the COVID-19 crisis is unparalleled in the academic literature where academic staff were 'forced' to adapt to the digital age almost immediately, so as to ensure millions of students worldwide could continue with their studies (Ledeman 2020). Most HEIs had plans to strengthen their digital footprint in the next decade or so. With this 
change, this paper looks at the perception of academics and the effects of the disruption from the Mauritian HE perspective with the following aim of

- understanding academics' preferences of technology to support online teaching and assessment;

- determining academics' experiences with the shift to a forced 'work from home' situation; and

- investigating the general impact of the pandemic on academics.

\section{Literature Review}

In Mauritius, due to the widespread of Coronavirus disease, both the school and university semester were disrupted. In a short time period, school teacher and academics had to move to online teaching by sitting in front of a computer screen and their students have to stay at home and take the courses through the internet. All universities' carefully crafted syllabi and years of curriculum content were suddenly shifted to fully online as dormitories closed, lectures discussions and even assessments were run through Zoom, Google and other online platforms (Lee 2020). Technology has its roles in the life of an academic. According to authors like Madhavaiah et al. (2013), technology has become very important in academia as it promotes communications and learning and appears to improve students' intelligence levels. Several authors such as Chen and Bonk (2008); Usluel and Mazman (2009); and Maro (2008) have identified various types of educational technologies which are being used in the education sector by academics. The acquaintance with the internet technologies is also a strong predictor of the acceptance of open distance learning (Liaw et al. 2008). The extensive use of various educational technology and modes of communication during lockdowns has been one of the most important decisions for HEIs and has influenced them in terms of, 'the methods used to deliver courses to students', the 'interaction between students and educators' and the facilities or support 'students gain access to learning content' (Wiid et al. 2015, p30). Hussain and Safdar (2008) described that technology allows academics to make maximum use of their time, coach students, identify students' problems and helps them with their academic activities. It has been observed that the use of systems for open distance education, student blogs, wiki groups, chats and instant messages on WhatsApp or other online tools 


\section{Upasana G. Singh \& Vandanah Gooria}

have become grafted onto traditional systems used at universities (Ketterl et al. 2009). During this COVID-19 pandemic, many universities around the world have resorted to the use of technology and have adopted open distance learning. However, the COVID-19 effects on Mauritian HEIs have been highlighted as follows:

- All HEIs were in lockdown, causing various, sudden physical and social disconnection between the student and the university (including resources such as the library), the student and the teacher, students and other students.

- HEIs were severely hit by COVID-19, resulting in the loss of foreign students.

- HEIs have adopted new educational protocols in a very short period of time in order to sustain Teaching and Learning (T\&L) for existing students. Therefore, academics have changed their teaching and assessment strategies.

- Academics and support staff had no option except to immediately adopt teleworking, where possible;

- HEIs have relied fully on technology and on the internet during lockdown in order to run all courses online.

- HEIs have moved to online learning, this immediate shift has entailed a radical change in the business model, with the potential for a broader customer base but lower fees (Economist 2020);

- Some HEIs have postponed examinations while others have changed to a more flexible mode of assessment by the move to virtual examinations and the postponement of intakes.

- The domestic student applications are likely to remain steady in the short term, but campus life will not completely return to normal. HEIs are under pressure to offer value-for-money with regards to courses and student support.

- A change in educational culture, shifting to the "new normal' in the education system has been seen.

- The lack of social interaction between students and academics during confinement has led to demotivation.

- There is more opportunity to recourse to open educational resources, Massive Open Online Courses (MOOCs) and free online platforms. 
- The HEIs will in all likelihood adopt the use of blended learning post COVID-19

- This shift has exposed universities to more external competition, with only prestigious institutions likely to capture a large market share of students.

Although the Massachusetts Institute of Technology (MIT) in Cambridge has been offering courses online for free since 2002, most actively teaching academics were unprepared for online teaching and had to devise ways of quickly moving their materials online when the pandemic hit (Witze 2020). Eady and Lockyer (2013) stated that academics have the opportunity to design learning experiences which are meaningful with the help of technology. By using technology appropriately, academics are able to design learning experiences that will be beneficial to students. On the other hand, Jhuree (2005) supports the previous authors by stating that technology creates a motivating learning setting in which students have the opportunity to be engaged with the course content, therefore making the students more interested in learning. This is the case as technology enables the course content to be more challenging but easier and motivating for academics, especially during the COVID-19 pandemic. Although it was time consuming and challenging, the academics were obliged to cope and take charge of the T\&L process across all universities. Course content can include several types of media - such as images or even games and this creates the interaction between the student and the course content, especially in the context of an open learning environment (Courville 2011). Therefore, technology shifts the educational process from being passive to active and interactive. During the global emergency, this has been a 'blessing in disguise' for both the academics and students.

The choice of an effective educational technological infrastructure by academics is essential in bridging the distance between the learner, the university and the provided learning material, and to embed social synergy within the learning environment, thus making learners more interactive and not just passive recipients of information (Filippidi et al. 2010). Technology also allows for the creation of an online platform where students can discuss topics either among themselves or with their teachers and therefore work collectively.

The major characteristic that metamorphosises the conventional learning environments to the Open and Distance Learning (ODL) systems is 
'the degree of technology usage' and this has transferred the control, trust and duty of the learning process to learners, providing them the chance to learn anywhere, anytime. This paradigm 'shift of control of the learning process to learners seems to positively influence their learning effectiveness' (Chou \& Liu 2005:69).

Groff (2013) also mentioned that technology creates the concept of an online learning environment where students can study from any part of the world. There is the opportunity for students to have access to several learning materials on the internet even if they are not physically present in classes. This is supported by Jung (2008) who states that with the increased use of technology, the quality of education is improved and students are able to learn at times and in places that suit them, thus decreasing the gap of reaching students in remote and underdeveloped areas. . Hussain and Safdar (2008) asserted that technology allows academics to make maximum use of their time, coach students, identify problems of students and help them with their academic activities. Some subjects are more difficult to understand and through the use of technology that can be used to create a virtual setting, academics can identify the weaknesses of the students from their feedback. During the crisis season, Academics have customised their teaching methods to ensure students understand content better than in traditional classrooms. Furthermore, Grinager (2006) explains that technology can assist academics as part of their own professional development, and therefore improve their teaching. COVID-19 acts as a spur to blended learning and most of the conventional institutions have become open to the idea of moving at least some of their teaching online. According to Grinager (2006), during online teaching, teachers can have more time to work with a small group of students or being also available to cater for individual attention. The teachers can even customise their teaching method to make students understand better than in traditional classrooms.

\section{Theoretical Background}

The Self-Determination Theory (SDT) relates to motivation in the process of teaching and learning. The SDT depicts a significant difference between two motivational issues in the context of the continual running of HEIs despite the lockdown: why versus what for. In this context, what is the purpose of HEIs' activity during confinement? And why do they want to achieve this goal? What 
are the reasons for trying to achieve this goal? (Lens et al. 2008). Furthermore, SDT encompasses three human needs; autonomy (e.g. by providing students with choices in their content, activities or demonstrations of learning), competence (the need to demonstrate a level of mastery in an area and being recognised for a specific expertise) and relatedness (the need for caring relationships with others which is fundamental in the social constructivist setting) (Deci \& Ryan 2008; Deci et al. 1994). Many factors contribute to the satisfaction of these needs, but the most important is the academics' style of engaging students in the open and online education environment. This study looks at the extent to which academics are motivated to shift into this new mode of working from home (teleworking) and is based on the SDT framework which demonstrates a deep understanding of the attitude of individuals towards motivation (Gaigné \& Deci 2005).

\section{Methodology}

The focus of this study was on academics in HE in Mauritius. An online questionnaire was developed to gather primary data. The questionnaire was disseminated through direct email invitation to academic staff from within the universities/institutions by the directors of each institution. The methodology adopted a mixed-method approach gathering both qualitative and quantitative data. Quantitative data focused on usage and adoption of technology for teaching, and assessment, prior to and during the pandemic. For the purpose of this paper, only the quantitative findings will be presented. The qualitative data will be discussed in a subsequent paper. A total of 37 questions were asked with 11 on demographic data and 16 requiring a rating on a scale. Data collection was open for a period of four weeks during lockdown. The online survey took approximately 15 minutes to complete and was anonymous. The final sample was 21 academics across four Mauritian HEIs (no academics participated from the 5th Mauritian HEI which was selected for the study). While the results are valid, the researchers are cognisant that these results cannot be projected onto a population since the sample size is too small.

Data were analysed using the statistical package, SPSS v 25. Tests used in the analysis include Frequencies were represented in tables or graphs; Chi-square goodness-of-fit-test - a univariate test, used on a categorical variable to test whether any of the response options are selected significantly 
more/less often than the others; Fisher's exact test - to see whether a significant relationship exists between two variables represented in a cross-tabulation; Binomial test - tests whether a significant proportion of respondents select one of a possible two responses; Wilcoxon signed ranks test - tests whether a mean rating score is significantly different from the central score of ' 3 ' on a 5-point Likert scale. The current research forms part of a broader study on the impact of the COVID-19 pandemic on academics at HEIs. Ethics approval was received from the University of KwaZulu-Natal, South Africa as per Protocol Reference Number HSSREC/00001284/2020. Participating Mauritian HEIs provided gatekeeper consent permitting the researchers to distribute the questionnaire to their academic staff.

The current research forms part of a broader study on the impact of the COVID-19 pandemic on academics at HEIs. Ethics approval was received from the University of KwaZulu-Natal, South Africa as per Protocol Reference Number HSSREC/00001284/2020. Participating Mauritian HEIs provided gatekeeper consent permitting the researchers to distribute the questionnaire to their academic staff.

\section{Discussion of Findings}

A total of 21 valid responses were received in this study from both public and private Mauritian HEIs. The demographic distribution of the respondents is summarised in Table 2.

Table 2: Summary of Respondents' Demographics

\begin{tabular}{|c|c|c|c|}
\hline $\begin{array}{l}\text { Variablel } \\
\text { Categories }\end{array}$ & $\begin{array}{c}\text { Frequency } \\
\text { (Percent) }\end{array}$ & $\begin{array}{c}\text { Variablel } \\
\text { Categories }\end{array}$ & $\begin{array}{c}\text { Frequency } \\
\text { (Percent) }\end{array}$ \\
\hline \multicolumn{2}{|c|}{ Age (years) } & \multicolumn{2}{|c|}{ Experience (years) } \\
\hline $20-30$ & $3(14.3 \%)$ & $1-5$ & $8(38.1 \%)$ \\
\hline $31-40$ & $11(52.4 \%)$ & $6-10$ & $5(23.8 \%)$ \\
\hline $41-50$ & $4(19.0 \%)$ & $11-15$ & $4(19.0 \%)$ \\
\hline $51-60$ & $2(9.5 \%)$ & $16+$ & $4(19.0 \%)$ \\
\hline$>60$ & $1(4.8 \%)$ & \multicolumn{2}{|c|}{ Institution Type } \\
\hline \multicolumn{2}{|c|}{ Gender } & Private & $4(19.0 \%)$ \\
\hline Female & $10(47.6 \%)$ & Public & $17(81.0 \%)$ \\
\hline
\end{tabular}


The COVID-19 Effect on Mauritian Higher Education

\begin{tabular}{|c|c|c|c|c|}
\hline Male & $11(52.4 \%)$ & & \multicolumn{2}{|c|}{ Academic Role } \\
\hline \multicolumn{2}{|c|}{ Qualification } & & Lecturer & $16(76.2 \%)$ \\
\hline $\begin{array}{c}\text { Undergraduate } \\
\text { degree }\end{array}$ & $1(4.8 \%)$ & & Senior lecturer & $3(14.3 \%)$ \\
\hline $\begin{array}{c}\text { Postgraduate } \\
\text { degree }\end{array}$ & $20(95.2 \%)$ & & $\begin{array}{c}\text { Associate } \\
\text { professor }\end{array}$ & $2(9.5 \%)$ \\
\hline & & & \multicolumn{2}{|c|}{ Tenure } \\
\hline & & & Permanent & $20(95.2 \%)$ \\
\hline & & & Contract & $1(4.8 \%)$ \\
\hline
\end{tabular}

The respondents were spread 'equally' across male/female and the majority of them $(52.4 \%)$ were aged 31-40 years. Almost all respondents $(95.2 \%)$ held a postgraduate degree. Lecturers $(76.2 \%)$ held the highest participation rate, with $38 \%$ of the respondents having more than 10 years of experience in academics. The majority $(95.2 \%)$ held permanent tenure.

To understand the effect that the COVID-19 pandemic has had on the primary teaching method adopted by these academics, the next question focused on the three dominant teaching types: fully contact-based (face-toface), fully online learning (no face-to-face) and the hybrid, blended learning.

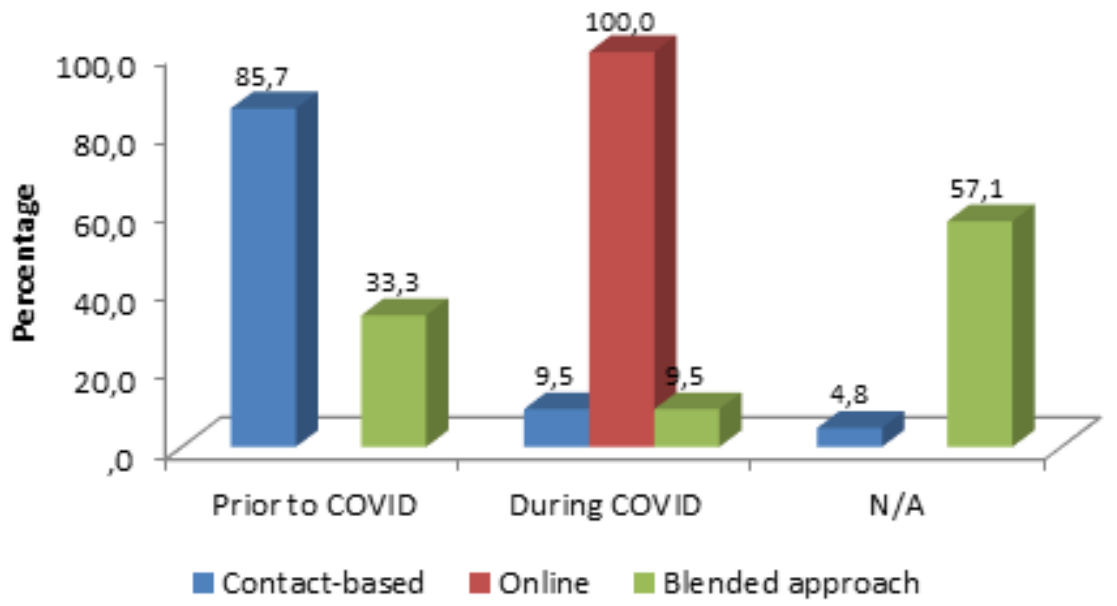

Figure 1: Primary Teaching Method 
As illustrated in Figure 1, there was a clear shift from face-to-face learning $(85.7 \%)$ and blended learning $(33.3 \%)$ prior to the COVID-19 pandemic, to online learning $(100 \%)$ during the pandemic. There was also a notable non-adoption of blended learning $(57.1 \%)$ during the pandemic. None of the respondents indicated usage of online learning prior to the pandemic.

Results from Fisher's exact test did not reveal any significant relationship between the type of institution and the use of any particular approach of teaching either prior to or during the pandemic (Blended $-p=.273$; Contact-based- $\mathrm{p}=1.000)$.

To ascertain the Mauritian academics' proficiency in adopting technology to support online teaching and online assessment, respondents were asked to rate their proficiency in adopting technology tools using the scale from $1=$ poor to $5=$ excellent. A Wilcoxon signed ranks test was applied to test if the average proficiency rating was significantly different from the central rating of ' 3 '.

During COVID $\square$ Prior to COVID

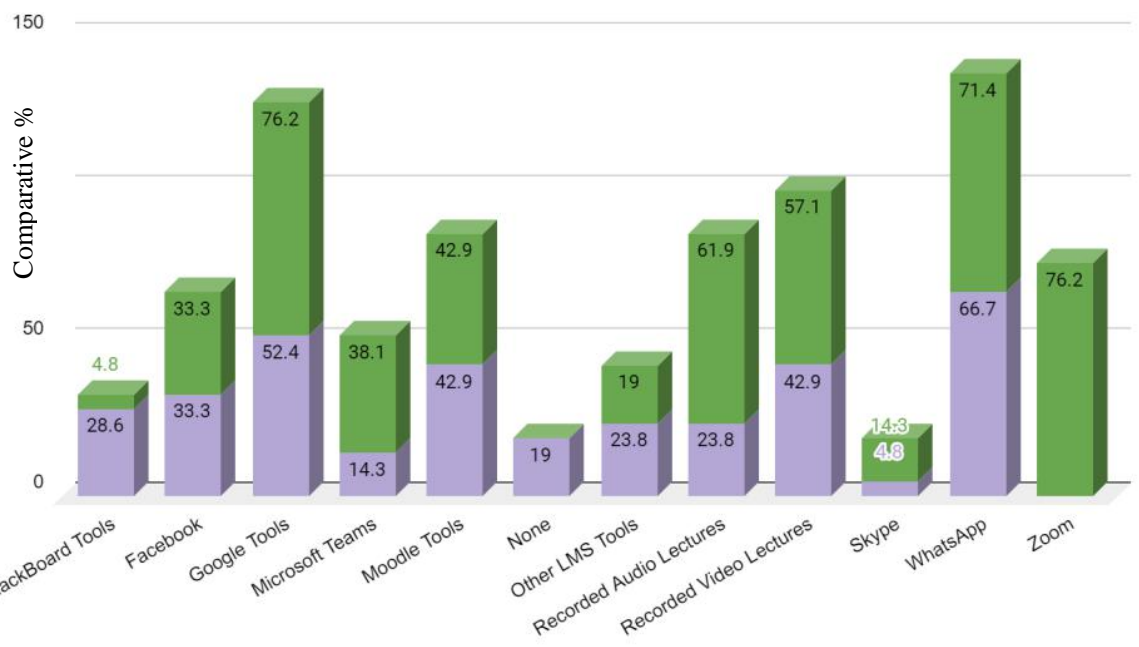

Figure 2: Teaching Tools Adoption Summary

Results showed that average proficiency ratings were significantly above the central rating of ' 3 ' for both teaching methods (mean rating $=4.14$, 
$\mathrm{p}<.0005)$ and assessment methods (mean rating $=3.90, \mathrm{p}<.0005)$. This indicates that the respondents rated themselves as better than average, tending towards excellent, in their proficiency in adopting technology for both teaching and assessment. This is in fact a promising and confident point to be noted here that Mauritian academics are ready to adopt and adapt any kind of online teaching techniques during and post COVID-19 and the adoption of new educational technology is quite significant for them to meet students' needs. To identify the tools most commonly adopted to support online teaching in Mauritian HEIs, prior to and during the pandemic, respondents were asked to indicate which, from a list of 12 tools, they adopted. Results are summarised in Figure 2 below.

As illustrated in Figure 2, the teaching tools most commonly adopted prior to the pandemic were WhatsApp (66.7\%), Google Tools $(52.4 \%)$, and Moodle Tools (42.9\%). During the pandemic, Zoom and Google Tools were the most popular (76.2\% each), followed by WhatsApp (71.4\%). A small number of respondents (19\%) did not use any form of online teaching tools prior to the pandemic. It appears from this data that the preparedness of academics and students to this new mode of teaching was mandatory. For the post-COVID-19 era, it is recommended that all Mauritian HEIs offer training to all academics and part time training on educational technology and provide guidelines to students to keep them on track with their studies by using the different modes of T\&L the university will adopt. The remote learning might enable academic luminaries to teach without any barriers and create opportunities for information sharing and career development through digital educational technology.

A Binomial test was conducted to identify if a significant proportion of the sample responded to usage of each of these tools prior to or during the pandemic. Results showed that the only tools significantly selected for use in supporting online teaching during the pandemic were Zoom and Google Tools (76\%, $\mathrm{p}=.027)$.

Similarly, respondents were asked to indicate the tools they adopted to support online assessment, prior to and during the pandemic. These results are summarised in Figure 3.

As illustrated, the prominent assessment tools adopted prior to the pandemic were Moodle Tools (33.3\%), Google Tools (28.6\%), and WhatsApp (28.6\%). However, during the pandemic Google Tools topped the list (71.4\%), 


\section{Upasana G. Singh \& Vandanah Gooria}

followed by Recorded Video Lectures (66.7\%), Zoom and WhatsApp (both $47.6 \%$ ). With the onset of the pandemic many academics willingly or unwillingly, had to rethink their teaching and assessment methods to support a new mode of teaching. This was supported by many institutions offering digital literacy and pedagogy training to equip academics with this transition to operating in an online space (Singh 2020a).

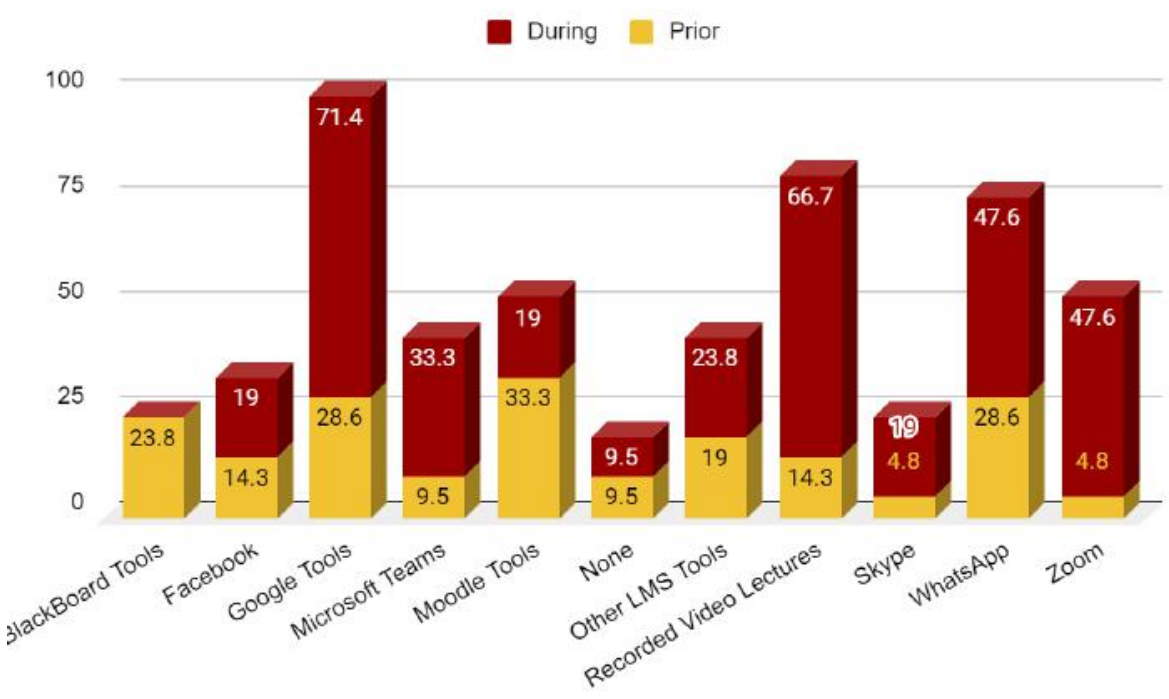

Figure 3: Assessment Tools Adoption Summary

Owing to the emergency of delivering online courses, it is noted that $19 \%$ of academics used the support of social media, specifically Facebook (FB) to deliver online classes, which students are always enthusiastic about using when interacting with classmates. However, it has been past evidence has shown that FB is not the most appropriate tool for education purposes and is rather regarded as students' 'personal' space (Banna, Lin, Stewart \& Fialkowski 2015).

Further statistical analysis indicated no significant usage of any of these teaching or assessment tools prior to or during the pandemic; in addition, there was no significant difference in adoption of any of these tools between public and private institutions. 
When asked to rate their proficiency in communicating with their students in an online environment during the pandemic, on a scale from $1=$ very difficult to $5=$ very easy, Mauritian academics found it significantly easy to communicate with their students (mean rating $=3.45$ is significantly greater than ' 3 ', $\mathrm{p}=.038$ ).

From Figure 4 it is noted that the biggest challenge Mauritian academics perceived that their students faced when moving to the online environment was the 'Lack of Interaction' (57.1\%). Thereafter, the infrastructural factors were reported - 'Access to devices' (42.9\%), and 'Access to connectivity’ (42.9\%). Social and emotional factors were less frequently cited.

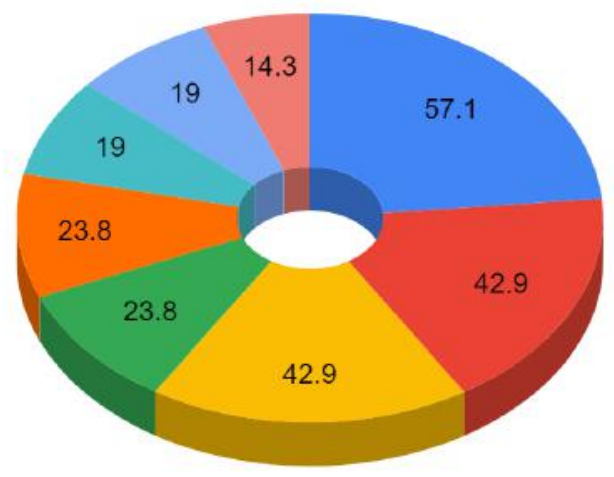

Lack of interaction

Access to devices

Access to connectivity

Fear of the unknown

Resistance to Change

Demotivation

None

Technology competence

\section{Figure 4: Mauritian Academics' Perceptions of Challenges Faced by Students in Moving Online}

In creating a vibrant online community, academics must facilitate sustained communication and engagement with course materials and use specially tailored online assignments (Bar 2011). Furthermore, Banna et al. (2015) highlight that engaged learning or learning that an instructor facilitates and is student focused, is a topic of importance in today's learning environment, which increasingly incorporates technology to smooth the know-ledge construction process. It is extremely frustrating to attend an online class and at 
the same time face technical and infrastructural challenges such as delay, poor internet connection or computer problems, etc. Students and academics should be readily prepared and provided with ample tutoring and time to familiarise themselves with the new online system and functions. In this context, around $42.9 \%$ claimed to have experienced technical and access problems.

None of the academics showed any signs of demotivating factors to shift to the online learning platform, although students demonstrated signa of demotivation. Concerning student-academic staff interaction, the social presence of the academic staff member is an integral component of a successful online course; the academic must perform activities that translate virtual interaction into an impression of a 'real' face to face interaction (Dixson 2010). The academics simply have to re-examine their traditional ways of teaching and redesign their course delivery with the aid of technologies in a studentcentered way, in order to motivate students and create the motivated learning space based on SDT theory during this sudden pandemic. Therefore, every setback for the academics during this crisis has become an opportunity for change. What is very important is that the goals and priorities of students and universities are met and surely, the transformation of knowledge is taking place. This pivotal moment is causing academics to revamp traditional teaching and learning processes and will mark the future of HE for the better transformation of digital learning.

When asked to indicate which methods, from a list of 6 methods, were used to support students during the pandemic, the top methods adopted by academics were 'Online lectures' (95.2\%), 'Direct Emails' (90.5\%), 'Online tutorials’ (76.2\%), and Phone (71.4\%) (cf. Figure 5 below).

\begin{tabular}{|c|c|c|}
\hline Method & \% & p-value \\
\hline Online lectures & 95 & $<.0005$ \\
\hline Online tutorials & 76 & .027 \\
\hline Emails & 90 & $<.0005$ \\
\hline
\end{tabular}

\section{Table 3: Significant Methods Adopted for Student Support}

As summarised in Table 3, Online lectures, online tutorials and personal emails were indicated by a significant proportion of the respondents as ways through which they supported their students successfully. 


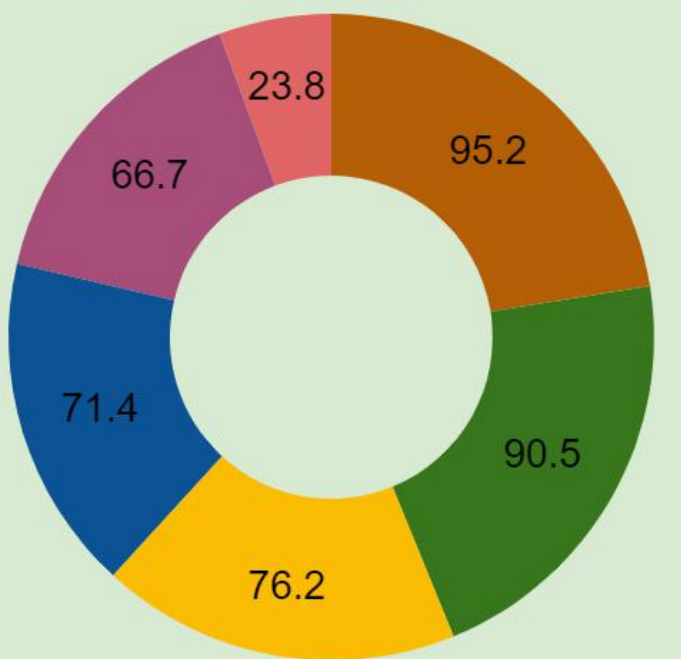

Online lectures

Emails

Online tutorials

Phone

Online assessment

Emails through LMS

Figure 5: Methods used by academics to support students during the pandemic

Academic support at HEIs takes different forms such as tutoring, guiding the students, counselling them and assisting them with their digital platform. These, in fact, are important roles for academics which help students to cope with their studies and not to drop out of their respective courses.

When rating the responsiveness of their students to the support, on a scale from $1=$ unresponsive to $5=$ very responsive, results from a Wilcoxon signed ranks test show that the mean rating of 3.86 is significantly higher than the central score of ' 3 ' $(\mathrm{p}=.002)$, indicating that they were more responsive than average. In the same way, the mean rating of the effectiveness of working with students online when using a scale of $1=$ not at all effective to $5=$ very effective was 3.67 which is also significantly higher than the average score of ' 3 , indicating better than average effectiveness, $\mathrm{p}=.006$.

The next section of the questionnaire focused on the shift to workfrom-home (WFH), and its impact on the lives of Mauritian academics.

As illustrated in Figure 6, the predominant challenges faced by Mauritian academics in the 'forced' WFH arrangements during the pandemic were 'Social isolation' (42.9\%), 'My Physical Workspace' (36.1\%), and 'General anxiety about COVID-19' (33.3\%). Further statistical analysis indicated that 
none of these challenges were indicated by a significant proportion of the respondents.

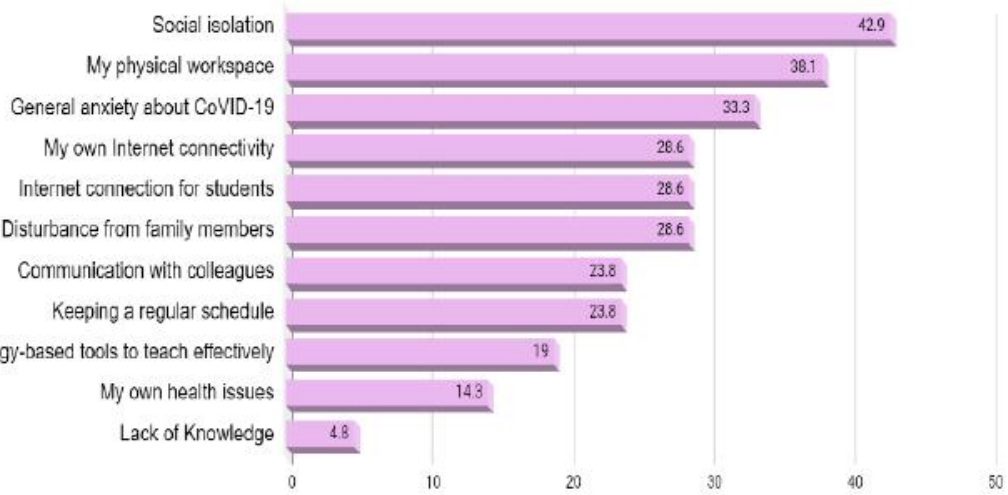

Figure 6: Challenges with the forced work-from-home scenario

The type of WFH arrangements used by academics to communicate with students and colleagues during the pandemic is summarised in Figure 7 below.

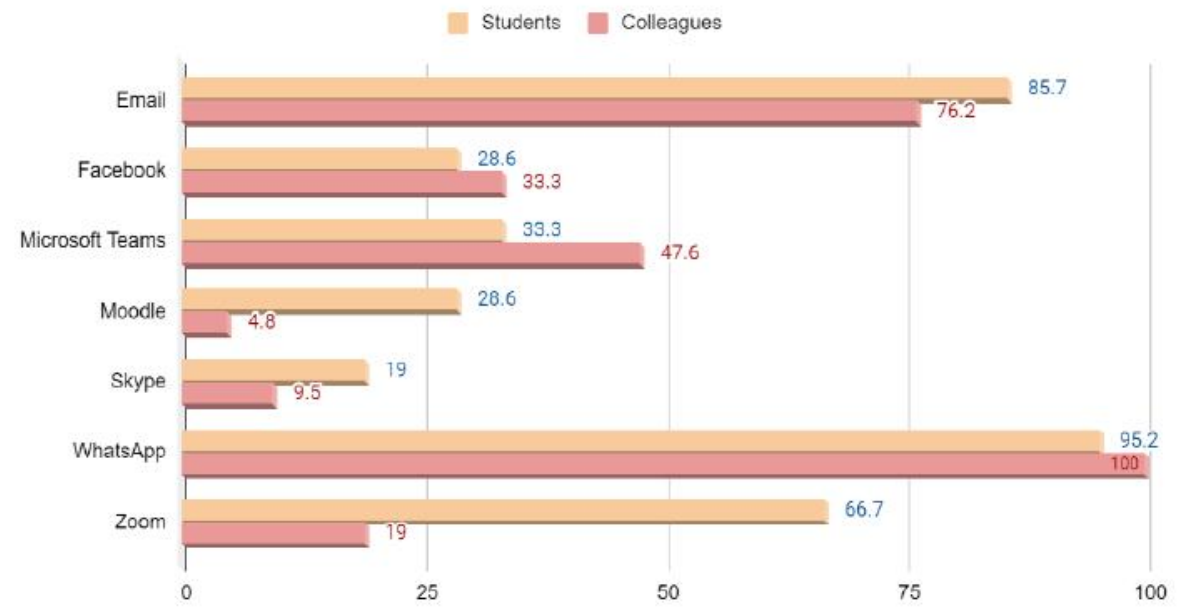

Figure 7: Work-from-home Communication Methods Adopted 
Marks (2020) stressed the importance of how institutions were forced by the pandemic to embrace home-based working (HBW) at 'break-neck' speed, with very little chance to consider the implication on academics and students. There have been concerns regarding physical workspace at home conducive to effective output, poor work-life balance and enhanced domestic hurdles and stress.

To support their communication between students and colleagues while working from home, Mauritian academics indicated that WhatsApp and emails were the most convenient tools. Both these tools were significantly adopted for communication with both students and colleagues, as summarised in Table 4 below.

\begin{tabular}{|c|c|c|c|c|}
\hline & \multicolumn{2}{|c|}{$\begin{array}{c}\text { Student } \\
\text { communication }\end{array}$} & \multicolumn{2}{c|}{$\begin{array}{c}\text { Colleague } \\
\text { communication }\end{array}$} \\
\hline Tool & $\mathbf{\%}$ & p-value & \% & p-value \\
\hline WhatsApp & 95 & .001 & 100 & $<.027$ \\
\hline Email & 86 & $<.0005$ & 76 & $<.0005$ \\
\hline
\end{tabular}

\section{Table 4: Significant Communication Tools Adopted}

The ASSET $@$ framework outlines eight basic skills that lecturers need to develop or possess to support a smooth transition from the face-to-face to the online teaching space, which will most likely find its balance in a blended space post COVID-19. It highlights the importance of good communication skills, to support students, especially considering the nuances of non-contact communication; and emotional intelligence by developing empathy for both students and fellow colleagues who may be studying or working from environments that are non-conducive to effective working or studying (Singh 2020b).

While results from a Chi-square goodness of fit test showed that no response option was selected by a significant number of respondents $\left(\chi^{2}(6)=11.333\right.$, $\mathrm{p}=.079)$.

A third of the respondents were comfortable with the work-from-home arrangement and suggested that they could sustain their current WFH arrangements indefinitely. 
Not sustainable now

One week

A few weeks

A month

Two months

Indefinitely

Other

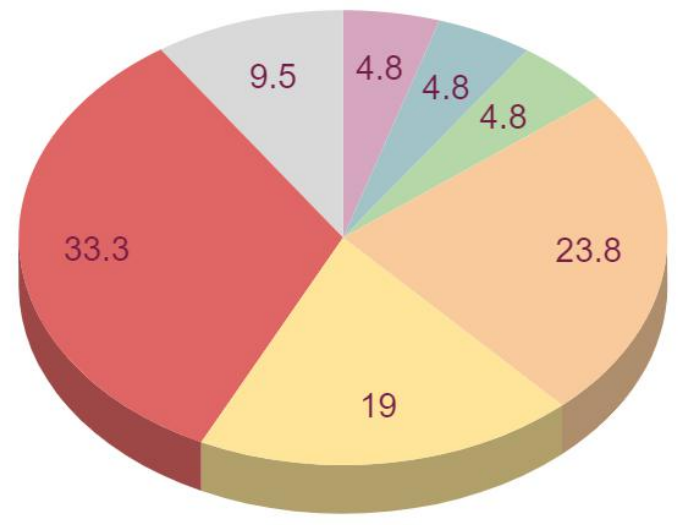

Figure 8: Duration that Respondents could Sustain their Current Workfrom-home Arrangements

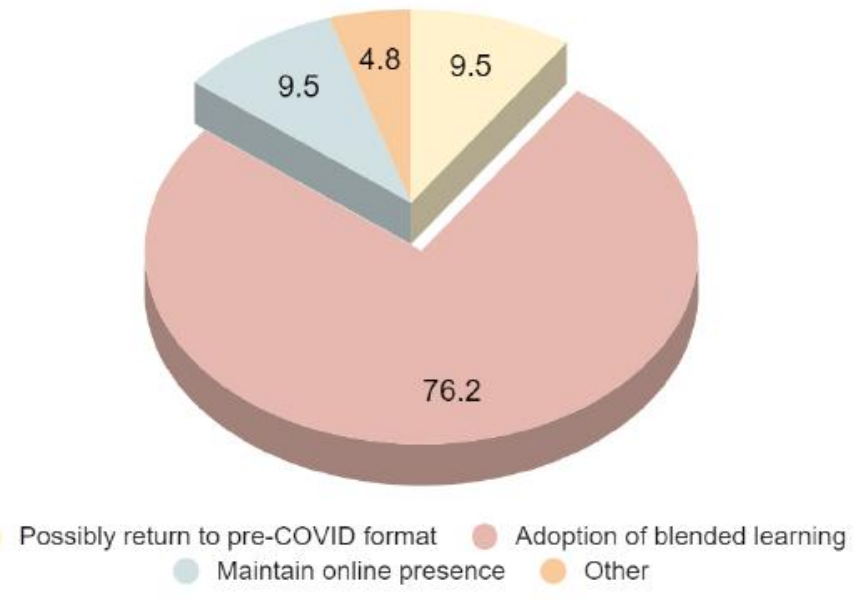

Figure 9: Future Shape of Institution 
A Chi-square goodness of fit analysis showed that a significant number of respondents $(n=16,76.2 \%)$ perceived that their Institution will adopt blended learning post the pandemic, ic $\left(\chi^{2}(3)=29.476, p<.0005\right)$, as shown in Figure 9. With the changes that have arisen due to the COVID-19 crisis, some institutions may no longer be viable and they will need to rethink their business model entirely in the education sector. Whatever the scenario beyond 2020, the landscape of HEIs remains a complex tapestry of goals, strategies, competing pressures and education sustainability. The reconstruction plan for Mauritius beyond 2020 may need health, security and quality education consideration at the heart of the strategy. Mauritian universities must accelerate plans for adopting digital technology and artificial intelligence as tools to uphold student learning outcomes and to reach a new population of students.

\section{Conclusion}

The demographics indicated that the majority of the respondents were middleaged males, with a large majority holding a postgraduate degree. The majority held permanent lecturer positions at their institution, indicating early career academics. There was a clear transition to online learning, with a notable increase in blended learning, during the pandemic. It is interesting to note that none of the respondents had adopted online learning prior to the pandemic. Encouragingly, that despite not having adopted online teaching prior to the pandemic, respondents rated themselves as better than average in their proficiency in adopting technology for both teaching and assessment. WhatsApp and Learning Management System (LMS) platforms, like Google and Moodle were the preferred choices for teaching prior to the pandemic. During the pandemic, the previously unadopted Zoom, claimed equal prominence with Google Tools. It was also encouraging to note that while a small number of respondents indicated that they had not adopted any online teaching tools prior to the pandemic, during the pandemic, all respondents were adopting some form of technology to support online teaching. A similar pattern was observed for online assessment tool adoption where LMS platforms such as Google, Moodle and WhatsApp were the preferred choice for assessment prior to the pandemic. During the pandemic, Google Tools dominated. The number of respondents that indicated they had not adopted any online assessment tools prior to the pandemic remained consistent during the pandemic. Amongst all 
the tools, Zoom and Google tools emerged as the most preferred communication digital platforms used by students in Mauritius for learning and interaction. There was no indication of any forms of difficulty faced by Mauritian academics in communicating with their students in the 'new' online environment. The lack of interaction and infrastructural issues associated with lack of access to devices and internet connection, were the main challenges Mauritian academics perceived that their students faced when moving to the forced online environment.

Direct contact methods such as communication during online sessions, personal emails and phone calls, were the most significant methods adopted by Mauritian academics in this shift to the online space. Mauritian academics noted that their students were responsive to their support. These academics found working in an online space an effective means of continuing with their academic activities to support students' learning. Thus, there was also a significant indication that these academics would continue to adopt online learning post-pandemic.

While Mauritian academics faced challenges with internet connectivity for themselves and their students, their main concerns with the forced shift to WFH were social isolation, lack of a physical workspace conducive to effective work and general anxiety about COVID-19. While Zoom was adopted for communication with students and MS Teams for communication with colleagues, during the pandemic, WhatsApp and Emails were the tools that were the most frequently used communication channels by both students, colleagues and academics.

Only $33 \%$ of Mauritian academics were comfortable with sustaining their current WFH arrangements indefinitely. The others indicated that they would be willing to sustain these WFH arrangements for shorter periods ranging from one month to one week. A significant number of respondents felt that their institutions would adopt a blended learning approach after the pandemic. Although the hard work of understanding education at the level of $\mathrm{HE}$ in a time of the pandemic is still ahead and determinant, it can be concluded that open distance learning is perpetual and cannot survive without effective and appropriate technology. The data stemming from this research provides evidence to support the argument that open and life-long learning is taking place at HEIs in Mauritius. Increased access to internet connectivity to improve and uphold equity and enable students to access courses remotely should be 
the priority of the government in the next budget as most of the public universities are moving to hybrid approaches, as depicted by this study.

\section{Limitations}

Data was collected during the latter stages of the lockdown in Mauritius (May to June 2020). This was a busy period for academics, having to transition to a fully online teaching and learning environment, in an attempt to ensure continuity of academic activities. Hence, despite numerous requests and extensions for participation, the response rate was low. This means that while the results may prove interesting, and provide an insight during the pandemic, they cannot be projected onto the general academic population due to the small sample size.

\section{Future Research}

The body of literature on the impact of COVID-19 on HEIs is still developing. Future research could focus on the lived experiences of Mauritian academics in the transition to the online environment and its sustainability after the pandemic, and lessons from working from home can be well documented. It would be beneficial to investigate the impact of the transition to the online environment on Mauritian students, administrative and support staff at Mauritian HEIs as well.

\section{Acknowledgements}

The authors would like to thank and duly acknowledge participating institutions for providing approval for the study. All the participating academics are also duly thanked for their support and active participation for completing the online questionnaires.

\section{References}

Appavoo, P., K.S. Sukon, A.C. Gokhool \& V. Gooria 2018. Technology Affordances at the Open University of Mauritius: Experiences from Developing Countries. (Technology for Efficient Learner Support 
Services in Distance Education.) Singapore: Springer Nature Pty Ltd. https://doi.org/10.1007/978-981-13-2300-3 8

Banna, J., M.F. Grace Lin, M. Stewart \& M.K. Fialkowski 2015. Interaction Matters: Strategies to Promote Engaged Learning in an Online Introductory Nutrition Course. Journal of Online Learning and Teaching June, 11,2: $249-261$.

https://www.ncbi.nlm.nih.gov/pmc/articles/PMC4948751/ (Accessed on 31 August 2020.)

Bar, H. 2011. The Online Theology Classroom: Strategies for Engaging a Community of Distance Learners in a Hybrid Model of Online Education. Teaching Theology \& Religion 14,1: 13 - 20.

https://doi.org/10.1111/j.1467-9647.2010.00668.x

Blin, M. 2020. Mauritius Heads into a Coronavirus Storm with Strong Social Welfare Buffers. The Conversation.

https://theconversation.com/mauritius-heads-into-coronavirus-stormwith-strong-social-welfare-buffers-135702\#comment_2204746.

(Accessed on 30 August 2020.)

Chen, W.C. \& C. Bonk 2008. The Use of Weblogs in Learning and Assessments in Chinese Higher Education: Possibilities and Potential Problems. International Journal of E-Learning 7,1: 41 - 65.

Chou, S.S. \& C.H. Liu 2005. Learning Effectiveness in a Web-based Virtual Learning Environment: A Learner Control Perspective. Journal of Computer Assisted Learning 2: 65 - 76.

https://doi.org/10.1111/j.1365-2729.2005.00114.x

Courville, K. 2011. Technology and its use in Education: Present Roles and Future Prospects. Presented at the 2011 Recovery School District Technology Summit, 6 - 8 June 2011, Baton Rouge, Louisiana.

Deci, E. \& R. Ryan 2008. Self-determination Theory: A Macrotheory of Human Motivation, Development, and Health. Canadian Psychology 49,3: 182 - 185. https://doi.org/10.1037/a0012801

Deci, E., R. Vallerand, L. Pelletier \& R. Ryan 1994. Motivation and Education:

The Self-determination Perspective. Educational Psychologist 26,3-4:

325 - 346. https://doi.org/10.1080/00461520.1991.9653137

Dixson, M.D. 2010. Creating Effective Student Engagement in Online Courses: What do Students Find Engaging? The Journal of Scholarship of Teaching and Learning 10,2: 1 - 13. 
Eady, M.J. \& L. Lockyer 2013. Tools for Learning: Technology and Teaching Strategies. Senior Deputy Vice-Chancellor and Deputy ViceChancellor (Education) - Papers. 1 January 2013. Available at: https://ro.uow.edu.au/cgi/viewcontent.cgi?article=1413\&context=asdpap $\underline{\text { ers }}$

Economist 2020. COVID-19: The Impact on Higher Education.

https://www.eiu.com/n/COVID-19-the-impact-on-higher-education/

(Accessed 17 August 2020.)

Filippidi, A., N. Tselios \& V. Komis 2010. Impact of Moodle Usage Practices on Students' Performance in the Context of a Blended Learning Environment. Social Applications for Lifelong Learning 4 - 5 November 2010.

Gaigné, M. \& E. Deci 2005. Self-Determination Theory and Work Motivation. Journal of Organizational Behavior 26: 331 - 362.

https://doi.org/10.1002/job.322

Ghandforoush, P. 2013. A Study of Perceptions of Online Education among Professionals. ERIC, International Association for the Development of the Information Society. https://eric.ed.gov/?id=ED562275

(Accessed on 14 September 2020.)

Grinager, H. 2006. How Education Technology Leads to Improved Student Achievement. Education Issues November 2006.

Groff, J. 2013. Technology-Rich Innovative Learning Environments. OECD CERI Innovative Learning Environment Project.

https://www.oecd.org/education/ceri/Technology-

Rich\%20Innovative\%20Learning\%20Environments\%20by\%20Jennifer \%20Groff.pdf

(Accessed on 17 August 2020.)

Hughes, A. 2009. Higher Education in a Wen 2.0 World: Report of an Independent Committee of Inquiry into the Impact on Higher Education of Students' Widespread Use of Web 2.0 Technologies. JISC. www.jisc.ac.uk/publications/documents/heweb2.aspx

(Accessed on 17 August 2020.)

Hussain, I. \& M. Safdar 2008. Role of Information Technologies in the Teaching and Learning Process: Perception of the Faculty. Turkish Online Journal of Distance Education 9,2.

Jhuree, V. 2005. Technology Integration in Education in Developing Coun- 
tries: Guidelines to Policy Makers. International Education Journal 6,4: $467-483$.

Jung, I. 2008. ICT and Quality Assurance to Support Ubiquitous Access to Distance Education: Promises, Realities and Recent Breakthroughs. $5^{\text {th }}$ EDEN Research Workshop 20 - 30 October 2008, Paris, France. https://www.slideshare.net/eden_(Accessed on 17 August 2020.)

Ketterl, M., R. Mertens, O. Vornberger 2009. Bridging Web 2.0 to Web Lectures. Emerald-Interactive Technology and Smart Education 6,2. https://doi.org/10.1108/17415650910968099

Lee, C. 2020. The Impact of COVID-19 on Higher Education: What will 20202021 Look Like? ttps://www.turnitin.com/blog/the-impact-of-COVID19-on-higher-education-what-will-2020-2021-look-like

(Accessed on 31 August 2020.)

Lens, W., L. Matos \& M. Vansteenkiste Janeiro/ Abril. 2008. Professores como fontes de motivação dos alunos: o quê e o porquê da aprendizagem do aluno. Educação Porto Alegre 31,1: 17 - 10.

Liaw, S.S., G.D. Chen \& H.M. Huang 2008. Users' Attitudes towards Webbased Collaborative Learning Systems for Knowledge Management. Computers \& Education 50: 950 - 961.

https://doi.org/10.1016/j.compedu.2006.09.007

Madhavaiah, G., C. Nagaraju \& S. Peter 2013. Importance of Technology in Teaching and Learning English Language. International Journal of Scientific Research and Reviews 2,3: 146 - 154.

Marks, A. 2020. COVID-19: Study Considers the Impact of 'New' Home Working Arrangements on Wellbeing.

https://www.stir.ac.uk/news/2020/05/COVID-19-study-considers-theimpact-of-new-home-working-arrangements-on-wellbeing/

(Accessed on 31 August 2020.)

Maro, A.H. 2008. Information Literacy Skills for Electronic Resources: A Study of the Students of the Open University of Tanzania. MA dissertation, University of Dar es Salaam.

Singh, U.G. 2020a. Academic Digital Literacy - A Journey we All Need to Take.

https://www.universityworldnews.com/post.php?story=20200630085507 $\underline{410}$ (Accessed on 31 August 2020.)

Singh, U.G. 2020b. UKZN Academic Develops Framework for Online Lear- 
ASSET@ (Academic Skillset. Available at: https://clms.ukzn.ac.za/ukznacademic-develops-conceptual-framework-for-online-learning/ (Accessed on 21 August 2020.)

Usluel, Y.K. \& S.G. Mazman 2009. Adoption of Web 2.0 Tools in Distance Education. World Conference on Educational Sciences 2009. www.sciencedirect.com (Accessed on 14 August 2020.) https://doi.org/10.1016/j.sbspro.2009.01.146

Wiid, J.A., M.C. Cant \& S.M. Kallier 2015. The Perceptions of Students on the Use of Social Networking Systems as a Teaching Tool in ODL Institutions. International Business \& Economics Research Journal 14, n.1. https://doi.org/10.19030/iber.v14i1.9029

Witze, A. 2020. Universities will Never be the Same after the Coronavirus Crisis. The Nature Newsletter \& Springer Nature. https://doi.org/10.1038/d41586-020-01518-y https://www.nature.com/articles/d41586-020-01518-y (Accessed on 31 August 2020.)

World Health Organisation 2020. WHO Coronavirus Diseases (COVID-19) Dashboard.

https://covid19.who.int/?gclid=EAIaIQobChMIuoTy3cjD6wIV3BoGAB 1MjgCoEAAYASAAEgKdJvD_BwE (Accessed on 30 August 2020.)

Upasana Singh Academic Leader \& Senior Lecturer Information Systems and Technology

Westville Campus, University of KwaZulu Natal

Durban

South Africa singhup@ukzn.ac.za

Vandanah Gooria Programme Manager and Lecturer Marketing, Management and Special Needs Management Open University of Mauritius v.gooria@open.ac.mu 


\section{Emerging Issues in Higher Education Leadership: Results from Round 1 of a Global Delphi Survey}

\section{Rob Elkington \\ ORCID iD: https://orcid.org/0000-0001-7939-6551}

\section{Abstract}

This chapter focuses on the emerging issues facing the leadership of Higher Educational Institutions (HEI) globally. The reader is alerted to the fact that many of these issues are emerging in the $21^{\text {st }}$ century due to the impact of the Fourth Industrial Revolution (4IR). A brief description of the 4IR is rendered to highlight the intersection of HEI leadership and the impact of this emerging new 4IR context. The chapter probes the issues facing the leadership of HEI through a robust literature review and the results of a first round Lockean Delphi survey of HE leaders in several countries such as Canada, the USA, and South Africa. The Delphi survey highlights four issues facing HE leadership, followed by suggestions for the second round Delphi survey to probe these four issues further.

Keywords: Higher Educational Institution (HEI), leadership, Fourth Industrial Revolution (4IR), Delphi survey, globalization, gender equity, racial equity, mentorship, e-leadership, funding

\section{Introduction}

Scholars suggest that we have entered the Fourth Industrial Revolution (4IR) and the impact of this revolution on society in general, and education, particularly are topics under in-depth analysis (Bonciu 2017a; Bonciu 2017b Chung 2017; Fonseca 2018; Kodama 2018; Zucconi 2016). This detailed analysis is no less acute, concerning our need to examine the type of leadership needed by higher education institutions (HEIs) to survive and thrive in this emerging context of the 4IR in which we see the integration of the real world 
(the physical world), with the biological world (particularly with humanity), and with the digital world (the virtual world) (Bonciu 2017a; Fonseca 2018; Panchak 2016). What type of leadership might be optimal for HEIs to ensure that faculty and students are equipped to address the emerging issues arising from the emerging 4IR context? Our research seeks to answer the question of the best leadership style for higher education (HE) in 4IR settings through iterations of Delphi surveys probing: 'what issues are emerging in higher education as weak signals that might require adaptation or change on the part of higher education leadership?'

\section{Method of Research: Lockean IS Delphi Survey}

In the first phase of our research, we seek to answer this question, "what issues are emerging in higher education as weak signals that might require adaptation or change on the part of higher education leadership', by reporting on the Delphi survey responses of thirty-one HE leaders. We attempted to survey a global sampling of HE leadership, but as the details in our table of respondents highlight, we could not secure responses from a range of countries. We hypothesize that this might be due to language barriers, a lack of time to respond due to the demands of leading in a global pandemic, or a lack of interest.

With so many contextual, cultural, and personal factors that could contribute to leadership in HE, and thus effective leadership development, we attempted to gain a 'snapshot' of the key issues challenging HE leadership within the current context. This 'snapshot' approach is best afforded by a Delphi survey as the Delphi presents a holographic-type image of the complex whole (Bowen 2009; Jain \& Sharma 2005). The Delphi survey was developed in the 1950's by the American military to assess the maximum nuclear payload required to serve as a deterrent to any Russian nuclear threat. This initial study was known as the 'Rand' study, and it brought together several experts in the field. These experts responded to a series of iterative surveys until a point of consensus was reached concerning the correct level of nuclear payload to serve as a deterrent to the Soviet Union.

There are five different types of Delphi methodologies (Linston \& Turoff 2002). Each type of Delphi method encompasses a different philosophical model or system. The particular Delphi Inquiring System, or methodology, that we used for this study into emerging issues in HE leadership was the Lockean Inquiring System. The Lockean IS is described as follows: 
In brief, Lockean IS are the epitome of experimental, consensual systems. On any problem they will build an empirical, inductive representation of it. They start from a set of elementary empirical judgements ('raw data', observations, sensations) and from these build up a network of ever expanding, increasingly more general networks of factual propositions. A typical Lockean point of view is the assertion that one doesn't need any theory in order to collect data first, only to analyze it subsequently (Linstone \& Turoff 2002: 20).

This Lockean IS Delphi approach for this particular research project has the strength of its 'ability to sweep in rich sources of experiential data'. The weaknesses, on the other hand, are those that beset all empirical systems. While experience is undoubtedly rich, it can also be extremely fallible and misleading (Linstone \& Turoff 2002: 22).

\section{Our Survey Within the Context of the Fourth Industrial Revolution (4IR)}

The 4IR is briefly described as,

... based on the connection of everything. [The] Keywords are 'automation' and 'connectivity. In other words, the fourth industrial revolution is an industrial revolution created by ICT convergence which are IoT (Intemet of Things), AI (Artificial Intelligence), Robot, Mobile, 3D Printer, Unmanned Vehicle, Drones, Nano and Biotechnology, Materials Science, Quantum Computer. The Hyper-connect revolution in which everything, people, things, space, everything connected and interacted, emerged as a new future paradigm. The scope of the connection has become possible from the 'IoT' to the 'IoE', and the 'offline' connection and intelligent IoE (Chung 2017).

With this understanding of the 4IR as a backdrop, we reached out to HE leaders in Western countries concerning their perceptions of issues emerging for HE leadership within this 4IR context. It seems evident that HEIs might be interested in understanding the symbiosis between the physical, biological, and digital entities and how the intersection of these might shape the learners of today for the reality of tomorrow (Kern 2017). A leadership question 
emerging for HEIs in this new 4IR context might be: 'Are the programs, methods, and delivery platforms currently deployed by higher education institutions relevant to the emerging 4IR?' (Zucconi 2016). This question of relevance is primarily a leadership question. The question of relevance relates to leadership if, for instance, we espouse Greenleaf's Servant Leadership approach that contends that it is the ethical responsibility of the leadership of an organization to anticipate the future challenges that might undermine the health or sustainability of the organisation (Spears \& Lawrence 2004).

As one theorist suggests, effective leadership is highly conceptual. This conceptual dimension of leadership possesses the capacity to understand where an organization is currently and where it needs to be in the emerging future (Katz 1955). With Katz's framework in mind and with the emerging 4IR as an overarching context, we framed our first Delphi question to read: 'What issues do you see emerging in the next three to ten years that are critical to higher education leadership?'.

At the outset, we thus distinguish between the HE leader and HE leadership (Dalakoura 2010). We, therefore, recognise the leader, which focuses on human capital, and leadership which focuses on social capital within the HEI (Grandy \& Holton 2013; Vardiman 2006). The notion of 'leader' describes the leadership capacity of an individual by incorporating elements such as the self-awareness, self-regulation and self-motivation of an individual. The term 'leadership', on the other hand, seeks to promote an organisational culture in which leadership processes and emergence are fostered and supported and in which leadership can emerge from surprising places and in unusual circumstances, such as the liminality we encounter in 4IR contexts (Vardiman et al. 2006).

Before we launched the Delphi Survey, we scanned the literature to gain insight into emerging issues in HE leadership. We share the results of the literature survey in the next section.

\section{A Review of the Literature}

\subsection{Issues Facing Higher Education Leadership - Overview}

Leadership is of considerable interest in contemporary scholarship on education administration, and this interest has increased over the last few decades (Alonderiene \& Majauskaite 2016; Eacott 2012). Effective leadership is perceived as the critical difference between success and failure for most 
organisations, and this is no less true of the HEI. However, according to Hornsby et al. (2011: 97),

... higher education is ill-prepared to navigate the pace and significance of change in the 21 st century. Leaders are pulled from among the faculty who generally resist being led anywhere; leading faculty is often referred to as herding cats and faculty training often does not provide support for those thrust into leadership roles.

In many organisations, there seems to exist a mistaken belief that because a person has technical expertise in a specific area, that technical expertise will automatically translate to leadership effectiveness. The skills approach to leadership (Northouse 2018: 56) highlights that individual attributes such as 'general cognitive ability, crystallized cognitive ability, motivation, and personality' are only one piece of a larger leadership skillset that must also include competencies such as 'problem-solving skills, social judgment skills, and knowledge'. It is difficult to determine if the practice of selecting leaders from amongst faculty further exacerbates the issues in $\mathrm{HE}$ leadership because faculty members are not always trained for leadership, or if these issues exist because of the powerful contextual drivers of the 4IR intersecting education institutions designed to function in the 2IR and 3IR. A summary of the leadership issues confronting HEIs as identified in the literature is presented in Table 1. We label these issues or problems as either 'Tame', 'Critical', or 'Wicked', as per Grint's taxonomy of problems - see Figure 1 below (Grint 2005). When analysing Grint's taxonomy, it is helpful to note the different leadership approaches suggested by the level or degree of complexity and severity of the problem.

When organizations face critical problems, the level of leadership is relatively mundane, requiring a command and control function. In this range, the leadership assesses the nature of the problem and then provides answers or solutions to the problems confronting the team or the organization. As one moves along the continuum in Grint's taxonomy, one is confronted by 'Tame' more complex problems. The leadership can invoke the traditional linear calculative rational decision-making model. When addressing Tame problems, the role of leadership is to develop processes that mitigate the expansion of the problem and address the systemic and root causes of the problem in ways that provide for organizational progress and health. 


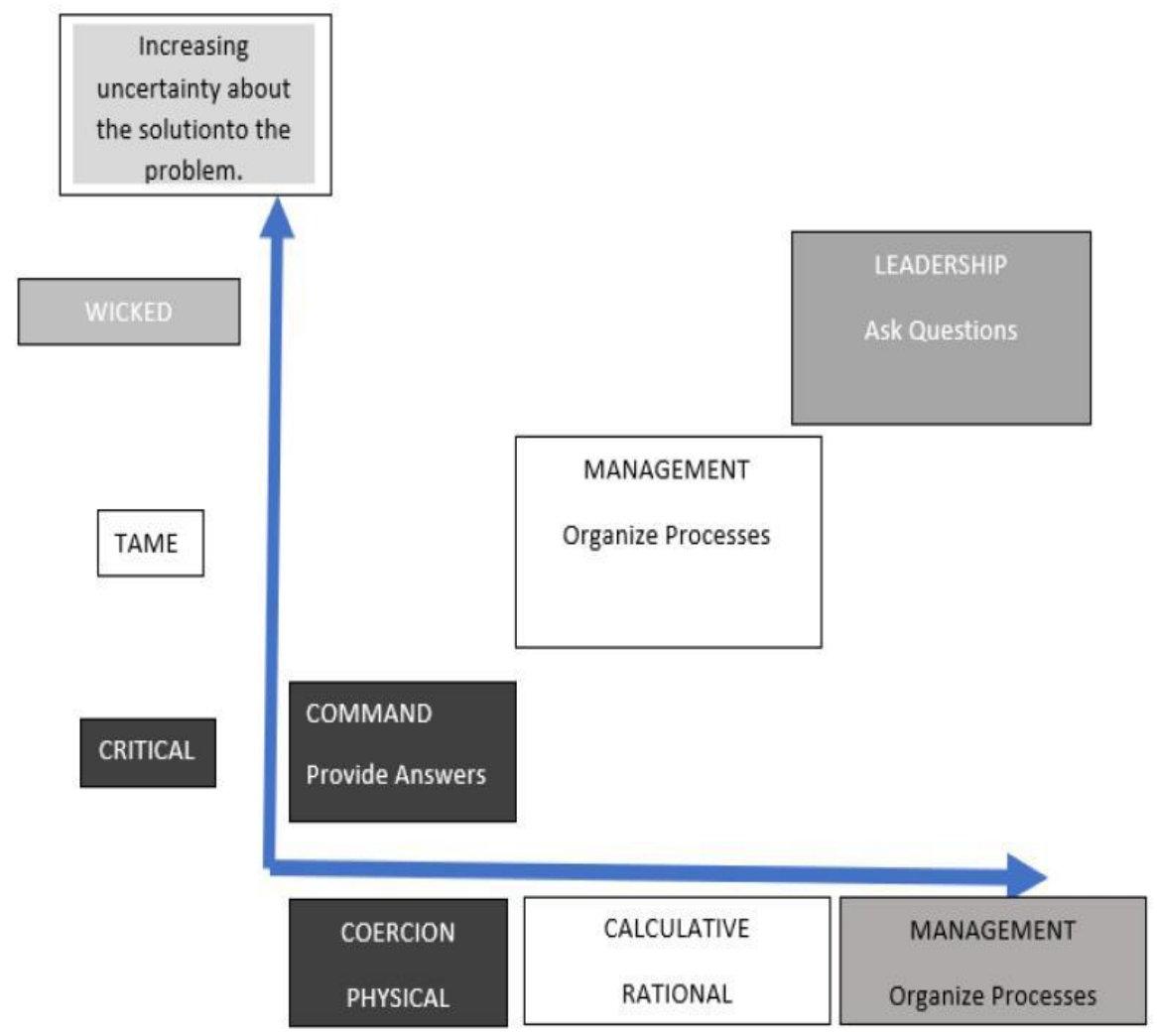

Figure 1. Grint's Taxonomy of Problems and the Social Construction of Leadership

However, when one confronts Wicked problems, problems that have no evident solution and are often vast in scope and highly complex, the role of leadership is not to provide answers. Rather, when confronting Wicked problems, leaders must design organizational contexts in which agile and collaborative problem-solving and decision-making can occur. When facing Wicked problems, leaders are not called upon to provide the right answers or the right solutions. In these 'Wicked problem' situations leaders are called upon to have the wisdom to ask the right questions - questions that open the door for creative engagement through the use of intentional critical thinking, the scraping and visualisation of big data, and the capacity to include a wide 
range of diverse stakeholders who have the freedom to voice their perspectives, ideas, and findings (Schrage 2017).

In Table 1 the issues and challenges currently facing HE leadership, as identified in the literature, are listed and assigned a value of 'Critical', 'Tame', or 'Wicked'.

It is interesting to note that the first three of these issues, globalization, status-quo thinking, and e-leadership, relate directly to the 4IR.

\section{Table 1: Issues and Challenges Currently Facing Higher Education Leadership}

\begin{tabular}{|c|c|c|}
\hline PROBLEM & DESCRIPTION & $\begin{array}{l}\text { CRITICAL， TAME， or } \\
\text { WICKED }\end{array}$ \\
\hline $\begin{array}{l}\text { Globalization } \\
(\text { Goddard 2015) }\end{array}$ & $\begin{array}{l}\text { The rapid and massive } \\
\text { movement of people } \\
\text { around the world } \\
\text { exposing countries to } \\
\text { new cultures, practices, } \\
\text { and economies. }\end{array}$ & $\begin{array}{l}\text { A Tame problem in that } \\
\text { management needs to } \\
\text { organise processes to } \\
\text { support international } \\
\text { students while also } \\
\text { developing Cultural } \\
\text { Intelligence as a skill } \\
\text { amongst faculty members. }\end{array}$ \\
\hline $\begin{array}{l}\text { Status Quo } \\
\text { Thinking } \\
\text { (Dervitsiotis } \\
\text { 2005; English \& } \\
\text { Ehrich 2015) }\end{array}$ & $\begin{array}{l}\text { The incapacity of higher } \\
\text { education leadership to } \\
\text { develop agility to } \\
\text { address turbulent } \\
\text { contexts. }\end{array}$ & $\begin{array}{l}\text { A Tame problem in that } \\
\text { this challenge can be } \\
\text { addressed through effective } \\
\text { leadership selection and } \\
\text { development. }\end{array}$ \\
\hline $\begin{array}{l}\text { E-Leadership } \\
\text { (Jameson 2013) }\end{array}$ & $\begin{array}{l}\text { The need to bridge } \\
\text { between education } \\
\text { technology and } \\
\text { leadership. There is a } \\
\text { gap in the research into } \\
\text { the type and process of } \\
\text { leadership needed for e- } \\
\text { learning contexts. }\end{array}$ & $\begin{array}{l}\text { A Tame problem in that } \\
\text { this challenge can be } \\
\text { addressed through further } \\
\text { research into e-leadership } \\
\text { and the outcomes of that } \\
\text { research integrated into } \\
\text { current e-leadership } \\
\text { contexts. }\end{array}$ \\
\hline
\end{tabular}




\begin{tabular}{|c|c|c|}
\hline $\begin{array}{l}\text { Mentorship } \\
\text { (Grogan \& } \\
\text { Crow 2004) }\end{array}$ & $\begin{array}{l}\text { The need to formalise and } \\
\text { standardise the mentor- } \\
\text { ship process as well as to } \\
\text { find effective mechanisms } \\
\text { for mentorship that } \\
\text { empower new leadership, } \\
\text { rather than entrenching } \\
\text { the old ways. }\end{array}$ & $\begin{array}{l}\text { A Tame problem that can } \\
\text { be addressed through } \\
\text { further research into best } \\
\text { practices and the } \\
\text { implementation of those } \\
\text { practices for effective } \\
\text { mentorship of new } \\
\text { leadership. }\end{array}$ \\
\hline $\begin{array}{l}\text { Gender Equity } \\
\text { (Fitzgerald } \\
\text { 2003; Hornsby } \\
\text { et al. 2011; } \\
\text { Killingsworth et } \\
\text { al. 2010) }\end{array}$ & $\begin{array}{l}\text { The need to identify the } \\
\text { impact of bias, and the } \\
\text { cultural hegemony of } \\
\text { male-dominated leader- } \\
\text { ship, and the infiltration } \\
\text { of this bias and hegemony } \\
\text { into leadership develop- } \\
\text { ment, as well as access to } \\
\text { leadership opportunities. }\end{array}$ & $\begin{array}{l}\text { Critical problem that can } \\
\text { be addressed in a systemic } \\
\text { way through effective } \\
\text { leadership policy and } \\
\text { interventions (Young et al. } \\
\text { 2006). }\end{array}$ \\
\hline $\begin{array}{l}\text { Racial Equity } \\
\text { (Fitzgerald } \\
\text { 2003; Rusch } \\
\text { 2004, Skerrett } \\
\text { 2011) }\end{array}$ & $\begin{array}{l}\text { The lack of racial integra- } \\
\text { tion and the lack of } \\
\text { representation within } \\
\text { higher education leader- } \\
\text { ship is clear (Fitzgerald } \\
\text { 2003; Rusch 2004). Some } \\
\text { researchers suggest that } \\
\text { the historical trajectory } \\
\text { actually places higher } \\
\text { education leadership and } \\
\text { education policy in a } \\
\text { mono-cultural paradigm } \\
\text { that seeks standardisation } \\
\text { as a supposed protection } \\
\text { of high education } \\
\text { standards (Skerrett 2011). }\end{array}$ & $\begin{array}{l}\text { Wicked problem, } \\
\text { potentially, since racism is } \\
\text { a wider societal problem } \\
\text { that is carried into the } \\
\text { education context. Societal } \\
\text { bias and governmental } \\
\text { policy changes might be } \\
\text { required to address this } \\
\text { issue. }\end{array}$ \\
\hline
\end{tabular}




\begin{tabular}{|c|c|c|}
\hline $\begin{array}{l}\text { Funding } \\
\text { (Andrews et al. } \\
\text { 2016; Davis et } \\
\text { al. 2015; } \\
\text { Jameson 2013; } \\
\text { Jusoh et al } \\
\text { 2015; Kalinski } \\
\text { et al. 2015; } \\
\text { Kezar \& Lester } \\
\text { 2009). }\end{array}$ & $\begin{array}{l}\text { As the global economy } \\
\text { slows, and as 4IR changes } \\
\text { the face of work, the } \\
\text { delivery models of } \\
\text { education, traditional } \\
\text { mechanisms and sources } \\
\text { of funding are under } \\
\text { strain. }\end{array}$ & $\begin{array}{l}\text { A Wicked problem since } \\
\text { the trajectory of funding } \\
\text { difficulty seems set within } \\
\text { the current context and } \\
\text { will only worsen as time } \\
\text { progresses. There is a need } \\
\text { for innovative thinking } \\
\text { around delivery models, } \\
\text { pricing, and many of the } \\
\text { 'extra' or 'hidden' costs } \\
\text { associated with higher } \\
\text { education. }\end{array}$ \\
\hline
\end{tabular}

\subsection{The Issue of 'Status Quo' Thinking or Inertia in a Volatility, Uncertainty, Complexity, Ambiguity (VUCA) Context}

Higher education leadership is not immune to the forces of Terra Incognitae (Lagadec 2009) and vu jádè (Day \& Harrison 2007). These terms, though used to describe the challenges facing government and business leadership, are no less appropriate for HE leadership. Terra Incognitae, as used by Lagadec (2009), refers to the notion that we are in uncharted territory, a world unknown. Vu jádè, as used by Day and Harrison (2007), refers to the sense that many in leadership feel that they have 'never been here before' and that they are traversing new and uncharted territory for which there exists no map or guideposts. These unstable environments call for a different style of leadership within HE. As one author so incisively asserts (Dervitsiotis 2005):

As a living system, a human organization evolves over time as a continually adaptive system. It is only with this mental 'lens' that we can make sense of and appreciate the strong interactions and emotional energy that a new meaning may release in individuals or teams in the workplace. Traditional leadership's usual response to 'hold things steady' trying to maintain the same strategy in periods of rapid change can be disastrous.

The notion that holding things steady in this period of rapid change might 
prove disastrous is also true for the leadership of HEIs (English \& Ehrich 2015). Status quo thinking, inaction in the face of globalization and the incapacity to adjust to the positive and challenging dimensions of functioning in a globalized context is just some of the challenges that leadership of HEIs face (Goddard 2010 2015). This status quo thinking in the face of globalization is further challenged by 'VUCA' (Bolman \& Deal 2015; Das \& Ara 2014; Drucker 2013; Halamka 2011; Hood 2015; Moore 2014). VUCA stands for 'Volatility, Uncertainty, Complexity, Ambiguity'. A great deal has been written about the type of leadership needed to thrive in a VUCA world (Bawany 2016; Bolman \& Deal 2015; Das \& Ara 2014). Many of the skillsets and mindsets that are suggested for business and military leadership may be transferable to education leadership. VUCA is a reality for every organisation in the 21 st century, and HE leadership needs to be aware of its presence and its antidote known as 'VUCA prime' (Lawrence 2013).

\subsection{The Issue of Globalization}

The impact of globalization is being felt by organizations in every sector, and especially those involved in education leadership (Goddard 2015). Globalization has resulted in the increased complexity of the leadership role in the HE environment (Drew 2010). While the context in which HEIs must function has changed dramatically in the face of globalization and VUCA, the leadership of those institutions may lack the agility necessary to adapt to the imposing challenges of globalization and of VUCA (English \& Ehrich 2015). It seems plausible then that there are multiple issues and problems that confront the leadership of HEIs. One way of identifying some of the emerging issues arising from globalization and VUCA is through alertness to 'weak signals' (Lagadec 2009). As Mack (2015: 45) suggests:

The search for weak signals, properly done, can enhance one's ability to spot problems early, share them with allies, and extend the senses of the organization beyond organizational boundaries. Locating leading edges of developments or warning early enough is critical. That means calling attention to developing trends neither too late nor too soon, as too late does no one much good (like yesterday's news) and comes close to embracing 'conventional wisdom', while too soon can also be problematic, with an overly visionary leadership team 
ending up too far ahead of other stakeholders and accordingly out of connection with 'real world' dynamics.

It is this search for these weak signals in HE leadership that informs our research and is further discussed in the 'methods' section of this paper. To quote Mack (2015: 45) again:

The reader might notice the use of the phrase 'leadership team', because I want to strongly reinforce that the search for weak signals simply cannot yield useful results as the exercise of a single visionary leader or analyst. It must be a team effort and ideally a community effort, involving coordinated work among concerned and relevant stakeholders to yield viable results over the longer term. As such, the broader the search process and the greater the number of scanning participants, the higher the chances of yielding relevant and useful data.

\subsection{The Issue of Mentorship}

Mentorship is valuable as a leadership development tool within HE settings (Sheridan et al. 2015).

It is suggested that individuals within HEIs that receive mentorship have greater satisfaction in the workplace and clearer direction for scholarly endeavours, which in turn contributes to higher levels of engagement, retention, and recruitment (Sheridan et al. 2015). Mentorship is also beneficial to support networking and socialization for minority faculty moving towards leadership in HEIs (Sheridan et al. 2015). However, with these benefits in mind, there is also a concern that in the mentoring process, atrophy is passed from experienced leadership to emerging leadership, or as Grogan and Crow (2004: 463) refer to it: 'Old Wine in New Bottles'. There is also a need to formalize and standardize the mentorship process within HEIs (Grogan \& Crow 2004; Johnson \& Ridley 2008).

Mentorship is perceived in most sectors as beneficial to the development of talent and an attribute of effective leadership (Reyes et al. 2014; Schafer 2009). Effective mentorship is a challenge within HE leadership, both in terms of its process (how to do it) and in terms of its purpose, including the need to ensure that we do not impose old and outdated experience onto new 
leadership emerging into new contexts (Grint 2007).

\subsection{The Issue of Gender Equity}

Tied to the question of mentorship and succession planning, both of which affect women leadership in general, and women leaders in HE in particular (Gipson et al. 2017; Shields \& Cassada 2016), is the looming issue of gender equity within HE leadership which emerges as a universal and global problem (Fitzgerald 2003; Hornsby et al. 2011). Fitzgerald (2003) highlights three ways in which gender equity manifests itself in HE leadership. The first domain or 'gender script' (2002: 56), refers to studies that provide demographic data and explore characteristics, attitudes, opinions and perceptions of selected issues. These data contribute to an understanding of the broader socio-political environment in which women as leaders operate as a numerical minority.

The second domain offers explanations of career patterns and issues related to career aspirations, access to leadership opportunities, employment strategies, mentoring, professional barriers, retention and experiences of women leaders. Arguably, the central focus of these studies is the way in which women leaders face occupational and professional challenges and can be termed 'discourses of opportunity'. That is, the achievement of women in acquiring and exercising leadership positions is related to opportunities of access and personal or professional strategies.

The final domain encompasses a wide range of inquiry that seeks to understand the nature of the various education, managerial and political roles and draws attention to issues of power, visibility, collaboration, conflict and change management. In subliminal and subtle ways, this literature provides a relief map of women's ways of knowing and leading and furthermore charts ways in which women inevitably exercise leadership in schools.

Some HE researchers suggest that gender inequity is subsumed in education leadership preparation and that opportunities for students to facilitate discussions regarding gender inequity need to be provided (Killingsworth $e t$ al. 2010).

In a bid to address gender inequity within HE leadership, Ohio State University created the President and Provosts Leadership Institute (PPLI) to develop a pool of women and underrepresented minority Faculty members who might move into leadership positions (Hornsby et al. 2011). The results of this initiative present a dualistic tension. Namely, women leaders emerged from the 
program ready to lead and took up administrative leadership; however, limited or no positions were available. As respondents to the post-PPLI training stated (Hornsby et al. 2011):

I don't think I will [have a leadership opportunity] unless I move to another position somewhere else... there is no opportunity on campus, and I do not think our leaders recognize the amount of learning an individual has [achieved] as a result of this program.

Another said,

This is a negative issue for me. I am now focusing on my research, so I can pursue a leadership role at another institution.

A third participant expressed surprise, in a private conversation, at having no leadership opportunities offered to her. The focus group discussions noted that deans do not always know what skills the PPLI graduate has and that the University does not leverage the graduates to the extent that it could.

It seems that within HE leadership, gender equity faces issues of inherent bias that permeates the messaging and training of women for leadership and access to leadership positions for women within HEIs. This is not just a North American phenomenon - it is a global issue (Sperandio 2010). Transformational learning around the issues of gender and leadership needs to occur at various levels as an intentional intervention if this problem is to be addressed and ultimately leveraged for HE leadership to thrive (Young et al. 2006).

\subsection{The Issue of Racial Equity}

Closely tied to the issue of gender equity within HE leadership is another issue of diversity and leadership, namely the inequity of racial integration and the lack of multi-ethnic representation within HE leadership (Fitzgerald 2003; Rusch 2004). Some researchers suggest that the historical trajectory places HE leadership and education policy in a mono-cultural paradigm that seeks standardization as the supposed protection of high education standards (Skerrett 2011). Longstanding stereotypes further supported this mono-cultural paradigm developed early on in the education process and perpetuated, sometimes unconsciously, in the structure of HE leadership choices and HE leadership 
structures (Fitzgerald 2003; Niesche \& Keddie 2011; Ward 2013). It is useful when thinking about gender inequity and racial inequity within HE leadership to grasp the nuances and layers of this type of discrimination within many HEIs globally. Women are disadvantaged compared to their male counterparts, but then it appears that women who are not of the preferred racial grouping are even further disadvantaged to take on formal leadership roles within HEIs. The privilege in North America, for example, might thus be constructed as white male first, white female second, non-white male third, non-white female fourth with the representation of each stratum in leadership lessening along the trajectory from white male to non-white female (Fitzgerald 2003).

Racism is a construct that is still deeply embedded in countries worldwide, and its effect is manifest across many domains in society. It appears that HE leadership selection is not immune to racism, and so it was surprising that it did not emerge as an issue in the first round Delphi survey. We do not think this means that gender and racial equity within HE leadership have been achieved. Instead, perhaps, it might reflect how we framed the question for the Delphi: What are the emerging issues confronting higher education leadership in the next three to ten years? Since gender bias and racial bias are positioned as longstanding and ongoing issues, the respondents possibly felt that these two issues fell outside the range of 'emerging issues ... in the next three to ten years.

\subsection{The Issue of E-Leadership}

Current HE leadership continually evolves around the advance of technology, and this evolution leads to another challenge confronting the leadership of HEIs, namely e-leadership (Jameson 2013). Jameson suggests that as part of a natural progression of education technology research, considerably more attention needs to be focused on research and development in e-leadership and the related fields of e-Management and e-Governance applied to education technology. What type of leadership is best suited to facilitate e-leadership? It appears that e-Leadership poses a significant challenge and that more empirical research into effective modalities of e-leadership is needed.

\subsection{The Issue of Funding}

Funding for HEIs is under stress globally. In the author's home province of 
Ontario, funding to HEIs has been cut by 10\% (Jones 2019). Funding for HEIs is uncertain (Davis et al. 2015) since governments change, and so do funding priorities. So too globalization and the interconnectedness of geopolitical factors upon HE funding have an impact on the sustainability of these institutions. Take, for instance, the result of President Trump's visa policies upon foreign student enrolment in the USA (Silman 2020) or Canada's recent diplomatic falling out with Saudi Arabia and the Saudi withdrawal of over eight thousand students from universities and colleges across Canada (Chase 2018). No less poignant is the recent impact of student activism upon funding for South African universities in the 'Fees Must Fall', movement, the activism alone costing universities in the tens of millions of dollars (South African currency = Rand) (Fihlani 2019). The pressure to attract and retain students in HE programmes is intense as funding issues become more and more acute, and students also advocate better quality education for a lower cost (Kalinski et al. 2015).

Having reviewed the literature around issues emerging in $\mathrm{HE}$ leadership, we now turn to the empirical research conducted through a Lockean Delphi survey of thirty-one $(n=31)$ HE leaders in several countries such as Canada, the USA, and South Africa.

\section{Research Objectives and Methodology}

The main research question of this study was as follows: What are the emerging issues higher education leadership is likely to confront in the next three to ten years?

The objective of this research was to understand the HE leadership's sense or perception of the challenges and issues likely to emerge in the next three to ten years. In a bid to assess HE leadership's understanding of the emerging issues confronting HE, a Lockean Delphi survey approach was adopted for this study. As discussed in the methods section previously, Delphi surveys have been used extensively for research that seeks to understand experts' perceptions of potential futures and so fit well as a method of choice for this study (Keeney et al. 2006; Morgan et al. 2013; Ouariachi et al. 2018; Skulmoski et al 2007; St. Pierre et al. 2006; Wilson \& Moffat 2010).

This study aimed to gain a broad and global perspective on emerging issues confronting HE leadership within the context of 4IR. The research fell short of achieving a global perspective because of the lack of response from 
HE leaders from Asian and Eurasian countries as well as South American countries. It might be that language, culture, and context impacted the response rate from these countries.

As a first step in the research process, we sought in this chapter to identify current problems and challenges facing HE leadership from the existing literature.

We then explored HE leadership's perceptions of emerging challenges through the instrument of a Delphi survey (Hasson et al. 2000; Skulmoski et al. 2007; Wilson \& Moffat 2010).

The research question: 'What are the emerging issues confronting higher education leadership in the next three to ten years?' was sent to over three hundred HE leaders around the world.

These leaders ranged from institutional Presidents and Vice Presidents, Deans, Associate Deans, and Faculty Chairs. The response rate of $10 \%(n=31)$ is said to be typical for a Delphi survey, and while this may appear to be a low response from participants, the evidence suggests that Delphi surveys seem to garner around a 10\% response rate (Cole et al. 2013). Due to the respondent's need to qualify as experts in the subject matter under review, it is helpful to note that Delphi surveys, therefore, reach out to a smaller pool of respondents (Albertson \& Cutler 1976). Some useful Delphi studies used only a 60 person expert panel, and there are Delphi studies whose respondent pool has been as low as 15 persons (Hasson et al. 2000). The authors using such low survey numbers did so because the experts were so specialised that securing respondents was challenging, and the high level of response required meant that a smaller pool would still render a rich data yield (Keeney et al. 2006). How then did our 31 experts respond to the question: "What are the emerging issues confronting higher education leadership in the next three to ten years?' Their responses are detailed for the reader in the following paragraphs.

\section{Findings \\ 4.1 Participant Profile}

A sample of 31 participants $(n=31)$ from around the world responded to the email invitation to participate in the Delphi survey. Over 300 invitations were sent out; therefore, our Delphi response rate was about 10\%. Table 2 indicates the profile of the respondents by gender and country of residence: 


\section{Table 2: Participant Profile}

\begin{tabular}{|l|l|l|}
$\begin{array}{l}\text { Number of } \\
\text { Participants }\end{array}$ & Country of Residence & Gender \\
\hline $\mathbf{3}$ & Australia & Male = 3 \\
\hline $\mathbf{7}$ & Canada & $\begin{array}{l}\text { Female = 5 } \\
\text { Male = 2 }\end{array}$ \\
\hline $\mathbf{1}$ & Kenya & Female = 1 \\
\hline $\mathbf{1 1}$ & South Africa & $\begin{array}{l}\text { Female = 3 } \\
\text { Male = 8 }\end{array}$ \\
\hline $\mathbf{1}$ & United Kingdom & Male = 1 \\
\hline $\mathbf{5}$ & $\begin{array}{l}\text { United States of } \\
\text { America }\end{array}$ & $\begin{array}{l}\text { Female = 2 } \\
\text { Male = 3 }\end{array}$ \\
\hline $\mathbf{3}$ & Unknown & Female = 3 \\
\hline
\end{tabular}

\subsection{Analysis of Results}

Once responses were received from the 31 participants from the above countries, and a substantial amount of time has elapsed with no further replies after the second round of invitations, the survey was closed, and the process of open and axial coding proceeded.

This open and axial coding resulted in four key areas of concern for HE leadership: Relevance, Funding, Leadership, and Student Quality. We highlight the density of certain themes or emerging issues as ' $n=$ number occurrences' in our discussion of the emerging issues below.

These four key areas are further defined by sub-issues, as evidenced in Figure 2, as articulated by the Delphi Respondents. We present these emerging issues in Figure 2 and in the paragraphs following Figure 2 below).

Open coding is 'the initial coding that takes place in a research project' (Coe et al. 2017: 104). In open coding, the data is broken down, examined, compared, conceptualised and categorised to generate an emerging set of categories and their properties (Coe et al. 2017). In open coding, we attempted to break the data into distinct sets of meaning by Analysing the text line by line for emerging units of data that represent some more general phenomenon (Goulding 2002). Concerning open coding, we used the digital tool Dedoose ${ }^{\circledR}$. Dedoose ${ }^{\circledR}$ enables the user to facilitate open coding rapidly with the advantage of linked Memos and the automatic emergence of critical themes as these are 
highlighted and labelled. Patterns begin to appear within Dedoose ${ }^{\circledR}$ when the researcher identifies commonly occurring ideas.

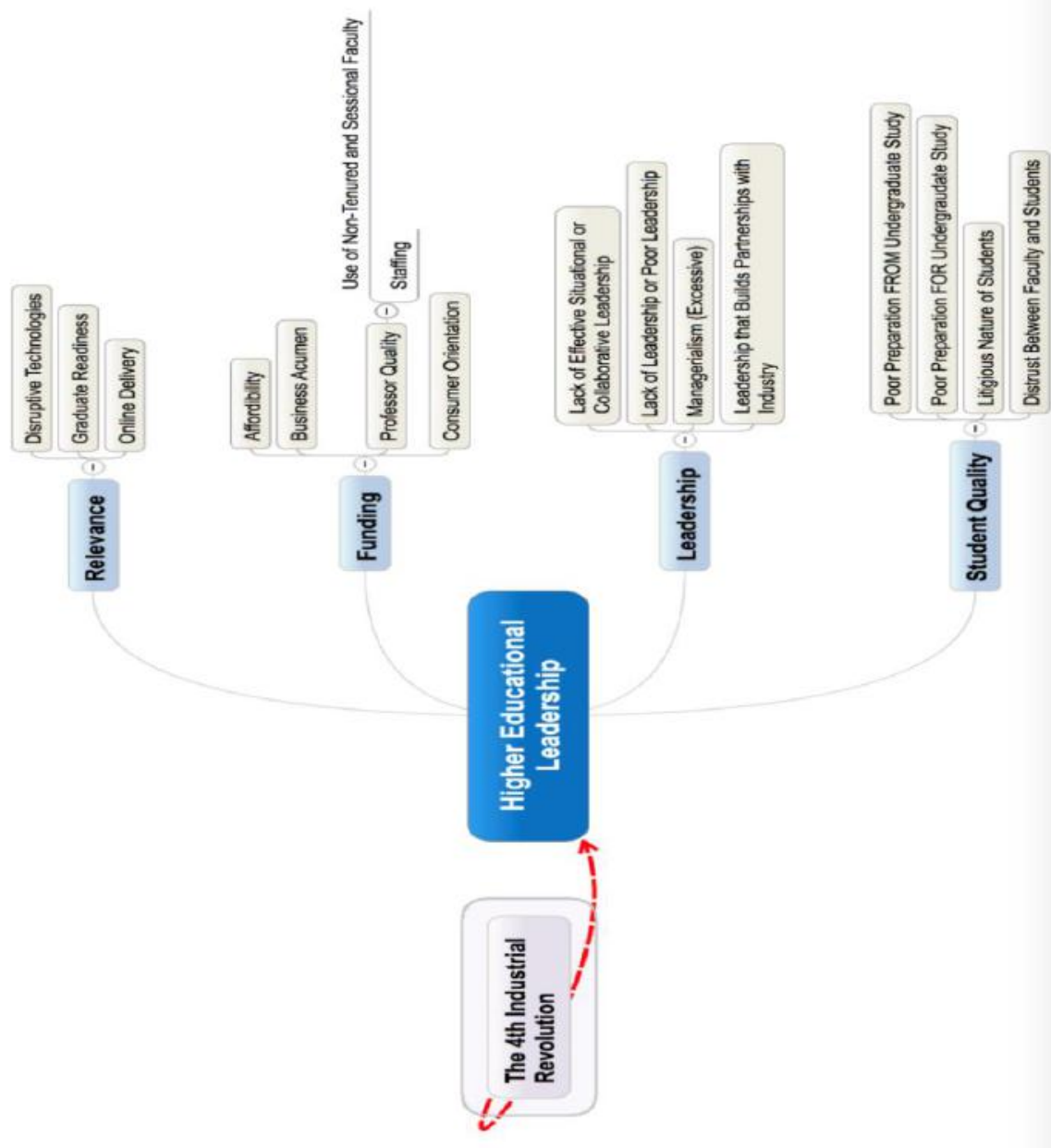

Figure 2: Mind Map of Delphi Survey Findings

In the coding process seven memos were drafted highlighting and discussing the key themes of, 'Developing Academics into Leaders', and, 
'Facilitative or Open Leadership', as well as, 'Managerialism', 'Funding', 'Student Quality', 'Graduateness', and ' $4^{\text {th }}$ Industrial Revolution'. These memos were helpful in the open coding process as critical themes began to emerge from the data and openness to the data's direction meant capturing these themes in a way that they could be returned to and reflected upon as the open coding process progressed (Goulding 2002). Another useful tool that assisted in abstracting the data emerging from the open coding is the word cloud feature in Dedoose ${ }^{\circledR}$.

Once the open coding reached a level of saturation, the next stage was axial coding (Coe et al. 2017). In axial coding, we attempted to refine and differentiate the categories resulting from open coding in which we linked subcategories to a category (Klenke 2016). In axial coding, we attempted to identify the properties of a category and its different but related dimensions (Given 2012). The computer-assisted qualitative data analysis software (CAQDAS) Dedoose ${ }^{\circledR}$ was helpful in the axial coding process because of the clear organization of themes and the ease with which sub-themes could be linked to the main themes within Dedoose ${ }^{\circledR}$.

\section{Major Issue \#1: Leadership (21 Occurrences)}

It is interesting to note that in a research project focused on emerging issues in HE leadership, it is 'leadership' that emerges as the number one issue confronting HE leaders. Four key themes emerged from the Delphi analysis:

1. Effective situational or collaborative leadership (6 occurrences).

2. A lack of leadership or poor leadership (6 occurrences).

3. Leadership that partners cross-sectorally (i.e. with industry and agriculture -4 occurrences).

4. Managerialism or 'excessive managerialism' (5 occurrences).

It seems that the leadership of HEIs is perceived by the followers (those being led), or by those participating in the leadership processes, as lacking leadership capacity and skill in the four areas indicated above. One wonders if the emerging context of 4IR and the rapid changes this new sociological phenomenon brings with it is part of several forces that create a perception of leadership incapacity for leaders who find themselves leading in Terra incognita (Lagadec 2009). 
It is also noteworthy that respondents articulated leadership deficiencies from what appears to be a 'deficit' mindset rather than from a 'positive' or 'growth' mindset. Is it possible that this deficit mindset highlights expectations that followers or co-leadership have that are not being met, as opposed to a sense that HE leaders are doing well, but could improve in certain areas? For instance, one respondent stated, 'we need leadership that is open to critical thinking and debate'. Another respondent said, 'we need leadership that collaborates with other universities rather than competes'. Yet another respondent suggested, 'we need effective leadership (department, faculty and institutionwide)' and a similar response that stated, 'there are limitations on effective management'.

It seems significant that throughout the range of responses, there prevails a sense of the lack of effective leadership expressed either in deficit terms of what leaders are not doing or being, i.e. that they 'should not be excessively managerial'.

Is it possible that in trying to frame their concerns around what the respondents to the survey perceive to be a lack of effective leadership amid the VUCA context (Bawany 2016), driven by the emerging 4IR, that HE leadership uses the handle 'management' or 'excessive managerialism' to denote the issue of 'status quo thinking?' This distinction between management as upholding the status quo, and leadership as a visionary change agent, is articulated by a wide range of leadership scholars (Daft 2018; Northouse 2018). Amid the VUCA context that 4IR invokes, visionary leadership is paramount to effectively navigate the rapid change occurring daily in every sector of society. Status quo thinking or excessive managerialism at the cost of quality innovation could be a fatal flaw in HEIs in the context of 4IR (Dervitsiotis 2005).

As detailed by other researchers, the liminality of VUCA invoked by 4IR should lead to 'communitas' (Day \& Harrison 2007; Leitch et al. 2013; Ndalamba et al. 2018). This 'communitas' would emerge as a heightened commitment to cross-sectoral partnerships and higher levels of collaboration between HEIs (Jäppinen 2014). Our respondents articulated their concerns that the HE leadership that they were a part of is not embracing this collaborative and agile form of leadership (Harrison 2016). Perhaps part of the catalyst of status quo thinking emerging within HE leadership is what Timothy Mack (2015) terms 'Response to Complex, Multi-Sector Changes'. He states:

Another trend involves the continuing inability (or lack of inclination) 
of many governments, organizations, corporations, and NGOs (nongovernmental organisations) to understand and address potential negative change. To put it in a more specific context, many organizations and companies adapt to change, not when they should but only when they must adapt, but their adaptations are often too late.

Perhaps it is incumbent upon HE leadership to develop 'Rapid Reflection Forces' (Lagadec 2009) that function to alert the leadership to weak signals through the procurement and analysis of big data, which 'feed leadership decision-making processes like never before' (Mack 2015: 42). The capacity for HE leadership to overcome status quo thinking in a VUCA environment might arise if that leadership can 'hold the ship steady' while leveraging 'experimentation at the margins' (Dervitsiotis 2010). Dervitsiotis highlights:

The appeal of multiple actions on the margins derives from management's inability to predict the future. This practice helps evaluate options that guard against anticipated uncertainty. In periods of rapid change, involving major shifts as to what is regarded as a proper way for the organization to conduct its business, experimenting through the parallel implementation of multiple small-scale actions provides valuable information from the exploration of the effectiveness of different strategic options.

This experimentation at the margins means that HE leadership invokes the option to avoid costly and potentially damaging mistakes by trying new solutions in situ on a smaller and manageable scale before mainstreaming those solutions that work while having the ability to jettison those that do not. It might be useful in the second round Delphi survey to highlight this notion of 'status quo' or 'laissez-faire' leadership as the most common emergent issue in the first round Delphi survey findings and request respondents suggest potential solutions to this challenge. Invoking this type of data-driven approach to leadership within HE organisations means that leadership styles might need to evolve to support a change-oriented leadership style (McCarthy et al. 2017).

\section{Major Issue \#2: Curriculum/ Cultural/ Subject Matter Relevance (18 Occurrences)}

When respondents mention 'relevance' as a major issue in HE contexts, and 
within HE leadership, they are referring to the challenge that HE leadership faces concerning keeping pace with the rapidity of change. It appears that emerging trends are such that the subject matter of today might be redundant in the world of tomorrow. The emerging issue of relevance seems to be felt even more acutely within the context of the emerging 4IR and the sense that the curriculum of the 2nd and 3rd industrial revolutions is hopelessly outdated for the new reality that is now upon us in the 4IR. As one respondent stated,

The challenge for higher education is to reinvent itself based on the needs of the future rather than [the] past.

Another aspect of relevance is not just that the curriculum be updated to match the emerging 4IR, but also that the pedagogy be updated to match the generation produced by the 4IR. As one participant put it:

Continuing to be regarded as THE source for learning in an increasingly sound bite news cycle and with information sources seemingly everywhere, it be a challenge to maintain the notion of University as a place where essential knowledge is conveyed that is different from consumerist knowledge that seems more appealing on the face of it - to the uninformed (e.g. Daniel Pink, Dan Airley, Malcolm Gladwell).

As we rapidly move into the context of the 4IR few are able to anticipate the kinds of employment changes accurately, employment losses (Bonciu 2017a), and scientific emergence that will accrue from the coalescence of the:

... physical (autonomous vehicles, 3D printing, advanced robots, new materials), digital (internet of things, relationship between things, and people connected by technologies and platforms), and biological (genetic sequencing and genetic engineering, synthetic biology and biological editing) (Kuruczleki et al. 2016).

The context of 4IR and the sophisticated elements highlighted by Bioncu and others lead to the question: 'What curricula innovations and learning modalities are needed to address the emerging world of 4IR?' (Kodama 2018). 
Another respondent highlighted this need for relevance by stating:

We need to prepare students for the new workforce (the 4IR and rapid changes in the labour market, AI (artificial intelligence) and automation, employer expectations and demands for more relevant evaluations of student skills and competencies.

Schwab (2016) highlights in his insightful work on 4IR that Creative Problem solving, and Critical Thinking will be the top two skills required by professionals in 2020. This change in focus supports the concern of our respondents that the curriculum of today is not preparing students for the world of tomorrow. An important question both from the literature review and from our respondents thus becomes whether or not HE institutions are shaping their learning profile to address this new priority.

Another aspect of 'relevance' for the development of the curriculum is the ability to contextualise curriculum to ensure that it is culturally relevant and culturally intelligent (Tuleja 2017). One respondent stated it in this way:

Students accessing higher education institutions come from varied backgrounds. Students are therefore from different socio-economic backgrounds. Leaders in higher education, therefore, need to ensure faculty or academics are aware of inequalities and diversity and considerations are made for these when delivering the academic project.

Yet another respondent stated it briefly in this way:

The second issue relates to curricula, i.e. curricula that students find relevant and decolonised.

\section{Major Issue \#3: Funding (17 Occurrences)}

At the outset, one might assume that the issue of funding is more of a developing economy issue than an issue facing first-world economies. Yet, the range of responses from representatives of both developing and developed economies highlighted that funding for higher education is a poignant issue facing higher education leadership. For instance, one respondent stated incisively, 'Budgets are shrinking globally, and we need to be able to fundraise 
and manage budgets appropriately'. Another respondent highlighted the emerging issue of 'Sustainability of higher education institutions in view of shrinking funding'.

Two critical issues related to funding emerged as sub-sets within this crucial issue facing HE, namely academic freedom and access. One respondent articulated the subject of the erosion of academic freedom because of diminishing funding as, 'government intervention/control (use of fiscal levers to achieve political ends)'. Other respondents highlighted the erosion of equitable access to $\mathrm{HE}$ when funding is limited, and thus HE becomes the purview of the wealthy.

\section{Major Issue \#4: Student Quality (12 Occurrences)}

It is interesting that some respondents perceive the issue of student quality as a systemic issue that is affected by the 'pipeline' of students emerging locally from what is seen as a less than stellar public and secondary school system. Respondents suggested that this 'low-quality pipeline' is another contextual issue affecting HE leadership.

Respondents also suggested that student quality as a HE leadership issue is further impacted by the litigious nature of students and the emerging distrust between faculty members and students. One other leadership issue emerging for HE leadership is that of the mental health of HE students and the role of leadership in supporting student mental health. As one respondent stated, 'Mental health, particularly of students, but also work-life balance for staff'.

\section{Discussion}

The main research question of this study is as follows: 'What are the emerging issues confronting higher education leadership in the next three to ten years?'

To address this research question, we reviewed the literature to identify emergent themes around critical issues likely to face HE leadership in perhaps the next three to ten years. Once we completed this literature review, we deployed a Delphi survey across 300 experts who serve as HE leadership. Arising from this Delphi survey and the process of open and axial coding, four significant issues emerged. The combined data of the literature review and the corresponding Lockean Delphi survey suggests that 4IR is a major contextual 
factor driving the issues emerging in HE. It is not the only factor, but it indeed appears as a significant factor. This 4IR driveshaft or context helps frame the research because effective leadership has healthy 'contextual awareness' (Daft 2018: 138), and it is thus useful to observe HE leadership around the world identifying 4IR by name as a backdrop to the issues they raised in their responses. As highlighted in the literature review, 'Leadership is arguably the central concept of interest in contemporary scholarship on education administration' (Eacott 2012). Some respondents drew a sharply distinctive line between what they term 'leadership' and 'excessive managerialism. This notion of excessive managerialism might also be interpreted as 'status quo thinking', a concept that emerged in the literature review.

The Delphi survey respondent experts suggest that HEIs globally are not staying relevant to the curricular requirements of the rapidly changing 4IR environment. Yet, according to Schwab (2016) and others, it may not be evident precisely what subjects and courses need to be included by HEIs to ensure that they can stay relevant. Perhaps this is a question for the second round of the Delphi survey.

The third major issue highlighted is that of funding. According to the respondents, funding brings stress to HE leadership in two key dimensions: lack of funding and the political leverage imposed by the government through the mechanism of funding. Perhaps in the second round, Delphi might also probe ways in which HE leadership is experimenting to address the funding challenge. It may also be appropriate to investigate how HE leadership segregates government funding from academic freedom and if this segregation is even possible.

The fourth major issue that emerged from our Delphi experts is the complicated matter of student quality. This issue is complex because the respondents perceive it as a systemic, process issue, in which the pipeline of student development from public school, through high school, and on into HEis less than adequate. How this problem might be addressed at the HE level is indeed a question for the second Delphi survey, with reflections from the literature, to seek to understand how HEIs might currently be addressing this emerging issue.

\section{Conclusion and Areas for Further Research}

The four major issues that emerged from this study are effective leadership, 
curricular and cultural relevance, funding challenges, and student quality. Each of these areas contained meaningful and relevant sub-sets of categories and related issues that further enriched an understanding of HE leadership's emerging issues. Practically speaking, it appears that HE leadership might benefit from the collective knowledge of these emerging issues on a global scale and capacitation or training in mindset and skillset to address these issues with effective leadership adequately.

The goal of the second round Delphi survey is to probe how HE leadership might transcend the excessive managerialism that is perceived as an impediment to their capacity to lead effectively in the VUCA context of 4IR. Further inquiry will be made concerning the ways in which HE leadership is addressing the challenge of contextual and cultural relevance with respect to curriculum development, funding challenges, and student quality.

\section{References}

Albertson, L. \& T. Cutler 1976. Delphi and the Image of the Future. Futures 8,5: 397 - 404. https://doi.org/10.1016/0016-3287(76)90003-3

Alonderiene, R. \& M. Majauskaite 2016. Leadership Style and Job Satisfaction in Higher Education Institutions. International Journal of Educational Management, 30,1: 140 - 164. https://doi.org/10.1108/IJEM-08-2014$\underline{0106}$

Andrews, D.R., S. No, K.K. Powell, M.P. Rey \& A. Yigletu 2016. Historically Black Colleges and Universities' Institutional Survival and Sustainability: A View from the HBCU Business Deans' Perspective. Journal of Black Studies 47,2: 150 - 168. https://doi.org/10.1177/0021934715622220 Authors, F. 2016. Learning to Love the 'VUCA' World with Shell and Nokia. Strategic Direction 32,1: $19-21$.

https://doi.org/10.1108/SD-10-2015-0159

Bawany, S. 2016. Leading Change in Today's VUCA World. Leadership Excellence February 33,2: 31.

Blackmore, J. 2002. Leadership for Socially just Schooling: More Substance and Less Style in High-risk, Low-trust Times? Journal of School Leadership 12: 198 - 222.

Bolman, L. G., \& Deal, T. E. 2015. Think or Sink - Leading in a VUCA World. Leader to Leader Spring, 201, 76: 35 - 40. 
Bonciu, F. 2017a. Evaluation of the Impact of the $4^{\text {th }}$ Industrial Revolution on the Labor Market. Romanian Economic and Business Review 12,2: 7-16. Bonciu, F. 2017b. The New Characteristics of Globalization and their Impact on the Design of a New International Economic Order. Global Economic Observer 5,1: $8-15$.

Chase, S. 2018. Saudi Arabia withdrawing Students from Canadian Schools, Suspending Flights. The Globe and Mail.

https://www.theglobeandmail.com/canada/article-saudi-arabia-towithdraw-all-saudi-students-studying-at-canadian/ (Accessed on 23 May 2021.)

Chung, C.-S. 2017. E-Government Future in the Era of $4^{\text {th }}$ Industrial Revolution. Information 20,5: 3539 - 3547.

Coe, R., Waring, M., Hedges, L. V., Arthur, J. 2017. Research Methodologies in Education. $2^{\text {nd }}$ Edition. Durham, UK: SAGE Publications.

Cole, Z.D., H.M. Donohoe \& M.L. Stellefson 2013. Internet-based Delphi Research: Case Based Discussion. Environmental Management. https://doi.org/10.1007/s00267-012-0005-5

Dalakoura, A. 2010. Differentiating Leader and Leadership Development: A Collective Framework for Leadership Development. Journal of Management Development 29,5: 432 - 441. https://doi.org/10.1108/02621711011039204

Daft, R. 2018. The Leadership Experience. $7^{\text {th }}$ Edition. Boston, MA: Cengage Learning.

Das, K.K. \& A. Ara 2014. Leadership in VUCA Worlsd: A Case of Lenovo. International Journal of Current Research 6,4.

Davis, A.P., E.B. Dent \& D.M. Wharff 2015. A Conceptual Model of Systems Thinking Leadership in Community Colleges. Systemic Practice and Action Research 28,4: 333 - 353.

https://doi.org/10.1007/s11213-015-9340-9

Day, D.V. \& M.M. Harrison 2007. A Multilevel, Identity-based Approach to Leadership Development. Human Resource Management Review 17,4: 360 - 373. https://doi.org/10.1016/j.hrmr.2007.08.007

Dervitsiotis, K.N. 2005. Creating Conditions to Nourish Sustainable Organizational Excellence. Total Quality Management \& Business Excellence 16,8 - 9: 925 - 943.

https://doi.org/10.1080/14783360500163078

Dervitsiotis, K.N. 2010. A Framework for the Assessment of an Organisation's 
Innovation Excellence. Total Quality Management \& Business Excellence 21,9: 903 - 918. https://doi.org/10.1080/14783363.2010.487702

Drew, G. 2010. Issues and Challenges in Higher Education Leadership: Engaging for Change. Australian Educational Researcher 37,3: 57-76. https://doi.org/10.1007/BF03216930

Drucker, P. 2013. Strategy in a VUCA World. Strategic Direction 29,10: 32 34. https://doi.org/10.1108/SD-10-2013-0089

Eacott, S. 2012. 'Leadership' and the Social: Time, Space and the Epistemic.

International Journal of Educational Management 27,1: 6 - 6.

https://doi.org/10.1108/09513541311289846

English, F.W. \& L.C. Ehrich 2015. Innovatus Interregnum: Waiting for a Paradigm Shift. International Journal of Educational Management 29,7:

851 - 862. https://doi.org/10.1108/IJEM-05-2015-0055

Fihlani, P. 2019. We are Students Tthanks to South Africa's \#FeesMustFall

Protests. BBC News https://www.bbc.com/news/world-africa-47952787

Fitzgerald, T. 2003. Interrogating Orthodox Voices: Gender, Ethnicity and Educational Leadership. School Leadership \& Management 23,4: 431444. https://doi.org/10.1080/1363243032000150962

Fonseca, L.M. 2018a. 4IR and the Digital Society: Concepts, Dimensions and Envisioned Benefits. Proceedings of the International Conference on Business Excellence 12,1: 386 - 397.

https://doi.org/10.2478/picbe-2018-0034

Fonseca, L. M. 2018b. 4IR and the Digital Society: Concepts, Dimensions and Envisioned Benefits. Proceedings of the International Conference on Business Excellence 12,1: 386 - 397.

https://doi.org/10.2478/picbe-2018-0034

Gipson, A.N., D.L. Pfaff, D.B. Mendelsohn, L.T. Catenacci \& W.W. Burke 2017. Women and Leadership: Selection, Development, Leadership Style, and Performance. https://doi.org/10.1177/0021886316687247

Given, L. 2012. Axial Coding. The SAGE Encyclopaedia of Qualitative Research Methods. Los Angeles, London, New Delhi: Sage Publishers. https://doi.org/10.4135/9781412963909.n30

Goddard, J. T. 2010. Toward Glocality.pdf. Journal of School Leadership 20. Goddard, J. T. 2015. A Tangled Path: Negotiating Leadership for, in, of, and with Diverse Communities. Leadership and Policy in Schools 14,1: 1-11. https://doi.org/10.1080/15700763.2014.983133

Grandy, G. \& J. Holton 2013. Leadership Development Needs Assessment in 
Healthcare: A Collaborative Approach. Leadership \& Organization Development Journal 34,5: 427 - 445.

https://doi.org/10.1108/LODJ-11-0090

Grint, K. 2007. Learning to Lead: Can Aristotle Help Us Find the Road to Wisdom? Leadership 3,2: 231 - 246.

https://doi.org/10.1177/1742715007076215

Grint, Keith. 2005. Problems, Problems, Problems: The Social Construction of 'Leadership'. Human Relations 58,11: 1467 - 1494.

https://doi.org/10.1177/0018726705061314

Grogan, M. \& G. Crow 2004. Mentoring in the Context of Educational Leadership Preparation and Development - Old Wine in New Bottles? Introduction to a Special Issue. Educational Administration Quarterly 40,4: $463-467$.

https://doi.org/10.1177/0013161X04267107

Halamka, J.D. 2011. Facing Down VUCA, and Doing the Right Thing. Computerworld 45,10: 30 .

Harrison, R.T. 2016. Leadership, Leadership Development and All that Jazz. Leadership 1980. https://doi.org/10.1177/1742715016681120

Hasson, F., S. Keeney \& H. McKenna 2000. Research Guidelines for the Delphi Survey Technique. Journal of Advanced Nursing 32,4: 1008 1015. https://doi.org/10.1046/j.1365-2648.2000.t01-1-01567.x

Hood, T. 2015. The Top Six Skills You Need to Thrive in a VUCA World.

2011. https://blionline.org/the-top-six-skills-you-need-to-thrive-in-avuca-world/

Hornsby, E., H.A. Morrow-Jones \& D. Ballam 2011. Leadership Development for Faculty Women at The Ohio State University: The President and Provost's Leadership Institute. Advances in Developing Human Resources 14,1: 96-112. https://doi.org/10.1177/1523422311428758

Jameson, J. 2013. E-Leadership in Higher Education: The Fifth 'Age' of Educational Technology Research. British Journal of Educational Technology 44,6: 889 - 915. https://doi.org/10.1111/bjet.12103

Jäppinen, A.-K. 2014. Collaborative Educational Leadership: The Emergence of Human Interactional Sense-Making Process as a Complex System. Complicity 11,2: $65-85$.

http://search.proquest.com/docview/1558844768?accountid $=14116 \% 5 \mathrm{C}$ nhttp://ensor.lib.strath.ac.uk/sfxlcl41?url ver=Z39.88-

2004\&rft_val_fmt=info:ofi/fmt:kev:mtx:journal\&genre=article\&sid=Pro 
Q:ProQ:education\&atitle=Collaborative+Educational+Leadership:+The $+\mathrm{Em}$

Jones, S. 2019. CBC Radio Special, Government of Ontario Budget.

Jusoh, A., A.S. Zulkifli, A.M. Rasli \& Y. Munir 2015. A View from Academic Administrators on the Characteristics of Future University. International Journal of Economics and Financial Issues 7-12.

Kalinski, F.A., W. Hightower, J.B. Johnson \& D. Ed 2015. Transforming Student Retention in Higher Education Online Programs in California Community Colleges: A Delphi Study. Dissertation by Irvine, California School of Education, June 2015.

Katz, R.L. 1955. Skills of an Effective Administrator. Harvard Business Review 33,1: $33-42$.

Keeney, S., F. Hasson \& H. McKenna 2006. Consulting the Oracle: Ten Lessons from Using the Delphi Technique in Nursing Research. Journal of Advanced Nursing 53,2: 205 - 212.

Kern, M. 2017. 3 Career Killers to Circumvent in 2017: Clearing the $4^{\text {th }}$ Industrial Revolution. Technology Enabled Learning Excellence Essentials August: $1-4$.

Kezar, A. \& J. Lester 2009. Supporting Faculty Grassroots Leadership. Research in Higher Education 50,7: 715 - 740. https://doi.org/10.1007/s11162-009-9139-6

Killingsworth, M.F., C.T. Cabezas, L.A.W. Kensler \& J.S. Brooks 2010. The Gender Dynamics of Educational Leadership Preparation: A Feminist Postmodern Critique of the Cohort Experience. Journal of Research on Leadership Education 5,12.9: 531 - 567.

Klenke, K. 2016. Qualitative Research in the Study of Leadership. $2^{\text {nd }}$ Edition. Bingley, UK: Emerald Publications.

Kodama, F. 2018. Learning Mode and Strategic Concept for the $4^{\text {th }}$ Industrial Revolution. Journal of Open Innovation: Technology, Market, and Complexity 4,3: 32. https://doi.org/10.3390/joitmc4030032

Kuruczleki, E., A. Pelle, R. Laczi \& B. Fekete 2016. The Readiness of the European Union to Embrace the Fourth Industrial Revolution. Management 11,4: 327 - 347. http://www.fm-kp.si/zalozba/ISSN/18544231/11 327-347.pdf

Lagadec, P. 2009. A New Cosmology of Risks and Crises: Time for a Radical Shift in Paradigm and Practice. Review of Policy Research 26,4: 473 487. 
http://onlinelibrary.wiley.com/doi/10.1111/j.1541-

1338.2009.00396.x/full

Lawrence, B.K. 2013. Kirk Lawrence Program Director UNC Executive.

Development $1-15$.

Leitch, C.M., C. Mcmullan \& R.T. Harrison 2013. The Development of

Entrepreneurial Leadership: The Role of Human, Social and Institutional

Capital. British Journal of Management 24,3: 347 - 366.

https://doi.org/10.1111/j.1467-8551.2011.00808.x

Mack, T.C. 2015. Career Development in the Future. Career Planning and Adult Development Journal 40 - 46.

McCarthy, J., D. Sammon \& C. Murphy 2017. Leadership Styles in a Data

Driven Culture. European Conference on Management, Leadership \&

Governance 313 - 321.

https://search.proquest.com/docview/1980087214/fulltextPDF/68F088D

4F66B4A6BPQ/1?accountid $=9840$

Moore, D.L. 2014. The Experience of Strategic Thinking in a Volatile,

Uncertain, Complex, and Ambiguous (VUCA) Environment. Available

at: https://apps.dtic.mil/sti/pdfs/ADA625056.pdf

Morgan, A.C., D.L. King, R.D. Rudd \& E.K. Kaufman 2013. Elements of an

Undergraduate Agricultural Leadership Program: A Delphi Study.

Journal of Leadership Education 12,1: 140 - 155.

Ndalamba, K.K., C. Caldwell \& V. Anderson 2018. Leadership Vision as a

Moral Duty. Journal of Management Development 37,3: 309 - 319.

https://doi.org/10.1108/JMD-08-2017-0262

Niesche, R. \& A. Keddie 2011. Foregrounding Issues of Equity and Diversity in Educational Leadership. School Leadership \& Management 31,1: 65 -

77. https://doi.org/10.1080/13632434.2010.545381

Northouse, P. 2018. Leadership: Theory and Practice. $8^{\text {th }}$ Edition. Los Angeles, London \& New Delhi: SAGE Publications.

Ouariachi, C.T., M.D. Olvera-lobo \& J. Gutiérrez-Pérez 2018. The Use of the Delphi Method to Define Criteria for Evaluating Online Climate Change Games. SAGE Research Methods Cases Part 2.

https://dx.doi.org/10.4135/9781526438317

Panchak, P. 2016. Of Technology and Transformation in the $4^{\text {th }}$ Industrial Revolution. Industry Week January /February, 6.

Reyes, D.J., B. Bekemeier \& L.M. Issel 2014. Challenges Faced by Public Health Nursing Leaders in Hyperturbulent Times. Public Health Nursing 
31,4: 344 - 353. https://doi.org/10.1111/phn.12078

Rusch, E.A. 2004. Gender and Race in Leadership Preparation: A Constrained

Discourse. Educational Administration Quarterly 40,1: 14 - 46.

https://doi.org/10.1177/0013161X03259110

Schafer, J.A. 2009. Developing Effective Leadership in Policing: Perils,

Pitfalls, and Paths Forward. Policing 32,2: 238 - 260.

https://doi.org/10.1108/13639510910958163

Schrage, M. 2017. How the Big Data Explosion Has Changed Decision

Making. Harvard Business Review 2017.

Schwab, K. 2017. The Fourth Industrial Revolution. Currency Publishers.

https://www.weforum.org/about/the-fourth-industrial-revolution-by-

klaus-schwab/

Sheridan, L.M.M., N.H. Murdock \& E Harder 2015. Assessing Mentoring

Culture: Faculty and Staff Perceptions, Gaps, and Strengths. Canadian Journal of Higher Education 45,4: 423 - 439.

http://journals.sfu.ca/cjhe/index.php/cjhe/article/view/184938

Shields, T. \& K. Cassada 2016. Examination of Access and Equity by Gender,

Race, and Ethnicity in a Non-traditional Leadership Development

Programme in the United States. Ethnicity in a Non-traditional Leadership

Development 2434,36:5: 531 - 550 .

https://doi.org/10.1080/13632434.2016.1247050

Silman, A. 2020. Trump's Cruel Attack on International Students. The Cut. https://www.thecut.com/2020/07/trumps-cruel-attack-on-internationalstudents.html (Accessed on 23 May 2021.)

Skerrett, A. 2011. On Identity, Diversity, and Educational Change. Journal of Educational Change 12,2: 211 - 220.

https://doi.org/10.1007/s10833-011-9153-2

Skulmoski, G., F. Hartman \& J. Krahn 2007. The Delphi Method for Graduate Research. Journal of Information Technology Education 6.

Spears, L.C. \& M. Lawrence 2004. Practicing Servant Leadership: Succeeding Through Bravery, and Forgiveness. Indianapolis: Josey Bass Publishers.

Sperandio, J. 2010. Modelling Cultural Context for Aspiring Women Educational Leaders. Journal of Educational Administration 48,6: 716 726. https://doi.org/10.1108/09578231011079575

St. Pierre, E.A., A.Y. Jackson, G.G. Lin, J.G. Scott, S. Wilson, M. Moffat, S.

Phase, I.I. Report, S. Keeney, F. Hasson, H. McKenna, J. Landeta, G. Rowe, G. Wright, C. Intelligence, L. Albertson, T. Cutler, H.J. Strauss \& 
L. Harmon 2006. Using a Delphi Survey to Identify Priorities. Futures, 16,6: 131 - 150. https://doi.org/10.1016/j.techfore.2005.09.002

Tuleja, E. 2017. Intercultural Communication for Global Business: How Leaders Communicate for Success. London \& New York: Routledge Press.

Vardiman, P. 2006. Environmental Leadership Development: Toward a Contextual Model of Leader Selection and Effectiveness. Development Journal. Available at:

http://www.emeraldinsight.com/journals.htm?articleid=1545743\&show= abstract

Vardiman, P.D., J.D. Houghton \& D.L. Jinkerson 2006. Environmental Leadership Development: Toward a Contextual Model of Leader Selection and Effectiveness. Leadership \& Organization Development Journal 27,2: 93 - 105. https://doi.org/10.1108/01437730610646606

Ward, C.J. 2013. Addressing Stereotypes by Moving along the Continuum of Cultural Proficiency. Voices from the Middle 20,3: 27 - 31.

http://ezproxy.umsl.edu/login?url=http://search.ebscohost.com/login.asp

$\mathrm{x}$ ?direct $=$ true $\& \mathrm{db}=$ eric $\& \mathrm{AN}=\mathrm{EJ} 1004190 \&$ site $=$ ehost -

live\&scope $=$ site $\% 5 C$ nhttp://www.ncte.org/journals/vm/issues/v20-3

Wilson, S. \& M. Moffat 2010. Using a Delphi Survey to Identify Priorities. British Journal of Healthcare Management 6: 284 - 290.

Young, M., M. Mountford \& L. Skrla 2006. Infusing Gender and Diversity Issues into Educational Leadership Programs: Transformational Learning and Resistance. Journal of Educational Administration 44,3: 264 - 277. https://doi.org/10.1108/09578230610664850

Zucconi, A. 2016. The Need for Person-Centered Education. Cadmus 3,1: 126.

Rob Elkington Adjunct Professor at the Ontario Technical University Faculty of Education; and Senior Lecturer Stellenbosch University School of Public Leadership $\underline{\text { Rob.Elkington@ontariotechu.ca }}$ 


\title{
Cultivating Socially Responsible Chartered Accountant Business Leaders through Education
}

\author{
Judith Terblanche ${ }^{1}$ \\ ORCID iD: http://orcid.org/0000-0002-5649-0083
}

Yusef Waghid

ORCID iD: http://orcid.org/0000-0003-2565-824X

\begin{abstract}
The Chartered Accountant profession is a valuable player in the business environment and members often take up leadership positions. Consequently, Chartered Accountants have the authority to make decisions that can impact society and the environment negatively unless social justice awareness is cultivated. South Africa seems to be in dire need of transformation through fostering equality and the redress of lived injustices, in which the chartered accountant profession can be enacted. However, this will require changes to the status quo. Higher education institutions are an identified space for the cultivation of the full humanity of individuals and this chapter reports on some of the recommendations to improve the chartered accountant educational landscape. This article argues for the enhancement of teaching and learning practices that support the outcomes and aims of democratic citizenship education, the equipping of the chartered accountant educator with the required pedagogical and philosophical knowledge and, incorporating a structured component of experiential learning into the curriculum. Through this article, the focus intentionally shifts from the mere focus on the technical ability of the chartered accountant to that of the required responsibility to lead justly in a transformative society.
\end{abstract}

Keywords: chartered accountant, democratic citizenship education, responsible leadership, teaching and learning practices

${ }^{1}$ Judith Terblanche is a CA(SA) and has been working since 2008 at SAICA accredited departments of Accounting. 


\section{Introduction}

In recent times, South African Chartered Accountant (CA) professionals were in the news for all the wrong reasons. Members of the profession were implycated in corruption, state capture, corporate scandals, and irregular accounting practices. The South African Institute for Chartered Accountants (SAICA) is the designated professional body mandated to protect the integrity of the CA profession in South Africa. The SAICA is officially endorsed by the South African Qualifications Authority (SAQA) to fulfil this important role. SAQA (2017) reports that the $\mathrm{CA}(\mathrm{SA})$ designation is a distinguished business qualification and members often fulfil the role of leaders in commerce. In the 2017 Nation Building Impact Report, SAICA states:

SAICA is committed to building the nation. By definition, the term 'responsible leadership' refers to business decisions that, next to the interests of shareholders, also take into account all other stakeholders, such as staff, clients, suppliers, the environment, the community and future generations. It is for this reason that the tenet of creating and maintaining a profession of empowered members who 'support the development of the South African economy' is central to SAICA's constitution (SAICA 2017: 6).

As business leaders, CAs therefore play a significant role in the South African society, by contributing to economic growth, creating employment opportunities, and (hopefully) investing in transformational and sustainable initiatives. Considering the controversies embroiling the profession in recent times, the question could rightly be asked as to whether CAs are appropriately provoked and cultivated through their qualifying journey to be socially responsible leaders who will act ethically.

This is of importance as South African citizens need to remain hopeful that meaningful change is a prospect; implying that the dire social reality of several citizens could improve, that greater equality could be achieved, and that reduced poverty through a decline in the unemployment rate is possible in the foreseeable future. The CA profession has a role to play in the realisation of this hope. To realise the hope of a democratic South Africa - and freedom and equality for all - the country needs democratic citizens who can participate in a democracy. Particularly so, (business) leaders, such as CAs, are required to lead ethically to redress unjust practices through the decisions they make 
and the policies and practices they implement.

Boulton and Lucas (2011), as well as Giroux (2011), argue that the higher education (HE) landscape is one of the few places where deliberate shaping of individuals could occur because of pedagogical practices. Walker (2008: 158) posits:

It is important to be clear that education as capability ought to be education also for the public and social good, as much as for the benefit of individuals. What makes schools, colleges and universities so important is that they have as their objective a changed human being. Education involves a becoming.

Subsequently, the possibility exists to cultivate citizens in being socially responsible through teaching and learning practices associated with Democratic Citizenship Education (DCE). Accordingly, DCE is explained as,

the preparation of young people to become knowledgeable, active and engaged citizens within their democracy. It aims to develop their capability for thoughtful and responsible participation as democratic citizens in political, economic, social and cultural life (Naval et al. 2002: 109 - 110).

Such an aim of education, or DCE, is in line with the role SAICA envisions CAs should play in the South African society (cf. SAICA 2017; SAQA 2017). The perceived outcomes of DCE could thus assist the profession in achieving their own objective of cultivating leaders who will lead both ethically and responsibly.

Consequently, Terblanche (2019) accentuates that there are five distinct themes associated with DCE that would lead to citizens who care, have compassion, are accountable and willing to partake in plausible transformation, namely:

- Democratic principles, that are constituted in South Africa through various pieces of legislation, are embedded in the practices, structures and policies of higher education institutions (HEIs) - the National Plan for Higher Education (Department of Education [DoE] 2001) and the Higher Education Act No. 101 of 1997 (Republic of South Africa [RSA] 1997). 
- Student participation is central to each educational encounter (cf. Means 2014).

- Teaching and learning practices associated with transformative education, are utilised by an educator (a key aspect in this chapter that will be discussed later).

- There is a particular focus on societal difficulties and finding solutions to these (cf. Veugelers 2007).

- There is an urgency towards cultivating the full humanity of students, with a focus on self and the other (Nussbaum 2003).

It is apposite to investigate the challenges that inhibit the CA educational landscape from achieving the outcomes as set out by DCE and SAICA. Elsewhere, relying on pragmatism as a research approach and deconstruction as research method, Terblanche (2019) identified some of the reasons as to why the CA profession might be struggling to cultivate socially responsible leaders. She contends (Terblanche 2019) occurs as a corollary of particular power relations in operation in the CA profession and the CA educational landscape that seems to delay the implementation DCE. The aim of this chapter is to make recommendations that could alleviate some of the current challenges.

\section{Brief Summary of the CA Educational Landscape, Power Relations and Weaknesses}

Terblanche (2019) joins several CA educators in documenting the route to qualification as a $\mathrm{CA}(\mathrm{SA})$. In short, there are two parts, namely the academic component and the training component. Firstly, candidates enrol for a dedicated three-year accounting undergraduate degree programme at a Department of Accounting (or equivalent), which is accredited by SAICA. This undergraduate degree programme is followed by a postgraduate qualification, which is also accredited by SAICA. SAICA conducts monitoring visits at HEIs to determine the suitability of the accreditation level that has been provided. Upon completion, students enter a three-year training contract with a SAICA-registered training office. Only after completion of the academic part and the training part, subject to the successful completion of the relevant examinations, can candidates obtain the CA(SA) designation (cf. Keevy \& Mare 2018; Rudman \& Terblanche 2012; Strauss-Keevy 2014; Venter \& De Villiers 2013). 
SAICA provides the accredited departments of Accounting and the registered training offices with a competency framework $(\mathrm{CF})$ for each part of the qualification route, listing all the competencies that should be developed in candidates during the academic part and the training part, respectively. In addition, SAICA sets two examinations which candidates need to complete successfully, namely the Initial Test of Competence (ITC) and the Assessment of Professional Competence (APC). The ITC is written shortly after students graduate from HEIs and before commencing the training contract. This is thus a reflection of how well the HEI has cultivated the required competencies. The APC is written after at least 20 months of being in a training contract and is therefore a reflection of whether the training office could develop the required competencies in their trainees. Before writing the APC, candidates need to complete a qualification that prepares them to write the examination (again this qualification is provided by a SAICA-approved service provider) (cf. Keevy \& Mare 2018; Rudman \& Terblanche 2012; Strauss-Keevy 2014; Venter \& De Villiers 2013).

Considering the aim of this chapter, that of focusing on the cultivation of socially responsible business leaders who make ethical decisions, it is important to note that some of the consequences are a direct result of the particular power relations that are at play in the CA educational landscape. Following from the above description of the CA educational landscape in South Africa, the profession, through SAICA, evidently has significant power and influence over the higher educational landscape. Specifically, the accreditation by SAICA of departments of Accounting, the issue of a CF by SAICA and the setting of the ITC by SAICA are three examples of how power is enacted by the profession. Elsewhere, in applying the seminal thoughts of the French philosopher Michel Foucault (1995), as theorised in his genealogical piece titled Discipline and punish: The birth of the prison, to the CA education landscape, Terblanche (2019) proffers that:

- the accreditation of HEIs by SAICA is an example of the disciplinary power mechanism of hierarchical observation;

- the issue of a CF by SAICA is an example of the disciplinary power mechanism of normalising judgement; and

- the setting of the ITC by SAICA is an example of the disciplinary power of the examination. 
The consequences of this power relation and three mechanisms of disciplinary power evident in the CA educational landscape can be summarised as follows (cf. Terblanche 2019; Terblanche \& Waghid 2020a; Venter \& De Villiers 2013):

The SAICA accredited Departments of Accounting are often driven by the performance of their graduates in the SAICA ITC examination. This is so because the results of the ITC examination affect the accreditation status, prestige, future student intake and monetary considerations for a particular department of Accounting. The CA academics aim to align the curriculum of their academic programme to that of the SAICA CF since the CF (inclusive of the content and required technical level of the content) serves as preparation guidance for the ITC examination. Consequently, teaching and learning practices are geared towards the coaching of being successful in the writing of examinations, rather than focusing on the well-rounded development of a student. Since teaching and learning are often confined to a classroom set-up, interaction with businesses and the community seems limited, thus resulting in a predominant pursuit of theoretical knowledge instead of a holistic realisation of the challenges in society and the possible impact of the decisions of business leaders on lived social realities in South Africa. In addition to being confined to a classroom set-up, the teaching style of the CA academics often entails the passive explanation (by an educator) of technical matters (to a student) contained in legislation or standards, rather than provoking a student to critically reflect on the material and knowledge content. As a result of the volume of the content listed in the CF qualification (and technical nature thereof), CA academics will seldom include additional learning material to those listed in the CF in their programs, e.g. research articles or philosophical discussions about the impact of business on the perpetuation of inequality. Lastly, the SAICA accreditation guidance refers to the fact that lecturers should be suitably qualified, implying that lecturers teaching in the academic programme should be $\mathrm{CA}(\mathrm{SA}) \mathrm{s}$. Consequently, academics are appointed for their unique professional competencies and skills and not for their educational or philosophical knowledge or background.

These consequences of the power relations depicted above, affect society directly as they limit the transformative power embedded within educational encounters to cultivate socially responsible citizens who will lead in an ethical way (Terblanche 2019). The next section focuses on possible solutions and a suitable response by the profession and CA educators, to 
address some of the challenges as a result of the manner in which power is enacted in the CA educational landscape.

\section{Some Thoughts on a Tenable CA Educational Landscape}

This chapter argues that the CA profession in general as well as SAICA and CA educators at SAICA-accredited HEIs need to respond rather swiftly as the profession has lost integrity and professionalism in the public domain due to the present and past association with possible corrupt and fraudulent practices. Elsewhere, we have argued extensively that an appropriate response will include firstly, the inclusion of research as pedagogical practice (Terblanche \& Waghid 2021) and secondly, the need to incorporate ubuntu principles whilst appropriately responding to the call for the decoloniality of the accounting curriculum (Terblanche \& Waghid 2020b). This chapter argues that the following aspects should also be addressed to increase the likelihood that aspiring $\mathrm{CA}(\mathrm{SA}) \mathrm{s}$ could be appropriately provoked and cultivated through education to become socially responsible leaders who make ethical decisions:

- implementation of particular teaching and learning practices associated with DCE;

- equipping the $\mathrm{CA}$ educator with pedagogical and philosophical knowledge; and

- considering the implementation of experiential learning.

In the sub-sections below, the chapter discusses each of these.

\section{Teaching and Learning Practices Associated with DCE}

Several factors influence whether the aim of DCE can be achieved, namely emancipated citizens who can participate in a democratic society; having a social awareness; acting ethically; and endeavouring to redress injustice. Amongst others, this chapter argues that the HEI (whether it is embedded in democratic principles, structures and processes or not); the what (curriculum content); the how (teaching and learning practices); and the who (the identity of the educator) are all factors that significantly affect the potential of the teaching-learning encounter. In this sub-section, the focus is on the how of teaching and learning. The question arises: which teaching and learning prac- 
tices are associated with DCE and support the outcomes envisioned through DCE?

Firstly, this chapter argues for the use of narrative reflection as teaching and learning practice. Vosloo (2012) argues that it will be very difficult for citizens (in this case, students) to pursue justice for all actively if one is not able to reflect deliberativel on the devastating consequences of the past. Such a use of memory could lead to a disruption of the present; a disruption necessary in South Africa, as the current perpetuated inequality is detrimental to social cohesion (Vosloo 2005). Besides tapping into the past to influence the future, narrative reflection also entails storytelling. With the sharing of oneself, we increase understanding between the self and the other. Enslin et al. (2001: 126) accordingly state:

Storytelling or narrative enhances the possibility of understanding across difference[s] by conveying the experiences, values and cultures of differently situated people. But narrative is not just a way of sharing experiences, or of encouraging tolerance; it has an epistemic function, providing access to social knowledge from the points of view of particular social positions.

Through such a process of sharing, students learn to truly listen to one another and reflect on different perspectives and experiences. As a result, deeper reflection, and space for questioning more deeply is opened up. In this way, students can challenge monolithic beliefs, which they always deemed as unquestioning truths (a consequence of a particular construct of knowledge) (Van Rinsum 2014). In addition to listening and to questioning one's own beliefs, storytelling also results in cultivating compassion (Zembylas 2006). Such encounters help students to see with fresh eyes, to notice the other, and to recognise a common humanity. In this way, human dignity is restored and the potential for transformation is enacted. It is important to expose aspiring students to the dire lived realities of others, as future $\mathrm{CA}(\mathrm{SA}) \mathrm{s}$ might feel the tension in their future leadership roles in decisions they make for the benefit of shareholders or the company, that might have serious consequences for marginalised communities or the environment.

Secondly, this chapter argues for dialogue as teaching and learning practice. In order to act rather than just talk about social injustice, citizens (students included) need to understand the outcomes of their future decisions 
on marginalised communities (and the environment), and dialogue as a practice could be a tool that might result in an ethical response. Mahlomaholo (2014: 681) argues:

Good democratic education should enable learners to know, but also to know that there are other ways of knowing and other things they do not know. The one truth is no longer sufficient and people need validation and communication with others to check their long-held belief systems.

Following from the above, this chapter argues that the educational space provides a diverse environment, which could result in the transformation of the self through deliberative communication (such as dialogue). Students are thus prepared to participate in a democratic society and to act responsibly. The practice of dialogue comprises articulating one's views; listening to the views of others; evaluating one's original views in light of new knowledge; and rearticulating one's transformed views. These phases are important, as equality is practiced in the process. Waghid (2018: 7) explains it as follows:

When one recognises others' differences, one does not necessarily agree with what one encounters. Instead, one gives recognition to a difference on account that one sees the point of the difference being enunciated. And, seeing the point of another's perspective is itself a recognition that others have something to offer that ought to be considered.

Cultivating this skill in future $\mathrm{CA}(\mathrm{SA}) \mathrm{s}$ is beneficial as the business environment, often driven by profit in a capitalistic market economy, will create opportunities where leaders will have to present ethical considerations before harsh or rash decisions are made that will only be beneficial in the short term.

Thirdly, we hold that engagement is necessary for teaching and learning. A democratic state can only function as intended, which is to ensure all citizens are free and equal, if they engage one another. A democracy relies on the engagement of its citizens. Citizens should learn what it means to engage and the education landscape should therefore provide the opportunities to foster opportunities for engagement. Noddings (2005: 11-12) explains it as follows: 
Life in a healthy democracy requires participation, and students must begin to practice participation .... Working together in small groups can furnish such practice, provided that the emphasis is consistently on working together - not on formal group processes or the final grade for a product .... It is not sufficient, and it may actually undermine our democracy, to concentrate on producing people who do well on standardized tests and who define success as getting a well-paid job. Democracy means more than voting and maintaining economic productivity, and life means more than making money and beating others to [acquire] material goods.

It is evident that this practice should be about the process of engagement itself and not about a pre-determined outcome. By involving students in the learning process, their worth and value are recognised, which could result in a feeling of lived freedom and equality. The CA(SA)s who have the expertise to make a difference in the lives of the less fortunate, might be equipped through the practice of engagement to contribute to solving societal problems in the industry within which they work or in the community where they live.

Lastly, we argue for imagination as a teaching and learning practice. Nussbaum (2003) purports that imagination as a capability could result in citizens (students) considering the plight of the silent other and providing solutions to current lived difficulties. Through the practice of imagination, the self, positions him/ herself in the place of the other. This allows for transformation in being and thought. Greene (2001) and Nussbaum (2002) argue that it will be beneficial to make use of teaching material deriving from the Humanities and the Arts to assist in the facilitation of imagination as teaching and learning practice. Ballantine (2017) reasons that the aesthetic dimension should not be an ad hoc addition to the chosen pedagogical strategy but should be central to it. Nussbaum (2009) concurs by explaining that the value deriving from the Humanities and the Arts for the development of the full humanity of individuals, inclusive of creative problem-solving abilities, is immeasurable. Similarly, in the same way that we are emotionally moved when we watch a beautiful movie or look at a painting, citizens - especially future business leaders, such as CA(SA)s who could influence the lives of others through their decisions - should be filled with compassion for those who experience dire lived realities, to such an extent that they actively pursue equality for all.

Teaching and learning practices, such as narrative reflection, dialogue, 
engagement and imagination, will assist in cultivating more plausible conditions for human encounters. The fullness of humanity, including morals and values, rather than mere technical skills of aspiring CA(SA)s will be developed, and in such a manner professionals will be able to participate in South Africa's democratic society to change the inequalities still prevalent in society. In such a way, through education, there is hope, not just for the country, but also that $\mathrm{CA}(\mathrm{SA}) \mathrm{s}$ will understand that they have a responsibility and must be held accountable. Furthermore, in this way, SAICA, the profession and CA educators will be making a meaningful contribution to realising the fourth sustainable development goal (SDG); that of education for a sustainable future, which implies social cohesion (United Nations Development Programme [UNDP] 2016).

Shawa (2019) argues that the teaching and learning practice used in the classroom is dependent on the educator. Consequentially, the how of education is influenced by the who of education. In the next sub-section, the chapter discusses the importance of the CA educator and the role of the CA educator in realising transformation through educational encounters.

\section{Equipping the Chartered Accountant Educator with Pedagogical and Philosophical Knowledge}

It is evident from the previous sub-section that, unless the CA educator is emancipated, open to transformation and willing to be shaped by the unknown, the prospect that teaching and learning practices supporting DCE will be implemented is slim. In this sub-section, the chapter firstly provides some insight into factors that could contribute to the shaping of the identity of the CA educator and then, in light of these factors, this chapter argues for the fact that CA educators should be equipped to teach towards transformation. Leibowitz (2012) rightly asks whether educators at South African HEIs are truly able to teach towards the goal of DCE, as all were inadvertently shaped by the atrocious past of the country and they carry that formed identity into the classroom. Terblanche (2019) reports that several factors contribute to the formation of the identity of the educator, amongst other cultural backgrounds, memories of the past, particular lived experiences, the consequences of current power relations and the influence of emotions. These factors influence whether the educator is emancipated and can see students as equals and as such allow space for student participation, whist demonstrating a willingness to listen and 


\section{Judith Terblanche \& Yusef Waghid}

learn from to the student.

In addition, Terblanche (2019) identifies three factors that uniquely contribute to the shaping of the identity of the CA educator. Firstly, the CA educator has confidence in the level and volume of technical knowledge and skills, as contained in the SAICA CF. Earlier in this chapter it was explained that aspiring $\mathrm{CA}(\mathrm{SA}) \mathrm{s}$ should obtain a three-year accounting undergraduate degree, followed by a post-graduate accounting qualification. Only after these dedicated four years of accounting studies, combined with two professional examinations and a further three years of training, do they earn the right to the CA(SA) designation. Winberg et al. (2016: 157) reason, '[m]ost academics feel comfortable in their home disciplines; this is their knowledge base from which their expertise develops', and this chapter argues that this is especially true for CA educators, as their own educational experience mainly entails the explanation of technical aspects in standards or pieces of legislation. Some distress is therefore experienced, which often leads to resistance to embrace change, when CA educators are asked to be 'educators', as in their mind they are 'professional chartered accountants', appointed for their professional skills (Winberg et al. 2016). The CA educators therefore often have little knowledge of the philosophy of education or educational principles, nor are they required to obtain such qualifications (Wood \& Maistry 2014). Requesting them therefore to use various teaching and learning practices might thus be too challenging, this chapter argues.

Secondly, CA(SA)s feel they belong to a specific community, that of the CA profession, due to their shared experiences towards qualifying, and this affects the identity of the CA educator. Hamilton (2007) argues that this feeling of community and belonging is strengthened, because when one finally has passed all examinations and developed the required competencies, then one is set apart, as one now has earned the right to use the designation CA(SA), and becomes part of the profession. All those who have equally earned the right to belong to the designated group, have endured the same challenges through the academic and training parts of the qualification, and they share a particular experience with fellow members of the specific community.

Thirdly, the CA educator's identity is shaped by the status of a CA(SA) in society, compared to that of a lecturer. SAICA themselves refer to a CA as a responsible leader in the business world. CA educators then often identify with the high esteem of the profession, as in their minds they are working in their capacity as a professional at the HEI (Venter \& De Villiers 2013). 
The result of these three contributing factors that shape the identity of the CA educator is that the educators align with the profession, rather than with the HEI. The risk exists that graduates (in this case, aspiring $\mathrm{CA}(\mathrm{SA}) \mathrm{s}$ ) will leave HEIs as technically skilled experts only, rather than as graduates whose full humanity has been developed for them to use their skill set to the advancement of society at large.

This chapter consequently argues that CA educators need to be equipped with the required philosophical and educational knowledge if the professsion is serious about transformation and responsible leadership for South Africa. The reason the chapter refers to the responsibility of the profession, is because of the power that the profession has over the qualification route and thus implicitly over the academic part at HEIs. Some of the consequences of these power relations (cf. Terblanche 2019) can be addressed if the profession, rather than HEIs, assist with equipping CA educators for their role of shaping responsible and ethical CA(SA)s. In meetings, SAICA often states that they have outsourced the educational aspect to educational experts and this chapter argues that this is exactly where the problem lies. The CA educators can hardly be called educational experts if they have little to no exposure to diverse educational philosophies and pedagogy. The CA educators are undeniably good at coaching students to pass examinations; surely not deemed 'education' in its pure form, namely that of the process where the full humanity of a student can be explored (and possibly transformed) and where the student has developed the ability to think critically. Wood and Maistry (2014) argue that accounting educators lack pedagogical knowledge and insight into diverse teaching and learning practices. Even after lecturing for a few years, there is still little evidence of growth in pedagogy, and therefore Wood and Maistry (2014) believe there is little evidence of continuing professional development (CPD) for accounting educators at HEIs. The chapter argues that, in the case of the CA profession, the appropriate stakeholder to instigate change might most likely be the profession through SAICA. SAICA advocates life-long learning and, as such, the profession has a CPD policy whereby members need to provide proof of continuous learning. This chapter argues that, through changes to the $\mathrm{CPD}$ policy for $\mathrm{CA}$ educators, and by providing suitable material and programmes, the profession can change the face of the CA educational landscape for the better. Positive changes can be seen merely by investing in the development of CA educators and equipping them to fulfil their mandate. 


\section{Experiential Learning}

Steinberg and Norris (2011) remark that, for students (citizens) to live by a social justice-orientated world view, they have to arrive at a particular intersection and the educational landscape could provide that place of intersection. At this intersection and through an educational encounter, the student and his/her identity meet with the lived reality of communities and particularly the challenges they face (Steinberg \& Norris 2011). South Africa needs its citizens to solve community difficulties. Through participation and having a social consciousness, inequality and poverty could be reduced (thus the solving of a lived societal problem). Waghid (2006: 327) posits, 'educational problem solving should not just be confined to university classroom activity but should extend beyond its boundaries', implying that students should demonstrate in a practical manner, rather than at a theoretical level (through assessment), that they have developed the required skills.

The chapter therefore argues, firstly, that the curriculum should include a community engagement component in order to cultivate problemsolving skills in a practical way. In addition, further benefits of such a practical exposure to societal problems (that require solving) are that students will notice and engage first-hand with possible dire social economic conditions, which could develop in students a social awareness and prompt future participation and ethical decision-making. Maré (2017: 47) explains this prompt that students require to think wider than just the self, as follows:

But first citizens must come to a realisation of the nature and consequences of an unequal world and society. We must disturb our unreflective cohabitation with inequality and not reduce the problem of poverty, where we can assuage the guilt through handouts or donations (valuable, but ...). Inequality is relational, with wealth and poverty, gross consumption by the few and starvation of others inextricably linked.

In their future leadership roles, $\mathrm{CA}(\mathrm{SA}) \mathrm{s}$ will have an influence on the wider society and the environment through the decisions they make. To cultivate in students the capability to recognise and consider the plight of the other, is therefore instrumental to future social cohesion in the country.

Secondly, this chapter argues that the curriculum should include a 
structured component of practical work experience in order to assist students to conceptualise difficult concepts in the volumes of technical theoretical content. Rudman and Terblanche (2012) highlight the advantages when practical work experience is indeed incorporated within the academic programme, as several other professions in South Africa already make use of a structured practical component within the academic programme. Not only will students be able to 'see' theory in action, but such an experience will also allow for mentoring opportunities. Zembylas and Iasonos (2010) claim that, through job shadowing, students are offered the opportunity to experience professionalism and ethical leadership in action. Such an exposure could instil in students a notion of what it means to be accountable to the trust which the public bestow on the profession and encourage them to act professionally and with integrity. Such a practical component also enables training offices to explicate the risks or complex accounting transactions within a chosen industry. Barac et al. (2016) report, 'more could be done to expose technical auditing staff to industry, commerce and non-audit work to further develop their capabilities, utilising individuals with actual experience of the industry to deliver some of this training'. If this was the finding pertaining to actual audit trainees, how much more will students require exposure to industries to truly understand the intrinsic aspects in relation to a particular industry? Students often fail an examination as they struggle to understand the scenario, as the industry is unfamiliar to them. Such a practical component could be coupled with a research project (Terblanche \& Waghid 2021).

In this section of the chapter, it reflected on three recommendations that the CA profession, SAICA and CA educators should consider in order to transform the CA educational landscape. Such recommendations would assist in the cultivation of socially responsible $\mathrm{CA}(\mathrm{SA})$ citizens who could lead ethically in future. The three recommendations are: using teaching and learning practices that support DCE, equipping the CA educator with the required pedagogical and philosophical education knowledge, and making use of experiential learning.

\section{Concluding Comments}

South Africa needs democratic citizens and ethical leaders. The CA profession can make a significant contribution, as CA(SA)s often take up leadership positions. To make such a significant contribution to the country, the profess- 
sion and individual members need to be open to change themselves to ignite societal change. The CA educational landscape is an area where changed behaviour could result in the transformation of citizens into democratic citizens who will act responsibly. For such changed behaviour to be realised, one needs to think and talk differently (Schwab 2018). For the CA profession, this should result in changing the conversation from technical competencies to responsible leadership. If the focus is on responsible leadership, the CA profession will contribute to changing the conditions for human engagement that will result in recognising the shared humanity within us all. Terblanche and Van der Walt (2019: 221) accordingly maintain that the CA profession and each member need to realise:

I am not enough or complete on my own, that the world does not exist only in alignment with my understanding, but that I need to encounter the other to become fully human. This realisation is in all probability not something that can be taught, but hopefully it can be discovered, nurtured and developed with the help of deliberative encounters.

This chapter argues for the introduction of some changes to the CA educational landscape that could assist in the encounter between the self and the other; an encounter that could assist in developing the full humanity of both the educator and the students. Rather than educating technically skilled experts with a notion of appropriate behaviour as contained in an ethical code of conduct, the profession could rather contribute by cultivating citizens, including CAs, who have a prescriptive morality. That means citizens (especially CAs) who will not try to avoid negative consequences by adhering to rules and regulations, but rather who will pursue justice for all and who will make ethical decisions as they will inevitably consider the silent and marginalised other (JanoffBulman et al. 2009).

Our position is that CA educators need to incorporate teaching and learning approaches, such as narrative reflection, dialogue, engagement and imagination in the educational space, as these practices could contribute to engendering democratic citizens that can hopefully participate transformatively in a democratic South Africa. However, for this to happen CA educators need to be equipped specifically as they often do not ground their work in any educational or philosophical theories. We opine that a structured practical component of experiential learning be incorporated into the curriculum. 
Responding in this way is responsible, especially as citizens need to remain hopeful that equality will be realised and that the ominous lived realities of millions can change. South Africa is facing severe challenges, amongst others, the high unemployment rate, poverty, inequality, a lack of social cohesion, a lack of economic growth, rampant corruption, and a lack of service delivery. The CA profession can be a valuable stakeholder in changing the social reality of South Africa as it is possible to implement these recommenddations. Yet, is it enough? What if the profession disrupts the status quo and in addition to implementing these recommendations, considers the inclusion of a community service period in order to obtain the right to use the CA(SA) designation? If the latter manifests, we would once again have to rethink the education of professionals in the CA discourse in the country.

\section{References}

Ballantine, C. 2017. Sounds Like a Better Future: Musicking for Social Change. In Ballentine, C., M. Chapman, K. Erwin \& G. Maré (eds.): Living Together, Living Apart? Social Cohesion in a Future South Africa. Pietermaritzburg: University of KwaZulu-Natal Press.

Barac, K., E. Gammie, B. Howieson \& M. van Staden. 2016. The Capability and Competency Requirements of Auditors in Today's Complex Global Business Environment. Edinburgh: ICAS.

Boulton, G. \& C. Lucas 2011. What Are Universities for? Chinese Science Bulletin 56,23: 2506 - 2517. Available at:

https://doi.org/10.1007/s11434-011-4608-7

(Accessed on 30 March 2020.)

Department of Education (DoE) 2001. National Plan for Higher Education in South Africa. Pretoria: Government Printer.

Enslin, P., S. Pendlebury \& M. Tjiattas. 2001. Deliberative Democracy, Diversity and the Challenges of Citizenship Education. Journal of Philosophy of Education 35,1: 115-130. Available at:

https://doi.org/10.1111/1467-9752.00213 (Accessed on 30 March 2020.)

Foucault, M. 1995. Discipline and Punish: The Birth of the Prison. New York:

Vintage Books.

Giroux, H.A. 2011. On Critical Pedagogy. New York: Continuum.

Greene, M. 2001. Variations on a Blue Guitar: The Lincoln Center Institute Lectures on Aesthetic Education. New York: Teachers College Press. 
Hamilton, S. E. 2007. Accounting for Identity: Becoming a Chartered Accountant. Doctoral thesis. Stirling: University of Stirling. Available at: https://core.ac.uk/reader/40041180 (Accessed on 30 March 2020.)

Janoff-Bulman, R., S. Sheikh \& S. Hepp. 2009. Proscriptive Versus Prescriptive Morality: Two Faces of Moral Regulation. Journal of Personality and Social Psychology 96,3: 521-537. Available at:

https://www.ncbi.nlm.nih.gov/pubmed/19254101 (Accessed on 30 March 2020.) https://doi.org/10.1037/a0013779 PMid:19254101

Keevy, M. \& D. J. Mare. 2018. Pervasive Skills Development for Aspirant Chartered Accountants: Academic Versus Training Programmes. Journal of Economic and Financial Sciences 11,1: 1 - 9. Available at:

http://dx.doi.org/10.4102/jef.v11i1.155 (Accessed on 30 March 2020.) https://doi.org/10.4102/jef.v11i1.155

Leibowitz, B. 2012. Understanding the Challenges of the South African Higher Education Landscape. In Leibowitz, B., L. Swartz, V. Bozalek, R. Carolissen, L. Nicholls \& P. Rohleder (eds.): Community, Self, Identity: Educating South African University Students for Citizenship. Cape Town: HSRC Press.

Mahlomaholo, S.M.G. 2014. Higher Education and Democracy: Analysing Communicative Action in the Creation of Sustainable Learning Environments. South African Journal of Higher Education 28,3: 678 - 696. Available at: https://hdl.handle.net/10520/EJC159159 (Accessed on 30 March 2020.) https://doi.org/10.20853/28-3-364

Maré, G. 2017. What Social Cohesion? Binding through Shared Austerity. In Ballentine, C., M. Chapman, K. Erwin \& G. Maré (eds.): Living Together, Living Apart? Social Cohesion in a Future South Africa. Pietermaritzburg: University of KwaZulu-Natal Press.

Means, A.J. 2014. Educational Commons and the New Radical Democratic Imaginary. Critical Studies in Education 55,2: 122 - 137. Available at: https://doi.org/10.1080/17508487.2014.903502 (Accessed on 30 March 2020.)

Naval, C., M. Print \& R. Veldhuis. 2002. Education for Democratic Citizenship in the New Europe: Context and Reform. European Journal of Education 37,2: 107-128. Available at: https://doi.org/10.1111/1467-3435.00097 (Accessed on 30 March 2020.)

Noddings, N. 2005. What Does it Mean to Educate the Whole Child? In a Democratic Society, Schools Must Go beyond Teaching Fundamental 
Skills. Educational Leadership 63,1: 8-13. Available at:

http://www.ascd.org/publications/educational-

leadership/sept05/vol63/num01/What-Does-It-Mean-to-Educate-the-

Whole-Child\%C2\%A2.aspx (Accessed on 30 March 2020.)

Nussbaum, M.C. 2002. Education for Citizenship in an Era of Global Connec-

tion. Studies in Philosophy and Education 21: 289 - 303. Available at:

https://doi.org/10.1023/A:1019837105053 (Accessed on 30 March 2020.)

Nussbaum, M.C. 2003. Cultivating Humanity in Legal Education. The

University of Chicago Law Review 70: 265-279. Available at:

https://chicagounbound.uchicago.edu/uclrev/vol70/iss1/18/ (Accessed on

30 March 2020.) https://doi.org/10.2307/1600558

Nussbaum, M.C. 2009. Education for Profit, Education for Freedom. Liberal

Education 95,3: 6 - 13. Available at:

https://www.aacu.org/liberaleducation/le-su09/le-su09_index.cfm

(Accessed on 30 March 2020.)

Republic of South Africa (RSA). 1997. Higher Education Act of the Republic

of South Africa, No. 101 of 1997. Pretoria: Government Printer.

Rudman, R.J. \& J. Terblanche 2012. The Perceived Advantage of Work Experience as a Learning Tool for Auditing Students. Southern African Journal of Accountability and Auditing Research 13,1: 57 - 71. Available at: https://hdl.handle.net/10520/EJC120954 (Accessed on 30 March 2020.)

South African Institute of Chartered Accountants (SAICA) 2017. 2017 Nation Building Impact Report. Available at:

https://www.saica.co.za/portals/0/documents/2017_SAICA_Nation_Buil ding Report.pdf (Accessed on 7 April 2019.)

South African Qualifications Authority (SAQA) 2017. Professional Designation: CA(SA) - Chartered Accountant (South Africa). Available at: http://pbdesig.saqa.org.za/viewProfessionalDesignation.php?id=8 (Accessed on 7 April 2019.)

Schwab, K. 2018. The Urgency of Shaping the Fourth Industrial Revolution.

World Economic Forum. Available at:

https://www.weforum.org/agenda/2018/01/the-urgency-of-shaping-the-

fourth-industrial-revolution/ (Accessed on 4 May 2019.)

Shawa, L.B. 2019. In Defence of Education that Embodies Decolonisation. In

Manthalu, C.H. \& Y. Waghid (eds.): Education for Decoloniality and Decolonisation in Africa. Basingstoke: Palgrave Macmillan. 
https://doi.org/10.1007/978-3-030-15689-3 5

Steinberg, K.S. \& K.E. Norris 2011. Assessing Civic Mindedness. Diversity \& Democracy. Civic Learning for Shared Futures 14,3: 12-14. Available at: https://www.aacu.org/publications-research/periodicals/assessingcivic-mindedness (Accessed on 30 March 2020.)

Strauss-Keevy, M. 2014. Education Programmes' Responsibilities regarding Pervasive Skills. Journal of Economic and Financial Sciences 7,2: 415 432. Available at: https://hdl.handle.net/10520/EJC157815 (Accessed on 30 March 2020.) https://doi.org/10.4102/jef.v7i2.148

Terblanche, J. 2019. Cultivating Socially Just Responsible Citizens in Relation to University Accounting Education in South Africa. PhD dissertation, Stellenbosch University. Available at:

https://scholar.sun.ac.za/handle/10019.1/107058

(Accessed on 15 May 2021.)

Terblanche, J. \& C. van der Walt 2019. Leaning into Discomfort: Engaging Film as a Reflective Surface to Encourage Deliberative Encounters. In Manthalu, C.H. \& Y. Waghid (eds.): Education for Decoloniality and Decolonisation in Africa. Basingstoke: Palgrave Macmillan.

https://doi.org/10.1007/978-3-030-15689-3 11

Terblanche, J. \& Y. Waghid. 2020a. A Foucauldian Analysis of the CA Profession in South Africa: Implications for Society. South African Journal of Higher Education 34,1: 1-17. Available at: https://doi.org/10.20853/34-1-3893 (Accessed on 15 May 2021.)

Terblanche, J. \& Y. Waghid. 2020b. The CA Profession in South Africa: In Dire Need of Decoloniality and Ubuntu Principles. Citizenship Teaching and Learning 15,2: 221 - 238. Available at:

https://doi.org/10.1386/ctl_00030_1 (Accessed on 15 May 2021.)

Terblanche, J. \& Y. Waghid. 2021. Implications for Society: Resistance from the Chartered Accountant Profession in South Africa to Including Re search as Pedagogical Practice. South African Journal of Higher Educa tion 35,3: forthcoming.

United Nations Development Programme (UNDP). 2016. Sustainable Develop ment Goals. Available at:

http://www.undp.org/content/dam/undp/library/corporate/brochure/SDG s_Booklet_Web_En.pdf (Accessed on 11 November 2018.)

Van Rinsum, H. 2014. Critical Hope: Deconstructing of the Politics of HOPE at a South African University. In Bozalek, V., B. Leibowitz, R. Carolissen 
\& M. Boler (eds.): Discerning Critical Hope in Educational Practices. London: Routledge. Taylor \& Francis.

Venter, E.R. \& C. de Villiers. 2013. The Accounting Profession's Influence on Academe: South African Evidence. Accounting, Auditing \& Accountability Journal 26,8: 1246-1278. Available at:

https://doi.org/10.1108/AAAJ-06-2012-01027

(Accessed on 30 March 2020.)

Veugelers, W. 2007. Creating Critical-democratic Citizenship Education:

Empowering Humanity and Democracy in Dutch Education. Compare 37,1: 105 - 119. Available at:

https://doi.org/10.1080/03057920601061893

(Accessed on 30 March 2020.)

Vosloo, R.R. 2005. Archiving Otherwise: Some Remarks on Memory and Historical Responsibility. Studia Historiae Ecclesiasticae 31,2: 379 399. Available at: http://hdl.handle.net/10500/4357

(Accessed on 30 March 2020.)

Vosloo, R.R. 2012. Memory, History, and Justice: In Search of Conceptual Clarity. Dutch Reformed Theological Journal 53,3: 215-227. Available at: https://doi.org/10.5952/53-0-235 (Accessed on 30 March 2020.)

Waghid, Y. 2006. University Education and Deliberation: In Defence of Practical Reasoning. Higher Education 51,3: 315 - 328. Available at:

https://doi.org/10.1007/s10734-004-6388-3

(Accessed on 30 March 2020.)

Waghid, Y. 2018. On the Relevance of a Theory of Democratic Citizenship Education for Africa. In Waghid, Y. \& N. Davids (eds.): African Democratic Citizenship Education Revisited. Cham: Springer International. https://doi.org/10.1007/978-3-319-67861-0

Walker, M. 2008. Human Capability, Mild Perfectionism and Thickened Educational Praxis. Pedagogy, Culture and Society 16,2: 149 - 162. Available at: https://doi.org/10.1080/14681360802142112

(Accessed on 30 March 2020.)

Winberg, C., V. Bozalek \& K. Cattell 2016. An Inter-institutional Postgraduate Diploma for University Teachers: Exploring Formative Feedback Data from the Position of Socially Just Pedagogies. Journal for New Generation Sciences 14,3: 144 - 161. Available at:

http://repository.uwc.ac.za/xmlui/handle/10566/3689 (Accessed on 30 March 2020.) 
Wood, N. \& S. M. Maistry. 2014. Professional Accounting Associations' Influence on Higher Education Accounting Pedagogy. Alternation Special Edition 12: 198 - 239. Available at:

http://alternation.ukzn.ac.za/Files/docs/21\%20SpEd12/09\%20Woo.pdf (Accessed on 30 March 2020.)

Zembylas, M. 2006. Witnessing in the Classroom: The Ethics and Politics of Affect. Educational Theory 56,3: 305 - 324. Available at:

https://doi.org/10.1111/j.1741-5446.2006.00228.x

(Accessed on 30 March 2020.)

Zembylas, M. \& S. Iasonos 2010. Leadership Styles and Multicultural Education Approaches: An Exploration of their Relationship. International Journal of Leadership in Education 13,2: 163-183. Available at: https://doi.org/10.1080/13603120903386969 (Accessed on 30 March 2020.)

Judith Terblanche Department: Accounting University: Western Cape

City: Cape Town Email: jterblanche@uwc.ac.za

Yusef Waghid Department: Philosophy of Education University: Stellenbosch City: Stellenbosch Email: yw@sun.ac.za 